EPA540-R-92-021

Directive 9345.1-05

September 1992

\title{
Guidance for Performing Site Inspections Under CERCLA
}

\section{Interim Final}

Hazardous Site Evaluation Division

Office of Solid Waste and Emergency Response

U.S. Environmental Protection Agency

Washington, DC 20460 


\section{NOTICE}

The procedures set forth in this document are intended as guidance to employees of the U.S. Environmental Protection Agency (EPA), States, and other government agencies. EPA officials may decide to follow the guidance provided in this directive, or to act at variance with it, based on analysis of specific site circumstances. EPA also reserves the right to modify this guidance at any time without public notice.

These guidelines do not constitute EPA rulemaking and cannot be relied upon to create any rights enforceable by any party in litigation with the United States.

Mention of company or product names in this document should not be considered as an endorsement by EPA. 


\section{DISCLAIMER}

This report was prepared as an account of work sponsored by an agency of the United States Government. Neither the United States Government nor any agency thereof, nor any of their employees, make any warranty, express or implied, or assumes any legal liability or responsibility for the accuracy, completeness, or usefulness of any information, apparatus, product, or process disclosed, or represents that its use would not infringe privately owned rights. Reference herein to any specific commercial product, process, or service by trade name, trademark, manufacturer, or otherwise does not necessarily constitute or imply its endorsement, recommendation, or favoring by the United States Government or any agency thereof. The views and opinions of authors expressed herein do not necessarily state or reflect those of the United States Government or any agency thereof. 


\section{DISCLAIMER}

Portions of this document may be illegible in electronic image products. Images are produced from the best available original document. 


\section{CONTENTS}

CHAPTER 1: INTRODUCTION $\ldots \ldots \ldots \ldots \ldots \ldots \ldots \ldots \ldots \ldots \ldots \ldots \ldots \ldots \ldots \ldots$

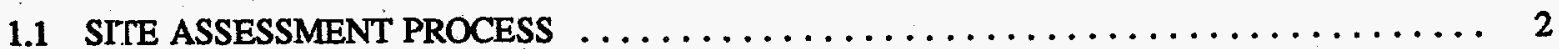

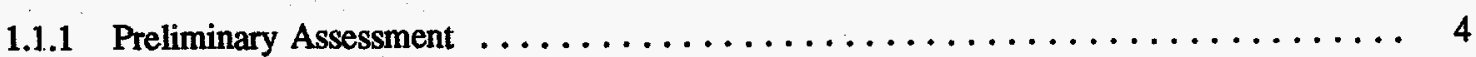

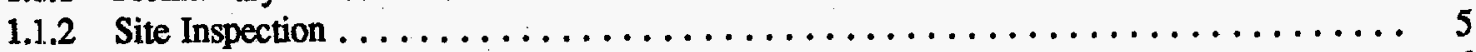

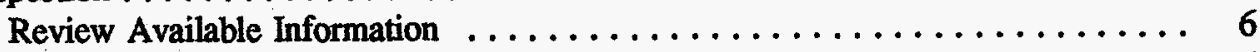

Organize Project Team and Develop Plans $\ldots \ldots \ldots \ldots \ldots \ldots \ldots \ldots \ldots \ldots$

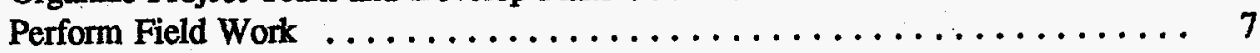

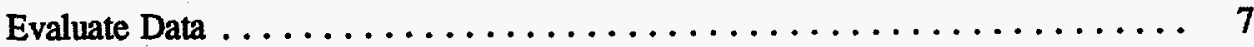

CHAPTER 2: SI APPROACHES $\ldots \ldots \ldots \ldots \ldots \ldots \ldots \ldots \ldots \ldots \ldots \ldots \ldots \ldots \ldots$

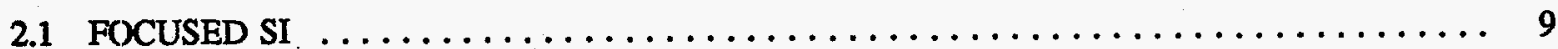

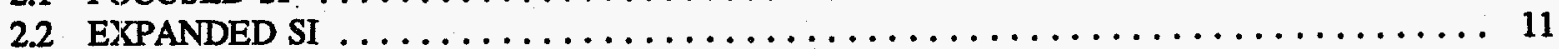

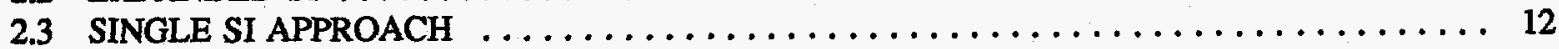

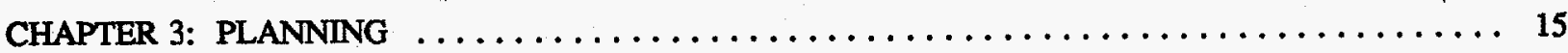

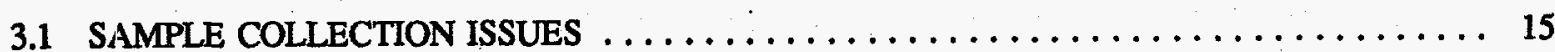

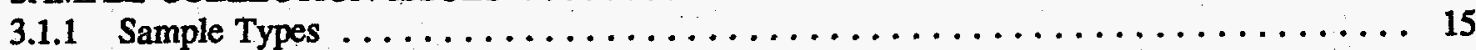

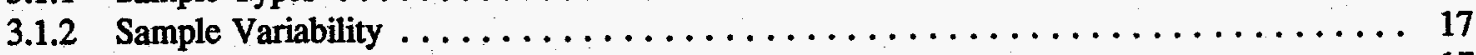

Sample Collection and Handling Variability $\ldots \ldots \ldots \ldots \ldots \ldots \ldots \ldots, 17$

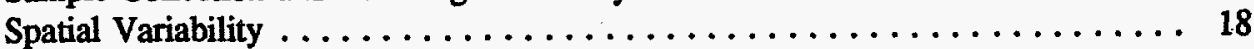

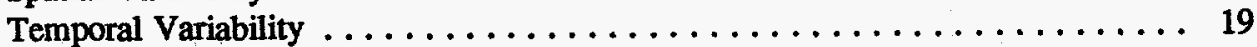

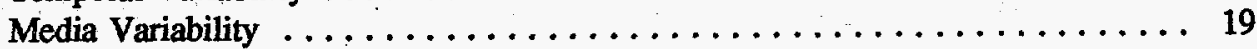

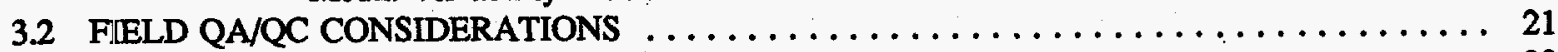

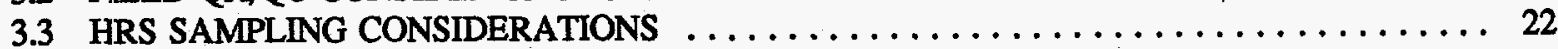

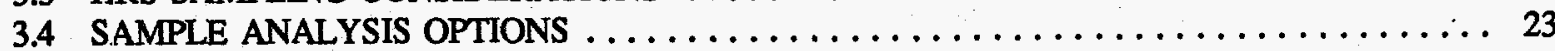

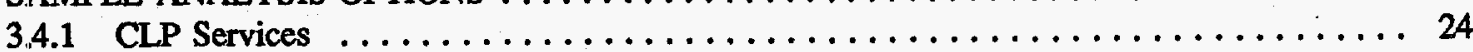

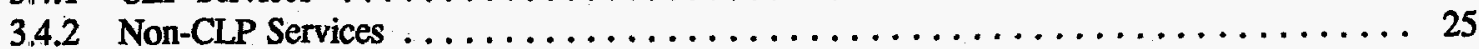

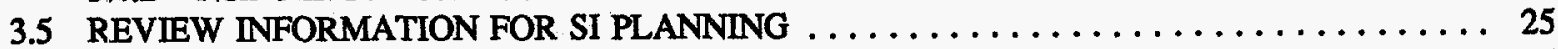

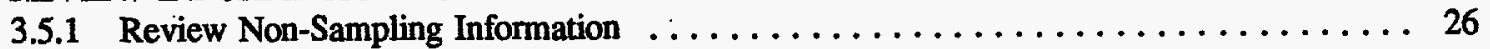

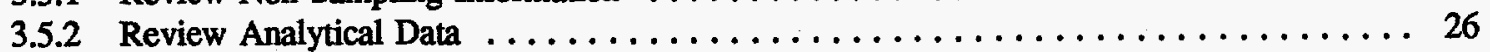

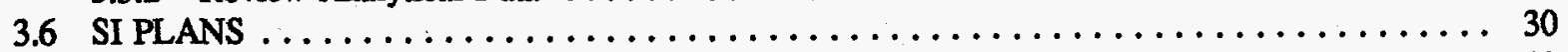

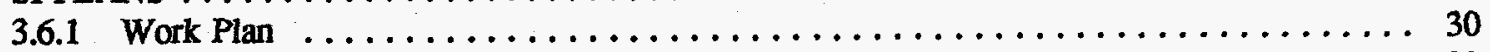

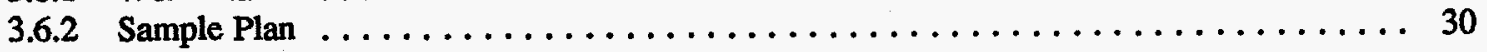

3.6.3 Health and Safety Plan

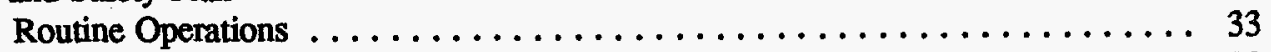

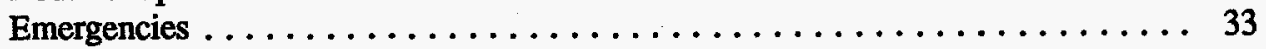

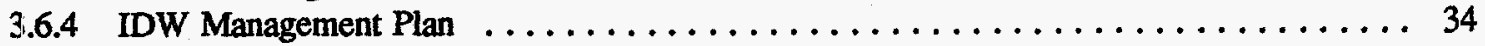

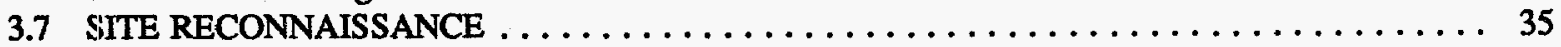

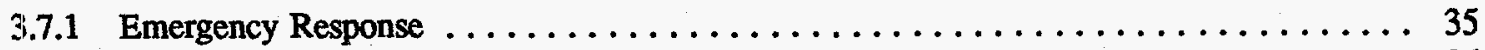

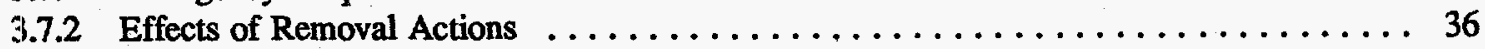

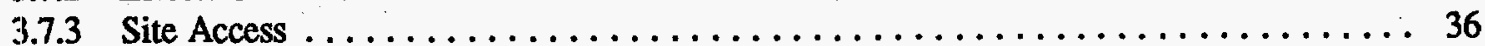

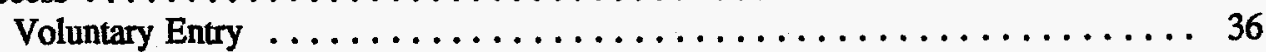

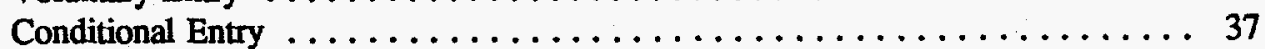


Entry With Warrant ................................ 37

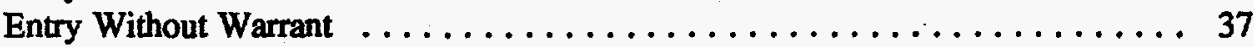

3.7.4 Community and Neighborhood Contacts $\ldots \ldots \ldots \ldots \ldots \ldots \ldots \ldots \ldots \ldots \ldots \ldots \ldots$

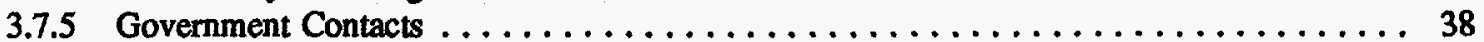

3.8 SITES CONTAINING RADIOACTIVE SUBSTANCES $\ldots \ldots \ldots \ldots \ldots \ldots \ldots \ldots \ldots$
$\ldots$

3.8.1 Key Radiation Site Personnel $\ldots \ldots \ldots \ldots \ldots \ldots \ldots \ldots \ldots \ldots \ldots \ldots \ldots \ldots \ldots$

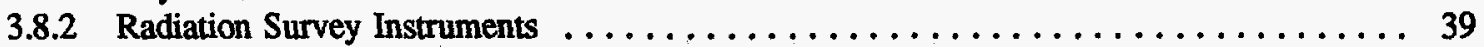

Gamma Detectors ........................... 39

Alpha and Beta Detectors $\ldots \ldots \ldots \ldots \ldots \ldots \ldots \ldots \ldots \ldots \ldots, 41$

3.8.3 Survey Techniques ............................... 41

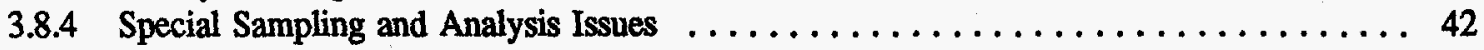

3.8.5 HRS Requirements for Radiation Sites $\ldots \ldots \ldots \ldots \ldots \ldots \ldots \ldots \ldots \ldots \ldots, 43$

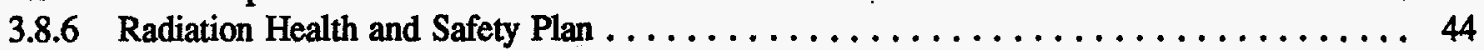

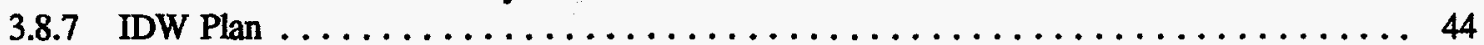

CHAPTER 4: SAMPLING STRATEGIES $\ldots \ldots \ldots \ldots \ldots \ldots \ldots \ldots \ldots \ldots \ldots \ldots \ldots \ldots \ldots$

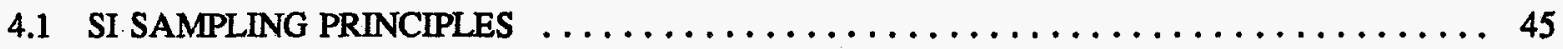

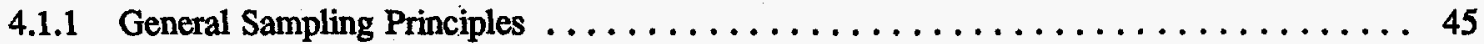

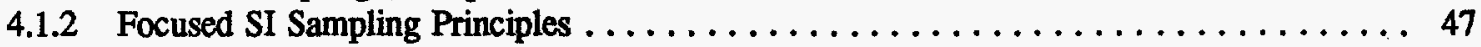

4.1.3 Expanded and Single SI Sampling Principles $\ldots \ldots \ldots \ldots \ldots \ldots \ldots \ldots \ldots, 48$

4.2 SOURCE CHARACTERIZATION $\ldots \ldots \ldots \ldots \ldots \ldots \ldots \ldots \ldots \ldots \ldots \ldots \ldots \ldots \ldots \ldots$

4.2.1 Focused SI Strategy_Source Characterization .................. 52

4.2.2 Expanded and Single SI Strategy-Source Characterization $\ldots \ldots \ldots \ldots \ldots \ldots \ldots 53$

4.2.3 Example of Source Sampling Strategy $\ldots \ldots \ldots \ldots \ldots \ldots \ldots \ldots \ldots \ldots \ldots \ldots \ldots \ldots \ldots$

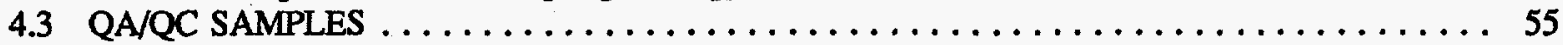

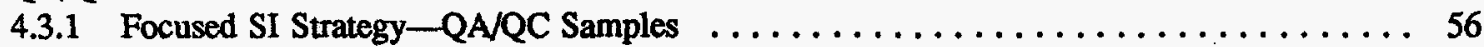

4.3.2 Expanded and Single SI Strategy-QA/QC Samples $\ldots \ldots \ldots \ldots \ldots \ldots \ldots \ldots, 56$

4.4 SAMPLE TO DEMONSTRATE A RELEASE $\ldots \ldots \ldots \ldots \ldots \ldots \ldots \ldots \ldots \ldots \ldots \ldots \ldots \ldots \ldots$

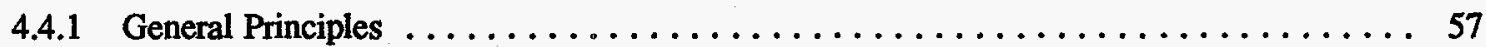

Background Sampling Considerations $\ldots \ldots \ldots \ldots \ldots \ldots \ldots \ldots \ldots \ldots$

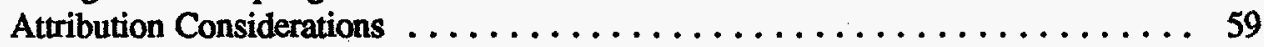

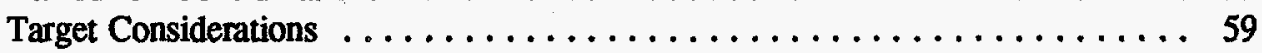

4.4.2 Focused SI Strategy-Sample to Demonstrate a Release ............... 60

4.4.3 Expanded and Single SI Strategy-Sample to Demonstrate a Release $\ldots \ldots \ldots \ldots \ldots 60$

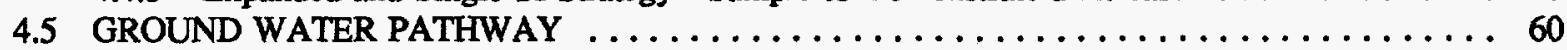

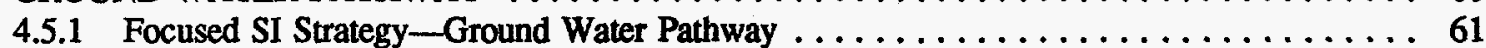

4.5.2 Expanded and Single SI Strategy-Ground Water Pathway $\ldots \ldots \ldots \ldots \ldots \ldots \ldots 62$

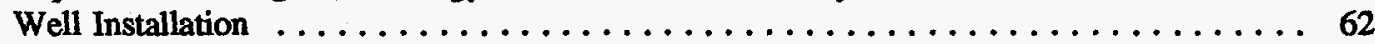

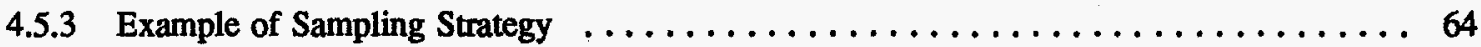

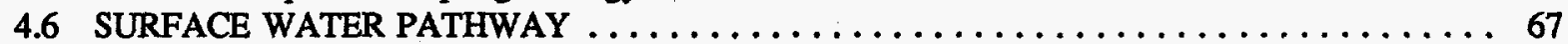

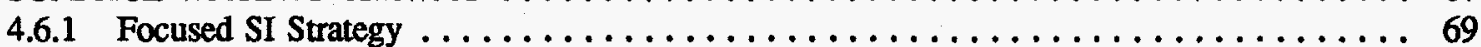

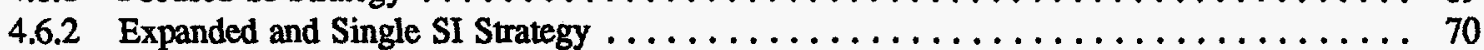

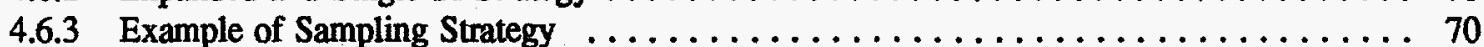

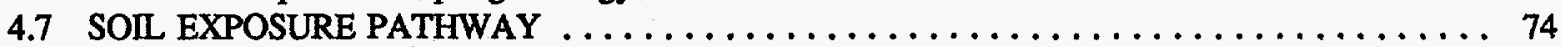

4.7.1 Focused SI Strategy vs. Expanded and Single SI Strategy $\ldots \ldots \ldots \ldots \ldots \ldots \ldots \ldots$

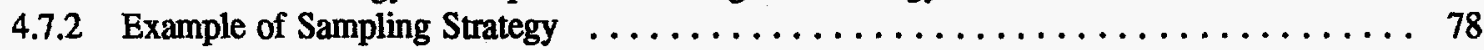

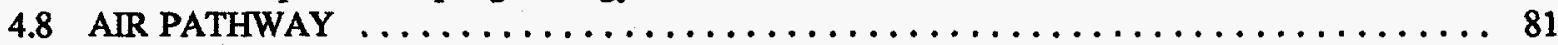

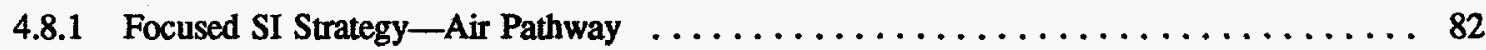

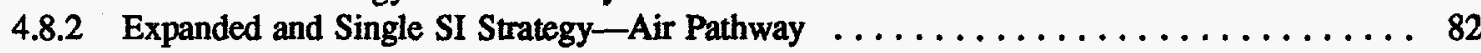

4.8 .3 Example of Air Sampling Strategy $\ldots \ldots \ldots \ldots \ldots \ldots \ldots \ldots \ldots \ldots \ldots \ldots \ldots \ldots$ 
4.9 SITES WITH RADIOACTIVE WASTES $\ldots \ldots \ldots \ldots \ldots \ldots \ldots \ldots \ldots \ldots \ldots \ldots \ldots \ldots$

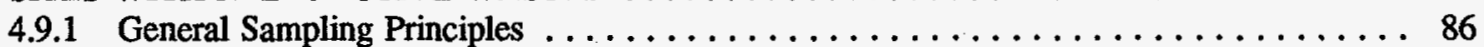

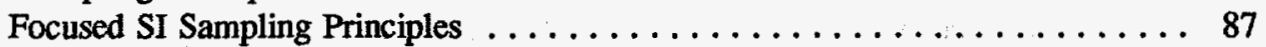

Expanded and Single SI Sampling Principles $\ldots \ldots \ldots \ldots \ldots \ldots \ldots \ldots .88$

4.9.2 Source Characterization $\ldots \ldots \ldots \ldots \ldots \ldots \ldots \ldots \ldots \ldots \ldots \ldots \ldots \ldots$

4.9 .3 QA/QC Samples . . . . . . . . . . . . . . . . . . . . . . . 89

4.9.4 Sample to Demonstrate a Release $\ldots \ldots \ldots \ldots \ldots \ldots \ldots \ldots \ldots \ldots \ldots \ldots \ldots . \ldots \ldots$

4.9.5 Ground Water and Surface Water Pathways $\ldots \ldots \ldots \ldots \ldots \ldots \ldots \ldots \ldots \ldots \ldots$

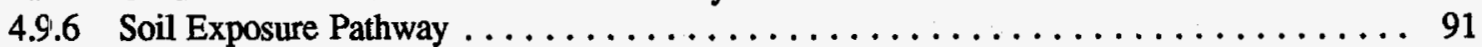

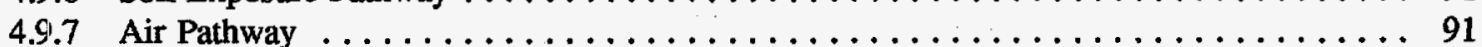

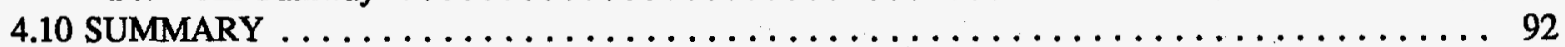

CHAPTER 5: SI EVALUATION $\ldots \ldots \ldots \ldots \ldots \ldots \ldots \ldots \ldots \ldots \ldots \ldots \ldots \ldots \ldots \ldots \ldots$

5.1 REVIEW AND VALIDATE ANALYTICAL DATA $\ldots \ldots \ldots \ldots \ldots \ldots \ldots \ldots \ldots \ldots$

5.2 IDENTIFY ANALYTICAL DATA FOR SCORING $\ldots \ldots \ldots \ldots \ldots \ldots \ldots \ldots \ldots \ldots$

5.3 EVALUATE NON-SAMPLING INFORMATION $\ldots \ldots \ldots \ldots \ldots \ldots \ldots \ldots \ldots \ldots \ldots \ldots \ldots$

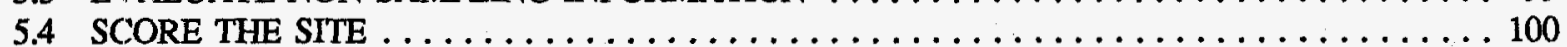

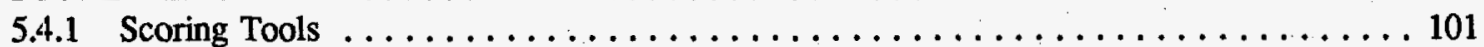

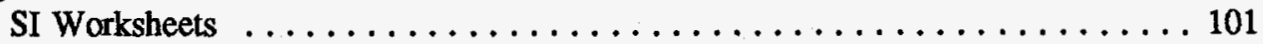

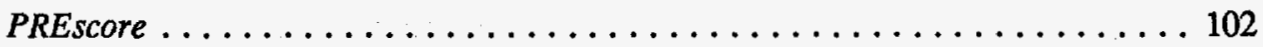

Other Scoring Tools . ........................ 103

5.4.2 Characterize and Evaluate Significant Site Sources $\ldots \ldots \ldots \ldots \ldots \ldots \ldots \ldots \ldots$

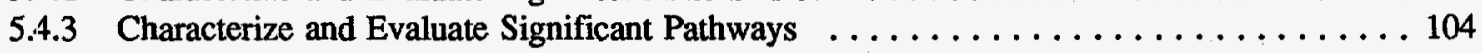

5.4.4 Evaluate Releases and Targets Exposed to Contamination . . . . . . . . . . . 105

5.4.5 Check Scoring and Collect Additional Information $\ldots \ldots \ldots \ldots \ldots \ldots \ldots \ldots \ldots$

CHAPTER $6:$ REPORTING REQUIREMENTS $\ldots \ldots \ldots \ldots \ldots \ldots \ldots \ldots \ldots \ldots \ldots \ldots \ldots$

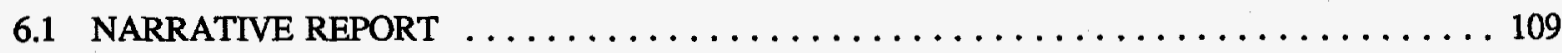

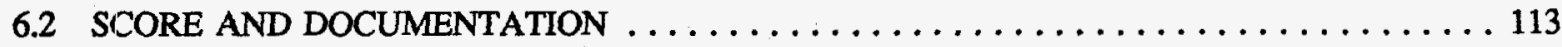

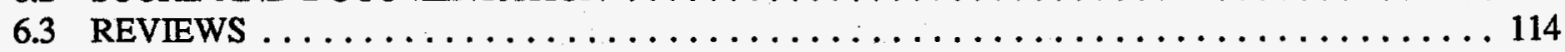

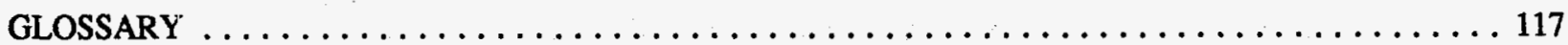

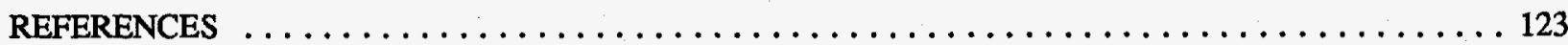

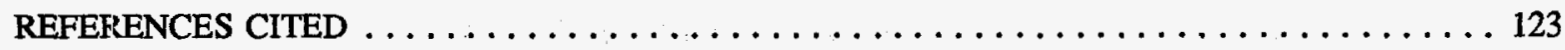

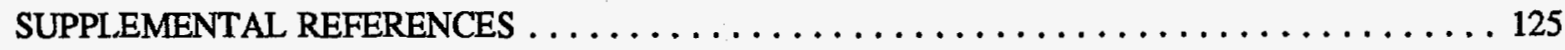

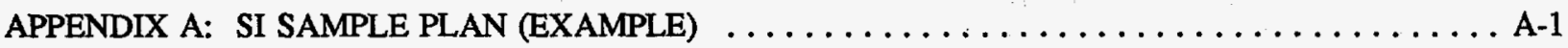

APPENDIX B: SI DATA SUMMARY $\ldots \ldots \ldots \ldots \ldots \ldots \ldots \ldots \ldots \ldots \ldots \ldots \ldots \ldots \ldots \ldots \ldots$

APPENDIX C: SITE INSPECTION WORKSHEETS $\ldots \ldots \ldots \ldots \ldots \ldots \ldots \ldots \ldots \ldots \ldots \ldots \ldots$ C-1

APPENDIX D: SI NARRATIVE REPORT (EXAMPLE) $\ldots \ldots \ldots \ldots \ldots \ldots \ldots \ldots \ldots \ldots \ldots \ldots \ldots$

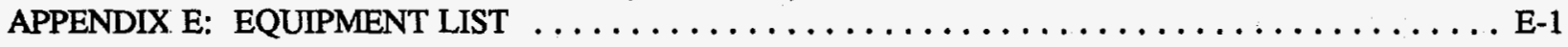




\section{FIGURES AND EXHIBITS}

Figure 1-1: Site Assessment in Superfund $\ldots \ldots \ldots \ldots \ldots \ldots \ldots \ldots \ldots \ldots \ldots \ldots \ldots \ldots \ldots \ldots$

Figure 1-2: The Remedial Phase of Superfund $\ldots \ldots \ldots \ldots \ldots \ldots \ldots \ldots \ldots \ldots \ldots \ldots \ldots \ldots$

Figure 2-1: Site Inspection Decision Tree $\ldots \ldots \ldots \ldots \ldots \ldots \ldots \ldots \ldots \ldots \ldots \ldots \ldots \ldots \ldots \ldots$

Exhibit 3-1: Checklist for Usability of Previous Analytical Data $\ldots \ldots \ldots \ldots \ldots \ldots \ldots \ldots \ldots \ldots$

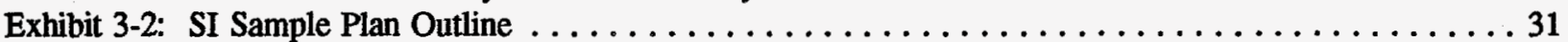

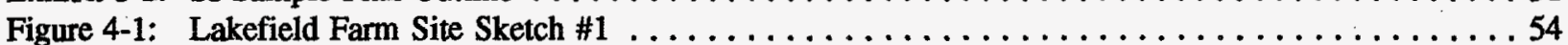

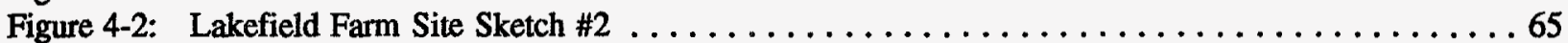

Figure 4-3: $\quad$ Lakefield Farm Site Sketch $\# 3 \ldots \ldots \ldots \ldots \ldots \ldots \ldots \ldots \ldots \ldots \ldots \ldots \ldots \ldots \ldots \ldots$

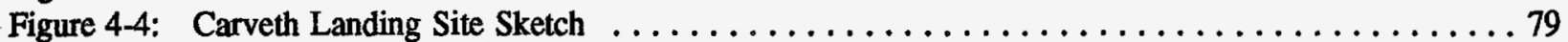

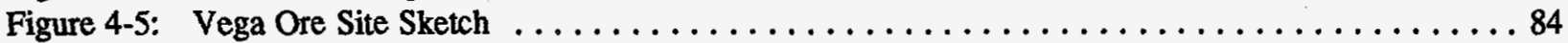

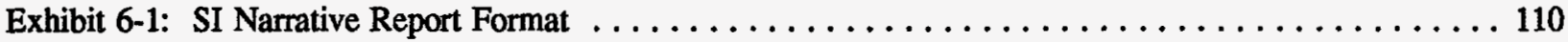




\section{TABLES}

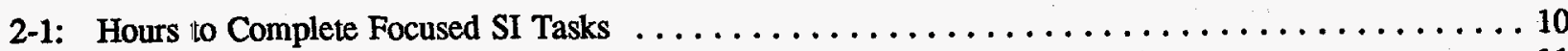

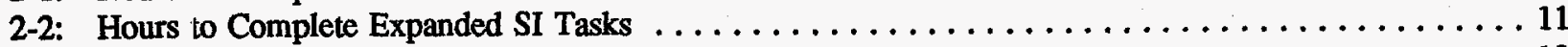

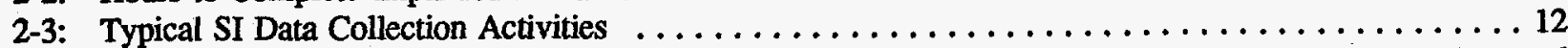

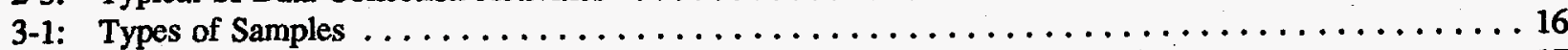

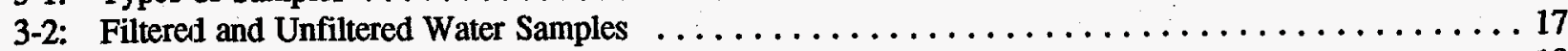

3-3: Potential Contaminants from Sampling Devices and Well Casings $\ldots \ldots \ldots \ldots \ldots \ldots \ldots \ldots \ldots 18$

3-4: Sampling Issues Affecting Confidence in Analytical Results $\ldots \ldots \ldots \ldots \ldots \ldots \ldots \ldots \ldots \ldots$

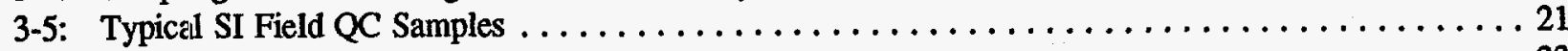

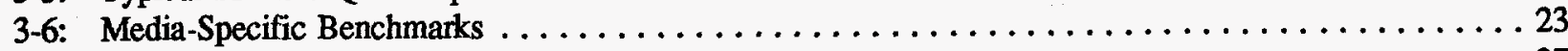

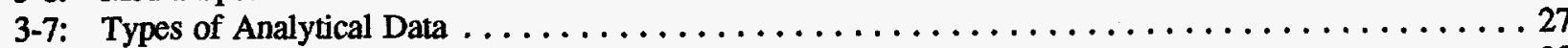

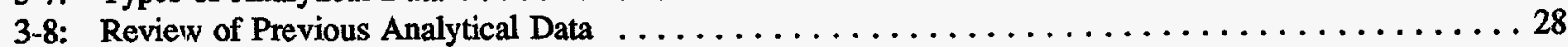

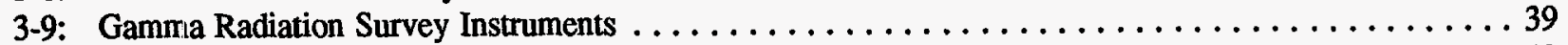

3-10: Alpha and Beta Radiation Survey Instruments $\ldots \ldots \ldots \ldots \ldots \ldots \ldots \ldots \ldots \ldots \ldots \ldots \ldots$

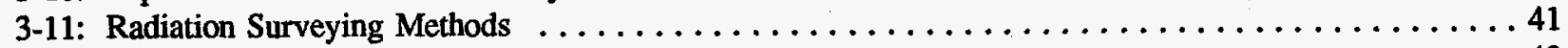

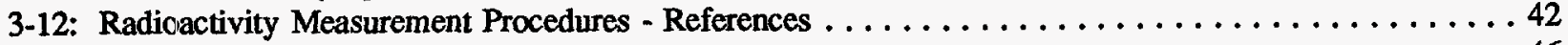

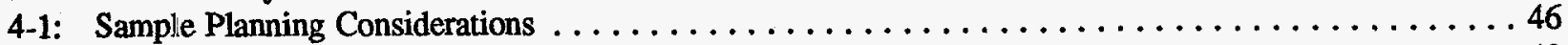

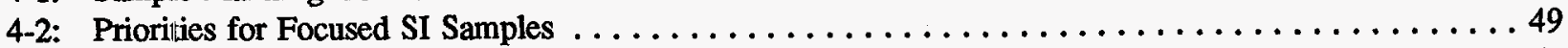

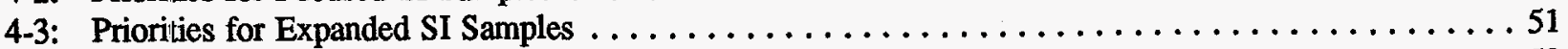

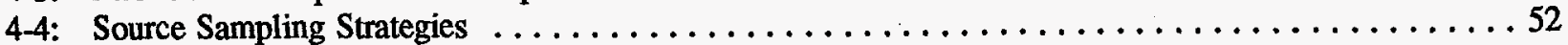

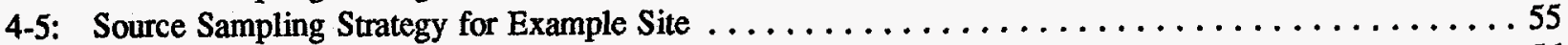

4-6: Guidelines for Minimum QA/QC Samples; Expanded SI or Single SI . . . . . . . . . . . 56

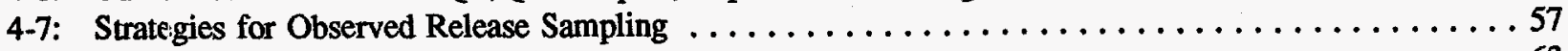

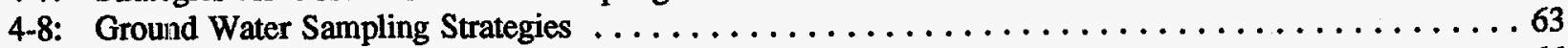

4-9: Ground Water Sampling Strategy for Example Site; Focused SI $\ldots \ldots \ldots \ldots \ldots \ldots \ldots \ldots \ldots 6$

4-10: Surface Water Samples to Support a Release and Target Contamination $\ldots \ldots \ldots \ldots \ldots \ldots \ldots \ldots$

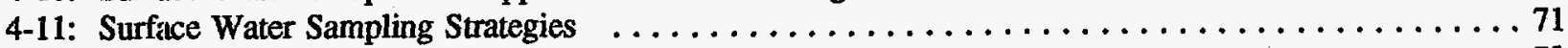

4-12: Surface and Ground Water Sampling Strategy for Example Site; Focused SI $\ldots \ldots \ldots \ldots \ldots \ldots 73$

4-13: Surface Water Sampling Strategy for Example Site; Expanded SI and Single SI . . . . . . . . . . 74

4-14: Soil Sampling Strategies $\ldots \ldots \ldots \ldots \ldots \ldots \ldots \ldots \ldots \ldots \ldots \ldots \ldots \ldots \ldots \ldots \ldots \ldots$

4-15: Soil and Surface Water Sampling Strategy for Example Site; Focused SI . . . . . . . . 80

4-16: Soil Sampling Strategy for Example Site: Expanded SI $\ldots \ldots \ldots \ldots \ldots \ldots \ldots \ldots \ldots \ldots \ldots \ldots$

4-17: Air Sampling Strategy for Example Site; Single SI $\ldots \ldots \ldots \ldots \ldots \ldots \ldots \ldots \ldots \ldots \ldots \ldots$

4-18: Summary of SI Sampling Strategy $\ldots \ldots \ldots \ldots \ldots \ldots \ldots \ldots \ldots \ldots \ldots \ldots \ldots \ldots \ldots$

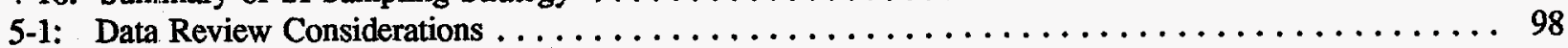

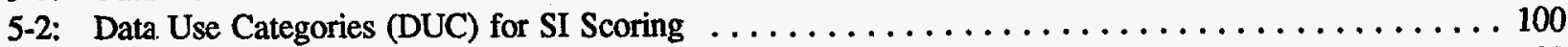

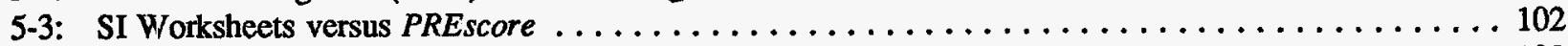

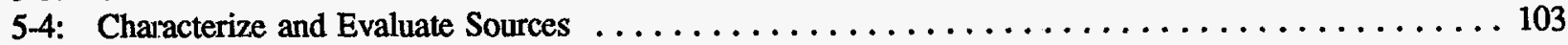

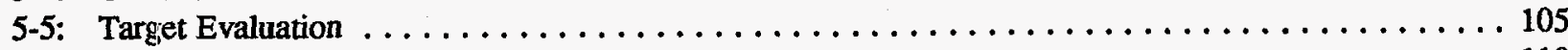

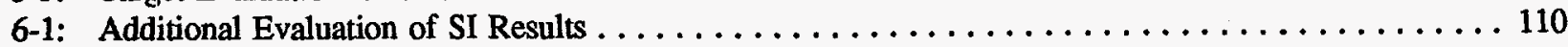




\section{EXECUTIVE SUMMARY}

This guidance presents EPA's site inspection (SI) strategy. The strategy discusses procedural guidelines to investigate potential Superfund (CERCLA) sites for evaluation pursuant to the Hazard Ranking System (HRS), revised in accordance with the Superfund Amendments and Reauthorization Act of 1986. The HRS is the primary means by which EPA evaluates sites for Superfund's National Priorities List (NPL).

EPA uses a multiphase evaluation process to determine appropriate action at Superfund sites. In the first phase, hazardous substance releases or threatened releases from a site are evaluated during two investigations: the preliminary assessment (PA) and the SI. During the PA, EPA collects background information to determine whether the SI is warranted. During the SI, EPA further evaluates the extent to which a site presents a threat to human health or the environment by, among other things, collecting and analyzing wastes and environmental media samples to determine whether hazardous substances are present at the site and are migrating to the surrounding environment. At the end of the SI, EPA decides whether the site qualifies for possible inclusion on the NPL or should be dropped from further Superfund consideration. Additionally, the SI supports removal and enforcement actions and collects data to support further Superfund or other response actions.

The SI is not intended to be a detailed extent-ofcontamination or risk assessment. Efforts requiring intensive background investigation or specialized techniques are normally part of the next phase in the Superfund process after a site is placed on the NPL and becomes eligible for remedial funding.

The most efficient investigative approach for the majority of sites recommended for further action after the PA is conducted in two steps: a focused SI followed by an expanded SI, if necessary. Other sites may require only a single SI, which is a combination of a focused SI and an expanded SI.

In general, the focused SI is limited to testing PA hypotheses to determine if the site warrants further Superfund investigation. The scope of the focused SI depends on the number of PA hypotheses requiring investigation, the questions remaining after the PA, and the number of migration and exposure pathways that significantly influence the further action recommendation. Focused SI sampling is not designed to document observed releases or observed contamination per HRS requirements. Hence, sampling during the focused SI may not include the full set of quality assurance/quality control (QA/QC) and background samples.

After the focused SI, one of three recommendations may be made:

- Site evaluation accomplished (SEA);

- Further action (e.g., expanded SI) recommended; or

- Preparation of an HRS package scheduled if all necessary data are available.

The objective of the expanded SI is to provide documentation for the HRS package to support NPL rulemaking. Remaining HRS information requirements are addressed and site hypotheses not completely supported during previous investigations are evaluated. Expanded SI sampling is designed to satisfy HRS data requirements by documenting observed releases, observed contamination, and levels of actual contamination at targets. In addition, investigators collect remaining non-sampling information. Sampling during the expanded SI includes background and QA/QC samples to fully document releases and attribute them to the site. Following the expanded SI, EPA site assessment managers assign the site a priority for HRS package preparation and proposal to the NPL.

In some cases, it may be possible to conduct a single SI instead of the focused and expanded SI. The single SI presumes that a site would not be screened by a focused SI and fulfills the functions of the expanded SI to collect analytical data and nonsampling information to complete an HRS package. The single SI is similar in scope to the expanded SI and may be appropriate for certain high priority sites that are highly likely to be placed on the NPL. 


\section{CHAPTER 1 \\ INTRODUCTION}

This document provides guidance for conducting site inspections (SIs) under CERCLA. Data collection requirements for these investigations are consistent with data needed for the revised Hazard Ranking System (HRS). This guidance discusses how to review and evaluate available information, plan an effective sampling strategy to acquire analytical data to evaluate a site according to the HRS, and prepare required reports and work products. Outlines and examples of completed work products are provided to illustrate content and length. This guidance will help investigators conduct efficient, high quality SIs that result in correct site recommendations on a nationally consistent basis.

The objective of an SI is to gather information to support a site decision regarding the need for further Superfund action. The SI is not a study of the full extent of contamination at a site or a risk assessment. The appropriate level of information gathered and analyzed to meet this objective can only be achieved through strategic planning to determine what data are essential to the decision.

The SI phase of the Superfund program is a dynamic, flexible process that should be tailored to the specific circumstances of individual sites; it is not a standardized process to be repeated at every site. The SI investigator, in coordination with EPA Regional and State officials, is responsible for the design and execution of the SI, and should determine how best to use the flexibility of this process. As conditions are tested and hypotheses are either confirmed or rejected, the investigation should be adjusted. These adjustments, like the site decision itself, involve balancing a wide variety of factors and exercising professional judgment.

This document contains six chapters:

- Chapter 1: Introduction provides background on the purpose and implementation of Superfund legislation, discusses the structure of the site assessment process, and provides specific details on the role of the preliminary assessment (PA) and SI in the site assessment process.

- Chapter 2: SI Approaches discusses the objectives, purpose, and scope of the SI, and provides guidelines for selecting the approach to investigate a site.
- Chapter 3: Planning provides an overview of sampling and analysis considerations and HRS analytical data requirements, discusses the importance of available data in developing SI plans, and provides guidelines for reviewing analytical data for SI planning.

- Chapter 4: Sampling Strategies discusses sampling principles to investigate site-specific conditions, test PA hypotheses, and document HRS information; presents sampling strategies for each pathway and for multiple pathways; and provides examples illustrating sampling strategies.

- Chapter 5: SI Evaluation addresses how to interpret and apply analytical data and nonsampling information.

- Chapter 6: Reporting Requirements discusses guidelines for preparing SI work products to report results, provides a detailed outline of a standard SI narrative report, and presents procedures for reviewing SI scores and documents.

Separate EPA documents provide key direction to implement the HRS and should be consulted as supplemental references:

- Guidance for Performing Preliminary Assessments Under CERCLA (OSWER Directive 9345.0-01A, September 1991) provides guidance for conducting the PA, including PA evaluation and the use of PA scoresheets. 
- Site Assessment Information Directory (SAID), 1991, is a directory of information sources for use in site investigations.

- Hazard Ranking System (HRS) Guidance Manual (OSWER Directive 9345.1-07, in development) provides guidance for scoring sites and discusses important HRS concepts.

- Management of Investigation-Derived Wastes During Site. Inspections (OERR Directive 9345.3-02, May 1991) presents general regulatory information and options to manage investigation-derived wastes (IDW) generated during SIs.

- Guidance for Data Useability in Site Assessment (OSWER Directive 9345.1-05, in development) provides guidance on how to collect and apply analytical data to support HRS scoring.

- Superfund Removal Procedures Manual (OSWER Directive 9360.3-01, December 1990) provides guidance on daily activities at removal sites. The manual consists of guidance documents on the following topics: Action Memorandum preparation, removal reporting, response management, removal enforcement for On-Scene Coordinators, public participation, removal decisions, special circumstances, consideration of ARARs, and State participation.

\subsection{SITE ASSESSMENT PROCESS}

In 1980, Congress enacted the Comprehensive Environmental Response, Compensation, and Liability Act (CERCLA) establishing the Superfund program to respond to releases and threatened releases of hazardous substances. CERCLA Section 105 required EPA to establish criteria for determining priorities among releases or threatened releases of hazardous substances for the purpose of taking remedial action. To meet this requirement, EPA developed the HRS (47 FR 31180, July 16, 1982) to evaluate sites for the National Priorities List (NPL). Sites on the NPL are eligible for Federally funded remedial action.

The Superfund Amendments and Reauthorization Act (SARA) of 1986 required EPA to revise the HRS to more accurately "assess the relative degree of risk to
CERCLA, as amended by SARA, required certain revisions to the National Oil and Hazardous Substances Contingency Plan (NCP) (40 CFR Part 300, March 1990) to implement the new authorities and responsibilities of the CERCLA amendments. The revisions to the NCP establish assessment programs to investigate releases:

- Section 300.410 establishes a phased investigation approach to address potential emergency response or removal situations, consisting of a removal preliminary assessment (PA) and a removal site inspection (SI) to evaluate whether a removal action is appropriate.

- Section 300.420 specifies the site assessment process-known as the preremedial process-which designates sites that qualify as priorities for longterm remedial evaluation and response. The process consists of a remedial PA (Section 300.420 (b)) and a remedial SI (Section 300.420 (c)).

The subject of this document is site evaluation within the site assessment process, and unless specifically identified as activities in the removal assessment process, PAs and SIs described in this guidance are the PAs and SIs specified under NCP Section 300.420 .

human health and the environment posed by sites." SARA also required the HRS to take into account recreational use of surface waters, contamination of the human food chain and drinking water supplies, and potential contamination of ambient air. EPA published the revised HRS on December 14, 1990 (55 FR 51532).

The site assessment process begins with site discovery, or notification to EPA of possible releases of hazardous substances. All sites are entered into CERCLIS, EPA's computerized inventory of potential hazardous waste sites. EPA then evaluates the sites using a phased investigation consisting of the PA and, 
if necessary, the SI. The PA is a limited scope investigation based primarily on available information and performed by EPA or States for every CERCLIS site. The PA distinguishes sites that pose no threat to human health and the environment from sites that may pose a significant threat. Sites that may pose a threat receive a further action recommendation after the PA and uridergo an SI, where investigators collect sufficient waste and environmental media samples to identify sites that have a high probability of qualifying for the NPL.

When the PA and SI are completed, EPA calculates the HRS site score and either recommends further investigation and possible proposal to the NPL or makes a "Site Evaluation Accomplished" (SEA) determination. A SEA recommendation drops the site from further Federal Superfund consideration; however, the removal program may continue to address threats and any site may be reassessed if new information becomes available. Information for dropped sites is provided to States or other regulatory. authorities, which may take action on their own. If no statutory provision or EPA policy indicates that the site should not be listed on the NPL, a site with an HRS score of 28.50 or greater is eligible for the NPL. These steps--discovery and entry into CERCLIS, PA, SI, HRS package preparation, and listing-make up the site assessment phase of the Superfund process (Figure 1-1). The remaining steps in the Superfund process are the remedial investigation/feasibility study (RI/FS), Record of Decision (ROD), remedial design/ remedial action (RD/RA), and operation and maintenance (O\&M) (Figure 1-2). Under Superfund's removal authority, the RI may start at any time during
The "Site Evaluation Accomplished" (SEA) recommendation replaced the "No Further Remedial Action Planned" (NFRAP) recommendation (see Henry Longest Memorandum, May 11, 1992). A SEA recommendation denotes that, to the best of its knowledge, EPA has completed its assessment at a site and has determined that no further steps to list the site on the NPL will be taken unless information indicating that this decision was not appropriate make a recommendation for listing appropriate at a later time. The CERCLIS qualifier remains " $N$ " as it was for NFRAP. The "NFA" indicator in the CERCLIS List.8 Report was changed to "SEA."

the site assessment. The RA for Fund-lead sites, however, can begin only after a site is on the NPL.

Sites placed on the NPL are subject to further investigation during the remedial phase. The objective of the remedial phase is to eliminate, reduce, or otherwise control risks to human health and the environment. The steps for selection and implementation of a remedy include the remedial investigation, feasibility study, record of decision, remedial design, and remedial action.

At any time during the site assessment process, conditions at the site may warrant removal actions. Removal actions, as defined in CERCLA Section 104,

FIGURE 1-1: SITE ASSESSMENT IN SUPERFUND

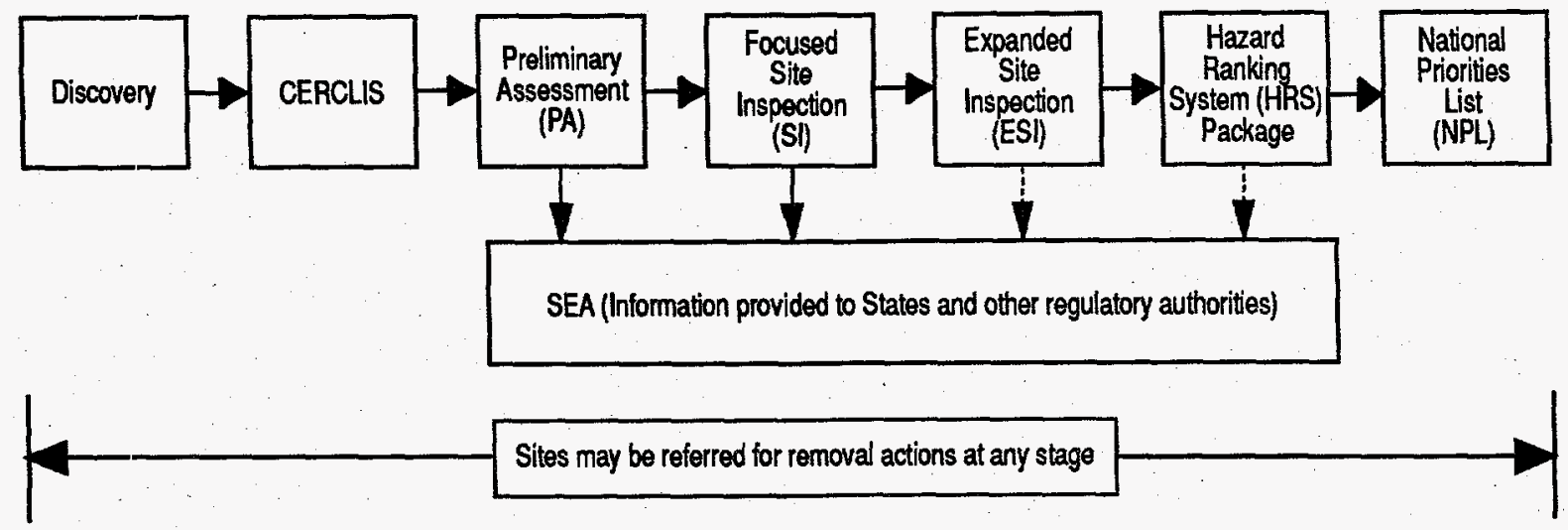


FIGURE 1-2: THE REMEDIAL PHASE OF SUPERFUND
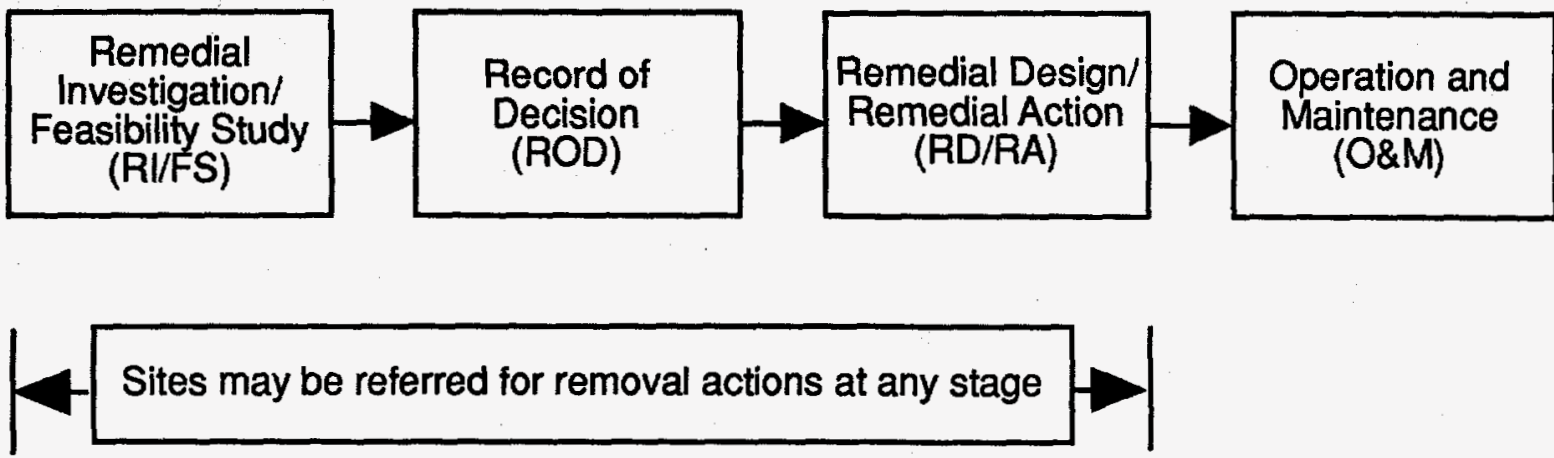

are actions taken to eliminate, control, or otherwise mitigate a threat posed to public health or the environment due to a release or threatened release of hazardous substances.

EPA has developed a new model for streamlining and accelerating the Superfund program, the Superfund Accelerated Cleanup Model (SACM) (OSWER Directives 9203.1-01, April 7, 1992 and 9203.1-03, July 7,1992$)$. SACM includes an integrated approach for site assessment. SACM implementation will change the structure and goals of the SI, but the content of the data collected will not change. The principles of site assessment and the concept of the focused SI contained in this document are quite consistent with SACM.

\subsubsection{Preliminary Assessment}

The PA distinguishes sites that pose little or no potential threat to human health and the environment from sites that warrant further investigation. The PA

The primary objective of the remedial site assessment program is to obtain enough data to evaluate sites under the HRS and identify those that should be on the NPL. The revised HRS requires more data than the original HRS, and the site assessment process has been restructured to balance the need to accurately assess site conditions with the need to conserve resources. also fulfills public information needs and supports emergency response and removal activities by providing specific background information.

The PA is a relatively quick, low-cost compilation of readily available information about the site and its surroundings. The PA emphasizes identifying populations and other targets that might be affected by the site. It includes a reconnaissance of the site and its surrounding environment but not sampling. The simplified approach used for the PA examines key HRS indicator factors that can be evaluated within the limited scope of the PA. Factors that are not critical to the score use reasonable default values and truncated evaluations.

The PA provides information on:

- Historical waste generation and disposal practices

- Hazardous substances associated with the site

- Potential sources of hazardous substances

- Important migration pathways and affected media

- A comprehensive survey of targets

- Critical sample locations for the SI

PA scoresheets identify critical HRS factors and provide instruction for their evaluation. Professional judgments made during the PA form the foundation for hypotheses that are tested during the SI.

Data important to the HRS may not be available during the PA-for example, analytical data on 
hazardous substance releases and targets exposed to actual contamination. For these factors, the site investigator exercises professional judgment applied in a reasonable and consistent manner to form hypotheses regarding the likelihood of release of hazardous substances and their migration to targets.

\subsubsection{Site Inspection}

Generally, the SI is the first investigation to collect and analyze waste and environmental samples to support a site evaluation according to the HRS. SI sample locations are strategically planned to identify the substances present, determine whether hazardous substances are being released to the environment, and determine whether hazardous substances have impacted specific targets. At the end of the SI, the investigator submits findings to EPA Regional and State officials who decide whether the site should undergo further investigation (resulting in possible NPL placement) or be dropped from further Federal Superfund consideration.

PA recommendations for further investigation may be based on at suspected threat without analytical documentation, since field samples are not taken. If, after sampling to test PA hypotheses, the site is found to present no significant threats to human health or the environment, the SI serves as a second screening investigation.

When initial site samples verify some or all PA hypotheses, or other data indicate the site poses a sufficient threat to warrant NPL consideration, the SI must be comprehensive and support HRS package preparation.

Often the scope of an SI can be limited to screening the site to confirm that it has no reasonable chance for placement on the NPL. A few strategically located samples may be enough to indicate that no further Superfund action needs to be planned. In such a case, collecting all information needed for HRS scoring is unnecessary. Instead, if critical questions remain after the PA regarding contamination that a few strategically placed samples could answer, the SI investigator can efficiently focus on those questions to determine how serious the threat posed by the site may be. This guidance manual refers to this type of SI as a focused SI.
At some sites, source, release, and target contamination are known during the PA from previous sampling investigations. Samples that focus on identifying substances and critical contamination to screen the site are not necessary. Instead, the scope of the SI is expanded to fully characterize the most significant threats posed by the site. An expanded SI should not result in a SEA recommendation; the option to perform an expanded SI should be reserved for sites that appear to qualify for the NPL.

An efficient way to fulfill both the screening and listing functions of the SI is to conduct the investigation in two parts: as screening (focused SI) and follow up, larger scale (expanded SI) investigations. Alternatively, the focused SI may collect enough information to document the HRS evaluation. And, as a final option, a single SI, generally expanded in scope, may satisfy HRS requirements without a screening stage.

Generally, the focused SI allows the investigator to determine if the site qualifies for the NPL or to support a SEA recommendation by testing PA hypotheses. It may be possible to prepare the HRS scoring package after the focused SI. However, most sites that are proposed for the NPL will require an expanded SI to complete sample and data collection to support an HRS package. Chapter 2 provides guidance on selecting an SI approach.

The SI consists of four major activities:

1) Review available information, including analytical data.

2) Organize project team and develop SI work plan, sample plan, health and safety plan, and investigation-derived wastes (IDW) plan.

3) Perform field work to visually inspect the site and collect samples.

4) Evaluate all data and prepare the SI report.

For some sites, the SI may involve additional tasks to help meet SI objectives and support HRS data requirements and emergency response and remedial efforts (see Guidance for Conducting Remedial Investigations and Feasibility Studies under CERCLA, OSWER Directive 9355.3-01). 
National Contingency Plan (NCP) Section 300.420 (c) (55 FR 8845) establishes two primary goals for the SI:

- To collect additional data to evaluate sites using the HRS, and

- To screen out sites that will not score high enough for the NPL.

Other SI goals are to support potential removal or enforcement actions and to collect data to support the remedial investigation and feasibility study (if the site is subsequently placed on the NPL) or response action under other authorities.

\section{Review Avallable Information}

Before developing SI plans, the investigator should review results from previous investigations, particularly analytical data. Site-specific analytical data may help guide further sampling, provide data to test site hypotheses, and evaluate threats to:

- Drinking water wells by migration of hazardous substances to ground water,

- Drinking water intakes by migration of hazardous substances to surface water,

- Fisheries and sensitive environments by migration of hazardous substances to surface water;

- Residents, students, and sensitive environments by soil contamination; and

- Populations and sensitive environments by migration of hazardous substances to air.

The SI investigator may need to update or reevaluate the basis of the screening decision for certain sites, for example, at sites with a PA not based on the revised HRS and at certain sites with an SI completed before 1989 where no decision has been made. Approximately 40 to 100 additional hours may be needed to:

- Gather the information necessary to update the PA evaluation.
- Formulate hypotheses regarding projected hazardous substance releases and targets suspected to be exposed to actual contamination.

- Document the findings in a narrative report and scoresheets (or deliverables specified by the Region or State).

The investigator should develop SI plans if the site warrants an SI (i.e., site score is greater than or equal to 28.50 ).

\section{Organize Project Team and Develop Plans}

After reviewing the assignment and the site data, the project team should be organized. A project team consists of administrative, scientific, technical, and field personnel with specific responsibilities contained in the plans. The team includes the project manager, field sampling personnel, health and safety officer, chemist, geologist, and subcontract administrator, among others. The project manager, generally referred to as the SI investigator in this guidance document, coordinates all project activities. This includes directing planning activities, managing dayto-day SI tasks, and ensuring that all field activities are documented. The field team supports plan development prior to conducting site work, as well as reconnaissance and field preparation activities. Upon completing field work, the team documents all field activities.

Most SI field teams require a minimum of four persons, including the health and safety officer, chemist, geologist, and subcontract administrator. The health and safety officer prepares the health and safety plan, ensures staff certification, reviews safety equipment checklists, and monitors health and safety procedures during the SI. The chemist performs field screening, recommends analytical services, and interprets and validates analytical data. The geologist evaluates hydrogeological information, interprets other geological data, and supervises geophysical activities. The subcontract administrator prepares bid specifications and procures and schedules special analytical services, drilling operations, and data validation contracts.

After evaluating previous results and all other pertinent information, the SI investigator prepares four plans to document SI procedures: 
- Work plan

- Sample plan

- Health and safety plan

- IDW management plan

These plans ensure thorough planning before field activities begin. Clear and concise plans are prerequisites for obtaining quality analytical data and making reliable conclusions.

The design of the work plan and sample plan is based on the objectives of the SI and HRS requirements. The sample plan includes justification for proposed sample locations and explicit instructions for sample collection. Health and safety plans describe procedures to protect workers according to specific standard operating procedures (SOPs). An IDW management plan is prepared in accordance with Management of Investigation-Derived Wastes During Site Inspections (OERR Directive 9345.3-02).

Chapter 3 of this document provides a detailed discussion of SI planning.

\section{Perform Fleld Work}

SI field work involves site reconnaissance, field observations and measurements, sampling, and health and safety monitoring.

A site reconnaissance (see Section 3.7) is conducted before field work begins to examine site and source conditions and to verify the practicality of sample locations. Sample analysis should be scheduled before field work begins.

SI field work typically takes two to six days. Typical field activities include: 1) completing field observations and site and pathway sketches that accurately identify sample locations; 2) locating and measuring distances to targets; 3) evaluating populations near the site; 4) collecting samples of source materials at the site and environmental media that may impact human and environmental receptors; 5) completing decontamination procedures; and 6) packaging and shipping samples to the laboratory for analysis. Field work may take longer for very large sites, sites with several sources, or expanded SI sites requiring installation of ground water monitoring wells. Chapter 4 discusses sampling strategies for the focused SI and expanded SI.

\section{Evaluate Data}

The investigator should assemble and summarize all data to evaluate the site. SI sample results should allow the investigator to evaluate:

- Site and source characteristics;

- Presence of contamination for specific HRS pathways; and

- Targets actually or potentially exposed to contamination for specific HRS pathways.

Chapter 5 discusses evaluating SI data.

Per Regional and State instructions, an HRS score is developed after the site data are evaluated. Three types of scoring tools are available: EPA's PREscore computer program; SI worksheets; and other evaluation tools developed by EPA Regional or State offices.

The investigator must prepare a narrative report highlighting significant findings, including the history and nature of waste handling at the site, known hazardous substances, pathways of concern for these substances, and the impact on human and environmental targets.

Other deliverables, as directed by EPA Regional or State officials, may include a summary record of the SI data (see Appendix B). Chapter 6 discusses SI reporting requirements.

Based on the conclusions of the SI, EPA makes one of three site decisions:

- Site evaluation accomplished (SEA);

- Further investigation; or

- Schedule preparation of the HRS package if all necessary data are available. 


\section{CHAPTER 2 SI APPROACHES}

This chapter discusses approaches for conducting an SI. These include the focused SI, expanded SI, and single SI options. The focused SI tests PA hypotheses requiring further investigation and may be used to screen sites to determine the need for further Federal Superfund action. The expanded SI gathers information to fulfill HRS requirements for sites with a high probability of qualifying for the NPL. The single SI approach combines the functions of the focused and expanded SIs and may be chosen under certain conditions.

\subsection{FOCUSED SI}

The goal of the focused SI is to obtain and analyze environmental samples, to investigate human and environmental exposure to hazardous substances, and to test PA hypotheses that are the basis of the further action conclusion. Any of the following hypotheses, or any combination of them, can result in a PA further action decision.

- Release and migration (or threatened release) of a hazardous substance to drinking water wells or intakes.

- Release and migration of a hazardous substance to surface water sensitive environments or fisheries.

- Presence of a hazardous substance on residential, school, or day care properties or terrestrial sensitive environments.

- Release of a hazardous substance into the air.

Because these hypotheses are often based on professional judgement rather than analytical data, the focused SI emphasizes obtaining critical analytical data of waste and environmental samples that are usually not available during the PA. The focused SI should reflect the HRS significance of hazardous substance migration from sources at the site and contamination of targets.

As an example of how to test a PA hypothesis, consider the following situation:

The PA for $\mathrm{ZZ}$ Metals, an abandoned plating facility, revealed that the only significant target is a shallow community well serving 50 people located 800 feet south of the site. PA investigators suspect that hazardous substances have migrated to this well, although no recent sample data are available to test this hypothesis.

The focused SI for ZZ Metals must include samples to test the PA hypothesis of contamination at the community well. Theoretically, this site could be screened from further Federal Superfund investigation by collecting only one sample from the well. If hazardous substances are not detected in that sample, the site would not score high enough for NPL consideration, regardless of other HRS scoring factors, such as waste characteristics. However, additional sampling will increase the degree of confidence in the conclusion and better characterize the site. Additional samples, for example from private wells, may be necessary to investigate public health and human exposure, even if contamination in those wells alone would not result in an HRS score greater than or equal to 28.50 .

Collecting samples to characterize sources helps determine whether hazardous substances are actually associated with the site. Where a hazardous substance problem exists, source sampling identifies the specific substances at the site. If only low levels of hazardous substances are detected, investigators will have more confidence using other analytical results (e.g., from an uncontaminated community well) to screen the site. Conversely, if a specific hazardous substance is found in both the community well and site sources, target contamination can tentatively be attributed to the site.

The focused SI typically requires 12 to 20 samples (average 15) to investigate PA hypotheses of target 
contamination and to determine the types of hazardous substances present at a site. The scope of a focused SI is defined by the number of critical hypotheses and questions remaining after the PA and the number of pathways contributing to the further action recommendation.

Conclusively attributing target contamination to the site or establishing the range of background levels for substances of concern are not necessary to test critical PA hypotheses and screen the site. The number of focused SI samples is typically less than the number of samples required to detect all hazardous substances present and to definitively attribute them to the site. More background, quality assurance, and quality control $(\mathrm{QA} / \mathrm{QC})$ samples may be needed to support HRS attribution requirements.

The hours to complete the focused SI varies with the amount of information available from the PA and the complexity of the site. On average, 350 to 450 technical hours are sufficient (Table 2-1). Most time will be spent preparing for the sampling visit and collecting samples in the field. At sites where the PA was conducted using the original HRS, additional hours will be necessary to update PA information and evaluate the site based on the revised HRS.

The investigator provides information to EPA officials at the end of the focused SI so that they may make one of three site disposition decisions:

- Site Evaluation Accomplished;
- Further action (e.g., expanded SI); or

- Schedule HRS package preparation if all necessary data are available.

To make a site disposition decision, EPA site assessment managers (SAMs) consider all data in light of the SI sample results to refine the site score developed at the PA. SAMs typically use EPA's PREscore computer program or SI worksheets to generate the site score for the focused SI. If PA hypotheses are confirmed, the SI site score will be high enough to warrant the expanded SI or preparation of the HRS package, since the threat or potential threat to human health or the environment can now be established. Otherwise, the site can be eliminated from further Superfund consideration at this time.

In most cases, a focused SI site score greater than 28.50 will approximate or represent a complete HRS site score that will be high enough for NPL consideration. However, in some instances, the focused SI score may be based on assumptions that have not been fully explored within the limited scope of a focused SI. Further investigation may change the site decision from further action to SEA. This can occur, for example, when hazardous substances detected during the focused SI at target locations are presumed to be from the site, but samples during the expanded SI reveal they are not attributable to the site. If attribution to the site is questionable or levels of contamination are very low, site assessment staff experienced in the HRS should review the analytical

TABLE 2-1: HOURS TO COMPLETE FOCUSED SI TASKS

\begin{tabular}{||l|c|c|}
\hline Task & Hours & Percent \\
\hline \hline PA review and work and sample plan development & 50 & 12.5 \\
\hline $\begin{array}{l}\text { Mobilization, travel, and demobilization } \\
\text { (1 to 3 days, 3 to 5 team members) }\end{array}$ & 150 & 37.5 \\
\hline $\begin{array}{l}\text { Sampling and data collection } \\
\text { (generally not for all four pathways) }\end{array}$ & 120 & 30.0 \\
\hline Report preparation, HRS evaluation, and reviews & 80 & 20.0 \\
\hline \multicolumn{1}{|c|}{ Total } & $\mathbf{4 0 0}$ & $\mathbf{1 0 0 . 0}$ \\
\hline
\end{tabular}


results and site score to make sure an expanded SI is warranted. This review also will help define activities and objectives for the expanded SI.

\subsection{EXPANDED S}

The objective of the expanded SI is to collect all data necessary to prepare an HRS scoring package to propose the site to the NPL. To fully evaluate the site and to fulfill HRS package documentation requirements, the SI investigator should:

- Investigate and document critical hypotheses or assumptions not completely tested during the focused SI.

- Collect samples to attribute hazardous substances to site operations.

- Collect samples to establish representative background levels.

- Collect any other missing HRS data for pathways of concern.

When environmental samples do not provide the information needed for HRS documentation requirements, investigators also may need to perform special field activities. The purpose of these procedures, which are beyond the screening scope of the focused SI, is to supply data to refine and document the site score. Special expanded SI field activities may include monitoring well installation, air sampling, geophysical studies, drum or tank sampling, borehole installation, and complex background sampling studies.
The expanded SI typically requires 25 to 35 samples (average 30) and 600 to 650 technical hours (Table 22). The complexity of the site and the need for special procedures will determine the scope of the investigation and whether additional technical hours are required.

Sampling during the expanded SI should be designed to support and document HRS requirements, including 1) observed releases of hazardous substances relative to background, 2) observed contamination, and 3) levels of contamination. The expanded SI investigator should collect a complete set of QA/QC and background samples to fully and confidently document and attribute releases to the site.

To illustrate the difference between expanded SI and focused SI sampling, again consider the ZZ Metals Site:

Focused SI sampling results showed high levels of phenol in the community well 800 feet south of the site and in sources at the site. However, wastes containing phenol are also associated with a second facility 600 feet southeast of the community well.

The expanded SI should investigate whether contamination in the community well can be attributed to ZZ Metals. This would require sampling selected wells located between $\mathrm{ZZ}$ Metals and the community well, plus additional wells between the

TABLE 2-2: HOURS TO COMPLETE EXPANDED SI TASKS

\begin{tabular}{||l|c|c|}
\hline Task & Hours & Percent \\
\hline $\begin{array}{l}\text { Previous irvestigation review (PA, focused SI) and work and } \\
\text { sample plan development }\end{array}$ & 130 & 20 \\
\hline $\begin{array}{l}\text { Mobilization, travel, and demobilization } \\
\text { (2 to 3 days, 5 team members) }\end{array}$ & 150 & 25 \\
\hline $\begin{array}{l}\text { Sampling and data collection } \\
\text { (generally not for all four pathways) }\end{array}$ & 240 & 40 \\
\hline Report preparation, HRS evaluation, and reviews & 100 & 15 \\
\hline \multicolumn{1}{|c|}{ Total } & $\mathbf{6 2 0}$ & $\mathbf{1 0 0}$ \\
\hline
\end{tabular}


An expanded SI is not necessarily larger in scope than a focused SI. The scope of an expanded SI depends on the HRS data gaps remaining after all previous investigations.

community well and the second facility. If no wells exist in these areas, ground water monitoring wells should be installed to determine whether ZZ Metals is contributing, at least partially, to the contamination of the community well.

The expanded SI also differs from the focused SI by emphasizing collection of all missing non-sampling information for pathways of concern. These data may be used to support previous documentation or references, fulfill remaining HRS data requirements, and identify other sources of contamination in the site vicinity. Table 2-3 compares focused SI and expanded SI data collection activities.

At the end of the expanded SI, the investigator prepares a report of all expanded SI findings and analytical results. Per EPA Regional and State instructions, the investigator should evaluate all site data according to the HRS. If the site is to be proposed for the NPL, assembling an HRS package will be scheduled. The HRS package consists of the HRS documentation record, reference materials, HRS scoresheets, and site narrative summary along with other administrative requirements as specified in Regional Quality Control Guidance for NPL Candidate Sites (OSWER Directive 9345.1-08, 1991). Preparing the HRS package is not part of SI activities; however, all data necessary to document an HRS score should be collected during the expanded SI.

\subsection{SINGLE SI APPROACH}

Investigators may consider performing a single SI if the quality of available data and site characteristics strongly indicate a significant threat. Another consideration to perform a single SI is whether all data necessary to document an HRS score can be collected efficiently at one time. A complex site may require a two-stage field investigation even if it is clearly an NPL candidate. For such a case, the investigator should restrict the scope of the focused SI to obtaining data needed to support efficient future sampling and to address HRS documentation requirements.

TABLE 2-3: TYPICAL SI DATA COLLECTION ACTIVITIES

\begin{tabular}{|l|c|c||}
\hline Activity & Focused SI & $\begin{array}{c}\text { Expanded and } \\
\text { Single SI }\end{array}$ \\
\hline \hline Non-sampling data collection & $\checkmark$ & $\checkmark$ \\
\hline Target sampling & $\checkmark \checkmark$ & $\checkmark \checkmark$ \\
\hline Source sampling & $\checkmark \checkmark$ & $\checkmark \checkmark$ \\
\hline Release sampling & $\checkmark$ & $\checkmark \checkmark$ \\
\hline Background sampling & $\checkmark$ & $\checkmark \checkmark$ \\
\hline Attribution sampling & - & $\checkmark \checkmark$ \\
\hline QA/QC sampling & $\checkmark$ & $\checkmark \checkmark$ \\
\hline Special data collection or sampling tasks & - & if necessary \\
\hline & KEY: $\checkmark \checkmark=$ Major activity \\
\end{tabular}


If the complexity of the site does not preclude a single phase field investigation, and if previous data fulfill the screening functions of the focused SI and indicate that the site will score high enough for NPL consideration, the focused SI may be bypassed. However, if conclusions are drawn exclusively from sample results, the investigator must be sure that previous analytical data are of sufficient quality to support the conclusions (see Section 3.5.2). Sample locations, sarnpling protocols, analyzed substances, and data validation procedures all influence how previous analytical data can be used at the SI (e.g, for HRS scoring, testing PA hypotheses, sample planning). Figure 2-1 outlines basic selection criteria for a single SI. Site conditions consistent with a single field investigation are discussed below.

Sites with Available Analytical Data: Municipal, county, State, or Federal authorities may have conducted prior sampling investigations at some sites. The effect this information may have on the scope of the SI depends on their quality (see Guidance for Data Useability in Site Assessment, in development) and whether they support or refute PA hypotheses. If previous analytical data clearly demonstrate that the site score will be high enough for NPL consideration, a single SI may be conducted, unless the complexity of the site dictates iterative sampling.

"Simple" Sites: Some sites have characteristics that simplify the HRS evaluation. For "simple" sites, it may be possible to compile all data necessary to prepare an HRS package (i.e., expanded SI objective) within the focused SI sampling budget. This is true for sites with:
- Well-defined source and waste characteristics

- No other potential sources of contamination in the area

- One pathway of concern

- Few targets requiring sampling

In a few cases, even in the absence of analytical data, site characteristics are well-defined at the PA stage. These sites may qualify for NPL consideration with limited sampling. For example, if the site historically operated as a wood treatment facility and is located immediately adjacent to surface water used by fishermen, a single investigation may be a reasonable approach. In this situation, it may be possible to characterize threats to the surface water pathway with a relatively limited investigation.

Remote Sites: Investigations at some sites require considerable travel because of remote locations. Travel-related activities often account for as much as 40 percent of the budget for such investigations. At sufficiently remote sites, a single SI may be costeffective, provided a second site visit will not be necessary later to collect missing data.

Potential Contamination Sites: Some sites are recommended for further action after the PA because the targets subject to potential contamination are significant. If available information indicates a strong likelihood of a release, the focused SI may be bypassed if the site score will be high enough for NPL consideration based on potential to release or an observed release only (as opposed to actual contamination). 
FIGURE 2-1: SITE INSPECTION DECISION TREE

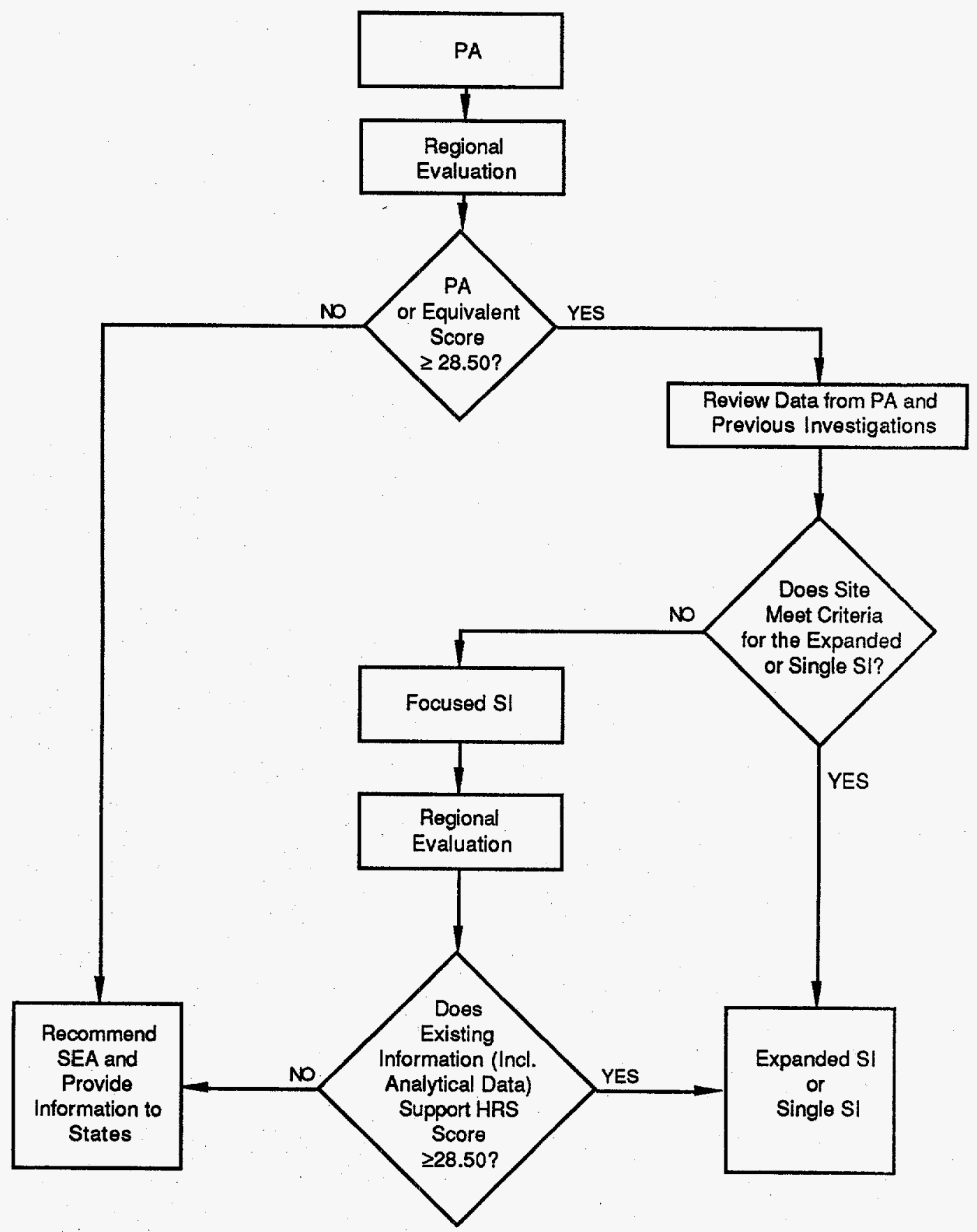




\section{CHAPTER 3 PLANNING}

Each SI requires a site-specific work plan, sample plan, health and safety plan, and investigation-derived wastes (IDW) plan. These plans help investigators adhere to planned procedures in their field work and identify potential sources of error that could jeopardize the quality of analytical data. Specific plans also facilitate the investigation by defining the activities that will produce information needed to meet SI objectives. This chapter discusses key elements to consider in SI planning and provides background information on sample collection issues to help design the SI and assess the usability of available data. This chapter also provides guidance on SI project management and on site reconnaissance. Special guidance on SI planning for sites containing radioactive substances is provided at the end of the chapter.

\subsection{SAMPLE COLLECTION ISSUES}

The SI collecis selective samples to demonstrate that hazardous substances are present and to determine whether they have migrated from their original locations. The SI differs from traditional approaches to environmental monitoring, for which samples are collected to represent "average" contamination in the environment. For SI selective and limited sampling, careful planning for data collection is essential to avoid sampling errors.

When sampling is limited, the probability of false negatives in samples increases. "False negative" means a hazardous substance is present but not detected. The potential for false negatives in samples underscores the importance of a well-designed sample plan for the site. Conclusions based on false negative data may result in decisions that do not protect human health and the environment. False positive samplesa substance is detected but is not present at the siteare also undesirable; however, they often can be identified by evaluating quality control sample results. The frequency of false positives is normally influenced by sampling and analytical procedures, and not by the sampling approach.

This section provides information on sample types and sample variability that will help the investigator design and implement an effective sample plan.

\subsubsection{Sample Types}

Normally, SI sampling strategies require biased sampling, also known as non-random or judgmental sampling. Biased sampling uses knowledge of the site and visual observations to propose sample types and locations. Table 3-1 summarizes sample types and their advantages and disadvantages.

SI samples are generally waste source samples or media (environmental) samples. Most SI samples are media samples of ground water, surface water, soil, or air. Analytical data from media samples indicate the presence or absence of hazardous substances released to the environment, exposure of humans to hazardous chemicals, or contamination of the environment. Because concentrations of hazardous substances in media samples may have been diluted by environmental influences, proper sampling procedures are particularly important-even minimal sample contamination or loss could significantly affect analytical results. Source sample results identify hazardous substances present and support attribution of contamination to site operations.

The SI sample plan may specify several types of samples. Grab samples represent chemical conditions at a specific location. They offer the most information regarding hazardous substance variability and are recommended to investigate observed releases 
TABLE 3-1: TYPES OF SAMPLES

\begin{tabular}{|c|c|c|}
\hline SAMPLE TYPE & ADVANTAGES & DISADVANTAGES \\
\hline $\begin{array}{l}\text { Biased } \\
\text { (non-random, } \\
\text { judgmental) }\end{array}$ & $\begin{array}{l}\text { Promotes timeliness } \\
\text { Uses knowledge of site } \\
\text { Focuses sampling effort }\end{array}$ & $\begin{array}{l}\text { Decreases representativeness } \\
\text { Increases chance of false negatives }\end{array}$ \\
\hline $\begin{array}{l}\text { Unbiased } \\
\text { (random, } \\
\text { systematic } \\
\text { grid) }\end{array}$ & $\begin{array}{l}\text { Increases representativeness } \\
\text { Reduces chance of false negatives } \\
\text { Allows limited site knowledge }\end{array}$ & $\begin{array}{l}\text { Increases cost } \\
\text { Increases time required }\end{array}$ \\
\hline Grab & $\begin{array}{l}\text { Increases representativeness and } \\
\text { variability }\end{array}$ & $\begin{array}{l}\text { Requires more samples } \\
\text { Requires careful placement }\end{array}$ \\
\hline Composite & $\begin{array}{l}\text { Reduces cost } \\
\text { Increases area of investigation } \\
\text { Reduces chance of false positives }\end{array}$ & $\begin{array}{l}\text { Provides average concentrations only } \\
\text { Allows substances to interact }\end{array}$ \\
\hline Media & $\begin{array}{l}\text { Supports releases } \\
\text { Supports target contamination }\end{array}$ & $\begin{array}{l}\text { May require off-site access permits } \\
\text { Subject to temporal variation }\end{array}$ \\
\hline Waste & $\begin{array}{l}\text { Optimizes contaminant identification } \\
\text { Supports attribution }\end{array}$ & $\begin{array}{l}\text { May result in elevated concentrations } \\
\text { May require sample dilution } \\
\text { May require special procedures and } \\
\text { equipment }\end{array}$ \\
\hline Filtered & $\begin{array}{l}\text { Allows comparison with drinking water } \\
\text { benchmarks }\end{array}$ & $\begin{array}{l}\text { Comparison with surface water } \\
\text { environmental benchmarks not valid } \\
\text { May increase sample handling errors }\end{array}$ \\
\hline Unfiltered & $\begin{array}{l}\text { Allows comparison with surface water } \\
\text { environmental benchmarks }\end{array}$ & $\begin{array}{l}\text { Comparison with drinking water } \\
\text { benchmarks not valid }\end{array}$ \\
\hline
\end{tabular}


and target exposure to contamination. Composite samples consisting of several grab samples represent average concentration values and may be used to identify hazardous substances present in sources.

Aqueous samples may be filtered or unfiltered. Most samples collested during the SI are unfiltered (see Table 3-2). Because laboratory analysis of unfiltered samples can release metals loosely bound to suspended solids in water, metal concentrations can be overestimated. For this reason, filtered samples are recommended to establish an observed release of metals in a drinking water supply, although either filtered or unfiltered samples are acceptable. Even highly turbid filtered water samples can be compared to health-based drinking water regulatory standards, such as Maxirnum Contaminant Levels (MCLs).

Monitoring well and surface water environmental target aqueous samples should not be filtered in the field, unless they are to be compared to filtered samples to establish observed releases. Likewise, filtering is not needed when establishing actual contamination of a drinking water supply by organics. Therefore, when the full range of hazardous substances at a site is unknown, collecting both filtered and unfiltered water samples may be warranted. Hazard Ranking System (HRS) Guidance Manual and Guidance for Data Useability in Site
Assessment (both in development) may provide more information on using filtered or unfiltered water samples for HRS scoring.

\subsubsection{Sample Variabllity}

The sample plan should minimize the potential for errors related to sampling procedures. Errors resulting from improper sampling are often several times more significant than errors introduced by analytical procedures. To minimize these errors, the investigator should: adhere to standard operating procedures (SOPs); choose appropriate sampling equipment, containers, and preservatives; and plan the sequence of, and schedule for, sample collection.

Samples may reflect variability in collecting and handling samples, or variability of hazardous substances with location, time, or medium.

\section{Sample Collection and Handling Variability}

Errors introduced by sample collection and handling variability can change sample concentrations due to incorrect sampling procedures, cross-contamination, and improper sample preservation. Variability caused by error can be reduced through training and by performing all sampling activities in accordance with SOPs. Adhering to SOPs can reduce or eliminate

TABLE 3-2: FILTERED AND UNFILTERED WATER SAMPLES

\begin{tabular}{||c|c|c|c||}
\hline $\begin{array}{c}\text { HRS PATHWAY/ } \\
\text { THREAT }\end{array}$ & METALS ANALYSIS & $\begin{array}{c}\text { ORGANIC } \\
\text { ANALYSIS }\end{array}$ & $\begin{array}{c}\text { SAMPLES FROM } \\
\text { KARST AQUIFERS }\end{array}$ \\
\hline \hline Ground Water & Filtered/Unfiltered & Unfiltered & Unfiltered \\
\hline $\begin{array}{c}\text { Surface Water } \\
\text { Drinking Water } \\
\text { Threat }\end{array}$ & Filtered/Unfiltered & Unfiltered & Not Applicable \\
\cline { 2 - 4 } $\begin{array}{l}\text { Environmental } \\
\text { Threal }\end{array}$ & $\begin{array}{l}\text { Filtered when compared } \\
\text { with MCLs, MCLGs', and } \\
\text { Screening Concentrations }\end{array}$ & Unfiltered & Not Applicable \\
\cline { 2 - 4 } & $\begin{array}{l}\text { Unfiltered when compared } \\
\text { with AWQCs }{ }^{2} \text { and } \\
\text { AALACs }\end{array}$ & Unfiltered & Not Applicable \\
\hline $\begin{array}{l}{ }^{1} \text { MCLG - Maximum Contaminant Level Goals } \\
{ }^{2} \text { AWQC - Ambient Water Quality Criteria } \\
{ }^{3} \text { AALAC - Ambient Aquatic Life Advisory Concentrations }\end{array}$ \\
\hline
\end{tabular}


variability within and between sites for a given sampling method. Collection and handling errors can rarely be corrected without additional sampling and analysis. Before implementing any non-standard procedure, the investigator must assess whether changes may jeopardize data quality.

Potential contamination problems attributable to sampling devices, sample containers, or construction materials include cross-contamination, hazardous substance sorption, and chemical leaching (see Table 3-3). The importance of decontamination increases when investigating barely detectable concentrations. By planning carefully, the investigator can reduce and possibly eliminate contamination. In particular, the SI investigator should remember that polyvinyl chloride (PVC) and other plastics (except Teflon®) tend to absorb organics, and that some halogenated organic compounds and pesticides adsorb to glass surfaces.

Contamination from substances leaching from sampling or monitoring equipment is a particular problem in water samples and may contribute to false negative or false positive results. Contaminants may have analytical interference effects, decreasing or even preventing quantification of the substances of concern. If any samples have been contaminated by equipment, resampling may be needed. Equipment decontamination is particularly important following sampling in areas of suspected high concentrations of hazardous substances. When possible, background and media samples should be collected before waste or source samples.

Confirming the purity of preservatives is important in planning. Contaminated, outdated, or improperly stored preservatives can place analytical results outside the limits of random error.

Holding time-how long a sample can be stored before preparation and analysis without significantly affecting the analytical results-will vary from sample to sample, depending on the substance, preservation technique, and analytical method.

\section{Spatial Variability}

Spatial variability-how substances and their concentrations vary from one location to anotherdepends on the substance and site conditions. As a general rule, variability increases as a source becomes less uniform. In some media, such as soils, spatial variability can be significant. Potential sampling problems due to spatial variation can be significantly

TABLE 3-3: POTENTIAL CONTAMINANTS FROM SAMPLING DEVICES AND WELL CASINGS

\begin{tabular}{|l|l||}
\hline \multicolumn{1}{|c|}{ MATERIAL } & \multicolumn{1}{c|}{ POTENTIAL CONTAMINANTS } \\
\hline \hline Rigid PVC-threaded joints & Chloroform \\
\hline Rigid PVC-cemented joints & $\begin{array}{l}\text { Methyl ethyl ketone, toluene, acetone, benzene, methylene } \\
\text { chloride, organic tin compounds, tetrahydrofuran, ethyl } \\
\text { acetate, cyclohexanone, vinyl chloride }\end{array}$ \\
\hline Flexible or rigid Teflon® tubing & None detectable \\
\hline Flexible polypropylene tubing & None detectable \\
\hline Flexible PVC tubing & Phthalate esters, other plasticizers \\
\hline Soldered pipes & Tin and lead \\
\hline Stainless steel containers & Chromium, iron, nickel, molybdenum \\
\hline Glass containers & Boron, silicon \\
\hline Source: Keith, 1991 & \\
\hline
\end{tabular}


reduced by using previous site information and professional judgment in choosing sample locations. Chapter 4 provides guidance in selecting locations.

For homogeneous sources (e.g., single phase liquid in a tank), spatial variability is reduced, and limited sampling to determine hazardous constituent or wastestream quantity may be appropriate. Representative sampling to determine the HRS hazardous constituent quantity at heterogeneous sources is generally not within the scope of an SI.

\section{Temporal Variability}

Hazardous substance concentrations may depend on variables such as the time of day or season of the year. Often the most important temporal variable is weather (i.e., temperature or rainfall). Because weather follows cyclical patterns over a day or year, time-dependent substance levels are expected to follow similar cyclical patterns. The investigator should identify the cyclical nature of the substance concentrations caused by temporal variability and sample when concentrations are expected to be highest. For example, during colder weather a volatile compound may be less readily released than during warmer weather.

For SIs, the duration and frequency of sampling are normally not a consideration, because one-time sampling usually accomplishes the objectives of the investigation. In some instances, however, seasonal variations or weather patterns may require more than one sampling episode.

\section{Medla Variability}

Sampling concerns vary according to medium (see Table 3-4). Each of the variability concerns discussed above may be affected by the particular medium

TABLE 3-4: SAMPLING ISSUES AFFECTING CONFIDENCE IN ANALYTICAL RESULTS

\begin{tabular}{|c|c|c|c|c|c|c|}
\hline $\begin{array}{l}\text { MAJOR } \\
\text { SAMPI_ING } \\
\text { ISSUES }\end{array}$ & $\begin{array}{c}\text { SOIL/ } \\
\text { SEDIMENT }\end{array}$ & $\begin{array}{l}\text { GROUND } \\
\text { WATER }\end{array}$ & $\begin{array}{l}\text { SURFACE } \\
\text { WATER }\end{array}$ & AIR & $\begin{array}{l}\text { AQUATIC } \\
\text { ANIMAL } \\
\text { TISSUE }\end{array}$ & $\begin{array}{c}\text { SOURCE } \\
\text { MATERIAL }\end{array}$ \\
\hline $\begin{array}{l}\text { Hazardous Substance } \\
\text { Migration }\end{array}$ & $\checkmark$ & - & 1 & $\checkmark$ & 一 & $\checkmark$ \\
\hline Temporal Variation & - & 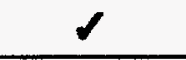 & 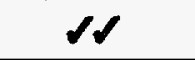 & $\checkmark$ & $\checkmark$ & - \\
\hline Spatial Variation & $\checkmark$ & - & 18 & $r$ & 一 & $d$ \\
\hline $\begin{array}{l}\text { Topographic and } \\
\text { Geological Features }\end{array}$ & $\checkmark 2$ & $A$ & 一 & $\checkmark$ & - & 一 \\
\hline Hot Spots & $d \Omega$ & - & - & - & 一 & 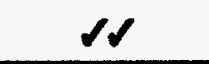 \\
\hline Sample Collection & $\checkmark$ & $\checkmark$ & $\Omega$ & $\Omega$ & 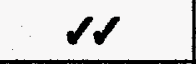 & $\checkmark$ \\
\hline $\begin{array}{l}\text { Sample Preparation } \\
\text { and Handling }\end{array}$ & $\mathscr{R}$ & $\checkmark r$ & 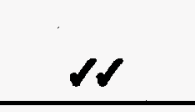 & $\checkmark$ & $\checkmark 4$ & $\checkmark$ \\
\hline Sample Storage & $一$ & $\checkmark$ & $\checkmark$ & $\checkmark d$ & $\checkmark$ & 一 \\
\hline Sample Preservation & - & $\checkmark$ & $\checkmark d$ & 一 & $d 4$ & 一 \\
\hline \multicolumn{7}{|c|}{ 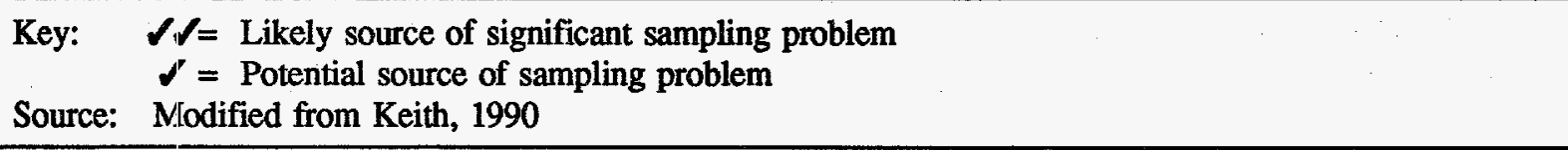 } \\
\hline
\end{tabular}


being examined. Sensitivity, precision, and accuracy of the analysis also are potentially affected by the medium.

For heterogeneous media (e.g., soil, surface water), strata should be defined and samples specified by stratum. Media heterogeneity influences both the sampling strategy and data usability.

Surface Water and Ground Water Samples: The heterogeneous nature of water often results in stratification of hazardous substances and requires special sampling and handling procedures. In deeper surface waters, flow may be reduced, resulting in chemical and thermal stratification. Stratification also may occur in lake and ocean samples and in locations where mixing occurs, such as the convergence of two streams or estuarine or near-shore environments. Density and solubility characteristics also can result in stratification. Some liquids, such as halogenated organic compounds, are heavier than water and will sink, while others, such as oils and solids, are lighter than water and tend to float on or near the surface. Surface water collected at the surface should not be compared to samples collected at depth. Samples collected in a tidally influenced area must not be compared to samples collected in fresh water. Aqueous samples must not be compared to sediment samples.

Background and environmental samples must be similar. For the ground water pathway, water samples should be collected from the same aquifer and at approximately the same depth (elevation) in the aquifer. Differences in physical parameters (such as iron content or $\mathrm{pH}$ ) may indicate that samples have been collected from different aquifers. Since different aquifers can have very different contamination levels and water chemistry, background wells used to establish observed releases must be screened in the same aquifer. Interconnected aquifers are not considered as one aquifer under the HRS, and samples from one aquifer generally should not be compared to samples from an interconnected aquifer to establish an observed release.

Sampling devices should be selected to minimize aeration of the water sample, thereby reducing volatilization or oxidation of hazardous substances. Aeration is a common problem when bailers are used to sample wells. If bailers are used, water field blanks are recommended to detect absorption of air contaminants introduced during sample transfer.

Soil and Sediment Samples: Heterogeneity of media, size, and distribution of particles, and bias introduced by sampling and analysis cause variability in soil and sediment samples. Substantial variability in a single soil type may result from lateral heterogeneity, soil horizons, and grain sizes. Primary soil heterogeneity is due to the parent material, as well as vegetation, slope, climate, and weathering. Vertically composite samples may help overcome the lack of homogeneity in the distribution of chemical species; however, peak values from composite samples may be diluted.

The investigator must document location, depth, and description of the soil to determine the relationship of background to other samples. If the depth and thickness of soil horizons vary with location, the SI investigator must ensure that samples to be compared are from the same horizons and soil types.

Air Samples: Atmospheric conditions are always a concern in air sampling, since some conditions tend to lower detectable concentrations. Conditions that may influence air sample results include:

- Wind speed and direction

- Temperature

- Relative humidity, including precipitation

- Terrain

- Atmospheric stability

Air sample results are unusable if wind direction was not monitored. Wind speed and direction data may be required to establish the migration pattern of emissions from a source. A slight shift in wind direction can substantially alter the amounts of hazardous substances collected in an air sample over a short period of time.

Tissue Samples: Significant variations often occur in sampling human food chain organisms. Differences between species, variations within the species, species mobility, and tissue differentiation present unique challenges. Factors that complicate tissue sampling include:

- Type of organism

- Age of individual 
- Population size

- Availability and cost of sampling materials

- Migratory organisms

- Seasonal, feeding, spawning, or other periodic activities that influence concentration or location of the substances within an organism

Individual organisms should be chosen at random from a well-defined population. Documentation should include the reasoning behind which parts (e.g., filet) of the specimen were analyzed and the accuracy of the measurement.

Containerized Material: Samples from containers (e.g., drums, tanks) can be heterogeneous, especially when different liquids are present, resulting in multiple layers of immiscible liquids. Sampling should be designed to obtain a representative sample of the liquid at all depths. Composite samples from various depths within the container may help overcome the heterogeneity, although hazardous substance concentrations may be underrepresented. If peak concentrations of various hazardous substances are required, several grab samples should be analyzed. Documenting collection procedures will be important to evaluate the use of these data.

\subsection{FIELD QA/QC CONSIDERATIONS}

Proper field documentation is an important part of the QA/QC program. Field documentation includes accounting for procedures or SOPs to record sample locations, label samples, maintain the chain-of-custody process, and document field observations and measurements. Any deviation from SOPs should be carefully noted. Failure to provide proper documentation can limit the use of analytical data, contribute to uncertainty in the analytical results, and compromise the legal defensibility of the data.

Collection and analysis of QC samples are important aspects of the QA/QC program. Sampling and analysis provide numerous opportunities for errors that contribute to the uncertainty of analytical results. Field QC samples help evaluate analytical results and field methods. Field QC samples must be collected, stored, transported, and analyzed in the same manner as site samples. The laboratory analyzing the samples should not know which are QC samples. These practices ensure that the $\mathrm{QC}$ results reflect routine procedure and reliably indicate the quality of field methods, analytical methods, and site sample data.

Table 3-5 summarizes field QC samples appropriate for the SI. Regional guidelines should be consulted to determine the number and type of $\mathrm{QC}$ samples, which may be the following:

Co-located or duplicates are usually two samples collected at the same time and location. They are used as measures of either the homogeneity of the medium sampled in a particular location or the precision in sampling.

TABLE 3-5: TYPICAL SI FIELD QC SAMPLES

\begin{tabular}{|c|c|}
\hline TYPE OF SAMPLE & PURPOSE \\
\hline Field Duplicate & To estimate medium homogeneity and sampling precision \\
\hline Field Blank & $\begin{array}{l}\text { To estimate bias caused by contamination introduced during field sampling and } \\
\text { laboratory analysis; to compare with laboratory method blank to determine source } \\
\text { of contamination }\end{array}$ \\
\hline Trip Blank & $\begin{array}{l}\text { To estimate bias due to contamination from migration of VOCs into the sample } \\
\text { during shipping from the field and storage at the laboratory }\end{array}$ \\
\hline Field Rinsate & $\begin{array}{l}\text { To estimate bias caused by contamination from sampling equipment; to indicate } \\
\text { cross-contamination, poor decontamination procedures, and potential contamination } \\
\text { due to sampling devices }\end{array}$ \\
\hline
\end{tabular}


A comprehensive and well-documented quality assurance/quality control (QA/QC) program is essential to obtain precise and accurate data that represent the site and are scientifically and legally defensible.

Replicates or splits are usually one sample that is divided and sent to the same or separate laboratories for analysis. Replicates are used to check instrument precision and accuracy of a laboratory analysis. Samples may be split for independent analysis.

Field blanks are samples of contaminant-free medium that are either transferred from one container to another in the field or exposed to field conditions. These samples are used as an indicator of sample contamination during the entire process, including sampling, transport, sample preparation, and analysis. They are especially critical as concentrations approach detection limits.

Trip or transport blanks are prepared from contaminant-free media prior to the SI in extra sample containers. They are kept unopened with site samples throughout the field investigation. They are used to measure possible contamination, particularly crosscontamination, introduced during collection, shipping, and storage of samples.

Field rinsates (or equipment blanks) are samples of deionized water (or the decontamination solution) flushed through sampling equipment (e.g., bailer, pump, auger) after decontamination and before resampling to monitor decontamination procedures. Although not routinely collected, field rinsates analyzed via field analytical screening techniques can be extremely valuable in indicating and correcting cross-contamination during sampling.

Field matrix spikes are samples prepared in the field by adding a known amount of contaminants to selected site samples. They are used to identify field, transportation, and matrix effects. Because of the possible sources of error in preparing field spikes, they are not recommended during the SI unless specialized technical support is available. Any results should be compared to laboratory matrix spike results.

\subsection{HRS SAMPLING CONSIDERATIONS}

Sample planning should reflect the importance of data collection in the HRS process. The investigator needs a good understanding of the HRS to develop an appropriate sample plan and to improve the quality and usefulness of SI information. The following HRS elements require sample data:

Site and Source Characterization: Analytical data are important in characterizing sites and sources, primarily to identify hazardous substances present in site sources. Analytical data also support determining hazardous waste quantity, delineating source dimensions, and investigating the degree of source containment.

Observed Releases and Areas of Observed Contamination: Analytical data may provide direct evidence of an observed release of hazardous substances to affected media, demonstrate significant contamination (observed contamination in the soil exposure pathway), estimate areas of contamination, and show that the contamination is attributable to the site. For an observed release (or observed contamination), significance relates only to the concentration found in a particular pathway or medium, not to the environmental or health effects of that release.

Levels of Contamination at Specific Targets: Analytical data are required to document actual contamination of targets, including wells and surface water intakes supplying drinking water; residential and school properties; and fisheries, wetlands, and other sensitive environments. If data do not demonstrate that targets are exposed to actual contamination, targets are evaluated as potentially exposed. The HRS levels of contamination are:

- Level I: Concentrations that meet the criteria for actual contamination (e.g., observed release or observed contamination), and are at or above media-specific benchmark levels (see Table 3-6).

- Level II: Concentrations that either meet the criteria for actual contamination but are less than media-specific benchmarks, or meet the criteria 
TABLE 3-6: MEDIA-SPECIFIC BENCHMARKS

\begin{tabular}{|c|c|}
\hline HRS PATHWAY/THREAT & BENCHMARKS ${ }^{1}$ \\
\hline Ground Water & $\begin{array}{l}\text { Maximum Contaminant Levels } \\
\text { Maximum Contaminant Level Goals } \\
\text { Screening concentrations }\end{array}$ \\
\hline \multicolumn{2}{|l|}{ Surface Water } \\
\hline Drinking Water Threat & $\begin{array}{l}\text { Maximum Contaminant Levels } \\
\text { Maximum Contaminant Level Goals } \\
\text { Screening concentrations }\end{array}$ \\
\hline Human Food Chain Threat & $\begin{array}{l}\text { Food and Drug Administration Action Levels } \\
\text { Screening concentrations }{ }^{33}\end{array}$ \\
\hline Environmental Threat & $\begin{array}{l}\text { Ambient Water Quality Criteria } \\
\text { Ambient Aquatic Life Advisory Concentrations }\end{array}$ \\
\hline Soil Exposure & Screening concentrations $\mathrm{s}^{23}$ \\
\hline Air & $\begin{array}{l}\text { National Ambient Air Quality Standards } \\
\text { National emissions standards for hazardous air pollutants } \\
\text { Screening concentrations }{ }^{2,3}\end{array}$ \\
\hline \multicolumn{2}{|c|}{$\begin{array}{l}{ }^{1} \text { See Superfund Chemical Data Matrix (SCDM) } \\
\text { 'Screening concentrations for cancer corresponding to concentrations for the } 10^{-6} \text { individual cancer risk for } \\
\text { oral exposure (inhalation exposure for the air pathway) } \\
\text { 3Screening concentration for noncancer toxicological responses corresponding to RfDs for oral exposure } \\
\text { (inhalation exposure for the air pathway) }\end{array}$} \\
\hline
\end{tabular}

for actual contamination based on direct observation.

- Potential: No observed release is required but targets must be within the target distance limit.

Level II contamination is assigned to targets meeting the criteria for actual contamination when none of the eligible substances for a pathway or threat has an established benchmark.

The HRS assigns different relative weights to targets associated with the three levels of contamination. For all pathways and threats, Level I contamination target values are multiplied by 10 , Level II contamination target values are multiplied by 1 , and potential contamination target values are multiplied by 0.1 . The presence of targets exposed to actual contamination may significantly affect the site score. Generally, actual contamination can only be supported with analytical sampling data; therefore, proper selection, collection, and handling of target samples is critical to the success of the SI.

Target Distances: In some instances, analytical data may be used to establish target distance limits. Analytical data also may be used to identify sample locations to make measurements for HRS data requirements (e.g., depth to aquifer, distance to surface water, distances to nearest targets).

\subsection{SAMPLE ANALYSIS OPTIONS}

The SI investigator must plan which analytical methods and services to use. Although laboratory analyses are routinely used, field analyses may often 
provide the type and quality of data needed to support site assessment decisions, and satisfy data quality objectives (DQOs). To select analytical methods and services, the SI investigator should consider:

- Available information to identify substances present

- Objectives of the SI (e.g., screening or listing)

- Quality of data needed to support decisions or planning activities

- Availability of services

- Desired turnaround time

- Anticipated number of samples to be analyzed

- Need for special separation or analysis techniques

- Need for lower detection limits

- Need for real-time monitoring

- Comparability and representativeness of data sets

In general, DQOs for analytical data generated during the focused SI may be less demanding than the objectives for data generated during the expanded SI. In addition, lower levels of data quality may be acceptable to screen a site rather than document a site score. The minimum data quality requirements for scoring depend on the specific HRS factor being evaluated. Investigators should be familiar with minimum data quality requirements so they may plan SI sampling and analysis strategies that accomplish the dual goals of meeting DQOs and minimizing sampling and analysis costs.

SI samples are analyzed by contract laboratory program (CLP) and non-CLP laboratory services. CLP services may be provided through routine analytical services (RAS) and special analytical services (SAS). Non-CLP services include field analytical support project (FASP) methods. The SI investigator should ensure that non-CLP services meet the DQOs of the SI.

\subsubsection{CLP Services}

CLP provides analytical services, including sample data management, through a nationwide network of laboratories under contract to EPA. CLP acceptance criteria ensure data of known quality with a high degree of confidence. CLP data satisfy the highest data quality criteria EPA has established for the HRS (i.e., Data Use Category (DUC) I). Therefore, CLP data can typically be used to evaluate all HRS factors requiring analytical data. Sometimes CLP data, like other analytical data, are qualified (e.g., J, R data codes), which may affect their application. However, since CLP codes are nationally consistent, defining how the data can be applied in scoring may be easily determined, as described in Guidance for Data Useability in Site Assessment. Non-CLP services may vary in their criteria for qualifying data, so the investigator should determine whether the laboratory's coding criteria are compatible with the DQOs of the investigation.

Under CLP, the majority of analytical needs are met through standardized laboratory services provided by RAS. RAS currently concentrates on analysis of organics and inorganics in water or solid samples. Other types of analysis may be scheduled as SAS. Among the SAS procedures are air and tissue sample analyses and detection of dioxins.

RAS provides broad-spectrum analyses for target analyte list (TAL) and target compound list (TCL) hazardous substances. TAL and TCL are recommended for SIs at CERCLA sites where the composition of wastes are not known. However, full TAL and TCL analyses may not be necessary for all investigations, especially if source hazardous substances are well known and analyses can be narrowed down to measure specific compounds. For example, results from previous investigations can be used to focus CLP analyses for specific substances or classes of substances (e.g., pesticides, volatile organic compounds) to investigate releases, observed contamination, or targets exposed to actual contamination. If partial analyses are scheduled, the investigator should determine whether the resultant data will be representative of the risks at the site and similar to other data sets.

The Users Guide to the Contract Laboratory Program (OSWER Directive 9240.0-01D) and the Samplers Guide to the Contract Laboratory Program (OERR Directive 9240.0-06) provide information on CLP services. Section 5 of $A$ Compendium of Superfund Field Operations Methods (OSWER Dir. 9355.0-14) explains procedures for using CLP laboratories and non-CLP laboratories. 


\subsubsection{Non-CLP Services}

Non-CLP services may provide data of quality similar to CLP. Non-CLP laboratories near the site may be appropriate if fast turnaround is needed. If non-CLP services are used, analytical protocols, data qualifier assignments, and reporting parameters and requirements need to be specified in the packages sent to bidders. For EPA-lead sites, laboratories receiving invitations to bid have usually been approved by the EPA Regional QA representative. For State-lead sites, non-CLP services are usually subcontracts with the prime contractor and are specified when the project is initiated.

Non-CLP data may be CLP quality (DUC I) or lesser quality (DUC II or III). For SI planning purposes, these categories are roughly comparable to the quality of data needed to document a site score, test site hypotheses, or plan sampling. Guidance for Data Useability in Site Assessment provides a detailed discussion of sample analysis considerations.

The SI may use FASP to provide onsite screening of samples for suspected hazardous substances. Field screening instruments range from the relatively simple (e.g., hand-held organic vapor detectors) to the more sophisticated (e.g., field gas chromatographs) and typically are calibrated to identify only selected substances. When the investigator is relatively certain of the hazardous substances expected to be found at the site, FASP methods may be appropriate.

As with non-CLP services, FASP and other field screening methods provide data of variable quality that are useful to plan SIs, test hypotheses, and to some extent, evaluate the HRS score. For example, screening data analyzed in the field can be used to establish source boundaries and select sample locations, thereby reducing CLP costs, particularly at larger hazarclous waste sites where widespread soil contamination is suspected. FASP data can also facilitate scoring releases and actual contamination. When field screening results are used directly to support scoring, 10 to 20 percent of the screening results should be confirmed by CLP analyses. However, such confirmation may not be necessary for the focused SI, depending on the quality of other analytical data.
FASP analyses (or other field screening analyses) may also help to:

- Design soil sampling grids.

- Select well locations based on soil gas monitoring.

- Select well screen depths.

- Determine the extent of hazardous substance migration.

- Estimate hazardous waste quantities (particularly based on area estimates).

In planning field screening services, the investigator should be aware of several important constraints:

- The hazardous substances must be confirmed by CLP quality data.

- Not all substances are amenable to field methods. Complex sample matrices, high hazard samples, and certain substances (e.g., dioxin) are best analyzed under the more controlled conditions of a fixed laboratory.

- The sample plan for field screening, like the CLP plan, must be reviewed by EPA Regional management.

- A QA plan specific to sampling and analysis should be prepared, including a description or reference to all analytical procedures.

\subsection{REVIEW INFORMATION FOR SI PLANNING}

Before developing SI plans, the investigator should compile all relevant and available site data. Review of the data should determine what additional work is needed and, for expanded SIs, any remaining nonsampling information needed for HRS documentation. Review of available information also will help avoid duplicating previous efforts and save resources.

Information describing hazardous waste sources, migration pathways, and human and environmental targets is available from many sources. Previous Superfund investigations typically supply the most useful information for SI planning. Other sources of information are site investigations conducted by other parties, investigations of nearby sites listed in CERCLIS, and the CLP Analytical Results Database 
(CARD), which compiles information on EPA environmental sampling.

The SI investigator should refine the site hypotheses as new information is gathered and the nature of the problem at the site is better understood. New information also may require updating the preliminary site score, or modifying the scope of the SI. The investigator should assess whether available information:

- Helps characterize site sources.

- Supports testing of site hypotheses.

- Provides information for site scoring.

- Guides further sampling and analysis.

- Indicates the need for emergency response actions.

- Indicates health and safety concerns.

The scope of the SI often depends on the quality of previous analytical data supporting the evaluation of significant pathways of concern. By reviewing available information, the investigator can determine the starting point of the SI and identify further information needed to test or substantiate site hypotheses and satisfy HRS data requirements. Each planned SI sample location should reflect these needs. The investigator may find that substantial data requirements have been satisfied and further sampling is not necessary. For example, when existing analytical data from a critical sample location (e.g., municipal well, fishery) adequately test or support a site hypothesis, resampling in this location may not be necessary.

\subsubsection{Review Non-Sampling Information}

The review of non-sampling information contributes to understanding the site. This knowledge serves two purposes:

- To help determine the scope of future sampling efforts by verifying the physical characteristics of the site and its surroundings, particularly target locations.

- To determine if existing hypotheses are sound.

Because site hypotheses are the basis of the sample plan, they should reflect current conditions and be well-founded. Inaccurate target information may preclude the development of realistic site hypotheses and an effective sample plan. For example, target information based on an outdated PA may not include a new housing development near the site. The investigator should update target information if necessary and determine the significant pathways of concern. Other circumstances that may warrant collecting additional non-sampling information prior to sample planning include flooding of the site, natural disasters, removal of wastes, and altered conditions.

Non-sampling information may come from a variety of sources, including EPA and other Federal agency studies, State and local environmental and health studies, academic studies, and the records of present and former owners and operators of the facility.

\subsubsection{Review Analytical Data}

The SI investigator should review any available analytical data for information to support the design of the sampling and analysis program, test site hypotheses, and document the site score. While analytical data collected for other purposes may not meet SI objectives, site-specific analytical data generally help to clarify the nature of the problem at the site, regardless of data sources or data quality. The scope of the review depends on the overall quality and quantity of data, the intended use of the data, and whether they are representative of current site conditions and comparable to SI data. Determining whether available data can be applied as SI-generated data requires the professional judgment of an experienced reviewer. Table 3-7 provides some general guidelines for using various types of data.

Both validated and non-validated analytical data may be available. Previous SI data generally will be validated and of CLP-quality. Non-validated data may contain false positives and false negatives, as well as quantitation, transcription, and calculation errors. If data of unknown or questionable quality are critical to make decisions, the investigator should review all available information to assess the level of certainty associated with the data. If these data are used for HRS documentation, they may have to be validated. 
TABLE 3-7: TYPES OF ANALYTICAL DATA

\begin{tabular}{|l|l|}
\hline TYPE OF DATA & \\
\hline \hline CLP & No specific limitations; used as necessary for all SI activities \\
\hline Qualified CLP & $\begin{array}{l}\text { Some general limitations depending on types of data qualifiers and bias (e.g., } \\
\text { unknown, low, high) associated with the data }\end{array}$ \\
\hline Non-CLP & $\begin{array}{l}\text { Few limitations if non-CLP data are shown to be equivalent to CLP data (e.g., level of } \\
\text { QA/QC documentation, level of laboratory performance, level of data quality, } \\
\text { independent data quality review) } \\
\text { Limitations if non-CLP data cannot be shown to be comparable to CLP data }\end{array}$ \\
\hline Field screening & Augments SI samples, especially to investigate area of contamination \\
\hline Owner/operator & Few limitations; used as necessary for all SI activities \\
\hline
\end{tabular}

The investigator may be able to determine the general quality of the data by reviewing QC data. False positives can occur when blanks are contaminated or pike recoveries are very high. False negatives can occur if spike: recoveries are very low. If hazardous substances are found in one duplicate but not the other, results may be false positives or negatives.

The investigator should ensure that non-SI analytical data accurately represent conditions at the site when used to test site hypotheses. For example, a release to ground water may be suspected based on site characteristicis (e.g., shallow ground water, heavy rainfall, high infiltration, waste disposal below ground) but not supported by non-SI analytical data. The non-SI data may be unreliable due to changed site conditions, or the samples may not have been collected from the appropriate location. These data should not be applied to override reasonable site hypotheses based on strong information on site characteristics unless the investigator is confident that sampling results are reliable, of adequate quality, and truly representative of the site.

Older data may not reflect risks from continuing hazardous substance migration, and partial analyses may not identify all hazardous substances present at the site. If previous samples were not collected from areas where contamination is suspected, false negatives may result. Careful review of both the sampling design and overall data quality helps determine whether non-SI data confidently test site hypotheses. Table 3-8 provides a general approach to review previous analytical data.

Combining data sets from different sampling and analyses events may not be appropriate when non-SI data are used to document the HRS evaluation. Problems in comparing sample results generally are caused by differences in the sample design and time periods-for example, a water sample collected during a period of high precipitation may not be comparable to a water sample collected during the dry season. Comparability also is a problem if analytical methods differ or if detection limits are unknown. The use of routine analytical methods simplifies comparability when combining data sets because all laboratories follow the same standardized procedures and reporting requirements.

The amount of previous analytical data varies substantially. Full data review may be appropriate for smaller amounts of data. For larger data volumes, the investigator may choose to screen for useful sample results before review. Different levels of data review allow the investigator to efficiently assess previous data within the time and resource constraints of the SI. Automated data review systems (e.g., Computer 
TABLE 3-8: REVIEW OF PREVIOUS ANALYTICAL DATA

\begin{tabular}{|l|l||}
\hline \multicolumn{1}{|c|}{ PROCEDURE } & \multicolumn{1}{|c|}{ CONSIDERATIONS } \\
\hline \hline Determine what data are available & $\begin{array}{l}\text { What are the types of previous data: CLP, non-CLP, field } \\
\text { screening, full TCL analysis, partial TCL analysis, owner/operator, } \\
\text { State? }\end{array}$ \\
\hline $\begin{array}{l}\text { Evaluate purpose and scope of } \\
\text { previous investigations }\end{array}$ & $\begin{array}{l}\text { Why were data collected? What type of investigation: State or } \\
\text { Federal facility investigation, enforcement action, emergency } \\
\text { response, RCRA facility inspection, general assessment of ground } \\
\text { water quality, environmental property assessment, NPDES permit } \\
\text { requirements? }\end{array}$ \\
\hline $\begin{array}{l}\text { Review sampling locations, dates, } \\
\text { depths, and sample descriptions }\end{array}$ & $\begin{array}{l}\text { Was the design of the sampling program similar to the SI } \\
\text { sampling strategy? Did it include background samples and field } \\
\text { QC samples? }\end{array}$ \\
\hline $\begin{array}{l}\text { Evaluate the sampling results and } \\
\text { hazardous substance concentrations }\end{array}$ & $\begin{array}{l}\text { Are a sample plan and sample location map available? Is a field } \\
\text { notebook available that describes all sampling activities? }\end{array}$ \\
\hline $\begin{array}{l}\text { Review field preparation and collection } \\
\text { techniques for previous samples }\end{array}$ & attached to data, and detection limits? \\
\hline $\begin{array}{l}\text { Review available laboratory } \\
\text { documentation }\end{array}$ & $\begin{array}{l}\text { Wre Qppropriate SOPs used for sample collection and handling? } \\
\text { What are the name of the laboratory, the type of analyses } \\
\text { performed, and the performance results? }\end{array}$ \\
\hline Assess usability of previous data & What is the overall usability of the data set? \\
\hline
\end{tabular}

Assisted Data Review and Evaluation (CADRE)) also should be used for large amounts of data.

The data review may focus on:

- The entire site

- Specific sample locations

- Specific hazardous substances

- Elevated substance concentrations

- Ranges of concentrations

- QC assessment

- Background levels

- Attribution considerations
SI DQOs should be flexible to allow use of lesser quality data for screening purposes. Different review levels and quality standards apply depending on the planned end use of data. For the expanded SI, the level of contamination at a target from the site generally requires appropriate background and attribution samples and may require documentation. However, screening a site from further investigation during the focused SI may not require the same analytical data quality as the expanded SI. To take maximum advantage of previous investigations, all data, including data of lesser quality, should be weighed during SI planning. 


\section{EXHIBIT 3-1: CHECKLIST FOR USABILITY OF PREVIOUS ANALYTICAL DATA}

1. Have samples been taken at the appropriate location, depth, or stratum to confidently test site hypotheses?

If the answer is "no," additional sampling will likely be needed to fully test hypotheses and provide a basis for the site disposition decision. The data may nevertheless be useful in developing sampling and analysis plans and identifying hazardous substances of concern.

2. Is documentation available to support the analytical procedures used to derive the data (e.g., laboratory QA/QC procedures, type of analyses, detection limits, and data review)?

3. Are representative background levels available for targets exposed to actual contarnination and hazardous substances that may demonstrate releases?

4. If background samples are available, are they temporally and spatially comparable to samples indicating releases and exposure of targets to actual contamination?

If the answer to questions 2, 3, or 4 is "no," the data may not support HRS documentation requirements and further review is needed to determine usability. However, the data may support testing of site hypotheses and development of a sampling strategy.

5. Do data provide evidence that attributes the hazardous substances detected in various media and waste samples to the site?

If the answer to question 5 is "no," additional samples will be needed to fully support releases and targets exposed to actual contamination.

If the answers to questions 1 through 5 are all "yes," the previous analytical data may support testing PA hypotheses, identification of hazardous substances of concern, development of a sampling strategy, and HRS documentation requirements, including releases and targets exposed to actual contamination. 


\subsection{SI PLANS}

Site-specific considerations identified during data review are addressed during development of the SI plans. Four plans are developed to help refine the objectives of the investigations and to ensure that SI activities proceed efficiently, safely, and on a nationally consistent basis:

- Work plan

- Sample plan

- Health and safety plan

- Investigation-derived wastes (IDW) plan

SI plans document procedures to be used, resources needed, and the rationale behind the anticipated tasks to ensure that all planning and review steps have been completed prior to starting field activities. The work plan primarily covers administrative activities, while the other three plans cover field activities. The sampling, health and safety, and IDW plans may be sections within the site-specific work plan, or separate documents.

All plans should be prepared with input from all agencies and organizations involved in SI activities. Lead personnel from these organizations should approve and sign all plans.

\subsubsection{Work Plan}

The work plan specifies administrative and logistical requirements. The purpose of the work plan is to efficiently schedule resources such as personnel, equipment, and laboratory services. Preparing the work plan requires a thorough understanding of the site, its surroundings, and the nature of possible contamination and hazards. Clear and concise work plans are prerequisites for obtaining quality analytical data and making reliable site recommendations.

In general, work plans should include:

- A summary of background information on the site, emphasizing how this information can help identify SI objectives;

- Objectives-for example, "to identify hazardous substances and document a release to surface water;"

- Schedule;
- A description of personnel, special training needs, organization of teams, and equipment requirements; and

- A description of any non-standard equipment and contract services needed.

The work plan must address general considerations and site-specific conditions:

- Hazards: What physical or chemical hazards may be encountered? How will they affect time, expense, personnel, or equipment requirements?

- Location: Is the site accessible? How far away is the laboratory or home office? Will samples be shipped or hand delivered to the laboratory?

- Schedule: Can the site be adequately sampled at this time of year, or will frozen ground or short daylight hours limit sampling? Have recent rains or dry periods affected water levels or created swampy conditions? Does the public frequent the site at certain times?

- Mobilization/demobilization: How much time and equipment are needed? Does anything have to be ordered?

\subsubsection{Sample Plan}

Exhibit 3-2 suggests a general outline for work plan elements combined into the sample plan. Appendix $A$ is an example of such a plan.

The sample plan can be incorporated into the work plan or it may be a separate document. During the focused SI, the PA hypotheses and assumptions, along with information from previous investigations, help identify the specific areas that require samples or additional data. Similarly, the focused SI results are used to identify any remaining HRS data requirements at the expanded SI. The sample plan specifies the locations, types, and number of samples and procedures. A typical sample plan describes:

- Field operations: Discusses the sequence for conducting field activities. Identifies the functions of each individual worker, specifying who will take samples, supervise chain-ofcustody procedures, maintain the field log book, and monitor the site for potential hazards. 


\section{EXHIBIT 3-2: SI SAMPLE PLAN OUTLINE}

\section{INTRODUCTION}

- Briefly state the authority and purpose for conducting the SI and the scope of the investigation. Discuss the objectives and goals of the SI.

\section{SITE DESCRIPTION AND REGULATORY AND OPERATIONAL HISTORY}

- Describe the site location. Identify the type of facility, whether it is active or inactive, and years of operation. Describe its physical characteristics and setting (e.g., local land use, climate, topography, geology, hydrology, hydrogeology). Include a map showing the location. Include a site plan or sketch showing features on and around the site.

- Describe historical site operations, including all past and current operations and conditions. Identify current and former owners/operators, types of site activities, wastes generated, and waste disposal practices. Identify all sources and source types. Provide the hazardous waste quantity disposed in each source, if possible, and provide volume or area of the sources. Identify hazardous substances associated with or detected in the sources. Describe source containment. Describe any spills that have occurred at the site.

- Specify whether any sources are regulated by RCRA. Describe past regulatory activities, including permils, permit violations, and inspections by local, State, or Federal agencies. If applicable, provide emergency response and waste removal information. Summarize analytical results of earlier investigations. Specify type of data (e.g., CLP, non-CLP, owner/operator).

\section{COLLECTION OF NON-SAMPLING DATA}

- Describe additional non-sampling information to be collected (e.g., aquifer boundaries, interconnections, and discontinuities; resources; drainage area; soil group; particulate migration factors) and the rationale for collecting this information. Discuss any field activities needed to obtain this information.

\section{SAMPLING ACTIVITIES}

- Discuss objectives of planned field activities. Describe procedures and necessary resources. Discuss the rationale for these tasks.

- Provide explicit instructions for all field activities, including field observations, sampling, environmental monitoring for health and safety purposes, and field QA/QC protocols. Reference appropriate Standard Operating Procedures (SOPs). Discuss purpose of both onsite and offsite reconnaissances and observations (e.g., to verify the selection of sample locations, to evaluate the degree of containment at site sources, to measure source dimensions, to verify distances to nearby targets, and to characterize additional sources of contamination not identified during previous investigations).

- Justify proposed sample locations. Discuss methods to more fully characterize wastes and sources. Identify specific targets to be sampled (e.g., drinking water wells or intakes, fisheries, sensitive environments) to test or substantiate target contamination hypotheses. Describe sampling strategy to test or substantiate observed release hypotheses and presence of media contamination (e.g., soil, ground water, sediment, air, surface water). 


\section{EXHIBIT 3-2: SI SAMPLE PLAN OUTLINE (concluded)}

- Include a map or site sketch showing previous and proposed sample locations.

- Summarize sample plan in a table, identifying sample types, sample numbers, sample locations, and sample-selection criteria. Describe methods of sample collection and preservation, field measurements, and analytical methods. Refer to Standard Operating Guidelines (SOGs) or provide a table or checklist describing the SOGs.

- Describe investigation-derived wastes (IDW) that may result from field activities. Reference the IDW plan that describes the management approach for non-hazardous and hazardous IDW.

\section{PROJECT MANAGEMENT}

- Identify all persons who will be involved in the field activities and discuss their specific responsibilities. Identify all safety and sampling equipment and supplies. Describe any contractual services needed to accomplish field activities. Summarize all transportation and shipping information.

- Describe community relations plans and meetings.

- Provide information on SI costs (e.g., number of technical hours; number of CLP, field screening, or other samples; subcontracting costs). Provide schedule for SI activities and deliverables. Summarize any special requirements that impact the SI (e.g., special safety considerations, special analytical services (SAS), or special equipment).

- Reference the work plan.

\section{ATTACHMENTS}

- Sample summary table

- Sample location sketch

- List of references cited in this plan

- Health and safety plan

- Appropriate SOPs and SOGs

- Sample locations and rationale: Identifies the location of each sample on a site map, explains the rationale for each location, and specifies the type (e.g., soil, sediment, water), volume, and number of samples.

- Field quality control samples: Identifies the number, location, and type of blank and duplicate samples.
- Sampling equipment decontamination: Identifies sample decontamination procedures, including decontamination solutions and any special handling.

- Analytical requirements and sample handling: Identifies the specific analysis parameters-for example, organics, metals, dioxins-for each sample. Identifies the preservation techniques 
and reagents for each sample. Specifies whether samples are to be filtered, and explains why. Identifies the equipment, sampling devices, and type of containers used for each sampling episode. Much of this can be addressed by referencing the appropriate field SOPs. Identifies any procedures not covered by, or that are different from, the SOPs.

- Sample delivery: Identifies where samples are to be delivered for shipment or analysis, where splits should be delivered if they are collected, and, if appropriate, specifies special storage or transport requirements.

\subsubsection{Health and Safety Plan}

The purpose of the health and safety plan is to establish requirements and procedures to protect the health and safety of investigative personnel and the nearby public. The plan must specify levels of protection necessary for each field activity, provide detailed instructions for routine operations and emergency situation responses (see below), list key safety personnel, and describe health and safety monitoring requirements. The health and safety plan is generally prepared after the sample plan and included as an appendix to the work plan. The health and safety plan must be distributed to all team members, discussed at a team meeting prior to site entry, and posted at a conspicuous location at the site before field activities begin.

\section{Routine Operations}

Safety practices for routine operations parallel standard industrial hygiene and industrial safety procedures. The health and safety plan at a minimum must:

- Describe hazards and risks associated with the field work to be performed at the site, including all known or suspected physical, biological, radiological, or chemical hazards.

- List key safety personnel and alternates. Also identify other key personnel assigned to various site operations. Indicate where telephone numbers, addresses, and organizations of these people will be posted.
- Designate levels of protection required by location or task, specifying types of respirators and clothing to be worn for each level.

- Designate work areas-exclusion zone, contamination reduction zone, and support zone - on the site map. Include zone boundaries and access control points for each zone. Indicate where the map will be posted.

- List security control procedures to prevent unauthorized access-for example, fences, signs, security patrols, and check-in procedures. Identify procedures to ensure personnel wear the prescribed protective clothing.

- Discuss environmental monitoring protocols at or around the site to indicate chemicals present, and their hazards, possible migration, and associated safety requirements.

- Specify routine and special training required.

- Describe procedures for weather-related problems, such as temperature extremes, high winds, rain, and snow. Identify shelters when necessary. Discuss procedures to minimize heat stress of field team members wearing protective clothing.

\section{Emergencies}

Emergencies resulting from fire, chemical exposure, physical injury, or other events require immediate responses to prevent harm to onsite workers, the public, property, or the environment. Contingency plans for managing emergencies should:

- Advise workers of their duties during an emergency-for example, site personnel should be designated as site safety officers, standby rescue personnel, decontamination personnel, and emergency medical technicians. Identify their functions and expertise.

- Identify the location of the nearest telephone.

- Designate emergency communications alternatives-for example, citizen band and hand-held radios. 
- Identify names, telephone numbers, and locations of local emergency response officials-for example, fire, police, explosives experts, and hazardous materials response units.

- Specify worker evacuation procedures.

- List onsite emergency equipment and all other local medical, rescue, transport, and fire-fighting equipment.

Emergency medical care is an important component of the health and safety plan. To ensure that injured workers are transported to the nearest medical facility and receive appropriate treatment:

- Identify the nearest medical or emergency care facility that handles chemical exposure cases. Record its location, travel time, directions, and telephone number.

- Identify the telephone number of the nearest ambulance service.

- Maintain accurate records on any exposure or potential exposure of site workers during emergencies.

- Specify decontamination procedures for injured workers, transport vehicles, medical facilities, or medical personnel.

\subsubsection{IDW Management Plan}

Management of Investigation-Derived Wastes During Site Inspections (OERR Directive 9345.3-02) presents a general regulatory background and options to manage IDW generated during SIs. These wastes include soil cuttings, drilling muds, purged ground water, decontamination fluids (water and other fluids), disposable sampling equipment (DE), and disposable personal protective equipment (PPE). The directive addresses typical IDW management scenarios, and describes cost-efficient methods of handling hazardous and non-hazardous IDW to:

- Minimize the quantity of wastes generated.

- Leave a site in same condition or not worse than prior to the investigation.

- Remove wastes that pose an immediate threat to human health or the environment.
- Comply with Federal and State applicable or relevant and appropriate requirements (ARARs) to the extent practicable.

Specific elements of the strategy are to:

- Characterize IDW by available information (e.g., manifests, Material Safety Data Sheets, previous test results, knowledge of the waste generation process, and other relevant records) rather than analyze IDW samples.

- Delineate an Area of Contamination (AOC) unit for leaving RCRA hazardous soil cuttings.

- Dispose of RCRA hazardous ground water, decontamination fluids, and PPE and DE (if generated in excess of $100 \mathrm{~kg} /$ month) at RCRA Subtitle C facilities.

- Leave onsite RCRA non-hazardous soil cuttings, ground water, and decontamination fluids, preferably without containerizing and testing.

EPA does not recommend removing wastes from all sites and, in particular, from those sites where IDW do not pose any immediate threat to human health or the environment. Removing wastes from all sites would not benefit human health and the environment and would be unduly expensive, thus impairing EPA's ability to successfully meet the goals of the site assessment program.

The NCP requires that IDW generated during SIs be managed in compliance with all ARARs to the extent practicable. In addition, other legal and practical considerations may affect the handling of IDW. Investigators should be familiar with OERR's IDW directive as well as the requirements of the NCP for identifying ARARs.

IDW from SIs may contain hazardous substances as defined by CERCLA Section 101(14) and listed at 40 CFR Part 302.4. Some CERCLA hazardous substances are RCRA Subtitle C hazardous wastes, while other substances may be regulated by other Federal laws such as the Safe Drinking Water Act, Clean Air Act, Toxic Substances Control Act, and Clean Water Act. EPA estimates that to date RCRA hazardous IDW have been generated at fewer than 15 percent of CERCLA sites. However, RCRA 
regulations, and in particular the RCRA Land Disposal Restrictions, are very important as potential ARARs since they regulate treatment, storage, and disposal of many of the most hazardous materials.

\subsection{SITE RECONNAISSANCE}

Site reconnaissance may occur prior to completing the SI sample plan, since the primary objective of site reconnaissance is to verify planned sample locations by examining the site and its surroundings. Before site reconnaissance field activities begin, the investigator should arrange for site access and prepare a specific health and safety plan, even if a reconnaissance was performed during a previous investigation. The investigator also should consider informing interested parties (e.g., community representatives, and local, State, or Federal officials) of upcoming field activities. Early contact should facilitate the reconnaissance and subsequent field sampling and alleviate possible negative impacts caused by site activities.

The site reconnaissance team should perform the following activities to verify the planned sample locations.

- Locate all sources.

- Determine the physical state of wastes deposited at the source.

- Identify each source type.

- Examine each source for evidence of hazardous substance migration.

- Evaluate the degree of source containment.

- Identify overland flow paths.

- Determine the distances from sources to onsite and nearby targets.

- Refine the site sketch depicting important features (e.g., source locations, nearby targets).

Investigators should allocate sufficient time to verify or, if necessary, modify sample locations based on site reconnaissance information. Preferably, a small crew should conduct the site reconnaissance prior to sampling. If an onsite reconnaissance was conducted recently, the site reconnaissance for SI sampling may be conducted on the first day of field activities.

Site reconnaissance also is important when evaluating the need for emergency response action at the site. Emergency response could include the stabilization or removal of wastes, fencing the site or specific sources, evacuation of nearby populations, and other activities that eliminate, control, or otherwise mitigate an imminent threat to human health and the environment. If monitoring equipment indicates radioactivity, field team members should immediately leave the site and notify the EPA Regional radiation program office.

\subsubsection{Emergency Response}

At any time during the Superfund process, an emergency response action (or removal) may be taken at the site. Removals typically are relatively shortterm actions designed to respond to situations that require immediate action to eliminate a present threat or avoid a more serious future problem. Some conditions that may result in a removal action include the threat of:

- Fire or explosion

- Direct contact with hazardous substances

- Continuing release of hazardous substances

- Drinking water contamination

Removal actions can include, but are not limited to:

- Fencing the site;

- Providing 24-hour security to restrict public access;

- Stabilizing waste sources, such as leaking drums or overflowing surface impoundments;

- Removing hazardous substances from the site;

- Capping areas of contamination;

- Evacuating local populations; and

- Providing alternative drinking water supplies.

While not every SI will be of interest to the Regional emergency response program, there will be a number of sites where it is important to consult with them. The Regional EPA site assessment contact, in conjunction with removal program personnel, will determine if a removal site evaluation is necessary. The SI investigator should review the PA to determine if the conclusions are still accurate. If there was a referral to the emergency response program at that time, the emergency response action memorandum and any follow up action should be included in the SI background material. If no referral was made, the SI investigator should assess site conditions to determine if an emergency response 
action is warranted. If this is the case, the SI investigator should involve emergency response personnel in planning SI field activities to determine if a removal action is appropriate. The emergency response representative should identify sampling information that should be collected during the SI that will assist future response activities. Likewise, if an immediate response is necessary, emergency response personnel may be able to collect valuable information to assist SI field activities.

\subsubsection{Effects of Removal Actions}

Removal actions may affect SI activities, including sample planning and site scoring. The effects of removal actions may be considered when evaluating the HRS score (The Revised Hazard Ranking System: Evaluating Sites After Waste Removals, OSWER Directive 9345.1-03FS). Three requirements that must be met for a removal to affect the site evaluation are:

- The removal action must physically remove waste from the site.

- The removal action must have occurred before approval of the SI work plan for non-Federal facilities, and 18 months after a Federal facility has been placed on the Federal Facilities Docket.

- The removed wastes must be disposed or destroyed at a facility permitted under RCRA, Toxic Substance Control Act (TSCA), or the Nuclear Regulatory Commission (NRC), as appropriate.

While removal actions may affect the way specific HRS factors are evaluated, the removal itself generally will not alter significantly the SI sampling strategy, which determines:

- Whether a hazardous substance has impacted a target;

- The types of substances at the site; and

- Whether a release has occurred.

If analytical data indicate that a release of hazardous substances has occurred before or after a removal, the removal does not negate this information. If a removal has eliminated the entire source, but professional judgment concludes that a release has occurred, samples should be collected. The resulting analytical data can be used to evaluate specific HRS factors, regardless of the status of the removal. The investigator is not responsible or required to document that the source and the threat of a release from the source has been completely eliminated.

If a removal has eliminated a portion of site sources, sample planning should focus on the remaining portion. Unless the potentially responsible party (e.g., site owner or operator) can document otherwise, the SI investigator can reasonably assume that the remaining portion contains the same hazardous substances as the removed portion. Note that the substance-specific waste characteristics factors (e.g., toxicity, mobility, persistence) cannot be based on a hazardous substance that was completely removed from a site through a removal; however, the investigator is not required to obtain substancespecific information.

\subsubsection{Site Access}

Legal access to the site must be obtained from the site owner before conducting a site reconnaissance. In some Regions, EPA personnel are responsible for obtaining access. In other Regions, State or contractor personnel may make access arrangements. While the owners, operators, or persons in charge of a site cannot prevent EPA's entering the property, they can require a court order. Four types of access agreements can be used for the SI:

- Voluntary entry (consenting)

- Conditional entry

- Entry with warrant (nonconsenting)

- Entry without warrant

The Regional SAM should consult with State counsel to ensure that all appropriate State requirements are met before initiating the SI. State laws for collecting evidence may be more restrictive than Federal laws, and noncompliance could result in suppression of evidence in a legal proceeding. Finalizing site access arrangements can take considerable time; hence these activities should be initiated early in the SI planning process.

\section{Voluntary Entry}

In general, the investigator should pursue voluntary entry first, followed by conditional entry, and if necessary, entry with a warrant. An entry is 
considered voluntary as long as the owner agrees. The field team must not exhibit any form or semblance of coercion to gain entry. Entry gained via verbal or physical threat may later be determined invalid, and any information obtained during inspection could become inadmissible in legal proceedings.

The investigator should confirm consent to entry by notifying the owner in writing of the activities to be conducted (e.g., sample collection, picture taking, visual observations). CERCLA requirements governing split samples and receipts take precedence over a State law when the State program is operating with Federal funds.

Upon arrival at the site, field team members should present their credentials and inform the owner/ operator or designee of the nature of the work and their authority for conducting the SI. If the owner withdraws corsent at any time, which is equivalent to refused entry, a warrant is required to complete the SI. Any information gathered before consent is withdrawn, including samples and photographs, can be used in a legal proceeding, as can any information obtained in an area open to the public.

\section{Conditional Entry}

The owner may consent to entry but impose conditions-for example, limiting areas of the site reconnaissance, limiting employees to be interviewed, or requiring confidentiality agreements. If avoiding conditional entry is not possible, accept only conditions that do not significantly interfere with the SI and note them in the logbook. State employees should consult with their own counsel or the EPA Office of Regional Counsel to determine if such agreements are acceptable or should be treated as a refusal of eniry. The field team should be informed about such conditions prior to arriving at the site.

\section{Entry With Warrant}

If consent cannot be obtained or is withdrawn, the investigator should seek an entry warrant. The SI must be conducted strictly in accordance with the warrant, which might, for example, restrict access to certain areas or records. Failure to do so could jeopardize the admissibility of the information obtained.
When refused entry, the investigator should note in the logbook the person refusing entry, the date and time of refusal, the reasons given for refusal, and other pertinent details. The investigator should then leave the premises and immediately seek a warrant.

\section{Entry Without Warrant}

Entry without a warrant is normally reserved for emergencies and instances where evidence might be lost if site entry is delayed. When ownership of an abandoned site cannot be determined, the investigator should discuss the need for a warrant with the EPA Office of Regional Counsel.

Some courts have ruled that inspections under the Federal Insecticide, Fungicide, and Rodenticide Act and the Toxic Substances Control Act involving industries that are highly regulated are not subject to warrant requirements. Investigators should consult with the EPA Office of Regional Counsel before entering a site without consent and without a warrant. Investigators should consider requesting assistance or backup from local police for this type of entry.

\subsubsection{Community and Nelghborhood Contacts}

Local representatives should be contacted in advance. Community relations coordinators can help identify appropriate representatives. Only designated team members should participate in discussions with local residents, remaining as factual as possible and avoiding expressing opinions or raising expectations for future action. Team representatives should always refer questions to the Regional SAM, who may:

- Explain the purpose of SI activities.

- Identify the site location.

- Explain the tasks to be performed.

- Identify a contact for further information.

- Determine whether meetings should be held and to whom the SI results and other information should be provided.

For guidance on community relations during SIs, see Community Relations in Superfund: A Handbook, Section 4.1 (OSWER Directive 9230.0-03C, January 1992). 


\subsubsection{Government Contacts}

EPA Regional management should contact appropriate municipal, county, State, and Federal officials before starting field work. These groups frequently have information on the site's waste practices, history, and compliance records, and may be aware of other investigations or enforcement activities at or near the site. Activities by other agencies do not provide sufficient reason to cancel or postpone the SI, but the work schedule can be adjusted if it does not compromise the health and safety of the public or the environment.

\subsection{SITES CONTAINING RADIOACTIVE SUBSTANCES}

SIs for sites containing radioactive substances require many of the same considerations for site-specific planning discussed in previous sections of this chapter. Investigators performing SIs at radiation sites also collect a limited number of selective samples, rather than an extensive number of "average" samples, to investigate sources and migration pathways and establish contamination levels at targets. Sample collection issues, including types, variability, and $\mathrm{QA} / \mathrm{QC}$ requirements, are generally similar for sites with radioactive substances.

The SI approach for radiation sites differs from nonradioactive sites based on HRS data needs, field instrumentation and procedures, sample collection and handling, laboratory support, and analytical methods.

This section provides a supplemental discussion of SI planning considerations for sites containing radioactive substances. Guidance is provided on radiation survey instruments and techniques, special sampling and analysis issues, and HRS requirements. This section also provides information on components of a radiation health and safety plan, an IDW plan, and supporting documentation.

For additional information on radiation concepts and terminology, background levels of radionuclides in the environment, and data usability considerations for radioactive substances, the SI investigator should refer to Guidance for Data Useability in Site Assessment.

\subsubsection{Key Radiation Site Personnel}

When planning SIs at sites containing radioactive waste, the SI investigator should consult with a health physicist and a radiochemist during all phases of sample planning and implementation. $A$ health physicist can assist the investigator by:

- Reviewing the site history and records to identify radionuclides and radioactive sources and waste streams;

- Planning samples and analysis, including the selection of field instruments;

- Implementing the SI sample plan and interpreting measurement data;

- Preparing and implementing a radiation health and safety plan, including training and monitoring SI personnel;

- Preparing and implementing IDW plans; and

- Determining data adequacy and usability.

The health physicist may facilitate planning field activities. For example, the health physicist may identify techniques, such as walkover and grid surveys, to locate radioactive contamination. A health physicist may know where maximum concentrations (hot spots) are likely to be found. Often, certain locations between, or at the fringe of, grid patterns should be investigated, such as near the foundations of structures or along a facility's sanitary sewer lines. Establishing actual contamination may hinge on this data. During field work, the health physicist may interpret measurements so that technical decisions can be made in the field.

A radiochemist can assist the investigator by:

- Specifying sample size, collection, handling, and holding time considerations;

- Establishing desired analytical sensitivities, turnaround times, and QA/QC requirements to meet data needs;

- Recommending radionuclide- and media-specific radioanalytical procedures;

- Selecting radiochemical laboratories;

- Interpreting radioanalytical data;

- Resolving data discrepancies and data gaps; and

- Determining data adequacy and usability. 
For health physics and radioanalytical support, the SI investigator should contact EPA Regional, laboratory, or Headquarters Office of Radiation Programs (ORP) staff.

\subsubsection{Radiation Survey Instruments}

In addition to laboratory analysis of collected samples, radionuclides can be investigated by a variety of field survey instruments and techniques. These instruments and techniques provide immediate information on the location and distribution of sources and releases of radionuclides, allowing rapid field screening of potential radiation sites.

The SI investigator should consider the capabilities and limitations of the various types of radiation survey instruments when planning field work. Instrument selection depends on several factors, including the type (alpha, beta, gamma, and $x$-ray) and energy of radiation emitted by each radionuclide of concem, expected concentrations (activity per unit mass) above background levels, shielding and selfabsorption by the contaminated material, and desired measurement sensitivity.

\section{Gamma Detectors}

Five types of field survey detectors are commonly. used for measuring gamma radiation exposure rates: ion chambers, pressurized ion chambers (PICs), Geiger-Mueller (GM) counters, sodium iodide (NaI) scintillation detectors, and organic scintillation detectors (see Table 3-9). NaI and organic

TABLE 3-9: GAMMA RADIATION SURVEY INSTRUMENTS

\begin{tabular}{|l|l|l|l||}
\hline INSTRUMENT & \multicolumn{1}{|c|}{ SPECIFICATIONS } & \multicolumn{1}{|c|}{ ADVANTAGES } & \multicolumn{1}{|c|}{ DISADVANTAGES } \\
\hline \hline Ion Chamber & $\begin{array}{l}\text { Moderate to high exposure rate } \\
\text { range: } 1 \text { to } 2,000 \mathrm{mR} / \mathrm{hour} \\
\text { Accuracy: } \pm 5 \% \text { at the high end } \\
\text { of the scale }\end{array}$ & $\begin{array}{l}\text { Reading is directly } \\
\text { proportional to radiation field } \\
\text { Suitable for high radiation } \\
\text { fields } \\
\text { Very portable }\end{array}$ & $\begin{array}{l}\text { Poor sensitivity } \\
\text { Inadequate for near- } \\
\text { background radiation } \\
\text { rates }\end{array}$ \\
\hline $\begin{array}{l}\text { Pressurized Ion } \\
\text { Chamber (FIC) }\end{array}$ & $\begin{array}{l}\text { Low range: } 1 \text { to } 500 \mu R / \text { hour } \\
\text { Accuracy: } \pm 5 \% \text { full scale }\end{array}$ & $\begin{array}{l}\text { Reading is directly } \\
\text { proportional to radiation field } \\
\text { Suitable for near-background } \\
\text { radiation rates }\end{array}$ & $\begin{array}{l}\text { Not as portable as ion } \\
\text { chamber } \\
\text { Allows fewer } \\
\text { measurements per day }\end{array}$ \\
\hline $\begin{array}{l}\text { Geiger-Mueller } \\
\text { (GM) Tube }\end{array}$ & $\begin{array}{l}\text { Moderate to high range: } 1 \text { to } \\
5,000 \mathrm{mR} / \mathrm{hour} \\
\text { Accuracy: } \pm 10 \% \text { full scale }\end{array}$ & $\begin{array}{l}\text { Also detects beta radiation } \\
\text { Very portable }\end{array}$ & $\begin{array}{l}\text { Poor sensitivity } \\
\text { Reading is not directly } \\
\text { proportional to radiation } \\
\text { field; response varies } \\
\text { with photon energy }\end{array}$ \\
\hline $\begin{array}{l}\text { NaI Scintillation } \\
\text { Detector }\end{array}$ & $\begin{array}{l}\text { Low range: } 1 \text { to } 5,000 \mu \mathrm{R} / \mathrm{hour} \\
\text { Accuracy: } \pm 10 \% \text { at high end to } \\
\pm 30 \% \text { at low end of scale }\end{array}$ & $\begin{array}{l}\text { Suitable for background } \\
\text { radiation rates } \\
\text { Very portable }\end{array}$ & $\begin{array}{l}\text { Reading is not directly } \\
\text { proportional to radiation } \\
\text { field; response varies } \\
\text { with photon energy }\end{array}$ \\
\hline $\begin{array}{l}\text { Organic } \\
\text { Dcintillation }\end{array}$ & $\begin{array}{l}\text { Low range: } 1 \text { to } 25 \mu R / \text { hour } \\
\text { Accuracy: } \pm 10 \% \text { full scale }\end{array}$ & $\begin{array}{l}\text { Suitable for background } \\
\text { radiation rates } \\
\text { Very portable }\end{array}$ & $\begin{array}{l}\text { Response is generally } \\
\text { linear with energy }\end{array}$ \\
\hline
\end{tabular}


scintillation detectors are used most often because of their portability and ability to measure exposure rates at and above natural background levels. These detectors usually record exposure rates in microroentgens per hour $(\mu \mathrm{R} / \mathrm{hr})$, microrem per hour $(\mu \mathrm{rem} / \mathrm{hr})$, or counts per minute $(\mathrm{cpm})$, which are converted to $\mu \mathrm{R} / \mathrm{hr}$ or $\mu \mathrm{rem} / \mathrm{hr}$ by an instrumentspecific calibration factor. The SI investigator should cross-check exposure rate measurements made with these detectors against a limited number of PIC measurements because the response characteristics of $\mathrm{NaI}$ and organic scintillations detectors are energy dependent. Although less portable than hand-held survey detectors, PICs provide a flatter response over a wider range of gamma energies.

Two other portable detectors may be useful in field surveys: high-resolution gamma spectroscopy systems (HRGS) and field instruments for detecting low energy radiation (FIDLER). HRGS typically use a germanium-lithium detector coupled to a multichannel analyzer to identify gamma-emitting radionuclides by determining the energies and relative detection frequencies of incident gamma and X-ray photons. The energy spectrum acquired from the analyzer is compared against reference spectra for known or suspected radionuclides. FIDLERs are specialized $\mathrm{NaI}$ detector systems that measure low-energy photon radiation from radionuclides such as plutonium or americium.

Prior to the field survey, all survey instruments should be calibrated for the range of gamma radiation energies expected. At a minimum, EPA requires a two-point energy calibration at 25 and 75 percent of full scale, performed annually by a certified laboratory using gamma standards traceable to the National Institute of Standards and Technology (NIST). A current calibration certificate must be provided for each survey instrument. Moreover, during the field survey, the proper operating response of each instrument should be confirmed daily using a gamma radiation check source in a reproducible geometry. The results of instrument checks should be recorded in the field notebook.

TABLE 3-10: ALPHA AND BETA RADIATION SURVEY INSTRUMENTS

\begin{tabular}{|c|c|c|c|}
\hline INSTRUMENT & $\begin{array}{l}\text { RADIATION } \\
\text { DETECTED }\end{array}$ & ADVANTAGES & DISADVANTAGES \\
\hline $\begin{array}{l}\text { Alpha } \\
\text { scintillation }^{\text {probe }^{1}}\end{array}$ & Alpha & $\begin{array}{l}\text { High detection efficiency } \\
\text { Very portable }\end{array}$ & $\begin{array}{l}\text { Very fragile } \\
\text { Measures only alpha particles }\end{array}$ \\
\hline $\begin{array}{l}\text { Air proportional } \\
\text { detector }\end{array}$ & Alpha & $\begin{array}{l}\text { Large surface area } \\
\text { High detection efficiency }\end{array}$ & $\begin{array}{l}\text { Very fragile } \\
\text { Measures only alpha particles } \\
\text { Affected by moisture }\end{array}$ \\
\hline $\begin{array}{l}\text { Geiger-Mueller } \\
(\text { GM) pancake } \\
\text { type probe }\end{array}$ & $\begin{array}{l}\text { Alpha, beta, and } \\
\text { gamma }\end{array}$ & $\begin{array}{l}\text { Large surface area } \\
\text { Detects all types of radiation }\end{array}$ & $\begin{array}{l}\text { Decreases ability to discriminate } \\
\text { among radiation types } \\
\text { Not recommended for measuring } \\
\text { alpha particles }\end{array}$ \\
\hline $\begin{array}{l}\text { Side-shielded } \\
\text { GM probe }^{1}\end{array}$ & $\begin{array}{l}\text { Beta and } \\
\text { gamma }\end{array}$ & $\begin{array}{l}\text { Discriminates between beta and } \\
\text { gamma radiation } \\
\text { Useful in high gamma radiation fields }\end{array}$ & $\begin{array}{l}\text { Gamma reading is not directly } \\
\text { proportional to radiation field; } \\
\text { response varies with energy }\end{array}$ \\
\hline
\end{tabular}




\section{Alpha and Beta Detectors}

Survey instruments for measuring alpha and beta radiation include alpha scintillation probes, air proportional detectors, GM pancake type probes, and side-shielded GM probes (see Table 3-10). Measurements made with alpha and beta detectors are usually recorded as counts per minute (cpm) per unit area for the active detection area of the probe. These measurements are then converted to activity units of disintegrations per minute (dpm) per unit area by an instrument-specific efficiency factor. Alpha and beta detectors should also be properly calibrated using appropriate NIST standards and their responses checked daily in the field.

Operation, maintenance, and calibration standards for radiation monitoring instruments may be found in the American National Standards Institute's Radiation Protection Instrumentation and Calibration (1978).

\subsubsection{Survey Techniques}

In planning SI sampling and field screening, the investigator should be aware that background levels of radioactivity and radiation exposure rates can vary significantly in the environment, both spatially and temporally. The accuracy of background level evaluations can be increased by using a combination of surveying methods and sampling, especially for soil and air releases at radiation sites. The SI investigator should research natural radiation exposure rates and background concentrations for all radionuclides suspected to be at the site.

In general, four types of radiation survey techniques may be used during focused and expanded SIs (see Table 3-11): walkover surveys, grid surveys, downhole gamma logging, and special purpose surveys. A walkover survey may assist planning focused SI samples by detecting hot spots and releases of radionuclides and aiding sample location selection. This survey is conducted by walking the site and offsite areas with a hand-held radiation detector. At sites with gamma-emitting radionuclides, gamma exposure rates are measured with a $\mathrm{NaI}$ or organic scintillation detector held one meter above the ground surface. Measurements may also be made closer to the ground to pinpoint gamma sources. At sites with radionuclides that do not emit gamma radiation, alpha and beta survey meters may be used to scan surface areas for elevated count rates. During the field survey, all areas with elevated exposure rates or count rates should be marked with survey stakes and measurement results recorded on the site map.

A grid survey during the expanded SI can refine gamma exposure rate measurements and help

TABLE 3-11: RADIATION SURVEYING METHODS

\begin{tabular}{|l|c|l||}
\hline \multicolumn{1}{|c|}{ SURVEY TYPE } & MEDIUM & \multicolumn{1}{c|}{ DATA PROVIDED } \\
\hline \hline $\begin{array}{l}\text { High Resolution Gamma } \\
\text { Spectroscopy }\end{array}$ & All & Identify specific gamma-emitting radionuclides \\
\hline Downhole Gamma Logging & Soil & $\begin{array}{l}\text { Identify distribution of gamma-emitting radionuclides } \\
\text { relative to soil depth }\end{array}$ \\
\hline Beta/Gamma Measurements & Soil & Identify distribution of radionuclides relative to soil depth \\
\hline $\begin{array}{l}\text { Gross Alpha or Gross Beta/Gamma } \\
\text { Measurements }\end{array}$ & All & Screen for radioactivity levels prior to laboratory analysis \\
\hline $\begin{array}{c}\text { Surface Area } \\
\text { Walkover Survey (Focused SI) }\end{array}$ & Soil & Identify hot spots for future investigation \\
Grid Survey (Expanded SI) & Soil & Establish areas of observed contamination \\
\hline \hline
\end{tabular}


delineate areas of surface contamination. In this type of survey, a grid system should be planned for the area of radioactivity determined during the focused SI. Additional survey measurements with other instruments may be planned at grid point locations to contribute to the evaluation of contaminated soil volume and hazardous waste quantity.

Downhole gamma logging may determine the distribution and depth of gamma-emitting radionuclides in soil. In this type of survey, a gamma radiation probe is lowered down a hole drilled in the soil, and exposure or count rate measurements are recorded at selected depths (typically every six inches). Downhole measurements taken at selected locations where gamma radiation has been detected are compared with similar measurements taken at background locations.

The SI investigator may plan special purpose surveying to support other SI activities related to quality assurance and the health and safety of field personnel. Examples of special surveying procedures may include GM and alpha scintillation detector surveys of surveying and sampling equipment, potentially radioactive structures, investigation-derived wastes, and decontamination process materials. The SI investigator should consult a health physicist during SI planning for guidance on: selecting, calibrating, and operating radiation survey meters; conducting survey techniques; and interpreting survey results. Additional guidance on survey instruments and techniques can be found in the references listed in Table 3-12.

\subsubsection{Special Sampling and Analysis Issues}

In planning radionuclide sampling and analysis, the SI investigator should be aware that radionuclide analyses are not currently conducted as part of CLP RAS. Instead, these analyses are conducted under SAS or a separate CLP-equivalent program. For information to evaluate and select laboratories with radioanalytical services, the investigator should contact EPA's National Air and Radiation Environmental Laboratory (NAREL) in Montgomery, Alabama, or the Nuclear Radiation Assessment Division of the Environmental Monitoring Systems Laboratory in Las Vegas, Nevada.

The Nuclear Radiation Assessment Division also provides quality assurance oversight for participating radiation measurement laboratories, including radionuclide analytical services through the Environmental Radioactivity Intercomparison Program. Quality assurance plans for all analytical procedures involving radioactive samples may be derived from several sources, including the U.S. Nuclear Regulatory Commission's Quality Assurance for Radiological Monitoring Programs (Normal Operations)-Effluent Streams and the Environment, Regulatory Guide No. 4.15, Revision 1 (1979) or American National Standards Institute's Quality Assurance Program Requirements for Nuclear Facilities, Report No. ANSI/ASME NQA-1 (1986).

TABLE 3-12: RADIOACTIVITY MEASUREMENT PROCEDURES - REFERENCES

Conference of Radiation Control Program Directors, Inc., 1979. Ionizing Radiation Measurement Criteria for Regulatory Purposes. Prepared for U.S. Department of Commerce, National Bureau of Standards. NBS GCR 79-173.

National Council on Radiation Protection and Measurements, 1985. A Handbook of Radioactivity Measurements Procedures. NCRP Report No. 58.

National Council on Radiation Protection and Measurements, 1978. Instrumentation and Monitoring Methods for Radiation Protection. NCRP Report No. 57.

Schleien, B., and Terpilak, M.S., Editors, 1984. The Health Physics and Radiological Health Handbook, Nucleon Associates, Inc. 


\subsubsection{HRS Requirements for Radlation Sites}

Section 7 of the HRS addresses sites containing radioactive substances, alone or in combination with other hazardous substances. Major HRS factors and special analytical data requirements are summarized below.

Human toxicity factors: Radionuclides are evaluated on the basis of carcinogenicity and are designated as weight-of-evidence category A carcinogens. Toxicity is determined for each radionuclide individually based on its slope factor values, expressed in terms of lifetime excess total cancer risk per unit of radioactivity ingested or inhaled. SCDM Part B (OSWER Directive 9345.1-13) provides toxicity values for a limited number of radionuclides.

In general, sites containing mixed radioactive and other hazardous substances are evaluated in greater detail than sites with only one of these types of hazardous substances. Human toxicity factor values are evaluatecl for radioactive and nonradioactive components separately; the substance posing the greatest hazard is selected based on toxicity, mobility, persistence, and/or bioaccumulation potential. Source hazardous waste quantity factors for mixed radioactive and other hazardous substances also are evaluated separately for radioactive and nonradioactive substances, and the combined quantities of both components are summed to derive the pathway hazardous waste quantity factor value.

Source Characterization: The quantity of radioactive substances in a source is based on the net activity content (after subtracting background levels) of all radionuclides present, rather than on their mass. To characterize sources, radioanalytical data are required to:

- Identify all radioactive substances and decay products present in the source.

- Determine the concentration of each radionuclide in the source.

- Determine the natural background concentration of each radionuclide.

- Delineate source dimensions (area, depth, volume).

- Investigate source containment.
Observed Releases and Areas of Observed Contamination: Observed release criteria for naturally occurring and ubiquitous man-made radionuclides in the environment require radioanalytical data to:

- Identify all such radionuclides and decay products present in each migration pathway.

- Determine the concentration of each radionuclide in these media.

- Determine the mean site-specific natural background concentrations of each radionuclide in each medium.

- Determine the minimum detectable activity (MDA) concentration for each radionuclide in each medium.

Observed release criteria for non-ubiquitous, manmade radionuclides in the environment require radioanalytical data to:

- Identify all such radionuclides and decay products present in each migration pathway.

- Determine the concentration of each radionuclide in these media.

- Determine the lower limit of detection (LLD) for each radionuclide in each medium.

In addition, observed contamination criteria for the soil exposure pathway require radioanalytical data to:

- Determine gamma radiation exposure rates at one meter above the surface of contaminated surficial materials (or one meter away from above ground sources).

- Establish natural radiation exposure rates at uncontaminated background locations.

Levels of Contamination at Specific Targets: Media specific benchmarks for radionuclides used to establish Level I and Level II contamination, in activity units rather than mass units, include:

- Maximum Contaminant Levels (MCLs) for the ground water pathway and the drinking water threat in the surface water pathway;

- Uranium Mill Tailings Radiation Control Act (UMTRCA) standards for the soil exposure pathway; and 
- Screening concentrations for radionuclides corresponding to a $10^{-6}$ lifetime cancer risk following lifetime exposure via inhalation (air pathway) or ingestion (ground water pathway, drinking water or human food chain threats, and soil exposure pathway).

Persistence: Persistence criteria for the surface water pathway require radioanalytical data to determine the effective radioactive and volatilization half-life for each radionuclide evaluated.

\subsubsection{Radiation Health and Safety Plan}

The basic techniques for protecting the health and safety of the field investigative team assessing a radiation site overlap those involving other hazardous substances. Important differences relate to the gamma radiation exposure pathway, monitoring procedures for radionuclide exposures, and regulatory requirements. Radionuclides emitting gamma radiation, even if contained in buried sources, may expose personnel. Exposure also may result from the inhalation and ingestion of contaminated air, water, and soil, from dermal contact or through open cuts. A health physicist should be onsite at all times during the SI to monitor the work of field personnel. All field personnel should meet minimum qualification criteria for radiation protection, as defined in the American National Standards Institute's Selection, Qualification and Training of Personnel for Nuclear Power Plants, Report No. ANSI/ANS-3.1 (1987).

Exposure conditions and limits are regulated under Federal statutes. Federal regulations require that records of personnel exposures must be maintained. These should include records of external and internal exposure, records of unusual exposure, records of exposure from previous employment, and records of special investigations.

The radiation health and safety plan should provide accurate monitoring and reporting of personnel exposures. The most common personnel radiation monitors are film badges or thermoluminescent dosimeters worn by individuals.

Several approaches may be used alone or combined to assess internal exposure. Air sample analysis may provide a quantitative assessment of radionuclides in breathing air. For gamma emitting radionuclides, calibrated whole body counters are commonly used to quantify the body burden of radionuclides. Since radionuclides once ingested or inhaled also may be excreted from the body, bioassays involving urine, blood, or feces can be used to assess body burdens for radionuclides.

In addition, adequate records should be maintained to document personnel qualifications (training, respirator fit test, medical exams, etc.), personnel access to controlled locations onsite, and analytical services for personnel dosimeters, bioassays, work area monitoring samples, and respirators.

EPA is developing an Agency-wide radiation health and safety program. SI investigators should contact ORP, the Safety, Health, and Environmental Management Division (SHEM), or Regional health managers for information on this program.

\subsubsection{IDW Plan}

Radioactive wastes generated during the SI must be packaged and removed according to Federal guidelines. Contract services are available for removal of radioactive wastes. The IDW plan should discuss all aspects of radioactive waste removal. The IDW plan also should include a plan for the storage and removal of rinsates that qualify as radioactive liquid waste. The investigator should consult with a health physicist to keep current with developing lowlevel radioactive waste (LLRW) regulations. Some States operate LLRW repositories. 


\section{CHAPTER 4 SAMPLING STRATEGIES}

This chapter discusses sampling strategies for the focused and expanded SI and provides guidelines for developing; sample plans. The chapter also discusses the conditions and objectives for the single SI approach. Special guidance on sampling strategies for sites containing radioactive substances is provided at the end of the chapter. The investigator should tailor sampling strategies to collect samples to demonstrate the presence of hazardous substances and determine whether those substances have migrated from sources or disposal locations. SI objectives and sampling strategies, however, may change as site-specific factors change or become kriown.

Because uncontrolled hazardous waste sites vary greatly in size and complexity, specific SI sampling guidelines that apply to all sites are not possible. The primary purpose of the SI sampling program is to assess the nature of the problem at the site, and to support response and further action decisions. Additional purposes include meeting public information needs and incorporating remedial investigation (RI) sampling objectives whenever possible. SI sampling is not meant to determine the full extent of a hazardous substance problem at a site, nor is it limited to the data needed to score the site according to the HRS.

Sample locations should be selected based on the likelihood of detecting hazardous substances at higher than background level concentrations. After reviewing available information, the investigator should prepare the SI sample plan, including the location, number, and types of samples to be collected. Table 4-1 presents sample planning considerations.

The investigator should also determine the parameters for sample analysis. If previous analytical results do not adequately assess all the potential hazardous substances, full target analyte list (TAL) or target compound list (TCL) analysis should be performed. However, full TAL or TCL analysis may not be required for SIs where previous analytical results address specific analytes or classes of substances (e.g., pesticides, volatile organic compounds). Partial analyses should be considered during planning because they are less expensive or may have lower quantitation limits than full TAL or TCL analysis.
Section 3.1.1 provides more information on sample types (e.g., media, waste, grab, field screening). Also, EPA's A Compendium of Superfund Field Operations Methods (OSWER Directive 9355.0-14) contains detailed information on sampling procedures and techniques.

\subsection{SI SAMPLING PRINCIPLES}

The following key principles can be the basis of an effective sample plan. Note that site-specific circumstances, including adverse weather, sampling equipment problems, sample location accessibility, health and safety concerns, and CLP scheduling may affect the application of these principles.

\subsubsection{General Sampling Principles}

Sample to Identify Targets Exposed to a Hazardous Substance: Identifying populations or sensitive environments exposed to hazardous substances is a critical early step in protecting public health and the environment under the Superfund program. The presence of contamination at a target contributes significantly to the HRS score and triggers a high priority for follow up action. Absence of target contamination is also important because it could indicate that public health is not endangered or that no further investigation is necessary. Sampling targets (e.g., drinking water wells and intakes, sensitive environments, fisheries) within target distance limits can accomplish two objectives during the SI:

- It may demonstrate a release. 
TABLE 4-1: SAMPLE PLANNING CONSIDERATIONS

\begin{tabular}{|c|c|}
\hline CRITERION & CONSIDERATIONS \\
\hline Sources & $\begin{array}{l}\text { Source types } \\
\text { Safety } \\
\text { Containment } \\
\text { Available data }\end{array}$ \\
\hline Number of pathways sampled & $\begin{array}{l}\text { Pathway media } \\
\text { Strata within HRS pathway media } \\
\text { Targets likely to be exposed to contamination } \\
\text { Probability of release to media } \\
\text { Probability of contamination attributable to the site }\end{array}$ \\
\hline Number of QC samples & $\begin{array}{l}\text { Screening vs. listing } \\
\text { Field duplicate, replicate, split } \\
\text { Number of samples } \\
\text { Blank (trip, field, equipment rinsate) } \\
\text { Field evaluation }\end{array}$ \\
\hline $\begin{array}{l}\text { Number of background and attribution } \\
\text { samples }\end{array}$ & $\begin{array}{l}\text { Screening vs. listing } \\
\text { Number of source samples } \\
\text { Alternative sources of contamination }\end{array}$ \\
\hline $\begin{array}{l}\text { Application (usability) of previous } \\
\text { samples }\end{array}$ & $\begin{array}{l}\text { Analytical results } \\
\text { Quality } \\
\text { Reliability } \\
\text { Sample dates, locations, and descriptions } \\
\text { Potential for data validation }\end{array}$ \\
\hline Analytical methods & $\begin{array}{l}\text { Previous analytical data } \\
\text { Costs } \\
\text { Detection limits }\end{array}$ \\
\hline
\end{tabular}

- A measurable concentration of a hazardous substance found at the target may be used to evaluate target exposure relative to mediaspecific benchmarks.

Analytical support to detect substances at or above benchmarks, particularly in drinking water samples, may require planning for special CLP analyses.

As a general rule, sample locations should be selected for targets that may be contaminated by hazardous substances likely to be attributable to the site. Sampling should focus on migration paths and the direction of nearest targets. The SI investigator should evaluate the likelihood of finding measurable concentrations at various distances from site sources.
Sample to Identify Hazardous Substances Present at the Site: The objective of sampling sources is to identify hazardous substances present and to support attributing them to the site. Source samples may not be necessary if previous data document the types of waste found at the site. However, if data are not available or reliable, sources and other possible wastedisposal locations may need to be sampled.

If multiple hazardous substances are suspected at the site, sampling should focus on the more mobile substances, which are generally easier to locate in a specific medium, particularly soil, because of their greater tendency to migrate. Most hazardous substances will segregate into one or more media based on their physical and chemical characteristics- 
for example, PCBs tend to bind to soils and may not be present in all pathways.

Sample to Demonstrate a Release: SI sampling should focus on demonstrating the release of a hazardous substance to a pathway, particularly when a release is either suspected during the PA and contributes significantly to the site score or was not fully documented previously.

To demonstrate a release, analytical data must:

- Indicate that the hazardous substance is present at levels significantly above background.

- Demonstrate that the significant increase is at least partially attributable to the site.

For the soil exposure pathway, the investigator must collect soil samples to support the presence of observed contamination in surficial materials.

Suspected releases that are not critical to the site screening or listing decision should not be sampled. An SI sampling approach should consider evaluating the non-critical pathway for potential to release and allocating samples for the factors critical to the site score.

Sample to Discriminate Among Alternative Sources of Contamination: If there are multiple sources of contamination in the area of the site being investigated, sampling should be designed to determine whether the site is at least partially responsible for the contamination (see Section 4.5.3).

Sample to Determine Representative Background Concentrations: To determine whether a hazardous substance is present significantly above background, the background level must be known. The investigator should consider whether the concentrations of hazardous substances are related to naturally occurring levels or offsite influences. Background samples are normally collected during the SI. However, in some situations they may not be required-for example, when the substance does not occur naturally and is known to be present at the site based on previous analytical data. The same methods should be used whenever possible to sample and analyze both background and elevated concentrations.
Sample to Verify Field and Laboratory Practices: QA/QC samples help to monitor any contamination introduced by field methods, evaluate laboratory analytical results, and help increase overall confidence in analytical results. QA (or performance) samples relate to procedures regarding program oversight, while QC samples relate to the methods themselves. During the SI, these samples should be collected using the same methods as for other samples-for example, the $Q C$ samples should be stored, transported, and analyzed in the same manner as site samples. Several types of QC samples may be collected, including split and duplicate samples, as well as field and trip blanks (see Section 3.3).

\subsubsection{Focused SI Sampllng Principles}

The focused SI emphasizes collecting analytical data to test site hypotheses generated during the PA and to determine the need for further investigation. During the focused SI, the investigator collects samples to determine the types of hazardous substances at the site, whether a hazardous substance has been released, and whether the release impacts targets.

During the focused SI, sampling should test hypotheses for the ground water and surface water pathways where a release suspected during the PA contributed significantly to the further action decision. Also, sampling may be warranted to test the presence of actual contamination for the soil exposure pathway. For sites with a suspected release and primary target hypotheses, sampling to demonstrate actual target contamination also tests the suspected release hypothesis.

Sample results will be the most important factor in determining whether or not a site will require further investigation after the focused SI. Making effective screening decisions with a limited number of samples depends on carefully planning the focused SI sampling strategy. Principles emphasized during the focused SI sampling include:

- Identifying targets exposed to a hazardous substance;

- Identifying hazardous substances present at a site; and

- Demonstrating a release. 
Other factors that may affect the sampling approach depend on the objectives of the investigation, number of site hypotheses to be tested, availability and quality of previous analytical results, and site characteristics. To illustrate the focused SI sampling strategy, consider the example in the sidebar.

Other considerations of focused SI sampling strategies include the following.

- Concentrate samples on major pathways affecting the score: For most sites, only certain pathways will be of concern after the PA. The importance of a specific pathway and the individual factor scores for a site must be taken into account when developing the focused SI sample plan. Sample collection should emphasize evaluating factors most critical to the site score.

- Use previous analytical data: If any previous data are usable for the focused SI (see criteria discussed in Section 3.2), they should be used to evaluate the site and facilitate planning sample locations. For example, if reliable previous data demonstrate site-related contamination in an area, do not resample these areas during the focused SI. Note that if previous analytical data indicate an HRS score of 28.50 or greater, the site may be a candidate for the single SI rather than a focused SI.

- Limit collection of background and QA/QC samples: Demonstrating a release or an actually contaminated target for screening purposes does not require the full complement of background and QA/QC samples needed for an expanded SI. Conserve field investigation hours and sampling costs by limiting the number of background and QA/QC samples, where appropriate.

Table 4-2 summarizes sampling criteria and considerations to help the investigator plan samples to meet focused SI objectives.

\subsubsection{Expanded and Single SI Sampling Principles}

All sampling principles are emphasized during the expanded and single SI; however, some principles may apply to a lesser extent depending on availability

\section{EXAMPLE OF FOCUSED SI SAMPLING STRATEGY}

A site advanced to the focused SI based solely on suspected contamination of nearby surface water used for recreational fishing. The SI investigator proposed to sample along the overland migration path towards surface water. However, those samples would not directly test the PA hypothesis that the fishery is exposed to contamination. Theoretically, a single sediment sample taken at a likely area of sediment accumulation in surface water near the probable point of entry (PPE) can test two hypothesessuspected contamination of a fishery and suspected release to surface water. A second sediment sample collected at the PPE would increase the probability of detecting contamination, increase confidence in the sample results, and may address quality control of sampling procedures. If a hazardous substance is not detected in the PPE sample, the site may receive a SEA recommendation. The investigator may consider collecting several sediment samples from the PPE since testing the hypothesis of an actually contaminated fishery is critical to the screening decision.

and quality of information (including previous analytical results) to support HRS documentation requirements. For most sites, not all pathways will prove to be of concern after the focused SI. The relative importance of the pathway for the site must be taken into account when planning expanded SI samples.

The primary objectives of the expanded SI are to collect fully documented data to prepare an HRS package and, for some sites, to collect field data for the remedial investigation (RI). Expanded SI sampling should be designed to completely investigate and document observed releases, observed contamination, and levels of target exposure to contamination. The focused and expanded SI may require different degrees of documentation for key HRS factors. For example, if the focused SI indicates that surface water sediments have high concentrations 
TABLE 4-2: PRIORITIES FOR FOCUSED SI SAMPLES

\begin{tabular}{|l|l||}
\hline \multicolumn{1}{|c|}{$\begin{array}{c}\text { SAMPLE BUDGET } \\
\text { CATEGORY }\end{array}$} & \multicolumn{1}{c|}{ PRIORITIES } \\
\hline \hline $\begin{array}{l}\text { Number of pathways to } \\
\text { evaluate with samples }\end{array}$ & $\begin{array}{l}\text { Sample pathways critical to PA further action recommendation } \\
\text { If multiple pathways are critical to screening decision, plan sampling to test } \\
\text { all critical hypotheses }\end{array}$ \\
\hline Number of targets sampled & $\begin{array}{l}\text { Sample primary drinking water wells and intakes suspected of exposure to } \\
\text { site-related contamination (see glossary: Primary Target) } \\
\text { Sample nearest targets or targets most likely to be exposed to site-related } \\
\text { contamination for critical pathways if contamination suspected during PA }\end{array}$ \\
& $\begin{array}{l}\text { If sample budget permits, take more than one sample at surface water and } \\
\text { soil target locations that are critical to the site decision }\end{array}$ \\
\hline Number of sources sampled & $\begin{array}{l}\text { Sample sources to identify hazardous substances present at site } \\
\text { If multiple sources exist, sample each different source type }\end{array}$ \\
\hline Number of release samples & $\begin{array}{l}\text { Sample to test if a release has occurred for critical pathways. When } \\
\text { possible, test release hypotheses in conjunction with target samples } \\
\text { If the magnitude of potentially contaminated targets is responsible for } \\
\text { screening decision, limit number of release samples }\end{array}$ \\
\hline $\begin{array}{l}\text { Number of background and } \\
\text { QA/QC samples }\end{array}$ & $\begin{array}{l}\text { Limit collection of background and QA/QC samples to those needed to } \\
\text { screen site. Background or QA/QC samples may not be necessary }\end{array}$ \\
\hline Other criteria & $\begin{array}{l}\text { Use previous analytical data to plan sample locations } \\
\text { Do not resample at locations where reliable previous analytical data detected } \\
\text { a hazardous substance }\end{array}$ \\
\hline
\end{tabular}

of metals, the expanded SI would include collecting samples to establish sediment background concentrations to attribute the metals to the site being evaluated, and samples to document surface water targets exposed to actual contamination.

The expanded SI also involves field activities to document aspects of the HRS evaluation that may be beyond the scope of a focused SI which is limited to screening. If necessary, the following may be expanded SI activities:

- Install monitoring wells.

- Collect physical parameter data of subsurface.

- Install boreholes.
- Collect non-routine soil gas or air samples.

- Conduct geophysical surveys to delineate areas of buried waste.

- Document waste characteristics for significant sources (e.g., hazardous waste quantity).

- Supplement documentation of releases and areas of contamination (e.g., fisheries, soils).

- Supplement documentation of targets exposed to actual contamination.

- Distinguish the level of contamination (e.g, Level I) for targets.

- Document complex attribution issues (e.g., industrial areas and ground water plumes).

- Support the quality of analytical data with additional QA/QC samples. 


\section{EXAMPLE OF EXPANDED SI SAMPLING STRATEGY}

A site advanced to the expanded SI based on observed contamination on school property and a suspected release to ground water. For the school property, surficial soil samples detected hazardous substances, but concentrations were not quite above health-based benchmarks. In addition, background soil sample analytical results were qualified (coded as "UJ") during data validation due to low recovery of internal standards. The data reviewer commented that these results were biased low, resulting in reported concentrations most likely below real concentrations. The investigator did not feel confident that these samples fully investigated contamination on the school property, and decided to resample during the expanded SI to document the threat to resident population targets for the soil exposure pathway, including the level of contamination for the student population.

For this site, the only background ground water sample collected during the focused SI was 2 miles from the site, and other sources of contamination were nearby. Drinking water wells were not likely to be exposed to actual contamination, while the school and several residential properties were likely to be exposed. The investigator determined that the soil exposure pathway was a greater threat than the ground water pathway, and designed a sampling strategy to fully document resident population threat targets. For this site, installing wells may not be necessary, because the ground water pathway can be evaluated based on potential to release and potentially contaminated targets.

The expanded SI may be used to refine estimates of hazardous waste quantity by sampling bulk source materials, such as tanks or containers. Other work may be necessary to demonstrate the boundaries of surficial contamination or the total number of contaminated drinking water wells, particularly if several nearby residential properties are likely to be contaminated, not all of which were sampled during the focused SI.

Other considerations for expanded SI sampling include:

- Collect samples to improve documentation for factors that significantly affect scoring: For example, if background levels for ground water are in question-perhaps due to data of unknown quality - and a release to ground water is critical to scoring, the investigator may sample to ensure valid data.

- Collect adequate background and QA/QC samples: Demonstrating a release or a target exposed to actual contamination requires the full complement of background and QA/QC samples to adequately document information for NPL purposes. Background and QA/QC samples should not be limited by the sample budgetcollecting these samples will prevent the need to return to the site. Section 4.3 discusses optimizing the number of QA/QC and background samples.

Field screening methods may be used during the expanded SI to further characterize the site, to identify CLP sample locations, or to support documentation requirements (e.g., designing soil sampling grids, selecting ground water well screen depths, and better describing the areas of surficial contamination). If soil samples need to be collected from adjacent residences or schools to document a sufficient number of resident population targets for the soil exposure pathway, field screening may be used to identify the samples submitted for CLP analyses.

Table 4-3 summarizes expanded SI sampling criteria and priorities to help the investigator plan and allocate samples for expanded SI objectives.

\subsection{SOURCE CHARACTERIZATION}

Characterizing sources generally requires collecting source samples to investigate the types of wastes deposited at the site and specifically to identify 
TABLE 4-3: PRIORITIES FOR EXPANDED SI SAMPLES

\begin{tabular}{|c|c|}
\hline SAMPLING CRITERIA & PRIORITIES \\
\hline $\begin{array}{l}\text { Number of pathways } \\
\text { sampled }\end{array}$ & $\begin{array}{l}\text { Sample pathways critical to site score } \\
\text { If multiple pathways are critical to site score, sample to fully document all } \\
\text { remaining site hypotheses }\end{array}$ \\
\hline Number of targets sampled & $\begin{array}{l}\text { Sample targets (e.g., drinking water wells and intakes, residential and school } \\
\text { properties, surface water sensitive environments and wetlands) most likely to } \\
\text { be exposed to site-related contamination } \\
\text { Resample targets where previous analytical results are questionable, or where } \\
\text { background concentrations are needed to document contamination of targets }\end{array}$ \\
\hline Number of sources sampled & $\begin{array}{l}\text { Sample sources to attribute hazardous substances to site } \\
\text { Sample to more fully describe areas of observed surficial contamination } \\
\text { If multiple source types exist at site, at a minimum, sample each different } \\
\text { source type }\end{array}$ \\
\hline Number of release samples & $\begin{array}{l}\text { Sample to document a release for critical pathways. When possible, collect } \\
\text { samples to document an observed release in conjunction with a target } \\
\text { exposed to actual contamination } \\
\text { Limit number of release samples to critical pathways }\end{array}$ \\
\hline $\begin{array}{l}\text { Number of background and } \\
\text { QA/QC samples }\end{array}$ & $\begin{array}{l}\text { Collect background and QA/QC samples necessary to confidently document } \\
\text { site score }\end{array}$ \\
\hline Other criteria & $\begin{array}{l}\text { Use previous analytical data to optimize sample locations } \\
\text { Do not resample at locations where reliable previous analytical data fully } \\
\text { documented a hazardous substance or a release unless samples are needed to } \\
\text { pair those with background samples taken at the same time }\end{array}$ \\
\hline
\end{tabular}

hazardous substances. Investigators should sample as many different types of sources as possible on the assumption that different hazardous substances will be found in different sources. A surface impoundment, for example, may yield different hazardous substances than a waste pile. Even if analytical data on hazardous substances are available, sources should be sampled to confirm the data. Source sampling could support attribution if the same hazardous substances or transformation products are detected in samples taken at release or target sample locations.
Samples from visibly contaminated soils may be more useful to characterize sources than samples from a specific drum or container because such samples may identify more hazardous substances. Also, sampling soils presents fewer safety issues than sampling containers. If little is known about historical site operations and no distinct sources exist, sampling where wastes are most likely to collect, such as onsite ditches, pools, drainage pipes, or other structures, may provide information on the types of substances previously handled. Historical aerial photos may 
show prior disposal areas and changes to site features or topography affecting the location of wastes.

When submitting a source sample for CLP special analytical services (SAS), the SI investigator should notify the laboratory of hazardous substances suspected in the sample, expected concentrations, and analytical protocols to be followed.

Table 4-4 compares the focused and expanded SI source sampling strategies.

\subsubsection{Focused SI Strategy-Source Characterization}

Identifying hazardous substances present at the site is a prime objective of the focused SI. Information on waste management practices or previous data from source areas can reduce the number of samples needed to characterize the sources. At the end of the focused SI, quality-assured analytical data (e.g., CLP data) should identify the specific hazardous substances

TABLE 4-4: SOURCE SAMPLING STRATEGIES

\begin{tabular}{|c|c|c|}
\hline CRITERION & FOCUSED SI & EXPANDED SI AND SINGLE SI \\
\hline Primary objective & $\begin{array}{l}\text { To identify hazardous } \\
\text { substances associated with site } \\
\text { sources; to confirm substances } \\
\text { known or suspected } \\
\text { To refine target distance limits }\end{array}$ & $\begin{array}{l}\text { To verify inconclusive data collected during } \\
\text { focused SI } \\
\text { In limited situations, to help quantify hazardous } \\
\text { waste quantity }\end{array}$ \\
\hline Data quality & All DUCs & $\begin{array}{l}\text { DUC-I for hazardous constituent quantity } \\
\text { DUC-I and DUC-II to establish heterogeneity } \\
\text { or homogeneity of wastes } \\
\text { All DUCs for other hazardous waste quantity } \\
\text { measures and to identify hazardous substances } \\
\text { associated with site sources }\end{array}$ \\
\hline $\begin{array}{l}\text { Samples to help } \\
\text { demonstrate observed } \\
\text { contamination }\end{array}$ & $\begin{array}{l}\text { Generally limited to samples } \\
\text { used to test a site hypothesis } \\
\text { regarding soil contamination } \\
\text { within } 2 \text { feet of surface }\end{array}$ & $\begin{array}{l}\text { Samples to further describe the areas of } \\
\text { observed contamination in the direction of } \\
\text { targets for the soil exposure pathway }\end{array}$ \\
\hline $\begin{array}{l}\text { Samples to help } \\
\text { evaluate source } \\
\text { containment or source } \\
\text { type }\end{array}$ & Generally not collected & $\begin{array}{l}\text { Generally only collected when the containment } \\
\text { factor value for a migration pathway is not } 10 \text {; } \\
\text { sometimes collected to demonstrate a biogas } \\
\text { release if air pathway is significant pathway }\end{array}$ \\
\hline $\begin{array}{l}\text { Samples to help } \\
\text { describe source } \\
\text { boundaries and estimate } \\
\text { hazardous waste } \\
\text { quantity }\end{array}$ & $\begin{array}{l}\text { Generally limited to surficial } \\
\text { samples within } 2 \text { feet of } \\
\text { surface } \\
\text { Generally limited to } \\
\text { contaminated soil sources }\end{array}$ & $\begin{array}{l}\text { In certain situations, samples to estimate the } \\
\text { depth of a source or to further describe the } \\
\text { area of sources other than contaminated soil } \\
\text { (e.g., landfill, land treatment, buried surface } \\
\text { impoundment) } \\
\text { In certain situations, samples to estimate } \\
\text { hazardous constituent quantity or hazardous } \\
\text { waste volume quantity }\end{array}$ \\
\hline
\end{tabular}


at the site and confirm the presence of substances known or suspected during the PA.

Samples should not be collected to directly establish the degree of containment for a source. Containment generally can be evaluated accurately by field observations. Samples collected to identify hazardous substances, however, may also document poor source containment, if necessary.

Samples to support estimates of source volume, hazardous constituents, and source area are generally beyond the scope of the focused SI. For source types with reasonably well-defined boundaries (e.g., surface impoundments, waste piles), physical measurements taken with a steel tape measure or laser range finder should be used to determine area and possibly volume dimensions. Hazardous waste quantity factor values are determined by calculating a hazardous waste quantity for each source and then assigning a factor value for a range of waste quantities. The ranges for these values are quite broad, so that a small increase in quantity, unless near a breakpoint, could have no impact on the factor value assigned. For example, a measure of hazardous waste quantity for the soil exposure pathway is areal extent of observed contamination. More than 78 acres of contaminated soil would be needed to increase the hazardous waste quantity factor value above the minimum value. Rather than determining the full areal extent of contamination, samples should focus on documenting contaminated targets. The SI investigator should bear in mind that actual contamination in water or air may be sufficient for a site to qualify for the NPL (i.e., HRS score greater than $\mathbf{5 7}$ for a single pathway).

\subsubsection{Expanded and Single SI Strategy- Source Characterization}

Source characterization sampling during an expanded and single SI should focus on HRS documentation requirements. As with the focused SI, background information on waste management practices or previous sampling efforts may significantly reduce the number of samples needed to investigate site sources. If data from site records and previous sampling investigations, including the focused SI, are of good quality, little or no source samples may be needed during the expanded SI.
Some samples used to identify hazardous substances may be used to document containment for a source. For some sites, limited samples may be collected during the expanded SI to evaluate the degree of containment for a source, or to determine whether the source is releasing methane or other biogases.

Sampling to document hazardous waste quantity estimates is generally beyond the scope of the expanded SI. Such sampling may be appropriate for some sources (e.g., containers such as drums and tanks with homogeneous wastes), but is generally not cost-effective given the wide ranges for hazardous waste quantity factor values and values that can be obtained using other tiers.

\subsubsection{Example of Source Sampling Strategy}

Located near a town of 10,000 people, the Lakefield Farm Site is an abandoned strawberry farm that was used for various types of waste activities for an unknown period (Figure 4-1). During the PA, three potential sources were identified: a wet surface impoundment with a volume of approximately 45,000 cubic feet of electroplating sludge; a drum storage area containing about 30 leaking drums, contents unknown, at the southeast corner of the site; and an area of stained soil near the site's western boundary.

As this example illustrates, understanding the scoring implications of the wide quantity ranges used to assign hazardous waste quantity factor values will help identify the samples necessary to determine substance-specific waste characteristics. Table 4-5 summarizes a suggested strategy to characterize the potential waste sources. For this site, it is reasonable to sample the soil underlying the drums, assuming it is representative of the drum contents. In general, when the contents of any container are unknown, the investigator should sample the soils near or beneath the source and not sample the contents of the source itself. Direct sampling of the containerized sources requires specialized expertise, such as the Technical Assistance Team. 
FIGURE 4-1: LAKEFIELD FARM SITE SKETCH \#1
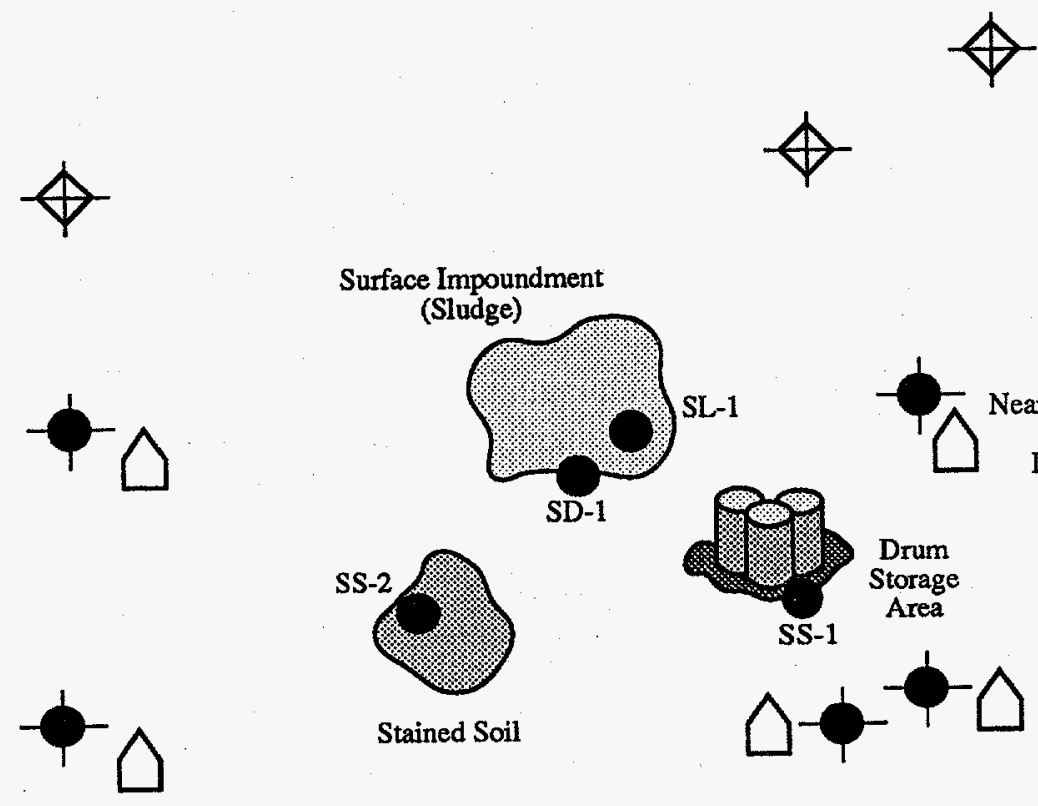

Nearest Well and Nearest
Individual
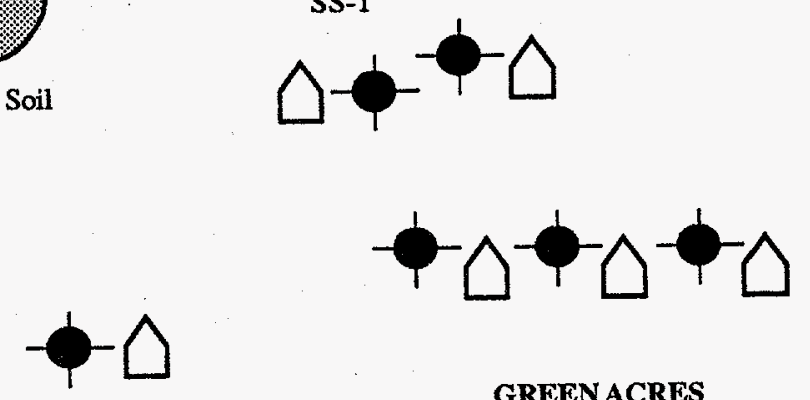

LAKEFTELD

FARM SITE

\section{GREENACRES}

SUBDIVISION

$\underline{\mathrm{KEY}}$
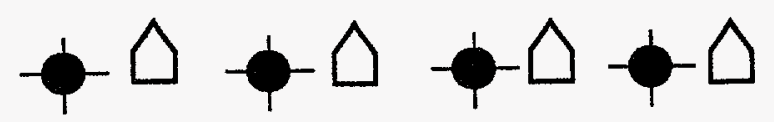

- Source samples

Drinking water well

Municipal Well

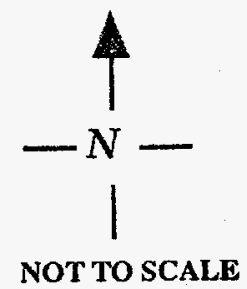

$\$$ Irrigation well

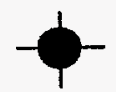


TABLE 4-5: SOURCE SAMPLING STRATEGY FOR EXAMPLE SITE

\begin{tabular}{|c|c|c|c|}
\hline $\begin{array}{l}\text { POTENTIAL WASTE } \\
\text { SOURCE AREA }\end{array}$ & $\begin{array}{c}\text { FOCUSED SI } \\
\text { SAMPLING STRATEGY }\end{array}$ & $\begin{array}{c}\text { HRS } \\
\text { CONSIDERATIONS }\end{array}$ & $\begin{array}{c}\text { NON-SAMPLING } \\
\text { DATA COLLECTION }\end{array}$ \\
\hline $\begin{array}{l}\text { Wet surface } \\
\text { impoundment }\end{array}$ & $\begin{array}{l}\text { Collect } 1 \text { composite source } \\
\text { sample of impoundment } \\
\text { sediments (SD-1) plus one } \\
\text { sludge sample (SL-1) to } \\
\text { evaluate hazardous } \\
\text { substances present }\end{array}$ & $\begin{array}{l}\text { More than } 675,000 \\
\text { cubic feet are needed } \\
\text { to increase HWQ } \\
\text { factor value to next } \\
\text { category value }\end{array}$ & $\begin{array}{l}\text { Obtain physical } \\
\text { dimensions of source; } \\
\text { evaluate containment. } \\
\text { Consider using aerial } \\
\text { photos }\end{array}$ \\
\hline Drum storage area & $\begin{array}{l}\text { Collect } 1 \text { composite } \\
\text { surficial soil sample (SS-1) } \\
\text { from beneath drums to } \\
\text { determine hazardous } \\
\text { substances present }\end{array}$ & $\begin{array}{l}\text { More than } 1,000 \\
\text { drums are needed to } \\
\text { increase HWQ factor } \\
\text { value to next category } \\
\text { value }\end{array}$ & $\begin{array}{l}\text { Verify number of } \\
\text { drums; evaluate } \\
\text { containment; look for } \\
\text { container markings; } \\
\text { examine area around } \\
\text { drums }\end{array}$ \\
\hline Stained soil & $\begin{array}{l}\text { Collect } 1 \text { composite } \\
\text { surficial soil sample (SS-2) } \\
\text { to determine if area is } \\
\text { contaminated and to } \\
\text { identify hazardous } \\
\text { substances }\end{array}$ & $\begin{array}{l}\text { More than } 78 \text { acres of } \\
\text { contaminated soil are } \\
\text { needed to increase } \\
\text { HWQ factor value to } \\
\text { next category value }\end{array}$ & $\begin{array}{l}\text { Obtain physical } \\
\text { dimensions of area; } \\
\text { evaluate containment }\end{array}$ \\
\hline
\end{tabular}

\subsection{QA/QC SAMPLES}

The investigator should collect appropriate QA/QC samples during the SI to confirm the collection of precise and accurate data that represent site conditions. EPA Regional guidelines suggest the number of QA/QC samples to collect. These samples (Table 4-6) should be collected, stored, transported, and analyzed in the same manner as the other site samples.

Several types of field QC samples may be used to monitor contamination of samples-for example, duplicate and split samples, as well as field and trip blanks (see Section 3.2). In general, 1 co-located and 1 replicate are taken for each 20 samples at a site. Some SIs will not require co-located or replicate samples if fewer than 20 samples are collected. Field blanks are required for ground water, surface water, and soil samples at the rate of 1 field blank per matrix per day, or 1 for each 20 samples at a site, whichever is fewer. Field blanks are not required for source material or air samples.
Trip blanks for each day of sampling are required for ground water, surface water, and air samples that involve volatile organics. Field matrix spikes are recommended only if the appropriate technical support is available. For some sites, an extra volume of liquid from a sample location is collected for matrix spike analysis; analysis of the spike is required by CADRE. If it is collected, the results should be compared with laboratory matrix spike results.

For both field and QA/QC samples, the investigator should be able to correlate results of specific sample analyses to those locations where samples were collected during the SI. During SI field work, the investigator should record information regarding sampling activities and observations, including sampling protocols and locations, as well as pertinent physical and topographic features of the site. A map showing sample locations, contaminated areas, and other features pertinent to data evaluation should be provided. In addition, notations concerning the SI samples should be made by either the investigator or the laboratory-for example, whether a sediment 
TABLE 4-6: GUIDELINES FOR MINIMUM QA/QC SAMPLES EXPANDED SI OR SINGLE SI

\begin{tabular}{||l|l|l|l||}
\hline \multicolumn{1}{|c|}{ MEDIUM } & \multicolumn{1}{|c|}{$\begin{array}{c}\text { REPLICATES/ } \\
\text { DUPLICATES }\end{array}$} & \multicolumn{1}{|c|}{ FIELD BLANKS } & \multicolumn{1}{c|}{ TRIP BLANKS } \\
\hline \hline Aqueous & 1 in 20 & 1 in 20 & 1 day of sampling \\
\hline Soil and sediment & 1 in 20 & 1 in 20 & Usually not required \\
\hline Air & 1 in 20 & Not applicable & 1 day of sampling \\
\hline Source material & 1 in 20 & Usually not required & Usually not required \\
\hline \hline
\end{tabular}

Sample requirements should be developed on a site-specific basis. Laboratory blanks and spikes are methodspecific and are not included in the table.

sample had coarse grains or fine grains, or whether a ground water sample was muddy or clear. These notations should accompany the data during reporting. Analytical data should be accompanied by a table or matrix that correlates field sample numbers with laboratory sample numbers.

Reported data should indicate whether samples were filtered or unfiltered. This information may be needed to compare background levels with site samples and to compare sample data with mediaspecific benchmarks.

\subsubsection{Focused SI Strategy-QA/QC Samples}

During the focused SI, only a few QA/QC samples should be collected to ensure that sample results have not been influenced by contamination introduced during field activities. Focused SI QA/QC samples might consist of one trip blank for each day of sampling activities along with one equipment rinsate blank for each matrix sampled. Blanks serve to indicate false positive sampling results, and to monitor the field team's sample handling and decontamination procedures.

At sites where both soil or sediment and aqueous samples are collected, the SI investigator should consider using only the aqueous trip blank and eliminating the soil or sediment trip blank. Aqueous blanks, unlike soil or sediment blanks, are used to detect organic and inorganic contamination. Generally, contamination introduced by improper field activities is more easily detected in the water matrix. The focused SI may also require one rinsate for soil or sediment sampling equipment and one rinsate for water sampling equipment.

Duplicate samples for data validation generally should not be collected during the focused SI since precision of the data generally will not affect the screening decision. Thus, a limited number of QA/QC samples may be sufficient to support focused SI objectives. Generally, these samples should represent 10 to 15 percent of the total number of samples collected.

\subsubsection{Expanded and Single SI Strategy- QA/QC Samples}

During the expanded and single SI, the full complement of QA/QC samples should be collected to ensure data of rigorous quality. In contrast to the focused SI strategy, duplicate samples for data validation may be appropriate to monitor the precision of the analytical data. Trip blanks should be collected for all media sampled during the expanded SI. If hazardous substance concentrations likely are to be near detection limits or near media-specific benchmarks, multiple samples at critical locations may also be appropriate.

In summary, a greater number of QA/QC samples may be necessary to support expanded SI objectives. As a general rule, these samples are 15 to 25 percent of the total number of samples collected. 


\subsection{SAMPLE TO DEMONSTRATE A RELEASE}

\subsubsection{General Principles}

This section discusses three considerations for sampling to demonstrate a release or observed contamination-background, attribution, and targetfollowed by focused and expanded SI strategies. Table 4-7 compares SI strategies to investigate a release.

To demonstrate a release by chemical analysis for a pathway, at least one sample must show contamination significantly above the background level for a hazardous substance. In the absence of any other evidence, the sampling strategy should generally specify collecting at least two samples from each appropriate pathway to demonstrate a release:

- One sample representative of background levels

- One sample downgradient (or downslope, downstream, downwind) of the source of contamination

Since concentrations of hazardous substances usually decrease with distance from sources, sampling near sources may also help to distinguish between alternative sources of contamination in the vicinity of the site.

\section{Background Sampling Considerations}

Establishing a release requires evaluating background. Background is the ambient concentration of a hazardous substance and includes naturally occurring concentrations, concentrations from man-made sources other than the site being evaluated, and concentrations from the site. Generally, background levels are best supported by chemical analysis.

Background and release samples and analyses should be similar, and should focus on the comparability of samples in representing target impacts. To establish background by chemical analysis, the location and number of background samples depends on:

- Hazardous substances present at the site and expected concentrations

- Availability and quality of previous information and analytical data

- Objectives of the investigation

- Site hypotheses to be tested

- Media variability

- Size of the site and number of sources types

- Pathway-specific considerations (e.g., geologic formations, types of surface water bodies)

- Other potential sources of contamination in the vicinity of the site

TABLE 4-7: OBSERVED RELEASE SAMPLING STRATEGIES

\begin{tabular}{||l|l|l||}
\hline \multicolumn{1}{|c|}{ CRITERION } & \multicolumn{1}{|c|}{ FOCUSED SI } & \multicolumn{1}{c|}{ EXPANDED SI AND SINGLE SI } \\
\hline \hline Objective & To test hypothesis (suspected release) & $\begin{array}{l}\text { To demonstrate a release based on HRS } \\
\text { documentation requirements }\end{array}$ \\
\hline Data quality & $\begin{array}{l}\text { Less rigorous (e.g, DUC-II) to rigorous } \\
\text { (e.g., DUC-I) }\end{array}$ & Rigorous (e.g., DUC-I) \\
\hline $\begin{array}{l}\text { Background } \\
\text { samples }\end{array}$ & $\begin{array}{l}\text { Limited, 1 background to 3 release } \\
\text { samples } \\
\text { May rely on published regional data }\end{array}$ & $\begin{array}{l}\text { 2 background to 3 release samples } \\
\text { Generally should not rely on published data } \\
\text { to establish background levels }\end{array}$ \\
\hline Attribution samples & $\begin{array}{l}\text { Limited to what is necessary to test } \\
\text { hypothesis (suspected release) }\end{array}$ & $\begin{array}{l}\text { Those necessary to attribute a portion of a } \\
\text { release to the site being evaluated }\end{array}$ \\
\hline QA/QC samples & $\begin{array}{l}\text { Limited to what is necessary to test } \\
\text { hypothesis (suspected release) }\end{array}$ & $\begin{array}{l}\text { Those necessary to obtain precise and } \\
\text { accurate data within the scope of the SI }\end{array}$ \\
\hline
\end{tabular}


In some situations, appropriate background sample collection may not be possible-for example, no sample could be taken that would represent surface water background levels for comparison with sample concentrations from an isolated pond adjacent to a site. In other situations, background samples may not be needed. For instance, if sample results over a period of time indicate that a well was once uncontaminated and is now contaminated, that well can establish its own background and release levels. Also, some man-made hazardous substances (e.g., chlorinated organic solvents, short-lived radioactive substances) are not naturally occurring or ubiquitous and can only be attributed to a man-made source. If the site is the only source of these substances, the background levels are assumed to be zero (or below detection).

An SI may not require sampling to establish background levels of a specific hazardous substance if the following conditions are met:

- The specific substance is known to be present at the site based on previous analytical data, historical records, or other information such as written statements.

- The specific substance is not known to be naturally occurring or ubiquitous.

- No other sources of contamination for that substance are identified in the vicinity of the site (particularly for nonindustrial areas).

The HRS documents an observed release in one of two ways:

- Direct observation: Material containing a hazardous substance is observed entering or is known to have directly entered the medium (i.e., ground water, surface water, or air) from the site (e.g, through direct deposition of substances below the water table, or an outfall discharging to surface water).

- Chemical analysis: Analytical evidence of a hazardous substance in a medium at concentrations significantly above the background level where a portion of the significant increase is attributable to site sources.
Potential background sample locations include nearby wells that are not expected to be influenced by the site or sediments from non-tidal surface water bodies upstream from the probable point of entry (PPE) to surface water. Background samples for each pathway are discussed in Sections 4.5 through 4.8.

Analytical data near method detection limits and qualified sample results complicate the use of background sample data. During the expanded SI, collecting additional background samples from representative locations may increase the confidence in determining the presence or absence of site contamination.

Some hazardous substances (e.g., lead, arsenic, copper) occur naturally in many areas. If they are used in scoring, background levels are best supported by samples of representative ambient conditions. Without site-specific background data, background levels may be based on other data for naturally occurring concentrations of the substance. The investigator should consider the following sources of information:

- Background sample data for other nearby CERCLA site investigations

- Local surveys by other Federal or State agencies (e.g., Soil Conservation Service, USGS, BLM, mining industry)

- Local universities (e.g., graduate theses)

- Natural concentration ranges and averages in soil

Published naturally occurring ranges of common metals and inorganics may sometimes be used to determine background levels and to assess whether site-specific substance concentrations are indeed representative of regional background variability. However, published values may not account for regional variations or unique site-specific characteristics. Even when concentration data from scientific literature may not be appropriate to establish a background concentration for the site, such data may be used to plan SI samples and to support data interpretation.

As a general rule, the investigator should use background concentration data from this sampling investigation. However, in the absence of data generated from a SI, published data may be used to 
establish background levels if documentation indicates that the published background data and the sample data showing contamination have similar characteristics, or are influenced equally by alternative sources of contamination. For the focused SI, sitespecific background data are less essential.

\section{Attrlbution Considerations}

To demonstrate an observed release, some portion of the release must be attributable to one or more sources at the site. Where attribution of hazardous substances is questionable, sampling should be designed to produce analytical data that demonstrate the site to be at least partially responsible for the contamination. Contributions from other sources of contamination may be differentiated by identifying a single hazardous substance that is unique to the site being evaluated (e.g., wastestream "fingerprinting"). This may require specific analysis and specific review of the data.

In many cases, the site being evaluated is not the only source. Complex attribution concerns (e.g., widespread ground water contamination involving several substances, soil contamination in an industrial area, sediment contamination in harbors) may require investigation better suited to the expanded SI. However, if attribution is not complex, it can be addressed during the focused SI. For many sites, attribution concerns may be addressed by characterizing sources at the site.

\section{Target Considerations}

When evaluating actual contamination, particularly the level of human food chain contamination (see Section 4.6), the investigator should note any potential for sampling errors and false assumptions affecting data representativeness. If the concentration of a hazardous substance meets actual contamination criteria and equals or exceeds its benchmark concentration, the sample location is considered subject to Level I contamination for that pathway or threat. If media-specific hazardous substance concentrations analyzed in the target sample meet the criteria for actual contamination for the pathway but are less than the media-specific benchmark, or if none of these hazardous substances have an applicable benchmark, Level II concentrations apply. Special " $\mathrm{I}$ "and " $\mathrm{J}$ " indices, based on screening concentrations,
In the HRS, significance relates only to the concentration found in a pathway, not to any health or environmental effects. A release may be below the recommended regulatory action level and still constitute an observed release. If the site qualifies for the NPL, remedial studies will determine the risks associated with the release and appropriate corrective actions. The criteria used to determine analytical significance include the following:

- A sample measurement confirms that the release is equal to or greater than the sample quantitation limit (SQL). The SQL is the amount of a hazardous substance that can be reasonably quantified, given the limits of detection for the methods of analysis and sample characteristics that may affect quantitation (e.g., dilution, concentration).

- If the background concentration is not detected or is less than the detection limit, a release is established if the sample measurement equals or exceeds the SQL. For HRS purposes, the detection limit used is the method detection limit (MDL) or the instrument detection limit (IDL) for realtime field instruments.

- If the background concentration equals or exceeds the detection limit, a release is established if the sample measurement is at least three times the background concentration and attribution is established.

are calculated when no hazardous substance individually equals or exceeds its benchmark concentration, and when more than one hazardous substance meets the criteria for actual contamination for the sample (or comparable samples). If either index equals or exceeds 1 , Level I concentrations apply for the sample location.

Under certain circumstances, sample data that are biased high may be used to score an observed release, but such data must only be used to establish Level II contamination, not Level I contamination and not hazardous waste quantity Tier A. 


\subsubsection{Focused SI Strategy-Sample to Demonstrate a Release}

Focused SI sampling does not require fully documenting observed releases, which often involves extensive background sampling as well as sampling to rule out other sources of contamination. To demonstrate a release, analytical data must indicate that a hazardous substance is present at an elevated level and is related to the site. Sampling to demonstrate actual target contamination also investigates a release hypothesis. The scope of the focused SI does not require collecting the full complement of background and field QA/QC samples, which can total as much as 30 percent of all samples for a complete listing investigation. Sampling to document attribution is typically an expanded SI activity. However, the focused SI can include some background and $\mathrm{QA} / \mathrm{QC}$ samples, according to Regional or State guidelines, to increase the investigator's confidence in the quality and representativeness of analytical results.

Focused SI sampling should concentrate on providing evidence of contamination in the ground water and surface water pathways where a release was suspected during the PA. Also, samples should be collected to support or refute the presence of surficial contamination for the soil exposure pathway. Air sampling is an expanded SI activity.

\subsubsection{Expanded and Single SI Strategy- Sample to Demonstrate a Release}

Expanded SI sampling should focus on demonstrating and documenting a release based on data of rigorous quality. The full complement of background, QA/QC, and attribution samples should be collected. In contrast to the focused SI, which tests the hypothesis of a release, expanded SI sampling should meet HRS documentation requirements for a release. The expanded SI should also include samples linking the presence and migration of hazardous substances to sources at the site.

Representative background samples may be difficult to collect if the sample medium is heterogeneous and the background samples are subject to interference from alternative sources of contamination (e.g., urban soils). If any existing background samples are subject to potential interference, the investigator should determine if they accurately represent background conditions by assessing whether the interference:

- Affects background and release samples significantly;

- Affects background and release samples equally;

- Affects background and release samples; and unequally and bias can be determined.

If the interference is insignificant, background samples from previous investigations may be used. Likewise, if both samples are affected equally, previous background data may be appropriate. If the samples are affected unequally, previous background concentrations biased high may be used; background concentrations that are biased low should not be used.

\subsection{GROUND WATER PATHWAY}

The ground water pathway score and the aquifers and wells to be sampled depend on the:

- Number of people served by each aquifer

- Likelihood of a release to each aquifer

- Likelihood that drinking water wells are contaminated by the site

To document a release to ground water by direct observation, material containing one or more hazardous substances must be known to have entered ground water through direct deposition or must be seen entering ground water. Direct deposition establishing a release may include injection and deposition of hazardous substances below the water table. In most cases, chemical analysis of ground water samples from an aquifer is preferred to establish a release.

To document whether a population is drawing from a contaminated drinking water supply, the analytical results must demonstrate a release to the pathway by

If SI targets include municipal wells hypothesized to be exposed to actual contamination, the investigator should review well monitoring data under the Safe Drinking Water Act to determine if the well has been properly monitored and if adequate data exist to determine whether the well is contaminated. 
HRS criteria. A drinking water well and its background well must be finished in the same aquifer and screened in a comparable zone.

Filtration of ground water samples for metals is one way to reduce the turbidity of highly turbid samples due to rushed well construction practices. However, if some samples are filtered, other samples should be filtered to ensure comparability. Unfiltered samples may be used to establish a release for many hazardous substances.

When sampling ground water, the investigator should:

- Collect the appropriate types of water samples.

- Collect only unfiltered metals samples from karst aquifers;

- Collect only unfiltered water samples for the analysis of organic substances;

- Collect background well samples from the same aquifer as the wells used to establish a release;

- Verify that samples are representative of the ground water at that location;

- Verify that the sample is not altered or contaminated by sampling and handling procedures; and

- Clearly designate whether data derived from the samples are from filtered or unfiltered samples.

If the wells are screened, the well screen intervals must be in the same aquifer, particularly when water occurs within small lenses isolated by clay segments in surrounding material (e.g, glacial terrain).

Even if interconnection of aquifers has been established, both background and release wells must be completed in the same aquifer. For example, a background sample from a bedrock aquifer must not be compared with a sample from a surficial alluvial aquifer, even though the two are hydrologically connected.

To the degree possible, background and observed release samples should be taken from approximately the same depth in the aquifer of concern. In determining depth, the investigator should consider elevation relative to a reference (e.g., mean sea level) rather than depth below the ground surface.

To the degree possible, well completion techniques should be similar for background and observed release wells. Because some hazardous substances adsorb to suspended matter, unfiltered water samples from separate wells that vary in suspended matter concentration may not be comparable. For example, an older drinking water well may provide water containing very little suspended matter, while a new or incomplete monitoring well may yield samples containing substantial suspended matter.

Background and release samples are best collected within 1 to 3 days. Background wells should be outside the influence of sources at the site. Ground water samples should not be affected by artifacts of sampling equipment or procedures.

\subsubsection{Focused SI Strategy-Ground Water Pathway}

Sampling to establish observed release is not necessarily a focused SI objective. Documenting an observed release for the ground water pathway according to the HRS may require installing monitoring wells, which is beyond the scope of the focused SI. If background data are critical to the site screening recommendation and no applicable wells exist, the investigator could establish background through one of the following:

- Published data on regional ground water quality

- Samples from a well potentially less influenced by the site (e.g., a more distant well)

- Reliable previous data from a nearby site

Every well identified as a primary target need not be sampled during the focused SI. The investigator should review PA scoresheets to select drinking water well sample locations most likely to detect hazardous substances. Investigators should sample existing wells if they are strategically located for critical site decisions.

If a release to ground water was hypothesized during the PA, the SI investigator should sample the nearest well suspected of contamination. If contamination of drinking water was hypothesized and the nearest well is not a drinking water well, sampling the nearest drinking water well in addition to the nearest well would be a feasible strategy; sampling the nearest drinking water well may be more informative and could serve to test both the release and contaminated target hypotheses. 
If actual contamination of drinking water wells is suspected, these wells should be sampled during the focused SI to test hypotheses and determine the level of contamination. If sampling every drinking water well suspected of contamination is not possible, nearby wells, especially municipal wells, should be sampled if there is a reasonable probability of detecting a release and target exposure. Additional sampling to more clearly define all contaminated drinking water wells may be conducted during the expanded SI, if necessary.

If a blended municipal water supply system has more than one well within 4 miles of site sources, the SI investigator should sample the nearest well of the system. If the direction of ground water flow is uncertain, the nearest wells reasonably expected to have contamination attributable to the site should be sampled. The investigator may also want to sample additional drinking water wells to ensure protection of public health.

Nearby wells drawing from the aquifer and screened at similar depths are potential background sample locations. The wells may be monitoring, private, public, industrial, or irrigation wells. The SI investigator can compare analytical results from drinking water wells with these background wells.

Background samples may not be necessary during the focused SI to confirm whether hazardous substances have migrated from some sites. For example, if the hazardous substances associated with the site are not naturally occurring and no other potential sources exist in the area, the focused SI investigator should collect the minimum number of background samples to screen the site. In this example, the focused SI investigator need not collect any background samples.

\subsubsection{Expanded and Single SI Strategy- Ground Water Pathway}

The expanded SI ground water pathway investigation should begin with a careful review of existing analytical data from wells within the vicinity of the site. The SI investigator should review existing data to identify abnormalities and any required resampling. For example, if a background sample contains an unusually high level of metals, the investigator should suspect artificially induced sample contamination (e.g., entrained sediments) and should review the data with the program staff responsible for collecting and analyzing the sample to determine if the contamination warrants resampling.

Samples from existing wells finished in the aquifer being evaluated or installation of monitoring wells may be necessary if no reliable data exist. The wells being evaluated for a release should also be finished in that aquifer and screened at a depth comparable to the background well. Multiple wells should be selected to increase the likelihood of intercepting the contaminated plume.

In most cases, a ground water background sample will be needed, requiring samples from a minimum of two wells to document a release. The selection of these wells depends on the direction of ground water flow. To determine flow direction, the investigator can:

- Install piezometers;

- Compare static water-level elevations in a series of wells completed in the same aquifer;

- Review published hydrogeologic reports; and

- Examine evidence of other previously investigated nearby ground water contamination.

One well in the aquifer being evaluated should generally be upgradient of the site to serve as a background measure. While an upgradient background well is preferred, any well outside (or, in some cases, within) the influence of sources at the site can be used to establish background levels.

If background wells are not available, a spring sample collected before the ground water reaches the surface may be used to establish background. A pipe should be inserted near the point of ground water discharge at the spring. The investigator should accurately document the sampling procedure in the field logbook. Table 4-8 compares the focused and expanded SI ground water sampling strategies.

\section{Well Installation}

Monitoring wells should not be installed unless they are necessary for the site score to be 28.50 or greater based on an observed release. It may not be necessary to document a release if the site will score 28.50 or greater due to other major pathways, or if 
TABLE 4-8: GROUND WATER SAMPLING STRATEGIES

\begin{tabular}{|c|c|c|}
\hline CRITERION & FOCUSED SI & EXPANDED SI AND SINGLE SI \\
\hline Primary objective & $\begin{array}{l}\text { To test hypotheses regarding a suspected } \\
\text { release or targets suspected to be exposed } \\
\text { to actual contamination } \\
\text { When possible, test release hypothesis in } \\
\text { conjunction with target sampling }\end{array}$ & $\begin{array}{l}\text { To demonstrate a release based on HRS } \\
\text { documentation requirements } \\
\text { To demonstrate targets exposed to actual } \\
\text { contamination and determine levels of } \\
\text { exposure }\end{array}$ \\
\hline $\begin{array}{l}\text { Data quality (see } \\
\text { section 5.2) }\end{array}$ & Less rigorous (e.g, DUC-II) to rigorous & Rigorous (e.g., DUC-I) \\
\hline $\begin{array}{l}\text { Average number of } \\
\text { samples }\end{array}$ & $\begin{array}{l}0 \text { to } 6 \text { depending on site hypotheses and } \\
\text { number of existing wells to sample }\end{array}$ & $\begin{array}{l}0 \text { to } 14 \text { based on HRS documentation } \\
\text { requirements }\end{array}$ \\
\hline Types of activities & $\begin{array}{l}\text { Sample existing wells } \\
\text { Install drive points or shallow boreholes } \\
\text { if there are no nearby wells }\end{array}$ & $\begin{array}{l}\text { Resample existing wells if previous data } \\
\text { did not conclusively demonstrate a release } \\
\text { or targets exposed to actual contamination } \\
\text { Sample wells not yet sampled } \\
\text { Collect multiple samples from drinking- } \\
\text { water wells where hazardous substance } \\
\text { concentrations are likely to be near } \\
\text { benchmarks } \\
\text { Install monitoring wells as needed }\end{array}$ \\
\hline Background samples & $\begin{array}{l}\text { Limited, } 1 \text { background per } 3 \text { release } \\
\text { samples } \\
\text { May rely on published regional data }\end{array}$ & $\begin{array}{l}2 \text { background per } 3 \text { release samples } \\
\text { Install background monitoring wells, if } \\
\text { necessary } \\
\text { Generally should not rely on published } \\
\text { data }\end{array}$ \\
\hline Attribution samples & Limited to testing release hypotheses & $\begin{array}{l}\text { Those necessary to attribute a share of a } \\
\text { release to the site }\end{array}$ \\
\hline QA/QC samples & Limited to testing release hypotheses & $\begin{array}{l}\text { Those necessary to obtain precise and } \\
\text { accurate data }\end{array}$ \\
\hline
\end{tabular}

the ground water pathway already scores high based on potential to release. Before deciding to install wells, the investigator should also consider:

- Unknown source of the contamination in nearby wells
- Depth to aquifer and type of geologic materials underlying site sources

- Likelihood of detecting contamination in the monitoring wells

- Installation costs

- Public health concerns 


\section{DNAPLs - A Special Case}

Dense nonaqueous phase liquids (DNAPLs) are separate-phase hydrocarbon liquids that are denser than water, such as chlorinated solvents, wood preservative and coal tar wastes, and pesticides. DNAPLs, also known as sinkers, move downward under the influence of gravity until reaching a less permeable formation where they may accumulate, move down-slope, or penetrate fractures. Special precautions need to be taken at sites with DNAPLs to ensure that drilling does not induce the spread of free-phase DNAPL contamination. Drilling should be suspended when a low-permeability unit or DNAPL is encountered. Fine-grained aquitards (such as clay or silt) should be assumed to permit downward migration of DNAPLs. For guidance on sites with potential DNAPL contamination, see Estimating the Potential for Occurrence of DNAPL at Superfund Sites, OSWER Directive 9355.4-07FS, 1992.

The primary objective of installing wells is to collect ground water data that can be used to establish a release. Other goals are beyond the scope of the SIfor example, to delineate a hazardous substance plume or track movement of a substance.

During monitoring well installation, the field team geologist should prepare a drilling log. The log should describe the general texture, color, size, lithology, and depth of the geologic materials encountered during drilling. Information obtained during well installation may be used to document potential to release factors, including lithology, hydraulic conductivity, travel time, and depth to aquifer.

Caution should be exercised when correlating data between drill holes. Extrapolations of data more than 20 feet apart are not acceptable in nonhomogeneous geologic environments. To assess the homogeneity of the subsurface geology, site-specific data should be compared to regional geologic information.

Drilling can create interconnections between karst aquifers. Installing wells in a karst aquifer is generally not recommended due to the high likelihood of introducing hazardous substances into karst aquifers.

\subsubsection{Example of Sampling Strategy}

The PA determined that residents near the Lakefield Farm Site rely on shallow domestic wells for drinking water. A municipal well that provides drinking water to about 10,000 people is located 0.5 mile southeast of the site. The municipal well and several nearby irrigation wells are screened in the deep aquifer, which appears to be interconnected with the shallow aquifer. The PA identified all domestic wells within 0.25 mile of the site and the municipal well as primary targets. The focused SI indicated ground water flows to the south. Several domestic wells appear to be downgradient from the site (Figure 4-2).

The SI investigator and EPA Regional site assessment manager planned a two-stage SI for this site because of the large number of ground water targets and the lack of reliable previous information. Based solely on the ground water pathway, the site will not score greater than 28.50 if evaluated on potential to release, given the maximum waste characteristics score this site could receive (18), and potentially contaminated ground water targets. The site will not score above the cutoff unless the municipal well (Sample GW-12) or four domestic wells, as well as domestic wells in the Green Acres subdivision, are exposed to actual contamination. Based on these considerations and source conditions described earlier, the focused SI required 18 samples-1 municipal well, 9 private wells, 4 source, 2 background, and 2 QA/QC - to test site hypotheses. If these wells are not contaminated, Lakefield Farm may not require further Superfund investigation.

Background conditions for the municipal well could be established by sampling the irrigation wells north of the site (GW-1 and GW-2), which draw from the deeper aquifer. Background samples might also be collected from the shallow aquifer to compare samples from the domestic wells. Field blank and equipment rinsate samples could be collected for QA/QC. Table 4-9 summarizes the suggested focused 
FIGURE 4-2: LAKEFIELD FARM SITE SKETCH \#2

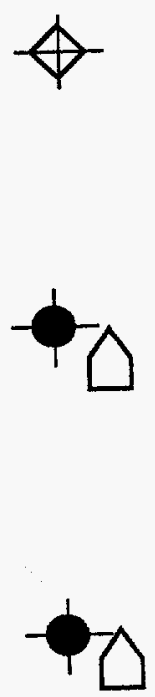

\section{KEY}

Drinking Water Well

- Source Sample

\$- Irrigation Well

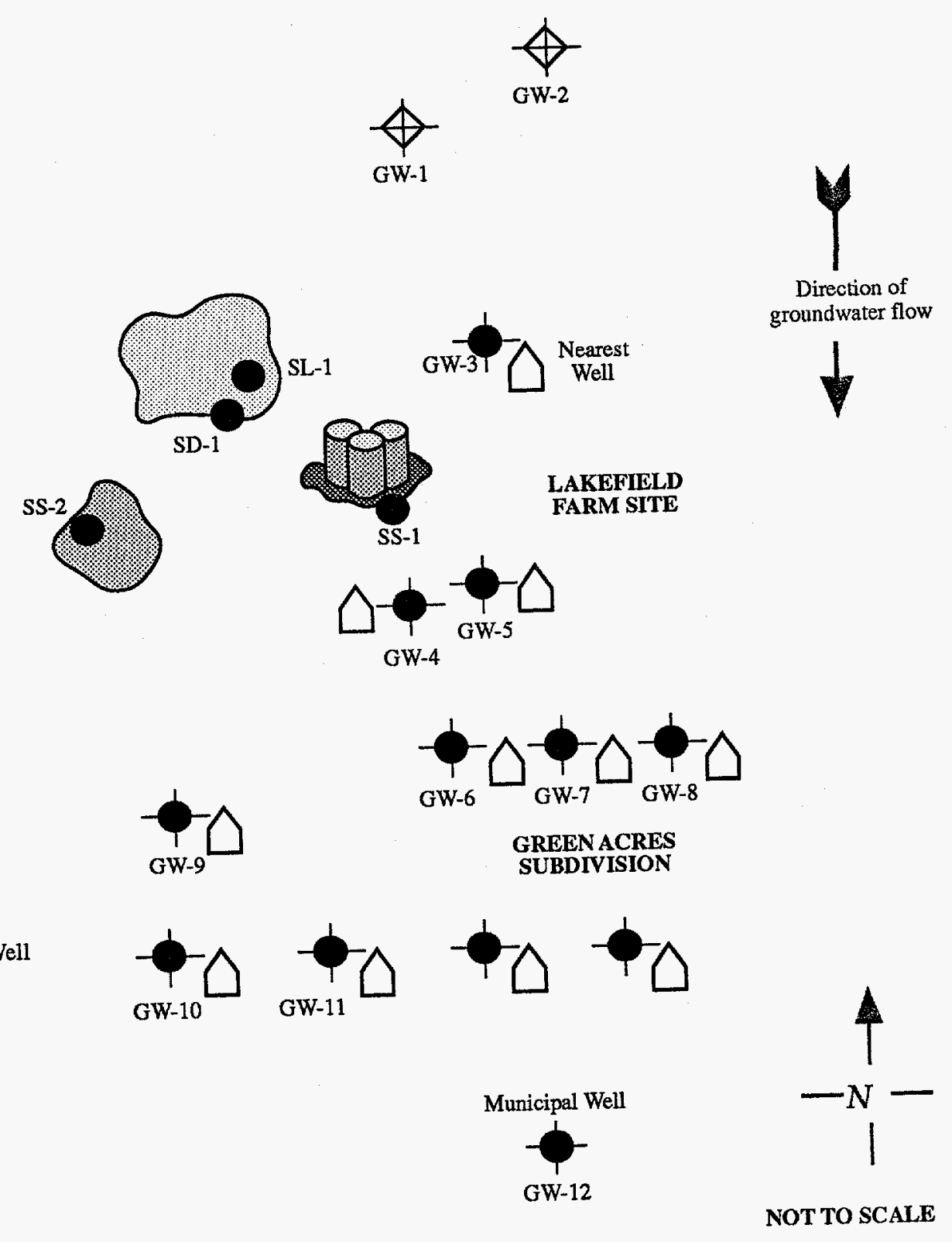


TABLE 4-9: GROUND WATER SAMPLING STRATEGY FOR EXAMPLE SITE FOCUSED SI

\begin{tabular}{|c|c|c|c|}
\hline SAMPLES & $\begin{array}{l}\text { SI SAMPLING } \\
\text { STRATEGY }\end{array}$ & HRS CONSIDERATIONS & $\begin{array}{c}\text { NON-SAMPLING } \\
\text { DATA COLLECTION }\end{array}$ \\
\hline $\begin{array}{l}\text { Municipal well } \\
\text { (GW-12) }\end{array}$ & $\begin{array}{l}\text { Collect sample prior to } \\
\text { treatment; sample to } \\
\text { document contamination, } \\
\text { identify hazardous } \\
\text { substances, and determine } \\
\text { level of contamination }\end{array}$ & $\begin{array}{l}\text { Determine municipal well } \\
\text { contamination, which is critical } \\
\text { to protecting public health and } \\
\text { the screening decision }\end{array}$ & $\begin{array}{l}\text { Verify aquifer from } \\
\text { which well draws; verify } \\
\text { population served }\end{array}$ \\
\hline $\begin{array}{l}\text { Domestic wells } \\
\text { (GW-3 through } \\
\text { GW-11) }\end{array}$ & $\begin{array}{l}\text { Sample nearest domestic } \\
\text { drinking-water wells } \\
\text { suspected of exposure to } \\
\text { contamination }\end{array}$ & $\begin{array}{l}\text { Determine domestic well } \\
\text { contamination, which is critical } \\
\text { to protecting public health and } \\
\text { the screening decision }\end{array}$ & $\begin{array}{l}\text { Verify aquifer from } \\
\text { which wells draw; verify } \\
\text { population served }\end{array}$ \\
\hline $\begin{array}{l}\text { Background } \\
\text { (GW-1, GW-2) }\end{array}$ & $\begin{array}{l}\text { Sample drinking water } \\
\text { aquifer; limit number of } \\
\text { background samples }\end{array}$ & $\begin{array}{l}\text { Sample to determine } \\
\text { concentrations of hazardous } \\
\text { substances }\end{array}$ & $\begin{array}{l}\text { Verify aquifer from } \\
\text { which well draws }\end{array}$ \\
\hline $\begin{array}{l}\text { Sources } \\
\text { (SD-1, SL-1, } \\
\text { SS-1, SS-2) }\end{array}$ & $\begin{array}{l}\text { Collect grab or composite } \\
\text { soil samples to identify } \\
\text { hazardous substances } \\
\text { present at site }\end{array}$ & $\begin{array}{l}\text { Do not sample to increase } \\
\text { hazardous waste quantity } \\
\text { (amounts are not close to HWQ } \\
\text { factor value breakpoints) }\end{array}$ & $\begin{array}{l}\text { Obtain physical } \\
\text { dimensions of surface } \\
\text { impoundment and } \\
\text { estimate area of } \\
\text { contaminated soil; verify } \\
\text { number of drums and } \\
\text { look for drum labels }\end{array}$ \\
\hline $\begin{array}{l}\text { Quality control } \\
\text { (Q-1, Q-2) } \\
\text { (Not shown) }\end{array}$ & $\begin{array}{l}\text { Monitor sample collection } \\
\text { and decontamination } \\
\text { procedures; } 1 \text { rinsate and } 1 \\
\text { field blank }\end{array}$ & & \\
\hline
\end{tabular}

SI sampling strategy. Other focused SI considerations include:

- Collecting a second sample from the municipal well to increase the chance of documenting contamination;

- Collecting additional samples to demonstrate background conditions;

- Verifying ground water flow direction by measuring water levels in wells; and

- Checking if contamination has been demonstrated in the deep aquifer within 2 miles of the site.
For this example, assume that focused SI sample results indicate that the municipal well sample was not contaminated, but one ground water sample (GW4) showed elevated concentrations of a hazardous substance also found during source sampling. Based on these results, the site score is not greater than the cutoff score: the site is screened from further Superfund consideration; and the expanded SI may not be necessary. The focused SI met its objectives, and EPA can refer the site and the contaminated domestic well to the appropriate authorities (e.g., removal program or State authorities). 
As a variation to this example, assume that two domestic wells south of the site were closed prior to the SI due to contamination by volatile organic compounds (VOCs), and just east of the site are two facilities that use solvents. In this scenario, it is uncertain whether Lakefield Farm has contributed to ground water contamination. Monitoring wells may need to be installed to attribute a portion of the contamination to the site. If ground water is the only significant pathway, and because attribution is critical to determine whether this site requires further Superfund attention, installing these wells may be planned as a single SI that bypasses the focused SI.

\subsection{SURFACE WATER PATHWAY}

In general, sample locations for the surface water pathway include rivers, brooks, or streams flowing through or adjacent to a source, as well as bodies of water that may receive overland runoff or leachate. Before identifying sample locations, investigators should determine whether overland runoff or ground water discharge to surface water can result in contamination of a surface water body. The likely overland runoff pathways may be determined by reviewing the drainage network in the vicinity of the site. Generally, if there are no surface waters within 2 miles of the site, the surface water pathway need not be evaluated.

The investigator should review the physical characteristics of the surface water migration route. Some hazardous substances mix and disperse rapidly in turbulent waters, while others may remain as a plug or plume for longer distances in less turbulent waters. The latter may reach a surface water target while still concentrated. The SI investigator should consider the influence of conditions such as rocky bottoms, rapids, and meanders on the likelihood of detecting hazardous substances.

The types and locations of water bodies near the site and the persistence of hazardous substances should be considered when developing the surface water sample plan. For abandoned or inactive sites, collecting sediment samples may be more appropriate than collecting aqueous samples. Flow rate is also a consideration because high-volume flows tend to disperse and dilute hazardous substances more quickly than low-volume flows.
An observed release to surface water may be documented through direct observation if material containing hazardous substances are:

- Seen entering surface water;

- Known to have entered surface water through direct deposition; or

- Present in a source area in contact with surface water through flooding.

A single, short-duration discharge of hazardous substances to surface water may establish a release, even without upstream and downstream samples. Leachate flowing from a source into surface water and an outfall from a surface impoundment discharging to surface water are examples of direct deposition into surface water. In these cases, samples (or other analytical evidence) should be collected to show that the leachate and outfall materials contain a hazardous substance.

Some analytical results will be compared with mediaspecific benchmarks. For drinking water targets suspected to be subject to actual contamination, samples (either aqueous, sediment, or sessile benthic) should be collected at or downstream of the targets to score Level I or Level II contamination. Only aqueous samples can be used to score Level I drinking water targets; aqueous, sediment, and sessile benthic organism tissue samples can be used to score Level II. Surface water samples that cannot demonstrate Level I contamination may still be used to support Level II contamination. Table 4-10 summarizes the types of samples for each surface water pathway threat and the level of actual contamination each sample type can support.

If documenting actual human food chain contamination is essential to the site recommendation, sediment samples should be considered in preference to catching and analyzing organisms. Tissue samples of aquatic food chain organisms may be collected during the expanded SI, if necessary, to evaluate immediate health and environmental threats. Prior to collecting samples, the investigator should review HRS guidance and food chain threat benchmarks for those substances expected to be present in fish tissue and benthic organisms. Sessile benthic human food chain organisms include mussels and oysters. Nonsessile benthic organisms include crabs, snails, 
TABLE 4-10: SURFACE WATER SAMPLES TO SUPPORT A RELEASE AND TARGET CONTAMINATION

\begin{tabular}{|c|c|c|c|c|c|c|}
\hline HRS Factors & Sediment ${ }^{1}$ & Aqueous & Effluent ${ }^{2}$ & $\begin{array}{c}\text { Sessile } \\
\text { Benthic } \\
\text { Organisms }\end{array}$ & $\begin{array}{l}\text { Non-sessile } \\
\text { Benthic } \\
\text { Organisms }\end{array}$ & $\begin{array}{c}\text { Finfish, } \\
\text { Amphibians, } \\
\text { and Reptiles }\end{array}$ \\
\hline Observed release & Yes & Yes & Yes & Yes & No & No \\
\hline Level I drinking water & No & Yes & No & No & No & No \\
\hline Level II drinking water & Yes & Yes & Yes & Yes & No & No \\
\hline $\begin{array}{l}\text { Level I sensitive } \\
\text { environments }\end{array}$ & No & Yes & No & No & No & No \\
\hline $\begin{array}{l}\text { Level II sensitive } \\
\text { environments }\end{array}$ & Yes & Yes & Yes & Yes & No & No \\
\hline Level I fisheries & No & No & No & $\mathrm{Yes}^{3}$ & Yes $^{3,4}$ & $\mathrm{Yes}^{3,4}$ \\
\hline Level II fisheries & $\mathrm{Yes}^{5}$ & Yes $^{5}$ & Yes $^{5}$ & Yes $^{3}$ & No & No \\
\hline \multicolumn{7}{|c|}{$\begin{array}{l}{ }^{1} \text { No benchmarks available; evaluate as Level II contamination. } \\
{ }^{2} \text { Does not require comparison to background to document a release. } \\
{ }^{3} \text { Sample only tissues of edible species to evaluate human food chain level of contamination. } \\
{ }^{4} \text { Can be used to score Level I targets, but not an observed release; must be collected within boundaries of } \\
\text { surface water contamination. } \\
5 \text { Targets can be evaluated if hazardous substance has a bioaccumulation factor value of } 500 \text { or greater. }\end{array}$} \\
\hline
\end{tabular}

crayfish, and lobsters. Examples of other aquatic human food chain organisms include fish, frogs, and eels. Samples may be collected at any point within or beyond a fishery boundary to evaluate actual human food chain contamination.

For water bodies where fishing is prohibited, if a hazardous substance for which the fishery was closed is found in a release sample within the boundaries of the closed fishery, samples from the water body can be used to score actual contamination even though no human food chain organism presently exists.

For the environmental threat, samples should be collected at, or downstream of, wetlands and other sensitive environments suspected of contamination. Only aqueous samples can be used to score Level I environmental contamination. If the investigator suspects that a wetland is exposed to contamination, in addition to samples near the PPE, two samples should be collected from the wetland which are at least 0.1 mile from the PPE into surface water. Data from unfiltered surface water samples should be compared to ecologically-based benchmarks.

Unfiltered samples may be used to establish a release. Water samples collected to analyze organic substances do not have to be filtered for comparison with drinking water benchmarks.

Special precautions should be taken to ensure that samples are representative of the surface water at that location, and that the sample is not altered or contaminated by sampling and handling procedures. Background samples should be collected in the same water body as samples used to investigate a releasefor example, the investigator should not compare a background sample from a small tributary and a release sample from a major river. In addition, chemical and physical properties of surface water can vary considerably within a small area. The lack of mixing in large, slowly flowing segments of rivers 
may affect background levels. Also, chemical transformations, biological influences, and physical transport mechanisms may affect surface water quality. Background and release samples should be collected during the same time period.

Other sampling considerations include:

- Weather conditions affecting streamflow

- Grain size, organic content, and structure of sediments

Higher streamflows generally carry more suspended solids but may dilute some dissolved substances. Streamflow volume and dilution may vary following heavy rainfall or snow melt. Some types of sediments may adsorb substances to a greater extent than others. For example, fine clay particles may adsorb metals to a greater extent than larger particles.

When investigating actual contamination or an observed release, the investigator should be aware of potential sampling errors and false assumptions affecting data representativeness. Such considerations are especially important when establishing actual contamination and determining level of contamination in the human food chain.

If necessary, an observed release can be established based on the chemical analysis of tissue samples from sessile benthic organisms. Samples of similar tissue should be obtained to document background. Comparing dissimilar tissues-for example, liver tissue and muscle tissue-may yield false positive of false negative results (i.e., significant differences between background and release samples attributable to tissue types rather than a release). Edible tissue samples are more appropriate for evaluating human health threats via the food chain. Where edible tissue samples are not available, the following is a hierarchy of preference for other sample types:

- Edible tissue samples with associated tissues attached or only partially removed

- Whole-body samples

- Samples of other specific tissues or organs

Samples should be obtained from the same species and from organisms of similar ages. As with other surface water samples, the investigator should descriptively document sample locations and note possible sources of influence on the analytical data.

\subsubsection{Focused SI Strategy}

Surface water should be sampled if a release to surface water was suspected during the PA and surface water targets are present (e.g., drinking water intakes, fisheries, wetlands and other sensitive environments). Before identifying sample locations for the surface water pathway, the investigator must review the drainage pattern in the vicinity of the site. Water bodies that receive leachate or runoff from sources at the site should be sampled.

During the focused SI, the investigator should select sample locations near or immediately downstream of the site PPE to the nearest surface water body. Sampling effluent discharge into surface water at the PPE could document direct observation of hazardous substances contaminating surface water. In this case, background comparisons are not required.

The investigator should review surface water targets evaluated as primary targets during the PA. To investigate threats to public health, all drinking water intakes suspected to be contaminated should be sampled regardless of scoring impacts. For the drinking water threat, aqueous or sediment samples should be collected at or downstream of the intake suspected to be exposed to contamination. (However, only aqueous samples can establish Level I drinking water contamination). And if multiple targets are present downstream of the PPE, the protection of public health may indicate collecting at least one sediment sample at or beyond each target likely to be contaminated.

Samples to establish background must be the same type as the samples collected to test surface water release hypotheses or targets exposed to contamination. Background sample locations for the surface water pathway include:

- Sediments from the surface water body upstream from the PPE and outside the area of hazardous substance influence from the site 
- Aqueous samples upstream from the PPE (only if drinking water intakes or sensitive environments are immediately downstream from the PPE)

\subsubsection{Expanded and Single SI Strategy}

Investigators should determine if analytical data from nearby surface waters are available. A minimum of two samples is needed to demonstrate a release:

- One upstream of the PPE to reflect background levels. It should be located within the same hydrologic setting as the downstream sample and, if possible, should not be influenced by other sources of potential contamination.

- One downstream reasonably close to the PPE.

If aqueous samples are planned, they should be collected prior to collecting sediment samples at the same location. In most cases, sediment samples are preferred to document a release to surface water because they are generally more likely to have concentrations significantly above background and they can support the evaluation of targets exposed to actual contamination. During the expanded SI, the investigator should consider collecting additional surface water samples for target locations not sampled during previous investigations. Expanding the boundaries of fishery contamination by collecting additional samples may be important if the human food chain threat has a major influence on the site score and if the waste characteristics factor category value is relatively low. Conversely, if the waste characteristic factor is relatively high, the boundaries of demonstrated contamination may not require expansion. Sampling to further document the extent of wetland contamination may also be warranted at some sites. Table 4-11 compares the focused and expanded SI strategies for surface water sampling.

\subsubsection{Example of Sampling Strategy}

Returning to the Lakefield Farm site example, the site description now includes the Apsley River, a moderate to large water body (streamflow 900 cubic feet/second), approximately 200 feet north of the surface impoundment (Figure 4-3). A recreational fishery is located within the river, and a 10-acre wetland lies 1 mile downstream from the PPE. An unnamed creek flows into Apsley about 750 feet upstream of the PPE, and an outfall to this creek is 1 mile upstream of this confluence. During the PA, the investigator suspected a release to the Apsley River from Lakefield Farm, and a release to ground water.

Because of significant threats to both ground water and surface water and because attribution is a problem, a focused SI is planned with an expanded SI to be performed if necessary. Focused SI sampling will test whether ground water and surface water targets are exposed to contamination.

If the number of samples to test all hypotheses exceeds the focused SI budget, a subset of these samples may be collected for the most important hypotheses to screen the site (Table 4-12). The previous ground water example specified 18 sample locations to meet focused SI objectives. To test surface water hypotheses, 5 additional sediment samples should be collected. A single sample from the municipal well (GW-7) or 3 samples from the river (SED-1, SED-4, and SED-5) may indicate whether further Superfund investigation is warranted.

Sediment samples may be collected from downstream wetland locations in addition to the 3 surface water samples identified above; however, these are not essential to test the suspected release to surface water. The SI investigator may perform other optional samples (e.g., a second background surface water sediment sample), and QA/QC samples (Q-1 through Q-4) consisting of 2 equipment rinsates, 1 trip blank, and 1 field blank.

Assume that focused SI ground water sample data do not detect hazardous substances at elevated concentrations. Fishery and wetland samples are contaminated with several heavy metals, and source samples from the surface impoundment at the site also contain some metals. Analytical results from the background samples were given "J" qualifiers and determined to be biased low. The investigator cannot conclusively determine whether the heavy metals found in the Apsley River are attributable to Lakefield 
TABLE 4-11: SURFACE WATER SAMPLING STRATEGIES

\begin{tabular}{|c|c|c|}
\hline CRITERION & FOCUSED SI & EXPANDED SI AND SINGLE SI \\
\hline $\begin{array}{l}\text { Primary } \\
\text { objectives }\end{array}$ & $\begin{array}{l}\text { To test hypotheses regarding a suspected } \\
\text { release and primary targets } \\
\text { When possible, sample at or beyond targets } \\
\text { to test release hypotheses }\end{array}$ & $\begin{array}{l}\text { To document a release based on HRS } \\
\text { requirements } \\
\text { To document targets exposed to actual } \\
\text { contamination and determine levels of } \\
\text { exposure }\end{array}$ \\
\hline Data quality & $\begin{array}{l}\text { Less rigorous (e.g, DUC-II) to rigorous } \\
\text { (e.g., DUC-I) }\end{array}$ & Rigorous (e.g., DUC-I) \\
\hline $\begin{array}{l}\text { Average } \\
\text { number of } \\
\text { samples }\end{array}$ & $\begin{array}{l}0 \text { to } 6 \text { depending on site hypotheses and } \\
\text { number of surface water targets to sample }\end{array}$ & $\begin{array}{l}0 \text { to } 14 \text { based on HRS documentation } \\
\text { requirements }\end{array}$ \\
\hline $\begin{array}{l}\text { Types of } \\
\text { activities }\end{array}$ & $\begin{array}{l}\text { Sample easily accessible surface water } \\
\text { locations } \\
\text { Sample sediments at or beyond targets most } \\
\text { likely to indicate contamination }\end{array}$ & $\begin{array}{l}\text { Resample surface water locations if } \\
\text { previous data did not document a release } \\
\text { or targets exposed to actual contamination } \\
\text { Sample surface water targets not yet } \\
\text { sampled, particularly sensitive } \\
\text { environments and wetlands } \\
\text { Collect multiple aqueous samples from } \\
\text { drinking water intakes where hazardous } \\
\text { substance concentrations are likely to be } \\
\text { near surface water benchmarks }\end{array}$ \\
\hline $\begin{array}{l}\text { Background } \\
\text { samples }\end{array}$ & $\begin{array}{l}1 \text { background per } 3 \text { release samples } \\
\text { May rely on published data }\end{array}$ & $\begin{array}{l}2 \text { background per } 3 \text { release samples } \\
\text { Should not rely on published data }\end{array}$ \\
\hline $\begin{array}{l}\text { Attribution } \\
\text { samples }\end{array}$ & Limited to testing release hypotheses & $\begin{array}{l}\text { Those necessary to attribute a portion of a } \\
\text { release to the site }\end{array}$ \\
\hline $\begin{array}{l}\text { QA/QC } \\
\text { samples }\end{array}$ & Enhance confidence in sample results & $\begin{array}{l}\text { Those necessary to obtain precise and } \\
\text { accurate data within the SI scope }\end{array}$ \\
\hline
\end{tabular}

Farm, or whether they had entered the river through the outfall to the unnamed creek upstream of the site. A goal of expanded SI sampling will be to document that any significant increase in heavy metals concentrations found in the river are at least partially attributable to the site.

During the expanded SI, outfall discharge samples should be collected to determine if heavy metals are being released to the creek (OUT-1). Samples (SW-1 and SED-1) upstream of this discharge point should also be taken to determine if other sources (or sites) are releasing heavy metals to surface water. To further demonstrate actual wetland contamination, both aqueous and sediment samples should be collected further downstream along the wetland at locations likely to be exposed to a release from the site. The aqueous samples may demonstrate Level I 
FIGURE 4-3: LAKEFIELD FARM SITE SKETCH \#3

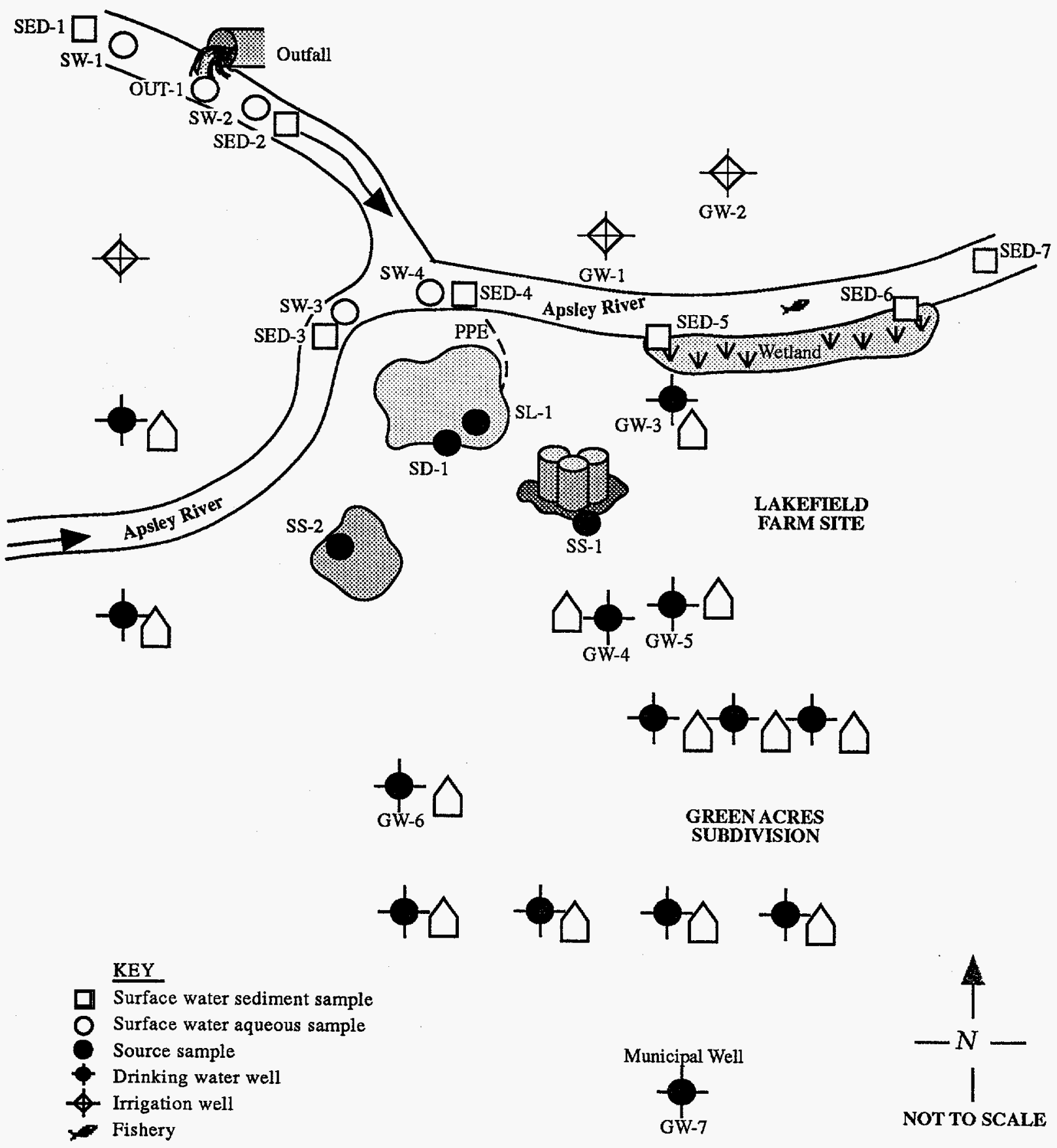

NOTE: Surface water aqueous and sediment sampling should begin downstream and progress upstream. In this example, sample SED-7 should be collected first, followed by SED-6 and so on upstream in reverse numerical order. 
TABLE 4-12: SURFACE AND GROUND WATER SAMPLING STRATEGY FOR EXAMPLE SITE FOCUSED SI

\begin{tabular}{|c|c|c|c|}
\hline SAMPLES & APPROACH & RATIONALE & $\begin{array}{c}\text { NON-SAMPLING } \\
\text { DATA COLLECTION }\end{array}$ \\
\hline $\begin{array}{l}\text { Municipal well } \\
(\mathrm{GW}-7)\end{array}$ & $\begin{array}{l}\text { Sample drinking water prior to } \\
\text { treatment; sample to document } \\
\text { contamination, identify } \\
\text { hazardous substances, and } \\
\text { determine level of } \\
\text { contamination }\end{array}$ & $\begin{array}{l}\text { Determining municipal } \\
\text { well contamination is } \\
\text { critical to protecting } \\
\text { public health and to the } \\
\text { site screening decision }\end{array}$ & $\begin{array}{l}\text { Verify aquifer from } \\
\text { which well draws; } \\
\text { verify population served }\end{array}$ \\
\hline $\begin{array}{l}\text { Domestic wells } \\
\text { (GW-3 through } \\
\text { GW-6) }\end{array}$ & $\begin{array}{l}\text { Sample nearest domestic wells } \\
\text { suspected to be exposed to } \\
\text { actual contamination }\end{array}$ & $\begin{array}{l}\text { Determining domestic } \\
\text { well contamination is } \\
\text { critical to protecting } \\
\text { public health and to the } \\
\text { site screening decision }\end{array}$ & $\begin{array}{l}\text { Verify aquifer from } \\
\text { which wells draw; } \\
\text { verify population served }\end{array}$ \\
\hline $\begin{array}{l}\text { Background for } \\
\text { ground water } \\
\text { (GW-1, GW-2) }\end{array}$ & $\begin{array}{l}\text { Sample drinking water aquifer; } \\
\text { limit number of background } \\
\text { samples }\end{array}$ & $\begin{array}{l}\text { Sample to determine } \\
\text { relative concentrations of } \\
\text { hazardous substances in } \\
\text { ambient conditions }\end{array}$ & $\begin{array}{l}\text { Verify aquifer from } \\
\text { which wells draw }\end{array}$ \\
\hline $\begin{array}{l}\text { Surface water } \\
\text { target locations }\end{array}$ & $\begin{array}{l}\text { Sample sediments to determine } \\
\text { if contamination is present in } \\
\text { the fishery (SED-4) or wetland } \\
\text { (SED-5, SED-6) }\end{array}$ & $\begin{array}{l}\text { Human food chain or } \\
\text { sensitive environment } \\
\text { contamination is vital to } \\
\text { the screening decision }\end{array}$ & $\begin{array}{l}\text { Verify linear footage of } \\
\text { wetland exposed to } \\
\text { actual contamination }\end{array}$ \\
\hline $\begin{array}{l}\text { Background for } \\
\text { surface water } \\
\text { (SW-1, SED-1) }\end{array}$ & $\begin{array}{l}\text { Limit number of background } \\
\text { samples }\end{array}$ & $\begin{array}{l}\text { Sample to determine } \\
\text { levels of hazardous } \\
\text { substances }\end{array}$ & $\begin{array}{l}\text { Collect information } \\
\text { about background } \\
\text { sample location, } \\
\text { including setting, flow, } \\
\text { and physical } \\
\text { characteristics (e.g., } \\
\text { sediment grain size) }\end{array}$ \\
\hline $\begin{array}{l}\text { Sources } \\
\text { (SD-1, SL-1, } \\
\text { SS-1, SS-2) }\end{array}$ & $\begin{array}{l}\text { Identify hazardous substances } \\
\text { present at the site through } \\
\text { composite samples }\end{array}$ & $\begin{array}{l}\text { Do not sample to } \\
\text { increase hazardous waste } \\
\text { quantity if amounts are } \\
\text { not close to HWQ factor } \\
\text { value breakpoints }\end{array}$ & $\begin{array}{l}\text { Obtain physical } \\
\text { dimensions of surface } \\
\text { impoundment and } \\
\text { estimate area of } \\
\text { contaminated soil; } \\
\text { verify number of drums } \\
\text { and look for drum } \\
\text { labels }\end{array}$ \\
\hline $\begin{array}{l}\text { Quality control } \\
\text { (Q-1 through } \\
\text { Q-4) } \\
\text { (Not shown) }\end{array}$ & $\begin{array}{l}\text { Monitor collection and } \\
\text { decontamination procedures; } 1 \\
\text { rinsate for ground water } \\
\text { equipment, } 1 \text { rinsate for } \\
\text { surface water equipment, } 1 \text { trip } \\
\text { and } 1 \text { field blank }\end{array}$ & & \\
\hline
\end{tabular}


contamination for the wetland, the sediment samples may demonstrate Level II. (The wetland sample locations should be at least 0.1 mile apart, the minimum frontage length needed to receive a nonzero factor value.)

Other background samples should be collected from the Apsley River upstream of the confluence with the unnamed creek. Samples from within the fishery should be taken to compare to background and attribution samples. Also, QA/QC samples should be collected following EPA Regional guidance. For this expanded SI example, 2 equipment rinsates, 1 trip blank, 1 duplicate, and 1 blank could monitor sample collection and handling procedures (Table 4-13).

\subsection{SOIL EXPOSURE PATHWAY}

The primary objective of soil exposure sampling is to identify whether residential or school properties are contaminated. Sample locations for the soil exposure pathway should:

- Document any observed contamination within property boundaries of a residence, school, day care center, or workplace, or within the boundaries of a terrestrial sensitive environment or resource;

- Document observed contamination significantly above background levels and attributable to the site;

\section{TABLE 4-13: SURFACE WATER SAMPLING STRATEGY FOR EXAMPLE SITE EXPANDED SI AND SINGLE SI}

\begin{tabular}{|c|c|c|c|}
\hline SAMPLES & APPROACH & RATIONALE & NON-SAMPLING DATA \\
\hline $\begin{array}{l}\text { Surface water } \\
\text { locations }\end{array}$ & $\begin{array}{l}\text { Sample sediments and surface } \\
\text { waters to confirm } \\
\text { contamination of surface } \\
\text { water targets, levels of actual } \\
\text { wetland contamination, linear } \\
\text { frontage of wetlands exposed } \\
\text { to actual contamination, and } \\
\text { attribution to the site }\end{array}$ & $\begin{array}{l}\text { Target samples should be } \\
\text { comparable to background } \\
\text { samples collected } \\
\text { If necessary, wetland } \\
\text { sample locations should be } \\
\text { selected to demonstrate } \\
\text { that at least } 3 \text { miles of } \\
\text { linear frontage are exposed } \\
\text { to actual contamination }\end{array}$ & $\begin{array}{l}\text { Measure linear frontage of } \\
\text { wetland exposed to actual } \\
\text { contamination }\end{array}$ \\
\hline $\begin{array}{l}\text { Background and } \\
\text { attribution } \\
\text { (SW-1, SED-1, } \\
\text { SW-2, SED-2, } \\
\text { OUT-1) }\end{array}$ & $\begin{array}{l}\text { Sample to determine if outfall } \\
\text { or another source upstream } \\
\text { may be contributing to } \\
\text { surface water contamination }\end{array}$ & $\begin{array}{l}\text { Sample to determine } \\
\text { relative levels of hazardous } \\
\text { substances in ambient } \\
\text { environment } \\
\text { Show contamination } \\
\text { attributable to site } \\
\text { Ensure sufficient } \\
\text { background samples for } \\
\text { listing documentation }\end{array}$ & $\begin{array}{l}\text { Research other potential } \\
\text { sources (e.g., industrial } \\
\text { areas) } \\
\text { Collect information about } \\
\text { background sample } \\
\text { location }\end{array}$ \\
\hline $\begin{array}{l}\text { Quality control } \\
\text { (QA-1 through } \\
\text { QA-5) }\end{array}$ & $\begin{array}{l}\text { Monitor sample collection, } \\
\text { decontamination, transport, } \\
\text { and handling procedures; } 2 \\
\text { equipment rinsates, } 1 \text { trip } \\
\text { blank, } 1 \text { duplicate, and } 1 \text { field } \\
\text { blank }\end{array}$ & $\begin{array}{l}\text { Ensure sufficient QA/QC } \\
\text { samples to validate } \\
\text { sampling and analytical } \\
\text { procedures }\end{array}$ & \\
\hline
\end{tabular}


- Delineate areas of surficial contamination at the site; and

- Identify the level of contamination within these areas.

Samples, including composite samples, must be collected within 2 feet of the surface. No impenetrable material (e.g., asphalt, concrete) should be present above the sample location. Most surface samples during the SI will be soil material, although some may be leachate, source material, sediment from overland runoff drainage ditches, and other surficial materials. Certain conditions are imposed on establishing observed contamination at a sample location. Similar to an observed release, analytical evidence should demonstrate whether the hazardous substance is attributable to the site and present at a concentration significantly above background levels. If no surficial contamination significantly above background levels and attributable to the site is detected, the soil exposure pathway cannot be evaluated.

Areas of observed contamination are delineated based on analytical evidence meeting the criteria for observed contamination. Observed contamination in the soil exposure pathway cannot be established by direct observation. Samples that contain hazardous substance concentrations significantly above background and are attributable to the site are used to document points of observed contamination. The most important analytical data for the soil exposure pathway are samples that establish observed contamination and level of contamination.

Documenting resident population targets requires detecting contamination (most commonly in soil) within the property boundary, within 2 feet of the surface on the property and within 200 feet of residences, schools, day care centers, or workplaces. The SI investigator should identify and sample routes through which hazardous substances may be transported by air or water. Physical site characteristics and background information, especially aerial photography, may help identify potential former disposal areas that are close to, or part of, residential properties.

The investigator should sample surface materials based strictly on identifying resident population threat targets. A minimum of three samples is necessary to estimate the area of observed contamination. Two samples may be sufficient to define a linear strip of contaminated soil, where targets within the strip are critical to the site score and area is not important. If a large number of residences (e.g., mobile home park, residential development on a landfill) are likely to lie within an area of contamination, estimating the boundaries of contamination, particularly during the focused SI, may be more practical. The expanded SI would include samples to distinguish levels of contamination within this area.

For sources other than contaminated soil (e.g., a surface impoundment), a single source sample demonstrating observed contamination may be used to identify the entire source as an area of observed contamination. Any sample establishing hazardous substance concentrations significantly above background levels indicates the source area is an area where observed contamination is greater than 0 . Thus, one point of known contamination may provide sufficient information for scoring. For contaminated soil, locations of samples that demonstrate observed contamination and the area between those locations comprise the area of observed contamination, unless information indicates otherwise.

To evaluate the level of contamination for each residential, day care, or school property, each area of observed contamination should be delineated according to concentration levels relative to benchmarks. For HRS scoring purposes, contamination can be inferred between 2 points of observed contamination based on site conditions; however, the population associated with the areas of inferred contamination are evaluated as Level II resident threat targets. The investigator should identify areas where observed contamination can and cannot be inferred. For decision-making purposes, the investigator may use analytical evidence with nonsampling evidence to infer or corroborate the area of observed contamination-for example, observation of stained soil coupled with analytical results from the stain. Other corroborative information may be:

- Data derived from other investigations, such as geophysical or soil-gas surveys;

- Documented historical waste deposition patterns

- Patterns of stressed vegetation;

- Infrared satellite imagery indicating soil anomalies; and 
- Topography and drainage patterns.

If samples not meeting the criteria for observed contamination are collected from within an area of inferred contamination, the investigator should evaluate whether the area of contamination needs to be refined or modified. For example, if liquid wastes containing hazardous substances were spilled at the site, areas of higher elevation than the spill generally should be excluded from the area of inferred contamination, even if they are within the originally inferred area. However, the scope of the SI generally does not warrant fully delineating areas that are not subject to observed contamination; instead, the primary objective is to identify targets that may be threatened by the site.

Special precautions should be taken to ensure the sample represents the surface at that location, and that the sample is not altered or contaminated by sampling and handling procedures. Soil samples collected for comparison should be the same soil type and from the same soil horizon. Considerable variability may occur between soil types as well as within a single soil type because of grain size, mineralogy, composition, soil horizons, and lateral heterogeneity. Soil type should be identified and delineated. For metals analysis, background, and observed contamination, soils should have similar texture, color, and grain size.

For general HRS purposes, grab samples are better than composite samples for the soil pathway. Where composite samples are needed, the SI investigator should avoid mixing soils from different properties. Also, all portions of the composite sample should be taken within 200 feet of the school or residence on the property.

Background samples generally should represent the uncontaminated area around the site. Background samples should be collected from undisturbed areas if the site is located near areas filled in with soils from different sources. However, if the site is located in fill material, the background sample should come from the fill. Soil within drainage channels (e.g., overland migration segments) may be subject to influences unrelated to the site and generally should not be used as background. Background and observed contamination samples should be collected within a reasonable time ( 1 to 3 days).
Data resulting from field screening methods may be useful to investigate source boundaries and areas of contamination. For example, if soil samples need to be collected from adjacent residences or schools to investigate resident population targets, field screening can help plan the locations of samples to be collected for CLP analysis. Field screening samples may support evaluation of observed contamination and reduce the number of CLP samples necessary to document the pathway score.

Establishing background conditions for the soil exposure pathway can be difficult, particularly when the hazardous substances found at the site are naturally occurring. Onsite samples to establish background should be collected from off-source surficial soils that are not likely to be impacted by the source. Similarly, the SI investigator should collect offsite samples to establish background conditions from shallow soils that are not impacted by other sources in the vicinity.

Results from other nearby site investigations can be used during the focused SI to establish background. Literature values, especially for naturally occurring substances such as metals in mining areas, may be used as background measures during the focused SI.

\subsubsection{Focused SI Strategy vs. Expanded and Single SI Strategy}

To plan target sample locations, the investigator should review PA conclusions of resident population targets suspected of exposure to contamination. Samples collected from a terrestrial sensitive environment must be within the delineated boundaries of the specific sensitive environment. To investigate the threat to workers at the site or at adjacent properties, samples must be collected on the facility property within 200 feet of the workplace.

For the expanded SI, the investigator only should use data of rigorous quality to support target exposure. Less rigorous data and non-sampling information may corroborate attribution and representativeness of samples. 
One or more background samples to compare to observed contamination areas are necessary to document contamination. Background samples should not be influenced by other potential sources of contamination. Generally, samples taken at a higher elevation than site sources can be used as background, unless the hazardous substances can be transported by wind. For all background sample locations, care should be taken to ensure that they are not affected by substances blown from the site.

Careful selection of background sample locations is important since any measurable concentrations of specific substances found at residences, schools, day care centers, workplaces, and terrestrial sensitive environments will be compared to background data. If several of these properties are present, observed contamination may be inferred between two points of observed contamination based on terrain, drainage, surficial runoff, elevation, and other site conditions unless available information indicates otherwise. However, populations associated with inferred contaminated properties cannot be scored as Level I resident threat targets. Sampling each property is not necessary, although documentation will be stronger if each property is sampled. Table 4-14 compares focused and expanded SI strategies for the soil exposure pathway.

TABLE 4-14: SOIL SAMPLING STRATEGIES

\begin{tabular}{|l|l|l||}
\hline CRITERIA & \multicolumn{1}{|c|}{ FOCUSED SI } & \multicolumn{1}{|c|}{ EXPANDED SI AND SINGLE SI } \\
\hline $\begin{array}{l}\text { Primary } \\
\text { objectives }\end{array}$ & $\begin{array}{l}\text { To test hypotheses regarding suspected } \\
\text { observed surficial contamination and } \\
\text { targets exposed to actual contamination }\end{array}$ & $\begin{array}{l}\text { To document target exposure to hazardous } \\
\text { substances related to site sources }\end{array}$ \\
\hline Data quality & $\begin{array}{l}\text { Less rigorous (DUC-II) to rigorous } \\
\text { (DUC-I); depends on objectives }\end{array}$ & Rigorous (DUC-I); depends on objectives \\
\hline $\begin{array}{l}\text { Average } \\
\text { number of } \\
\text { samples }\end{array}$ & $\begin{array}{l}\text { 0 to 10 depending on site hypotheses and } \\
\text { resident population to investigate }\end{array}$ & $\begin{array}{l}\text { 0 to 20 based on documentation requirements } \\
\text { and number of sources and targets }\end{array}$ \\
\hline $\begin{array}{l}\text { Types of } \\
\text { activities }\end{array}$ & $\begin{array}{l}\text { Sample source and target areas indicating } \\
\text { possible surficial contamination, exposed } \\
\text { or within 2 feet of surface }\end{array}$ & $\begin{array}{l}\text { Resample locations if previous data did not } \\
\text { demonstrate areas of observed contamination or } \\
\text { targets exposed to actual contamination } \\
\text { Sample other resident target properties not yet } \\
\text { sampled } \\
\text { Collect multiple samples from properties where } \\
\text { hazardous substance concentrations are likely to } \\
\text { be near benchmarks }\end{array}$ \\
\hline $\begin{array}{l}\text { Attribution } \\
\text { samples }\end{array}$ & Limited & $\begin{array}{l}\text { As many as necessary; research natural soil } \\
\text { concentrations as well as development history in } \\
\text { the area to select critical background sample } \\
\text { locations; use aerial photographs. }\end{array}$ \\
\hline $\begin{array}{l}\text { QAVC } \\
\text { samples }\end{array}$ & As approved by Regional guidelines & $\begin{array}{l}\text { Manimum 1 split and 1 blank or per Regional } \\
\text { guidelines }\end{array}$ \\
\hline \hline
\end{tabular}




\subsubsection{Example of Sampling Strategy}

The Carveth Landing Site is a dump near a residential neighborhood and elementary school (Figure 4-4). The PA reported that dumping occurred for an unknown period of time and allegedly included paints, organic and inorganic substances, and construction debris. The area is devoid of vegetation. Sources at the site include several piles of 5-gallon containers and two poorly defined areas of stained soil. Pigeon River, which flows at 1600 cubic feet per second (cfs) and is located 400 feet east of the site, has flooded the site twice in the past 7 years. Commercial and recreational oyster beds are downstream of two PPEs to surface water. The PA concluded that flooding may have carried hazardous substances into surface water and onto adjacent school and residential properties. Hazardous substances associated with the site are not known, but could involve metals typically found in paints.

A two-stage SI was planned for Carveth Landing because testing critical PA hypotheses could screen the site or identify significant threats. Sample planning involved the following considerations: 1) surface water and soil exposure are both pathways of concern; 2) hazardous substances present at the site are poorly-defined, some of which may be naturally occurring; and 3) source information is poor. Focused SI samples were collected to test the suspected release to Pigeon River, identify the hazardous substances present, and determine whether any suspected resident population threat target is exposed to actual contamination.

During the focused SI, soil source samples were collected to identify hazardous substances: two samples from each stained soil area and two samples near the container piles (SS-1 through SS-6). These samples also helped characterize areas of surficial contamination and attribute possible contamination of residential properties to site sources. Samples were collected from properties most likely to exhibit surficial contamination. A significant objective was to demonstrate contamination on the school property.
During the focused SI, samples (SS-1 and SS-2) were collected from the school and from the three nearest residential properties, all within 200 feet of the residences and school building. Two background soil samples (SS-7 and SS-8) were collected 12 inches below the surface in offsite soils.

Establishing a release by direct observation was considered for the surface water pathway; however, the available site information could not conclusively demonstrate that material containing hazardous substances was present at the site during flooding. Therefore, focused SI sampling included two sediment samples (SED-3 and SED-4) from locations where overland runoff from site sources entered surface water (i.e., PPEs) to test a suspected release to Pigeon River and actual human food chain contamination. Background surface water sediment samples (SED-1 and SED-2) were collected near the right and left banks of Pigeon River, 200 and 800 feet upstream of the most upstream PPE into Pigeon River. QA/QC samples consist of two equipment rinsates ( 1 for sediment and 1 for soil) and a field blank (Table 415).

Although lead concentrations in this focused SI example are above soil exposure pathway benchmarks, the concentrations are not significantly above background soil levels. For this example, the background samples were inadvertently taken within an area of soil contaminated by automobile emissions, floods, wind-blown wastes, or naturally high lead concentrations.

The expanded SI includes 2 additional source samples (XS-1 and XS-2) and more soil samples to document observed contamination at the site, on the properties sampled during the focused SI, and on other residential properties potentially affected by the site (Table 4-16). Background soil lead concentrations should be researched by literature values and additional background samples (XS-3 through XS-6 and XS-10) collected at locations less influenced by potential sources of lead contamination. Soil samples from residential properties southeast of the site should also be taken since they are closer to the river. In addition, samples from targets previously sampled during the focused SI should be taken if background samples collected during the focused SI are not similar to the additional target samples. 
FIGURE 4-4: CARVETH LANDING SITE SKETCH

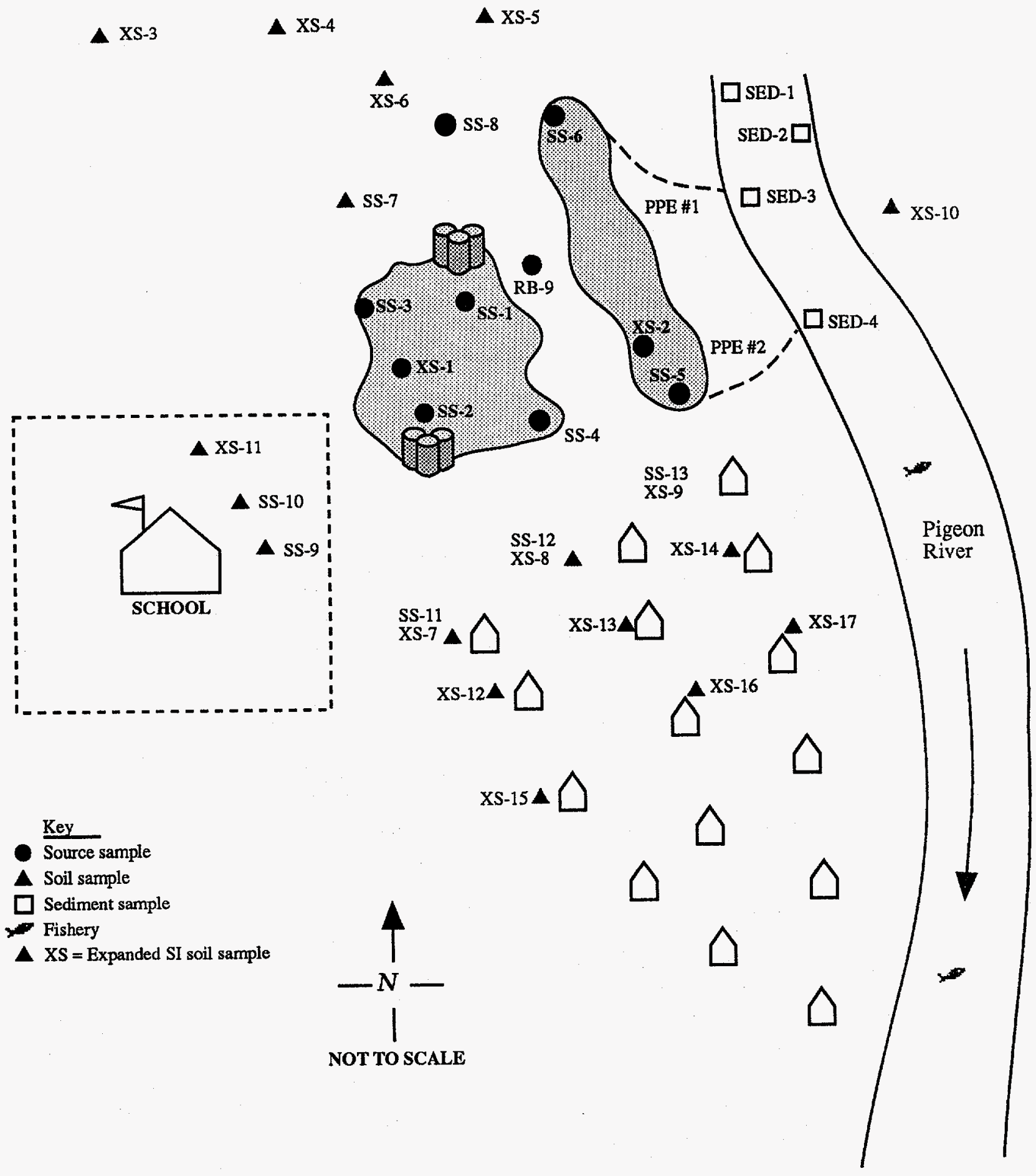


TABLE 4-15: SOIL AND SURFACE WATER SAMPLING STRATEGY FOR EXAMPLE SITE FOCUSED SI

\begin{tabular}{|c|c|c|c|}
\hline SAMPLES & APPROACH & RATIONALE & NON-SAMPLING DATA \\
\hline $\begin{array}{l}\text { Surface water } \\
\text { locations } \\
\text { (SED-3, } \\
\text { SED-4) }\end{array}$ & $\begin{array}{l}\text { Sample sediments to } \\
\text { demonstrate a release; } \\
\text { determine if contamination is } \\
\text { present and level of } \\
\text { contamination }\end{array}$ & $\begin{array}{l}\text { Investigate release to } \\
\text { surface water and } \\
\text { determine if fishery is } \\
\text { exposed to actual } \\
\text { contamination }\end{array}$ & $\begin{array}{l}\text { Document use of river for } \\
\text { fishing; estimate annual } \\
\text { commercial food chain } \\
\text { production for oysters }\end{array}$ \\
\hline $\begin{array}{l}\text { Residential soil } \\
\text { samples }\end{array}$ & $\begin{array}{l}\text { Sample to determine if } \\
\text { nearby residential properties } \\
\text { (SS-11, SS-12, SS-13) and } \\
\text { the school yard (SS-9, SS-10) } \\
\text { are exposed to surficial } \\
\text { contamination }\end{array}$ & $\begin{array}{l}\text { Investigate population } \\
\text { exposure to hazardous } \\
\text { substances }\end{array}$ & $\begin{array}{l}\text { Determine number of people } \\
\text { per residence and number of } \\
\text { students attending school }\end{array}$ \\
\hline $\begin{array}{l}\text { Background } \\
\text { soil } \\
\text { (SS-7, SS-8) }\end{array}$ & Limited & $\begin{array}{l}\text { Sample to determine } \\
\text { relative levels of } \\
\text { hazardous substances } \\
\text { under ambient conditions } \\
\text { and to better define } \\
\text { effects of flooding at site }\end{array}$ & $\begin{array}{l}\text { If available, obtain historical } \\
\text { aerial photographs and } \\
\text { FEMA maps } \\
\text { Research natural } \\
\text { background levels of metals }\end{array}$ \\
\hline $\begin{array}{l}\text { Background } \\
\text { surface water } \\
\text { (SED-1, } \\
\text { SED-2) }\end{array}$ & $\begin{array}{l}\text { Collect sediment samples } \\
\text { upstream of PPEs } \\
\text { Ensure samples are beyond } \\
\text { tidal influence of hazardous } \\
\text { substance migration }\end{array}$ & $\begin{array}{l}\text { Sample to determine } \\
\text { relative levels of } \\
\text { hazardous substances } \\
\text { under ambient conditions }\end{array}$ & $\begin{array}{l}\text { Research other potential } \\
\text { sources of hazardous } \\
\text { substances }\end{array}$ \\
\hline $\begin{array}{l}\text { Sources } \\
\text { (SS-1 through } \\
\text { SS-6) }\end{array}$ & $\begin{array}{l}\text { Identify hazardous substances } \\
\text { present at the site; sample to } \\
\text { test hypothesis of surficial } \\
\text { contamination }\end{array}$ & $\begin{array}{l}\text { Do not sample to } \\
\text { increase hazardous waste } \\
\text { quantity because amounts } \\
\text { are not close to HWQ } \\
\text { factor value breakpoints }\end{array}$ & $\begin{array}{l}\text { Estimate physical } \\
\text { dimensions of stained soil; } \\
\text { count paint pails and look } \\
\text { for drum labels }\end{array}$ \\
\hline $\begin{array}{l}\text { Quality control } \\
\text { (Q-1 through } \\
\text { Q-3) }\end{array}$ & $\begin{array}{l}\text { Monitor sample collection } \\
\text { and decontamination } \\
\text { procedures; } 2 \text { rinsates and } 1 \\
\text { trip blank }\end{array}$ & & \\
\hline
\end{tabular}


TABLE 4-16: SOIL SAMPLING STRATEGY FOR EXAMPLE SITE EXPANDED SI

\begin{tabular}{||l|l|l|l||}
\hline \multicolumn{1}{|c|}{ SAMPLES } & \multicolumn{1}{|c|}{ APPROACH } & \multicolumn{1}{c|}{ RATIONALE } & NON-SAMPLING DATA \\
\hline \hline $\begin{array}{l}\text { Resident samples } \\
\text { (XS-7, XS-8, XS- } \\
9, \text { XS-11 through } \\
\text { XS-17) }\end{array}$ & $\begin{array}{l}\text { Sample to document } \\
\text { resident targets and levels } \\
\text { of actual contamination }\end{array}$ & $\begin{array}{l}\text { To establish observed } \\
\text { contamination on residential } \\
\text { and school properties, target } \\
\text { samples must be 3 or more } \\
\text { times the ambient } \\
\text { background levels }\end{array}$ & $\begin{array}{l}\text { Determine number of } \\
\text { residents, property } \\
\text { boundaries, and number of } \\
\text { students }\end{array}$ \\
\hline $\begin{array}{l}\text { Background } \\
\text { (XS-3 through } \\
\text { XS-6, XS-10) }\end{array}$ & $\begin{array}{l}\text { Sample areas less } \\
\text { influenced by site; } \\
\text { document contamination } \\
\text { attributable to site }\end{array}$ & $\begin{array}{l}\text { Show that target } \\
\text { contamination is attributable } \\
\text { to the site, rather than other } \\
\text { potential sources of lead; } \\
\text { ensure sufficient } \\
\text { background samples for } \\
\text { HRS documentation }\end{array}$ & \\
\hline $\begin{array}{l}\text { Quality Control } \\
\text { (Q-1 through } \\
\text { Q-6) }\end{array}$ & $\begin{array}{l}\text { Monitor sample collection } \\
\text { and decontamination } \\
\text { procedures; transport and } \\
\text { handling procedures; } \\
\text { equipment rinsates, 2 } \\
\text { duplicates, 1 field blank, } \\
\text { 1 replicate }\end{array}$ & $\begin{array}{l}\text { Ensure sufficient QAVCC } \\
\text { samples for HRS } \\
\text { documentation }\end{array}$ & \\
\hline
\end{tabular}

Expanded SI QA/QC samples for this example (Q-1 through Q-6) include 2 equipment rinsates, 2 duplicates, 1 field blank and a replicate sample at the site owner's request.

\subsection{AIR PATHWAY}

Generally, air sampling is an expanded SI activity. If suspected air pathway contamination hypothesized during the PA or focused SI is solely responsible for further investigation (i.e., all other pathways have minimal effect on scoring), air samples should be collected during a single or an expanded SI. Formal air sampling to document a release is limited to the single or expanded SI unless there is concern about an immediate threat to human health.

The SI air sampling strategy requires understanding the types of hazardous substances associated with the site. The most dispersible substances should be identified. Air sampling should be conducted either before or after all other sampling activities (i.e., not during field activities that may release substances to the air). Air sampling may require returning to the site, for example, on a dry warm day when the potential for volatilization is high. Air sampling should be avoided if the site or nearby facilities are discharging substances to the atmosphere.

Hazardous substances can be released into the atmosphere by wind, fire, explosion, evaporation, sublimation, and industrial processes. Defining the likely path and dispersion of a release to air requires information on release characteristics and atmospheric conditions. Emissions of contaminated fugitive dusts (e.g., contaminated soil particles) originating from a source can result from a combination of factors at the site, such as wind erosion, heavy equipment or vehicular traffic, and incineration. The likelihood of a release to air also depends on the type of source 
containing hazardous substances, the chemical properties of these substances, and the thickness of cover at the source.

An observed release to air may be documented through direct observation. An example is observation of particulate matter entering the atmosphere directly and information indicating the material contains one or more hazardous substances. In this case, a photograph referenced in the field logbook may be adequate to document direct observation (e.g., a dust cloud from a tailings pile). A sample of particulate material from the pile detecting hazardous substances strengthens the documentation of the release by direct observation.

Unlike other pathways, direct sampling of air targets suspected to be exposed to contamination is not required; an air observed release allows any person regularly present or any sensitive environment within the distance category, or a closer one, to be evaluated as subject to actual contamination. Investigators should note the distance from sources at the site to air sample locations. Monitoring stations should be placed near source areas to maximize the use of data in HRS air target evaluations. A release into the air of an enclosed structure is not considered an observed release.

Samples should be representative of the location and not be altered by sampling and handling procedures. Background air samples and samples establishing an observed release should be collected in a similar setting and at the same time. Background samples should be outside the influence of sources to ensure that hazardous substances detected in release samples are attributable to the site.

\subsubsection{Focused SI Strategy-Air Pathway}

Air sampling for CLP analysis should not be conducted during the focused SI. However, an ambient air "screening" program may be warranted for health and safety monitoring and to initially assess a release. This program should examine specific hazardous substances with a high propensity for a release (e.g., VOCs). However, data collected during the screening program typically do not fulfill HRS documentation requirements.
For the focused SI, the investigator should review the results from the PA and other investigations. For sites with several pathways of concern, field instruments such as an OVA or HNu should be used to refine the evaluation of a suspected release to air. Readings above background in a zone near undisturbed source areas, or particulate matter observed migrating from source areas, could be used to evaluate an observed release to air during the focused SI. Further investigation during the expanded SI would pursue documenting the release. If the air pathway scored greater than 57 during the PA and is the only pathway responsible for the further action recommendation, the single SI option is appropriate.

For VOCs, the screening program could include an initial survey using portable instruments designed to provide a field-expedient measure of total VOCs. The initial survey locates and delineates potential emission sources for formal air sampling during the expanded SI. During the focused SI, field screening methods-for example, collecting air samples with a field gas chromatograph equipped with a photoionization detector-may be useful.

\subsubsection{Expanded and SIngle SI Strategy-Alr Pathway}

Air sampling may be appropriate during the expanded SI if air is a pathway of concern or if public health is threatened in the vicinity of the site. Investigators should review the likelihood of atmospheric releases (gases and particulates) from site sources. Of all HRS pathway media, air may be most dependent on weather, particularly wind speed and direction, temperature, and relative humidity. A minimum 12hour sampling time is recommended during hot and dry weather to compensate for possible variations in these factors over time.

The predominant wind direction should be determined throughout the time period of sampling. Air should generally be sampled upwind of sources for background measures. Formal air sampling during a single SI should include a complete set of background samples because of the level of effort involved in an air sampling program. This differs from the guidelines for other pathways. Air should be sampled downwind of sources to investigate a release. Up 
wind and cross-wind samples may also be acceptable for background. Multiple background and target samples should always be considered. Background and observed release samples should be taken at the same time from approximately the same heights above the ground. Samples collected at great heights (e.g., rooftops) are not useful. Samples from very low heights are also not encouraged because field activities, particularly surface disturbance, may introduce artificial contamination. In general, dust or wipe samples are not recommended to establish a release to air. Analytical results from these samples are not usable to document a release to air for HRS scoring package purposes.

Soil samples may not qualify to document an observed air release by chemical analysis since substances may have migrated via non-atmospheric transport mechanisms. Soil-gas surveys, although sometimes useful in determining the placement of air monitoring stations, do not provide the quality of data needed to document an observed release to air. Although methane may support a release of other hazardous substances from a source, methane cannot be used as the observed release substance because it is not a designated hazardous substance under CERCLA Section 101(14). In addition, methane alone (which can occur naturally) does not indicate that hazardous substances are present or migrating from a site.

For sites where several pathways are of concern, field instruments such as an OVA or HNu should be used to refine the evaluation of a release to air. Readings above background near undisturbed source areas or particulate matter observed migrating from source areas should be documented during the expanded SI.

\subsubsection{Example of Alr Sampling Strategy}

Vega Ore is a remote site near Smalltown where ore is processed for the extraction of lead, zinc, and silver (Figure 4-5). The site has been operating since 1930 , and current activities are very limited. Waste sources include three tailings piles, a drum storage area for acids, and an aboveground tank.

The nearest residence is 1000 feet from a tailings pile. Smalltown relies on drinking water from an intake 3 miles away. A National Park is located 900 feet from the site. A total of six ranches within 0.25 mile of the site rely on both bottled water and cisterns for drinking water. Based on PA research, the significant threats posed by Vega Ore involve suspected migration of hazardous substances through air that may impact people and sensitive environments. No ground water targets exist, and the nearest surface water body is more than two miles from the site.

Because only the air pathway significantly affects the example site score, a single SI is planned for Vega Ore to investigate a release to air and targets exposed to actual air contamination within the 0.25 -mile target distance category. Table 4-17 summarizes a suggested air sampling strategy for Vega Ore. Air samples to demonstrate targets exposed to actual contamination should be collected at locations outside source boundaries. These locations should be within the boundaries of the National Park and the other areas within the 0.25 -mile radius.

Soil samples from sources should be collected to help attribute hazardous substances found in the release samples to Vega Ore. Five source samples (SS-1 through SS-5) should be taken, including 1 sample from each tailings pile, 1 from soils in the drum storage area, and 1 from soils near the above-ground tank. Air sampling should be designed to collect particulates since the largest quantities of hazardous substances associated with the site (i.e., lead, zinc, silver) do not typically exist as gases in the environment. Sampling should occur when the prevailing easterly winds are steady and other weather conditions are suitable. Wind speed and direction, air temperature, and other atmospheric characteristics should be continuously monitored and noted in the logbook.

All air samples should be taken during the same time period, and sample collection should run for at least 12 hours (air samples to establish Level I contamination for lead must be collected over a 24 hour period). A high-flow pump may be used to collect both background and release samples through a filter cartridge. Air sample stations should be placed both upwind (A-1 through A-3) and downwind (A-4 through A-8) of site sources. Cross-wind 
FIGURE 4-5: VEGA ORE SITE SKETCH

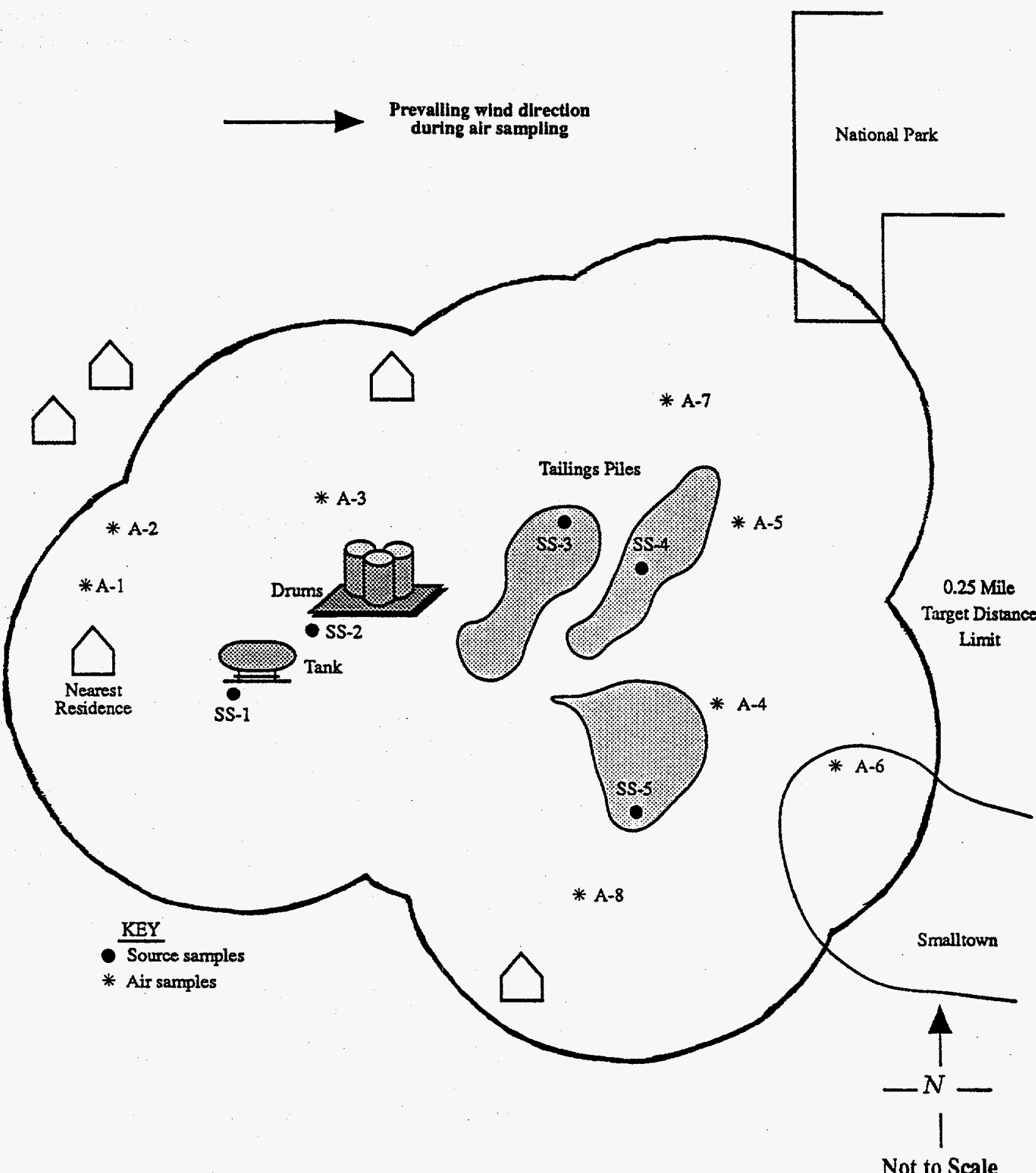


TABLE 4-17: AIR SAMPLING STRATEGY FOR EXAMPLE SITE SINGLE SI

\begin{tabular}{|c|c|c|c|}
\hline SAMPLES & APPROACH & RATIONALE & NON-SAMPLING DATA \\
\hline $\begin{array}{l}\text { Release and } \\
\text { Air Targets } \\
\text { (A-4 through } \\
\text { A-6) }\end{array}$ & $\begin{array}{l}\text { Sample to test if } \\
\text { contamination is present and } \\
\text { determine level of actual } \\
\text { contamination } \\
\text { Monitor wind speed, } \\
\text { direction, and other } \\
\text { atmospheric conditions }\end{array}$ & $\begin{array}{l}\text { Determining whether the } \\
0.25 \text {-mile target distance } \\
\text { category is exposed to } \\
\text { actual air contamination is } \\
\text { vital to investigating the } \\
\text { public health and the } \\
\text { screening and listing } \\
\text { decisions }\end{array}$ & $\begin{array}{l}\text { Determine population of } \\
\text { Smalltown lying within the } \\
0.25 \text {-mile target distance } \\
\text { category from site sources } \\
\text { Determine number of } \\
\text { workers at Vega Ore } \\
\text { Determine boundaries of } \\
\text { National Park }\end{array}$ \\
\hline $\begin{array}{l}\text { Support for } \\
\text { Release and } \\
\text { Air Targets } \\
\text { (A-7, A-8) }\end{array}$ & $\begin{array}{l}\text { Sample to test if other } \\
\text { sources of air contamination } \\
\text { exist in the site vicinity, or } \\
\text { if wind direction changes } \\
\text { during the sampling event; } \\
\text { establish cross-wind sample } \\
\text { stations }\end{array}$ & $\begin{array}{l}\text { Support determining } \\
\text { whether the } 0.25 \text {-mile target } \\
\text { distance category is } \\
\text { exposed to actual air } \\
\text { contamination }\end{array}$ & \\
\hline $\begin{array}{l}\text { Background } \\
\text { (A-1 through } \\
\text { A-3) }\end{array}$ & $\begin{array}{l}\text { Sample to collect } \\
\text { background levels of } \\
\text { ambient air concentrations }\end{array}$ & $\begin{array}{l}\text { Sample to determine } \\
\text { relative levels of particulate } \\
\text { hazardous substances in } \\
\text { ambient conditions } \\
\text { Ensure sufficient } \\
\text { background samples for } \\
\text { listing purposes }\end{array}$ & $\begin{array}{l}\text { Identify other sources of } \\
\text { particulate emissions in } \\
\text { area } \\
\text { Collect descriptive } \\
\text { information for all } \\
\text { background sample } \\
\text { locations }\end{array}$ \\
\hline $\begin{array}{l}\text { Sources } \\
\text { (SS-1 through } \\
\text { SS-5) }\end{array}$ & $\begin{array}{l}\text { Identify hazardous } \\
\text { substances present at the site } \\
\text { through surficial soil } \\
\text { samples and tailing samples }\end{array}$ & $\begin{array}{l}\text { Do not sample to increase } \\
\text { hazardous waste quantity } \\
\text { (amounts are not close to } \\
\text { HWQ factor value } \\
\text { breakpoints) }\end{array}$ & $\begin{array}{l}\text { Obtain physical } \\
\text { dimensions of tanks, } \\
\text { drums, and tailings piles, } \\
\text { and estimate area of } \\
\text { contaminated soil; verify } \\
\text { number of drums and look } \\
\text { for drum labels }\end{array}$ \\
\hline $\begin{array}{l}\text { Quality control } \\
\text { (Q-1 through } \\
\text { Q-4) } \\
\text { (Not shown) }\end{array}$ & $\begin{array}{l}\text { Monitor sample collection } \\
\text { and decontamination } \\
\text { procedures; } 2 \text { trip blanks } \\
\text { and } 2 \text { duplicates }\end{array}$ & $\begin{array}{l}\text { Ensure sufficient QA/QC } \\
\text { samples for listing purposes }\end{array}$ & \\
\hline
\end{tabular}


sample stations may be appropriate depending on atmospheric, weather, and site characteristics, and the potential for other sources of air contamination to contribute to particulate concentrations. QA/QC samples (Q-1 through Q-4) could include 2 trip blanks (i.e., the sampling event will take 2 days) and 2 duplicates. A field blank is not normally required.

For specific procedures on air sampling, refer to the National Institute for Occupational Safety and Health (NIOSH) Manual of Analytical Methods, Volumes 17, and EPA's A Compendium of Superfund Field Methods.

\subsection{SITES WITH RADIOACTIVE WASTES}

This section provides guidance for performing SIs at sites with wastes containing radioactive substances. For field investigations of sites with radioactive wastes, the SI investigator should refer to EPA's Radiochemical Procedures Manual (1984) and the Department of Energy's EML Procedures Manual (1983). The SI investigator should also consult the EPA Regional, laboratory, or Headquarters Radiation Programs staff. In addition, the following references provide useful information:

- National Council on Radiation Protection and Measurements, 1976. Environmental Radiation Measurements, NCRP Report No. 50

- U.S. EPA, 1979, Radiochemical Analytical Procedures For Analysis of Environmental Samples. EMSL-LV-0539-17

- U.S. Nuclear Regulatory Commission, Radiological Assessment: A Textbook on Environmental Dose Analysis. NUREG/CR3332. Till and Meyers (Eds.).

Sampling strategies for sites with wastes containing radioactive substances are similar to those described in previous sections for other hazardous substances, but with some important differences. These differences can be attributed, in part, to:

- Higher specificity and sensitivity of procedures used to detect radionuclides in the environment; and
- Special data requirements for scoring radiation sites under the HRS.

The SI investigator should be aware of special precautions in sampling, handling, and disposing of radioactive materials, and should work with an EPA health physicist or radiochemist in planning the sampling strategy.

\subsubsection{General Sampling Principles}

In general, sampling strategies for sites with only radioactive substances are less complex than strategies for sites with other hazardous substances. The sensitivities, specificities, and instantaneous readout capabilities of many field instruments facilitate investigating sources and releases of radioactive substances. Field identification and monitoring of specific radionuclides, source locations, release points and distances to targets can be used to focus sampling efforts and reduce the number of samples required for scoring. In addition, real-time radiation measurements allow modification to the sample plan, alert site personnel of unsafe radiation exposure levels, and permit the monitoring of collection and decontamination procedures.

Prior to developing the SI sample plan, the SI investigator should review PA and previous sampling data regarding sources and pathways with known or suspected radioactive substances to plan samples. Also, early in the SI planning process, the investigator should review section 7 of the HRS and be familiar with the data requirements of radionuclide-specific factors that require special sampling. For example, calculations of factor values for radionuclide benchmarks and hazardous waste quantity require that measurements be reported in activity units rather than mass units.

The investigator should review available site data to identify potential radionuclides. Data sources can include records of the site operating history, handling and disposal manifests, radioactive materials licenses issued by the Nuclear Regulatory Commission (NRC) or through State agreement, and previous sampling and analysis. Interviews with former employees can also provide useful information on site operations. The investigator should use these records to construct an initial list that contains the following data for each radionuclide: 
- Atomic number and atomic weight

- Radioactive half-life

- Principal decay modes and radiation energies and abundances

- Chemical and physical forms

- Decay products

Half-life information is critical to determine persistence factor values and the degree of activity equilibrium between decay products. Half-life also affects holding times for analyses.

The type (alpha, beta, gamma photons and $\mathrm{x}$-rays), abundance, and energies of the radiation emitted by a radionuclide are unique. Sampling and analysis procedures, radioanalytical methods, and radiationdetection instruments must be consistent with the decay mode and radiation energies and abundances of the radionuclide.

Bioaccumulation potential and metabolic behavior of a radioisotope are governed by its chemical and physical form, not by its radioactive properties. The toxicity of a radioisotope depends on its radioactive properties. Since radionuclides may be released to the environment as solids, liquids, or gases in a variety of chemical forms, oxidation states, and complexes, information on the most likely chemical and physical form of each radionuclide at the time of production, disposal, release, and measurement is important for developing initial sampling strategies.

Radioactive decay of an isotope of one element may result in the formation of an isotope of a different element or a different isotope of the same element. Resulting decay products have physical and chemical properties different from the parent radionuclide. Often, a decay product is also radioactive and decays to form another radioactive substance. Decay products should be considered on a substance- and site-specific basis in the evaluation of factor values for radionuclide toxicity, hazardous waste quantity, and mobility and persistence because:

- Total activity content and potential hazard of a sample may be underestimated if decay products are not included;

- Decay products may be more toxic, either alone or in combination, than the parent radionuclide; and
- Environmental transport, fate, and bioaccumulation characteristics of decay products may be substantially different from those of the parent radionuclide.

In selecting detection instruments and procedures, the SI investigator should consider the following conditions for each radionuclide in each media sample:

- Type, abundance, and energy of radiation emitted by radionuclides of concern

- Expected activity concentrations of radionuclides in sources and environmental media

- Background concentration

- Turnaround time for analyses

- Required analytical sensitivity

- Data requirements for specific HRS factors

The SI investigator should schedule analyses with laboratories that can provide radioanalytical services through the CLP SAS or a CLP-equivalent program. The investigator must specify radiochemical methods and $\mathrm{QC}$ test requirements. These should be compared with the lists of procedures for radionuclides, matrices, detection limits and sample collection, preservation, holding times, and shipping requirements supplied by each candidate laboratory. The investigator should review the radioactive materials license and conditions of each sampling laboratory to ensure that the laboratory can accept the samples for analysis.

\section{Focused SI Sampling Principles}

Similar to other sites, the focused SI at radiation sites uses analytical data to test PA hypotheses and to recommend the site for further evaluations. However, the focused SIs sampling strategy to investigate radioactive substances relies more heavily on field instruments and methods to:

- Locate elevated sources of radioactivity and external radiation exposure rates;

- Determine the identities and activity concentrations of radionuclides in situ;

- Estimate areal extent of contamination;

- Identify major migration pathways;

- Confirm releases; and

- Confirm offsite contamination. 


\section{EXAMPLE OF A FOCUSED SI SAMPLING STRATEGY AT A RADIATION SITE}

From 1910 until 1952, the ACD Corporation produced luminescent aircraft cockpit dials using radium-based paint. The area immediately surrounding the ACD factory supports a residential population of about 18,000 . Historical records indicate that the factory received substantial quantities of unprocessed radium ores during its years of operation. These ores were unloaded at a bay adjacent to railroad tracks. The abandoned factory grounds cover about 20,000 square feet and the property is accessible to the public due to a broken security fence.

A review of available records suggested that processed radium ores were discarded at the factory. The PA site visit confirmed the presence of several large piles of processed radium ore and smaller amounts of unprocessed radium ore discarded along the railroad tracks. A drinking water aquifer lies approximately 30 feet below the site.

The SI investigator conducted a walk-over gamma radiation survey of the site and collected a limited number of samples to test the PA hypotheses that site sources and soils on adjacent residential properties contained elevated levels of radium. The investigator identified $\mathrm{Ra}-226$ and its decay products as the primary radionuclides of concern and assumed that these radionuclides were present in equal activity concentrations. Background samples were not collected, but natural activity concentrations for radium in soil, water, and air were noted from scientific reports for the surrounding region.

Survey measurements identified at least 17 source waste piles with gamma radiation exposure rates significantly above background levels. The soil on four residential properties adjacent to the site also showed significant exposure rate readings. Four surface soil samples were collected: one from an ore pile on the factory grounds and the others from the front yards of three of the homes. Every sample contained highly elevated radium concentrations. Results of the single ground water well sample (900 feet from the site) were negative. Based on these documented levels of radioactive contamination and confirmed exposure of targets, the investigator recommended this site for an expanded SI.
The number of focused SI sources and environmental samples should be kept to a minimum. Sampling and surveying efforts should focus on investigating target exposure to contamination. The criteria and planning considerations in Table 4-2 apply to sites with radioactive wastes.

\section{Expanded and Single SI Sampling Principles}

Similar to sampling strategies for other hazardous substances, expanded and single SI strategies for radiation sites collect data to:

- Determine site-specific background radioactivity concentrations and exposure rate levels;

- Confirm the identities and activity concentrations of all principal radioactive substances of concern, including decay products;
- Document releases to principle pathways;

- Document Level I and Level II contamination; and

- Support QA/QC requirements.

Table 4-3 applies to expanded SI sampling for radionuclides.

\subsubsection{Source Characterization}

Evaluations of the hazardous waste quantity factor values for radionuclides differ from the approaches used for other hazardous substances in three primary ways:

- Activity units, rather than mass units, are used to evaluate sources. 
- To evaluate radionuclide constituent quantity (Tier A), calculation of the estimated net activity content for the source is based on the activity concentration above the respective background concentration for each radionuclide attributable to the source.

- Only two tiers, Tier A (radionuclide constituent quantity) and Tier B (radionuclide wastestream quantity), are used for determining hazardous waste quantity factor values.

To determine a source hazardous waste quantity factor value based on radionuclide constituent quantity data, the source area and depth (or volume) and the net activity concentration of each radionuclide in the source or area of observed contamination must be obtained.

Surface exposure rate surveys are often used to assess areal extent of observed contamination for the soil exposure pathway. These exposure rates are measured in microroentgens per hour at 1 meter above ground level using hand-held survey meters. Measurements are recorded at grid intersections, and must be accompanied by a set of $x$ - and $y$-reference coordinates. These measurements should be sufficient to locate maximum gamma exposure rates and indicate zones of equal exposure around these points.

Down-hole gamma logging is performed to estimate depth of contamination. This survey uses gamma sensitive probes lowered into drilled holes to provide measurements of the gamma exposure rate or gamma count-rates at predetermined depth intervals. An expanded SI may require a number of down-hole measurements. Depths of each bore hole should extend to the bottom of the contaminated layers plus at least 1 foot. When grade levels are approximately equal, boreholes should terminate at the same depth.

\subsubsection{QA/QC Samples}

The types and numbers of QA/QC samples required for focused and expanded SIs at radiation sites are essentially identical to those recommended in Section 4.3 and Table 4-6 for other hazardous substances, with two exceptions. Trip blanks and matrix spike analyses may not be required for radionuclide sampling because of the remote possibility of crosscontamination.

\subsubsection{Sample to Demonstrate a Release}

The criteria to establish a release by direct observation are pathway-specific and are discussed in each pathway section. The criteria and significance levels to establish an observed release through the analysis of samples for radionuclides differ considerably from the criteria used for other hazardous substances (see HRS Section 7). Radionuclide criteria are divided into three groups:

- Radionuclides that occur naturally or ubiquitous manmade radionuclides in the environment

- Manmade radionuclides that are not ubiquitous in the environment

- External gamma radiation (soil exposure pathway only)

To establish an observed release based on sample analysis for the ground water, surface water, and air pathways for naturally occurring or ubiquitous manmade radionuclides, the measured concentration (in units of activity concentration, such as $\mathrm{pCi} / \mathrm{g}$, $\left.\mathrm{pCi} / \mathrm{L}, \mathrm{pCi} / \mathrm{m}^{3}\right)$ of a given radionuclide in the sample must be at a level that:

- Equals or exceeds a value of two standard deviations above the mean site-specific background concentration for that radionuclide in that type of sample; or

- Exceeds the upper-limit value of the range of regional background concentration values for that specific radionuclide in that type of sample.

In both cases, some portion of the increase must be attributable to the site to establish an observed release.

To establish areas of observed contamination for the soil exposure pathway, the measured concentration of naturally occurring or ubiquitous manmade radionuclides in soil samples (in activity units) must meet the above criteria, and the radionuclide must be present at the surface or covered by 2 feet or less of cover material.

To establish an observed release for manmade radionuclides without ubiquitous background concentrations in the environment, the following criteria must be met: 
- The measured activity concentration of a given radionuclide in the sample must equal or exceed the SQL for that radionuclide in that specific medium.

- The increase in the sample activity concentration for that radionuclide in a specific medium must be attributable to the site.

Under special circumstances, the following sets of criteria may apply. If the radionuclide concentration equals or exceeds the SQL, but its release can be attributed to one or more sites, the measured concentration of that radionuclide in the sample must also:

- Equal or exceed a value of two standard deviations above the mean concentration of that radionuclide contributed by those neighboring sites; or

- Equal three times its background concentration, whichever is lower.

To establish observed contamination for the soil exposure pathway, the measured concentration of a nonubiquitous manmade radionuclide in soil samples must meet the criteria listed above, and the radionuclide also must be present at the surface or covered by 2 feet or less of cover material.

For the soil exposure pathway, observed contamination is also established if the gamma radiation exposure rate equals or exceeds a level equal to twice the site-specific background gamma radiation exposure rate. Some portion of the increase in the gamma radiation exposure rate must be attributable to the site. If gamma-emitting radionuclides can be detected where persons may be exposed to gamma radiation, the radionuclides do not have to be present at the surface or covered by 2 feet or less of cover material to establish observed contamination.

Level I and Level II actual contamination of targets evaluation uses different media-specific benchmarks for radioactive substances (see HRS Section 7). For the soil exposure pathway, Level I concentrations are assigned automatically to a sampling location if the external gamma radiation exposure rate (in units of $\mu \mathrm{R} / \mathrm{hr}$ measured with a survey instrument at 1 meter above the ground surface) equals or exceeds two times the background level.

\subsubsection{Ground Water and Surface Water Pathways}

In addition to the guidance provided in Sections 4.5 and 4.6, the SI investigator should be aware of special considerations for collecting and analyzing ground water and surface water aqueous samples and surface water sediment and tissue samples for radioactive substances. The SI investigator should check with EPA Regional, laboratory, or Headquarters Radiation Programs staff for guidance and standard procedures manuals (U.S. EPA, 1984, and U.S. DOE, 1983) and special instructions regarding sample collection, handling, and preservation.

With the exception of tritium, water samples for radionuclides should be collected in clean plastic or teflon containers. Tritium samples should be collected in glass containers only. The standard preservation technique for radionuclides in water is acidification to a $\mathrm{pH}$ of less than 2 using nitric or hydrochloric acid. Preservatives should be added as soon as possible after filtration. The following are exceptions:

- Tritium, C-14, and isotopes of iodine should not be acidified and analysis should be conducted as soon as possible after collection.

- Cesium radioisotopes should be preserved with hydrochloric acid only.

In all cases, the laboratory performing the radioanalysis should be contacted prior to sample collection for their recommendations on sample handling and preservation.

The volume of water sampled can range from a few milliliters to several liters, depending on the decay mode, radiation abundance and half-life of the radionuclide, expected concentrations, and the sensitivity of the radioanalytical method. The laboratory should be consulted for recommendations. Holding times for water samples depend primarily on the half-life of the radionuclide. Again, the analytical laboratory should be consulted on this issue. Radionuclide water concentrations are reported in activity concentration units, usually in picocuries per liter $(\mathrm{pCi} / \mathrm{L})$. 
Like SIs for non-radioactive waste investigations, radioactive sediment samples are taken to establish a release to surface water and to document targets exposed to actual contamination. If surface water sediment and aqueous samples are co-located, the sediment samples should be collected after the aqueous samples. In some cases where high levels of gamma-emitting radionuclides have been released, submersible radiation detection survey probes and instruments may aid in the selection of sediment sample locations.

Handling and preservation techniques for surface water sediment samples are similar to those for soil samples. Core sediment samples are usually frozen in the collection tubes, sectioned (1 to 6 inches in length depending on analytical sensitivity), air- or ovendried, ground, and analyzed either intact or after radiochemical separation and concentration.

For surface water tissue sampling and analysis, two key factors should be considered: the species of aquatic organism sampled; and the portion of the organism analyzed. Radionuclide concentrations in aquatic organisms can vary among different species based on feeding habits, habitat, and position in the food chain. Certain radionuclides may also concentrate in specific tissues. For example:

- Strontium-90, cesium-137, manganese-54, and radium tend to concentrate in the shells of freshwater crustaceans and mollusks.

- Cobalt- 60 accumulates in the kidney.

- Iron-55 and iron-59 accumulate in the spleen and kidney.

- Zinc-65 accumulates in the spleen and liver.

Tissue sampling locations and methods for radionuclides are similar to those described in Section 4.6. Tissue samples are normally frozen before analysis. Special care should be taken when wet- or dry-ashing biological samples containing polonium, cesium, lead, manganese, or cobalt are being analyzed to avoid volatilization of these radionuclides. Tissues containing radionuclides should not be dry-ashed or treated with oxidizing agents. If tissue sample analysis is necessary to evaluate actual contamination of a fishery, replicate samples may be needed due to the uncertainty of the exposure history of these organisms.
Concentrations of radionuclides in surface water sediment and tissue samples are generally reported in activity concentration units of picocuries per gram $(\mathrm{pCi} / \mathrm{g})$ or per kilogram $(\mathrm{pCi} / \mathrm{kg})$ on a wet weight basis.

\subsubsection{Soil Exposure Pathway}

In addition to the guidance provided in Section 4.7, the SI investigator should be aware of special considerations for collecting and analyzing soil for radioactive substances.

In general, no preservation techniques are required for radionuclide soil samples. However, soil samples with high organic levels should be dried or ashed, with the following exceptions:

- Aliquots of soil samples selected for H-3 should not be dried or ashed.

- Aliquots of soil samples selected for C-14 should not be ashed or leached with acid.

- Aliquots of soil samples selected for elements with volatile oxidized forms (e.g., I, Tc) should not be treated with oxidizing acids.

- Aliquots of soil samples selected for Ra-226 analysis by gamma spectrometry should be dried, crushed, or sieved, but an appropriate post-preparation holding time is necessary to reach equilibrium with radon daughters.

Holding times for soil samples depend primarily on the half-lives of the radionuclides to be analyzed. Soil sample amount depends on a number of factors, including (but not limited to) the decay modes, halflives and expected concentrations of the specific radionuclides, analytical sensitivity, and analysis time. Concentrations of radionuclides in soil are generally reported in activity concentration units of picocuries per gram (pCi/g) of dry soil.

\subsubsection{Air Pathway}

In addition to the guidance provided in Section 4.8, the SI investigator should be aware of special considerations for collecting and analyzing air samples for radioactive substances.

In general, suspended radioactive particulates should be collected on a filter using a high-volume sampler 
at high flow rates ( $>20 \mathrm{ft}^{3} / \mathrm{min}$ ). For radiochemical analysis, membrane filter paper are preferred because they are readily ashed. Either membrane filters or glass fiber filters are suitable for direct counting of activity on the filter. Collection efficiencies for both types of filters remain high (> 99 percent) over a wide range of particle sizes and filtration velocities, however both produce moderately high pressure drops and are fragile. Radioactive air samples are usually collected over a period of several hours to days. The laboratory performing the analyses should be consulted for recommended sampling procedures and times prior to collection. Filter sample measurements should be delayed for at least 5 hours after collection to allow for the decay of short-lived radon progeny that are also collected on the filter from ambient air. Gaseous isotopes of iodine (primarily I-131) should be collected on an activated charcoal cartridge or on silver zeolite. Particulate iodine should be collected on a glass fiber or membrane filter. Normally, both gaseous and particulate iodine are collected simultaneously in a sampling apparatus consisting of a particulate filter, charcoal cartridge, and vacuum pump in series.

Tritium, in the form of tritiated water vapor, is usually collected from the atmosphere onto silica gel (see NCRP, Tritium Measurement Techniques, NCRP Report No. 47, (1976)). Tritium vapor should be sampled at high flow rates for a few days to collect larger sample volumes and increase detection sensitivity. However, care must be taken to control the flow rate and sampling time to avoid oversaturation of the gel with water vapor. Temperature and humidity are important factors to consider in determining sampling times and flow rate. Air sample volumes for radionuclide analyses normally range from 1 to 30 or more cubic meters. Concentrations of radionuclides in air samples are usually reported in units of picocuries per liter of air $(\mathrm{pCi} / \mathrm{L})$ or in units of picocuries per cubic meter of air $\left(\mathrm{pCi} / \mathrm{m}^{3}\right)$.

\subsection{SUMMARY}

SI objectives determine the types, number, and location of samples to collect. By evaluating the benefits of sampling at specific locations and assessing the validity of analytical data available before sampling, the investigator will be able to achieve the dual goals of meeting SI objectives and conserving Superfund resources. Because the SI is a limited-scope, biased sampling event, strategic selection of sample locations is perhaps the most critical decision that will affect the success of the investigation. Table 4-18 summarizes the focused and expanded SI strategies designed to optimize selection of sample locations. 
TABLE 4-18: SUMMARY OF SI SAMPLING STRATEGY

\begin{tabular}{|c|c|c|c|}
\hline FACTOR & $\begin{array}{c}\text { PA } \\
\text { STRATEGY }\end{array}$ & FOCUSED SI STRATEGY & EXPANDED AND SINGLE SI STRATEGY \\
\hline $\begin{array}{l}\text { Hazardous } \\
\text { substance } \\
\text { characteristics }\end{array}$ & $\begin{array}{l}\text { Maximum values } \\
\text { assumed }^{1}\end{array}$ & $\begin{array}{l}\text { Sample sources to identify specific hazardous } \\
\text { substances present at the site. }\end{array}$ & Same \\
\hline $\begin{array}{l}\text { Hazardous waste } \\
\text { quantity }\end{array}$ & Calculated value & $\begin{array}{l}\text { Review PA data; obtain additional records; obtain } \\
\text { source quantity and area measurements; do not sample } \\
\text { to determine hazardous waste quantity; contaminated } \\
\text { soil source area may be estimated based on visual } \\
\text { observations. }\end{array}$ & $\begin{array}{l}\text { Review previous data; in limited cases, sample to } \\
\text { determine hazardous waste quantity; contaminated soil } \\
\text { source area may be further characterized based on } \\
\text { analytical data. }\end{array}$ \\
\hline $\begin{array}{l}\text { Release to ground } \\
\text { water }\end{array}$ & Suspected release & $\begin{array}{l}\text { Sample nearest well suspected to be exposed to } \\
\text { hazardous substances. Sampling to test a suspected } \\
\text { release could be conducted in conjunction with } \\
\text { sampling to test contaminated target hypothesis. }\end{array}$ & $\begin{array}{l}\text { Sample wells likely to be exposed to hazardous } \\
\text { substances. Sampling to document a release could be } \\
\text { conducted in conjunction with sampling to document } \\
\text { targets exposed to actual contamination. Install and } \\
\text { sample monitoring wells if ground water pathway is } \\
\text { significant to scoring and attribution is an issue. If } \\
\text { necessary, resample focused SI locations. }\end{array}$ \\
\hline $\begin{array}{l}\text { Drinking water } \\
\text { targets exposed to } \\
\text { actual ground } \\
\text { water } \\
\text { contamination }\end{array}$ & Primary targets & $\begin{array}{l}\text { Sample nearest drinking-water wells suspected to be } \\
\text { contaminated. Sample municipal wells, regardless of } \\
\text { depth, if reasonable probability of site related } \\
\text { contamination. }\end{array}$ & $\begin{array}{l}\text { Sample drinking-water wells likely to be } \\
\text { contaminated. Sample municipal wells, regardless of } \\
\text { depth, if there is some reasonable probability of site } \\
\text { related contamination. If necessary, resample focused } \\
\text { SI locations. Note that for metal analysis, filtering } \\
\text { may be necessary. }\end{array}$ \\
\hline $\begin{array}{l}\text { Release to surface } \\
\text { water }\end{array}$ & Suspected release & $\begin{array}{l}\text { Sample at or just downstream of the probable point of } \\
\text { entry. Sampling to test a suspected release could be } \\
\text { conducted in conjunction with sampling to test a } \\
\text { contaminated target hypothesis. Also consider direct } \\
\text { observation option. }\end{array}$ & $\begin{array}{l}\text { Sample at or just downstream of the probable point of } \\
\text { entry. Sampling to document a release could be } \\
\text { conducted in conjunction with sampling to document } \\
\text { targets exposed to actual contamination. If necessary, } \\
\text { resample focused SI locations. Also consider direct } \\
\text { observation option. }\end{array}$ \\
\hline
\end{tabular}


TABLE 4-18: SUMMARY OF SI SAMPLING STRATEGY (CONTINUED)

\begin{tabular}{|c|c|c|c|}
\hline FACTOR & $\begin{array}{c}\text { PA } \\
\text { STRATEGY }\end{array}$ & FOCUSED SI STRATEGY & EXPANDED AND SINGLE SI STRATEGY \\
\hline $\begin{array}{l}\text { Drinking water } \\
\text { targets exposed to } \\
\text { actual surface } \\
\text { water } \\
\text { contamination }\end{array}$ & Primary targets & $\begin{array}{l}\text { Collect sediment and aqueous samples at or beyond } \\
\text { the point of drinking water withdrawal prior to } \\
\text { treatment. Note that Level I contamination can only } \\
\text { be scored based on aqueous sample results. }\end{array}$ & $\begin{array}{l}\text { Collect sediment, aqueous, and benthic samples at or } \\
\text { beyond points of drinking water withdrawal prior to } \\
\text { treatment. If necessary, resample focused SI } \\
\text { locations. Note that Level I contamination can only } \\
\text { be scored based on aqueous samples. Note that for } \\
\text { metal analysis, filtering may be necessary. }\end{array}$ \\
\hline $\begin{array}{l}\text { Human food } \\
\text { chain organisms } \\
\text { exposed to actual } \\
\text { surface water } \\
\text { contamination }\end{array}$ & Primary targets & $\begin{array}{l}\text { Collect sediment and aqueous samples from within or } \\
\text { beyond the fishery boundary and as close to the PPE } \\
\text { as possible. Tissue samples should generally not be } \\
\text { collected at the focused SI. }\end{array}$ & $\begin{array}{l}\text { Collect sediment, aqueous, and benthic tissue samples } \\
\text { from within or beyond the fishery boundary. Collect } \\
\text { other tissue samples (e.g., fish) from within or beyond } \\
\text { the boundaries of actual fishery contamination. If } \\
\text { necessary, resample focused SI locations. Note that } \\
\text { Level I contamination can only be score based on } \\
\text { tissue samples. Only collect tissue samples if human } \\
\text { food chain threat is significant to scoring. }\end{array}$ \\
\hline $\begin{array}{l}\text { Sensitive } \\
\text { environments } \\
\text { exposed to actual } \\
\text { surface water } \\
\text { contamination }\end{array}$ & Primary targets & $\begin{array}{l}\text { Collect sediment and aqueous samples at or beyond } \\
\text { the sensitive environment. Sampling to test suspected } \\
\text { contamination of a surface water sensitive } \\
\text { environment may be conducted in conjunction with } \\
\text { sampling to test a suspected release to surface water. } \\
\text { If possible, collect at least two samples } 0.1 \text { miles } \\
\text { apart to test suspected contamination of a wetland. } \\
\text { Note that Level I contamination can only be scored } \\
\text { based on aqueous sample results. }\end{array}$ & $\begin{array}{l}\text { Collect sediment and aqueous samples at or beyond } \\
\text { the sensitive environment. Sampling to document a } \\
\text { release to surface water may be conducted in } \\
\text { conjunction with sampling to document targets } \\
\text { exposed to actual contamination. If possible, collect } \\
\text { at least two samples } 0.1 \text { miles apart to document } \\
\text { contamination of a wetland. Note that Level I } \\
\text { contamination can only be scored based on aqueous } \\
\text { sample results. }\end{array}$ \\
\hline
\end{tabular}




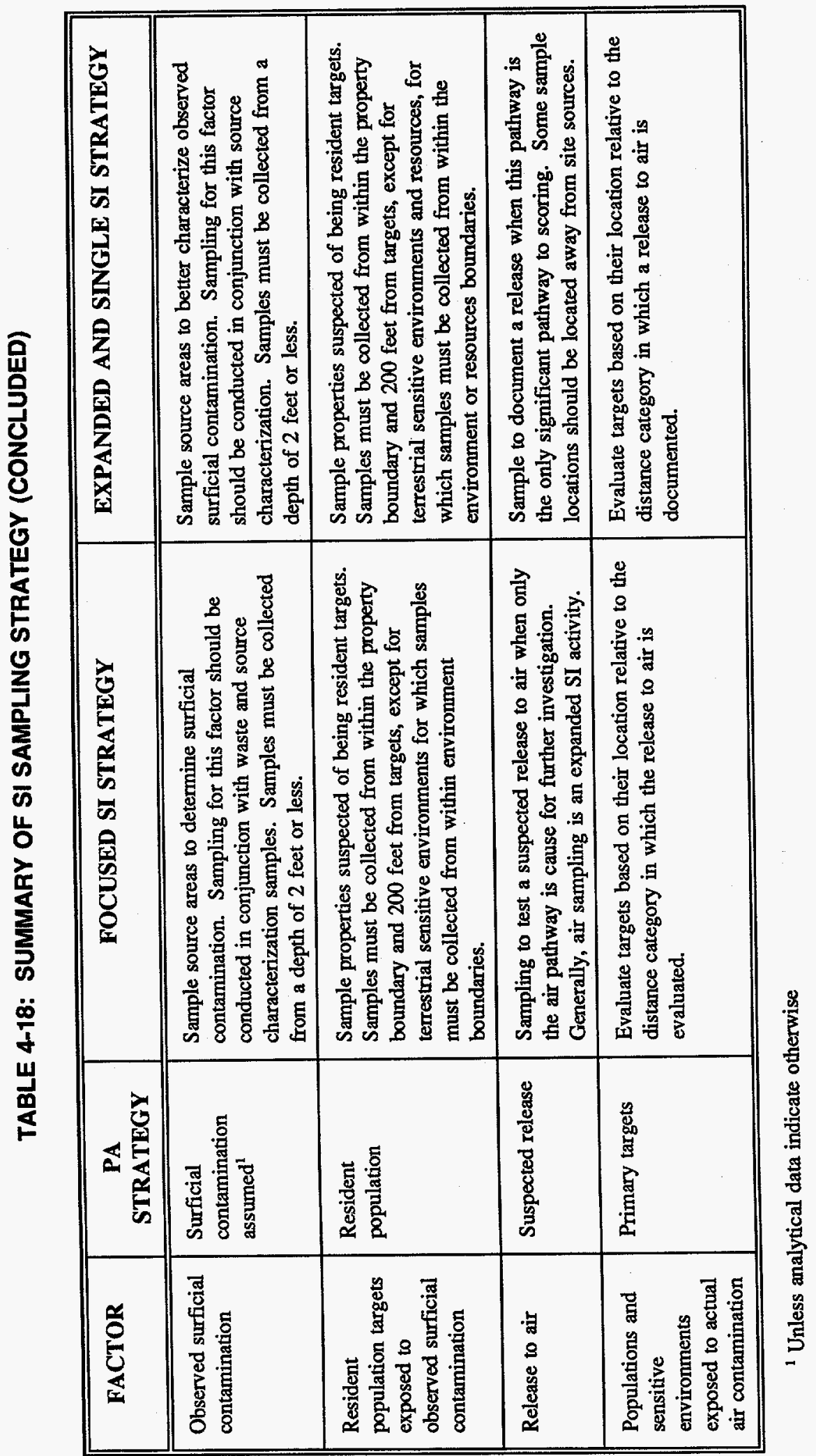





\section{CHAPTER 5 SI EVALUATION}

This chapter discusses activities that occur after analytical data and non-sampling information from the SI have been received or collected. These activities include review and validation of analytical data, identification of analytical data for scoring, review of non-sampling information, and site scoring.

The most important decision made after any SI is whether further investigation is necessary. If so, the investigator should establish the purpose and scope of the additional investigation. If not, the site is ready to be scored or deemed SEA. The type and quantity of scoring information needed depend on the objectives of the SI-for example, the data needed to screen the site from further Superfund investigation will differ from the data needed to fulfill HRS documentation requirements.

\subsection{REVIEW AND VALIDATE ANALYTICAL DATA}

Before scoring the site, the investigator should evaluate previous results (e.g., PA, earlier SI, State investigations, emergency response actions, owner/operator investigations) and new SI results. These results include analytical data and non-sampling information. Chapter 3 of this guidance discusses evaluating previous results in planning the SI; this section discusses how to integrate all data for scoring.

All analytical data should be evaluated for validity and applicability before scoring. Site assessment validation includes review of laboratory analyses and comparison of the body of data to performance criteria. The investigator or project chemist should evaluate analytical data and laboratory information to determine whether sampling protocols and procedures used Regionally approved methods. The reviewer should examine:

- Sampling dates, locations, depths, and descriptions

- Sample collection and preparation techniques
- Laboratory preparation techniques, analytical methods, and analytical results

- Method detection limits or sample quantitation limits

- QA/QC samples

- Documentation

The investigator, assisted by the project chemist, QA/QC personnel, and the laboratory, is responsible for obtaining valid and usable analytical data. Table 5-1 identifies data review considerations.

Laboratory data packages are validated according to guidelines established in the SI work plan. Items reviewed during the data validation process depend on the QA objectives of the data user (usually determined by EPA Regions or States). Data that may need to be validated include:

- Sample holding times

- Initial and continuing calibration verification

- Interference check sample for inorganics

- Determination of bias (percent recovery)

- Precision (e.g., replicate analysis)

- Detection limits

- Confirmed identification data

Professional judgment is used to validate the overall data package. The reviewer should comment on SI sample sets if several QC criteria are out of specification. The additive nature of $\mathrm{QC}$ factors out of specification is difficult to assess, but the reviewer should inform the user about data quality and limitations. This helps avoid applying the data inappropriately, while still allowing exclusion of the data. The reviewer should be provided with the data quality objectives (DQOs) of the SI samples. 


\section{TABLE 5-1: DATA REVIEW CONSIDERATIONS}

Review data reports for transcription and typographical errors (e.g., 0.5 v. .05; ppb v. ppm)

Determine if sampling protocols were appropriate

Compare data against field and trip blanks to detect cross-contamination

Compare field replicates samples

Review laboratory QC (e.g., laboratory blanks, method standards, spike recovery, duplicates)

Summarize detection limits for non-detectable results

Review detection limits for positive but non-quantifiable data

Review sampling program design for assessing media variability

Review background concentrations to help identify site-specific contamination

Delete unusable data, attach qualifiers to usable data, and explain limitations of qualified data

Guidance for Data Useability in Site Assessment discusses data validation procedures in more detail.

The reviewer verifies the usability of analytical results by reviewing QC samples and qualifiers. Routine CLP analyses have well-defined reporting requirements, while special CLP analyses and non-CLP analyses have differing requirements. The review assesses overall analytical performance, considering both the laboratory and the methods. In some cases, the data reviewer may have to notify the laboratory to resolve performance problems (e.g., to retrieve missing information, request re-analysis of samples from extracts, or request construction and re-interpretation of analytical results).

The scope of data review depends on user requirements. Communication between the data reviewer and the project chemist is crucial during data evaluation. The chemist should interpret issues resulting from the data review and correlate analytical review with site-specific information, such as physical conditions at the site that affect sample results.

During data validation, problems with the data package sometimes prevent the reviewer from adequately qualifying the data, especially if raw data, chain-ofcustody, traffic reports, or data reporting forms are missing. If the reviewer's sample calculations do not match the laboratory results, the reviewer should contact the laboratory. Samples analyzed according to special CLP methods (or non-CLP methods) may require verification of sample quantitation limits, methods of extraction (particularly for fish tissue), and analytical procedures.

\subsection{IDENTIFY ANALYTICAL DATA FOR SCORING}

Investigators may use analytical data differently to screen a site than to list a site. Investigators should refer to Guidance for Data Useability in Site Assessment and Hazard Ranking System (HRS) Guidance Manual for further information on the application of analytical data and guidelines to apply data to list sites. The following HRS aspects generally depend on analytical data:

- Observed releases

- Observed contamination (soil exposure pathway only)

- Targets exposed to actual contamination

- Levels of target contamination

- Hazardous waste quantity, particularly constituent quantity

The investigator's professional judgment determines whether the quality of analytical data are adequate for 
scoring. Sometimes non-CLP data provided by other parties or generated by EPA during previous investigations, such as emergency response actions, may be used. Examples include the following.

- Analytical data obtained from the site owner without accompanying $\mathrm{QA} / \mathrm{QC}$ information may be used if the data are reasonable for their intended use and can be applied in a similar manner as SI analytical data.

- Data supplied by local or State authorities (e.g., county health department) indicating high concentrations of a particular hazardous substance in surficial soils at the site may be used if that substance can be attributed to the site.

The SI investigator must attempt to obtain QA/QC documentation for the results. Concentrations from non-CLP data provided by other parties or from previous EPA investigations most likely support observed contamination and should be used to evaluate waste characteristics and other HRS factors (e.g., containment, human population targets).

The primary source of laboratory services for the SI are Regional Laboratories and the CLP. However, other analytical services may be more appropriate than CLP and generate data of comparable or acceptable quality. The minimum data quality acceptable for SI scoring depends on:

- Intended use of the data (e.g., to screen or list the site);

- Specific site hypothesis being tested (e.g., suspected surficial contamination); and

- Particular HRS factor being evaluated (e.g., hazardous waste constituent quantity).

CLP data may be qualified during laboratory analysis or data validation. Qualified data may be more useful for focused SI screening than to meet the listing objectives during a single or expanded SI. Qualified data (coded as "J", "U", "UJ", or "R") generally represent estimated concentrations that are qualitatively correct but may not meet specifications for quantitative accuracy and precision. Qualified data may be used only if the bias (unknown, low, high) associated with the data and the reasons for qualification are known. Some qualified data still may not be appropriate to develop a score for listing. The investigator should refer to Guidance for Data Useability in Site Assessment and Hazard Ranking System (HRS) Guidance Manual for detailed information on using qualified data to list a site.

Analytical data of unknown quality are generally not adequate to score a site. However, previous data meeting minimum usability requirements may be combined with SI data to test site hypotheses. Similarly, data not meeting minimum requirements may be used if subsequently confirmed by SI data.

EPA has established three data use categories (DUCs) (see Table 5-2):

- DUC-I data (e.g., CLP data) are the most rigorous and are associated with a high degree of confidence.

- DUC-II data lack the detailed validation procedures of DUC-I.

- DUC-III data (e.g., qualitative concentration ranges reported by health and safety monitoring instruments) are the least rigorous and are associated with a low degree of confidence.

Examples of analytical data not adequate to test hypotheses or to score an SI include:

- Background samples with higher concentrations of hazardous substances than onsite samples

- Ground water samples where the matching blanks show contamination possibly due to improper sampling procedures

- Volatile organic analyses for aqueous surface water samples qualified due to excessive holding times

If the analytical data are not adequate to test hypotheses or to score the site, the investigator should talk to EPA Regional officials. The investigator should determine whether the SI objectives can be met regardless of inadequate analytical data. Chapter 6 discusses where additional evaluation may be needed.

\subsection{EVALUATE NON-SAMPLING INFORMATION}

The SI investigator should evaluate the quality of all non-sampling information and identify factors requiring 
TABLE 5-2: DATA USE CATEGORIES (DUC) FOR SI SCORING

\begin{tabular}{|l|l|l||}
\hline \multicolumn{1}{|c|}{ HRS FACTOR } & SI SCREENING & LISTING \\
\hline \hline Observed Release/Observed Contamination & $\begin{array}{l}\text { DUC-I } \\
\text { DUC-II } \\
\text { DUC-III }\end{array}$ & $\begin{array}{l}\text { DUC-I } \\
\text { DUC-II }\end{array}$ \\
\hline $\begin{array}{l}\text { Hazardous Waste Constituent Quantity } \\
\text { (Tier A) }\end{array}$ & $\begin{array}{l}\text { DUC-I } \\
\text { DUC-II }\end{array}$ & DUC-I \\
\hline $\begin{array}{l}\text { Hazardous Wastestream Quantity (Tier B), Hazardous Waste Volume } \\
\text { Quantity (Tier C), or Area Quantity (Tier D), although rarely based } \\
\text { on sample results }\end{array}$ & $\begin{array}{l}\text { DUC-I } \\
\text { DUC-II } \\
\text { DUC-III }\end{array}$ & $\begin{array}{l}\text { DUC-I } \\
\text { DUC-II }\end{array}$ \\
\hline $\begin{array}{l}\text { Area of Observed Contamination } \\
\text { DUC-I } \\
\text { DUC-II } \\
\text { DUC-III }\end{array}$ & $\begin{array}{l}\text { DUC-I } \\
\text { DUC-II }\end{array}$ \\
\hline Targets Exposed to Actual Contamination & $\begin{array}{l}\text { DUC-I } \\
\text { DUC-II } \\
\text { DUC-III }\end{array}$ & DUC-I \\
\hline Hazardous Substances Associated with Site Sources & $\begin{array}{l}\text { DUC-I } \\
\text { DUC-II } \\
\text { DUC-III }\end{array}$ & $\begin{array}{l}\text { DUC-I } \\
\text { DUC-II }\end{array}$ \\
\hline
\end{tabular}

additional information. If site conditions have changed since the previous investigation, non-sampling information should be updated during the SI. Changes in site conditions also may affect the SI sampling strategy. Nearby target information, in particular, should be evaluated if considerable time has elapsed since the information was collected. For example:

While assembling reference materials during the focused SI, the investigator noticed that the SI field logbook mentioned a closed chemical plant adjacent to the site. When the PA was performed, she considered the plant employees the nearest individual factor (air pathway). After further research, she learned the plant had been closed; its closing had no relationship to the site she was evaluating. The HRS value for this factor was modified since the chemical plant was now abandoned and its employees were no longer air pathway targets.
The investigator should ensure that the quality of nonsampling information is acceptable. In some cases, this review will identify factors requiring additional information, such as streamflow or census data.

\subsection{SCORE THE SITE}

After reviewing and verifying the SI results, the SI investigator must evaluate the site score according to the HRS. The primary difference between PA and SI scoring involves key HRS factors that require analytical data. Several tools are available for scoring:

- SI worksheets

- PREscore software package

- Other evaluation tools developed by EPA Regional or State offices

The general approach for site scoring, applying any of these tools, is to characterize and evaluate sources and significant pathways, evaluate releases and targets 
exposed to contamination, check scoring, and collect additional information, if needed. This approach may be modified according to the amount of available site information and the types of investigations that have been performed at the site.

For some sites, a preliminary screening score should be calculated. If the screening score is based on nonsite specific data-for example, best estimates, information from a nearby CERCLA site, or regional geologic information-the investigator may have to collect more information before completing the site score. The screening score should be evaluated to determine whether more data or additional samples should be collected. As new data become available, the screening score should be updated.

The investigator may use the SI Data Summary tool (Appendix B) to compile analytical data and nonsampling information. These sheets also may serve as a checklist to:

- Summarize previous and new information.

- Identify quantitatively important HRS factors.

- Identify factors that have not been fully evaluated.

- Document data by reference.

- Focus additional data collection efforts.

Completed SI Data Summary sheets may facilitate entering data into PREscore or other SI scoring tools.

Generally, if the contribution of a pathway or threat to the overall score is minimal, it should still be qualitatively discussed in the SI narrative report, particularly if partial data are available. This discussion will help present a more complete picture of the conditions and threats at the site and may provide useful information for planning remedial investigations and other work, if necessary.

Investigators should refer to Hazard Ranking System (HRS) Guidance Manual for guidelines to evaluate HRS factors. This directive provides general and technical guidance for investigators applying the HRS to prepare packages for NPL consideration, including general rules for organizing data and information, clarification of HRS terms and concepts, policy issues, effective scoring strategies, and instructions for relatively complex HRS factors.

\subsubsection{Scoring Tools}

SI worksheets (provided in Appendix C) and other evaluation tools support site screening scores. $P R E s c o r e$ supports both screening and listing scores. The focused SI investigator may rely on any of these scoring tools. PREscore should be used to evaluate the site score for the expanded or single SI.

\section{SI Worksheets}

The SI worksheets may be appropriate to score most sites. The investigator may use the worksheets when the SI tests a limited number of hypotheses that are responsible for the PA further action recommendation, for example, a suspected release to surface water and a primary target such as a fishery exposed to actual contamination. In this example, no other pathway or combination of pathways scored high enough to warrant further site investigation. The SI worksheets generate a representative site score without requiring the entry of more complete data into PREscore.

The SI worksheets build on PA information and hypotheses by explicitly evaluating analytical data generated during the SI and other investigations. The worksheets quantitatively evaluate the key HRS factors affecting the site score, saving resources by reducing data and documentation requirements for the focused SI. Materials to assist scoring include instructions to evaluate HRS factors, scoresheets, hazardous substance value look-up tables, and hazardous substance chemical benchmark tables. The SI worksheets differ from the PA scoresheets in two significant areas:

- Tables to identify hazardous substances detected in observed releases and at exposed targets replace PA "criteria lists." The tables allow determining the level (i.e., Level I or Level IIsee Section 5.4.4 of this guidance) of contamination at exposed targets based on sample concentrations. Applying analytical data, the HRS terms "observed release" and "actual contamination" replace the PA terms "suspected release" and "suspected contamination."

- SI worksheets add substance-specific factors (e.g., toxicity/mobility, toxicity/persistence) and waste characteristics values from 0 to 100 ( 0 to 1,000 for surface water food chain and environmental threats). 
The SI worksheets may be used to evaluate all pathways to reflect the relative importance of each pathway to the overall site evaluation. Minimally contributing pathways or threats should be scored, even if only partial data (e.g., information collected during the PA) are available. For these lesser pathways and threats the SI investigator should provide a brief qualitative discussion of available information in the SI narrative report to present a more complete picture of the conditions and threats at the site. Such information may be used to plan the expanded SI, if necessary, or to identify additional non-sampling information needs. Scoring all pathways also helps reduce "false negatives" in screening process results.

\section{PREscore}

PREscore automates operations to assign HRS factor values, allowing entry and evaluation of site information, including sampling data, hazardous waste quantity and waste characteristics, physical parameters of the site, population data, and other target information. PREscore includes PREprint, a program that prints HRS scoresheets and a documentation record for sites to be considered for the NPL.
PREscore is the appropriate tool to score some sites, particularly if the focused SI tests several hypotheses and CLP analytical data establish observed releases sufficiently for HRS documentation. PREscore also may be the best tool if the site score is primarily based on potential to release for a significant migration pathway or multiple pathways. Finally, PREscore helps propose and screen alternative scoring scenarios (e.g., scoring multiple aquifers or watersheds, observed release versus potential to release), and can save considerable time in evaluating substance-specific waste characteristics.

PREscore should be used to develop the site score for listing purposes (e.g., at the end of the single or expanded SI). This program calculates HRS factors from raw data, retrieves values from hazardous substance look-up tables, calculates site scores, and generates HRS documentation and other records. PREscore assists investigators in meeting HRS requirements and minimizes potential mathematical errors in scoring. The PREscore user must be familiar with all aspects of the HRS. See PREscore Software Users Manual \& Tutorial (OSWER Directive 9345.104, 1991) for instructions.

TABLE 5-3: SI WORKSHEETS VERSUS PREscore

\begin{tabular}{||l|l|l||}
\hline \multicolumn{1}{|c|}{ CRITERIA } & \multicolumn{1}{|c|}{ SI WORKSHEETS } & \multicolumn{1}{c|}{ PREscore } \\
\hline \hline Amount of Information & $\begin{array}{l}\text { Sufficient for screening } \\
\text { Incomplete information is } \\
\text { generally acceptable }\end{array}$ & $\begin{array}{l}\text { Sufficient for screening or } \\
\text { listing } \\
\text { Generally requires complete } \\
\text { information }\end{array}$ \\
\hline Quality of Analytical Data & Variable & High \\
\hline Effort, Resources Available & Lower & Higher \\
\hline $\begin{array}{l}\text { Importance of Potential to Release } \\
\text { Factors }\end{array}$ & $\begin{array}{l}\text { Lesser importance, evaluates } \\
\text { only the most critical } \\
\text { potential to release factors }\end{array}$ & $\begin{array}{l}\text { Higher importance, evaluates } \\
\text { all potential to release factors }\end{array}$ \\
\hline Scorer's HRS Experience & Low & High \\
\hline Number of Pathways to Evaluate & All pathways & Significant pathways \\
\hline $\begin{array}{l}\text { Test Scenarios, Calculate HWQ and } \\
\text { SCDM Values }\end{array}$ & Tricky & Easy \\
\hline
\end{tabular}


HRS pathways posing significant threats to human health and the environment should be scored using PREscore. The term "significant" applies not only to the overall level of relative threat at the site compared to other sites, but also to the level of relative threat for an individual pathway at the site compared to the level of relative threat for other pathways at that same site.

Other less significant pathways or threats may be scored using PREscore if:

- Complete information is available for the pathway or threat;

- An observed release (or observed contamination) has been demonstrated for the pathway or threat, regardless of the number of targets exposed to actual contamination; and

- An observed release has not been demonstrated for the pathway or threat, and a large number of targets are exposed to potential contamination.

A combination of the SI worksheets and PREscore may be appropriate to score sites. For example, the SI worksheets may be used to develop a preliminary screening score, i.e., a "back of the envelope" score to scope results and the next steps. After a reviewer experienced with the HRS ensures the SI worksheets justify a more complete scoring effort, the investigator would use $P R E$ score to evaluate and document the site score. If the SI worksheets indicate that the site score will be less than 28.50 , PREscore may not be necessary. Applied this way, both tools can complement each other to help focus scoring efforts and save resources.

\section{Other Scoring Tools}

In addition to PREscore and the SI worksheets, other scoring tools are sometimes used by EPA Regional or State offices. These tools should be applied in a consistent manner when developing SI scores. In all cases, these tools should reflect HRS requirements to the extent practicable, and training should be provided to allow investigators to efficiently score sites.

\subsubsection{Characterize and Evaluate Signiflcant Site Sources}

The investigator should briefly characterize each source (see Table 5-4) by assessing:

- Hazardous substances associated with the source;

- Hazardous waste quantity; and

- Pathways for which the source is evaluated.

Containment characteristics should be investigated for sources that do not contribute to a release to a migration pathway or for any pathway evaluated based on potential to release. Once all sources are characterized for each pathway, target distance limits can be measured.

TABLE 5-4: CHARACTERIZE AND EVALUATE SOURCES

\begin{tabular}{||l|l||}
\hline \multicolumn{1}{|c|}{ ITEM } & \multicolumn{1}{|c|}{ SCORING CONSIDERATIONS } \\
\hline \hline Location & Refer to site map or sketch. \\
\hline Hazardous Substances & $\begin{array}{l}\text { Consider analytical data and historical records. Hazardous } \\
\text { substances should be associated with the source or the site in } \\
\text { general. }\end{array}$ \\
\hline Hazardous Waste Quantity & $\begin{array}{l}\text { Consider analytical data, historical records, field } \\
\text { observations, and aerial photos. Consider qualifying } \\
\text { removals. }\end{array}$ \\
\hline Eligible Pathways & Indicate pathways for which the source is evaluated. \\
\hline $\begin{array}{l}\text { Containment Characteristics } \\
\text { (If necessary) }\end{array}$ & $\begin{array}{l}\text { Identify source type. Consider construction diagrams, } \\
\text { historical records, field observations, and analytical data. }\end{array}$ \\
\hline
\end{tabular}


For each source, the investigator should characterize wastes deposited to identify the specific hazardous substances associated with the source. Substancespecific characteristics (e.g., toxicity, mobility, persistence) then can be evaluated.

Only substances associated with documented or suspected pathway contamination and substances associated with a source having poor or no containment for the pathway being evaluated are considered. Where a substance can be identified as being present at the site, but the sources of that substance cannot be identified, the substance is considered to be present in all sources at the site,except for sources where available information has ruled out the presence of that substance.

In some cases, samples collected during the SI may be used to refine the hazardous waste quantity evaluation for site sources. For example, surficial soil samples collected during the focused SI may indicate that the area of observed contamination is greater than that indicated by the PA. In most cases, however, the limited number of samples collected during the SI generally will not be sufficient to calculate hazardous waste constituent quantities but may be used to document other hazardous waste quantity measures, such as volume or area of the source.

Investigators should evaluate the sources of site contamination. SI investigators need not fully evaluate sources, but should briefly describe in the narrative report any source that cannot release hazardous substances to a particular migration pathway, cannot be adequately characterized due to poor or incomplete information (e.g., no reliable evidence indicates the source received hazardous waste), or which has been eliminated by a qualifying removal (see The Revised Hazard Ranking System: Evaluating Sites After Waste Removals, OSWER Directive 9345.1-03FS, 1991).

\subsubsection{Characterize and Evaluate Significant Pathways}

The pathways posing the most significant threat to human health and the environment should be identified and characterized. For example, more than one aquifer may be threatened by hazardous substance releases from the site; therefore, each aquifer should be evaluated for its contribution to the ground water pathway score. Similarly, all watersheds threatened by the site should be considered in evaluating the surface water pathway.

Frequently, sites are recommended for further investigation because a single pathway or threat scores 57 or greater; the evaluation of other pathways or threats may increase a site score already greater than the cutoff score. In many cases, an observed release or observed contamination and targets exposed to actual contamination are needed for the site score to be greater than or equal to 28.50 based on a single pathway or threat. Types of single significant hazards for which a site score may be above the cutoff score include:

- If ground water is the only pathway evaluated, either an observed release or potential to release to large target populations is critical.

- If the surface water drinking water threat is the only threat evaluated, either an observed release or potential to release to large target populations is critical.

- If surface water human food chain threat or environmental threat is the only threat evaluated, a fishery or sensitive environment exposed to actual contamination is critical.

- If surface water human food chain threat is the only threat evaluated, observed release to surface water, but not to the fishery, is critical.

- If soil exposure is the only pathway evaluated, areas of observed contamination and a resident population or terrestrial sensitive environment are critical.

- If air is the only pathway evaluated, an observed release and a population or sensitive environment near the site are critical.

The SI investigator need not score a specific pathway for a given site if:

- No significant targets are associated with the pathway.

- All sources at the site have a containment factor value of 0 for the migration pathway, and no 
observed release to that pathway has been demonstrated.

- No observed contamination is established for the soil exposure pathway (e.g., no surficial contamination within 2 feet of the ground surface has been documented).

Pathways or threats that do not significantly contribute to the site score may not require evaluation. However, if the resulting site score is near the cutoff when one or more pathways are not scored, the investigator should score pathways that initially appeared not to be significant.

\subsubsection{Evaluate Releases and Targets Exposed to Contamination}

Table 5-5 provides general considerations to evaluate targets for each pathway. In addition, the investigator should verify the consistency of target information between pathways. Note that populations vary between pathways. For example, targets for the soil exposure nearby population threat are evaluated based on travel distance, while targets for the air pathway are evaluated based on straight line distance. Also, soil exposure nearby population includes only students, day care centers, and residents, while the air pathway population also includes workers regularly present.

TABLE 5-5: TARGET EVALUATION

\begin{tabular}{||l|l||}
\hline \hline PATHWAY & \multicolumn{1}{c|}{ TARGET CONSIDERATIONS } \\
\hline \hline Ground \\
water & $\begin{array}{l}\text { Determine targets for each aquifer separately } \\
\text { Determine targets exposed to actual contamination and the level of contamination } \\
\text { Determine any aquifer discontinuities or interconnections within defined distance limits } \\
\text { Determine population served by each target } \\
\text { Evaluate standby wells } \\
\text { Identify and verify blended water-supply systems } \\
\text { Identify resource uses and Wellhead Protection Areas, if necessary }\end{array}$ \\
\hline $\begin{array}{l}\text { Surface } \\
\text { water }\end{array}$ & $\begin{array}{l}\text { Identify water bodies within the target distance limit; determine flow rates (or depths for } \\
\text { oceans and Great Lakes); determine whether each water body is fresh water, salt water, } \\
\text { or brackish } \\
\text { Identify significant surface water targets } \\
\text { Determine targets exposed to actual contamination and the level of contamination } \\
\text { Identify drinking water intakes and populations served; evaluate standby intakes } \\
\text { Identify and verify blended water-supply systems } \\
\text { Calculate potentially exposed target values after applying dilution weighting factors } \\
\text { Identify resource uses, if necessary }\end{array}$ \\
\hline $\begin{array}{l}\text { Soil } \\
\text { exposure }\end{array}$ & $\begin{array}{l}\text { Determine approximate area of observed contamination } \\
\text { Determine whether contamination occurs within the property boundaries of residences, } \\
\text { day care centers, or schools, or on terrestrial sensitive environments or resources } \\
\text { Determine targets exposed to actual contamination and level of contamination } \\
\text { Identify workers and resource uses, if necessary }\end{array}$ \\
\hline Air & $\begin{array}{l}\text { Evaluate people regularly occupying areas near or on site sources } \\
\text { Verify populations near the site (e.g., within 1 mile) } \\
\text { Determine targets exposed to actual contamination and level of contamination } \\
\text { Identify sensitive environments near the site (e.g., within 1 mile) } \\
\text { Identify resource uses, if necessary }\end{array}$ \\
\hline
\end{tabular}


Investigators also should make sure that a population is scored for the distance category in which the target is located.

The SI often tests the likelihood of a release or exposure by collecting a limited number of samples to determine whether a pathway exhibits evidence of contamination. For screening purposes, this evidence need not meet HRS requirements to document an observed release (or contamination), but needs to show that it is likely to be documented upon further investigation.

SI samples collected at appropriate locations can be used to evaluate specific substances associated with site operations and containment at a specific source and to test hypotheses regarding suspected releases and targets exposed to actual contamination. For example:

Based on historical records indicating that plating wastes containing chromium were generated and disposed onsite, a suspected surface water release was hypothesized at the PA. If SI sediment samples from a nearby surface water body receiving runoff from the site show concentrations of chromium above background levels, they could be used to establish a release. However, if these samples showed no elevated concentrations of chromium, the surface water pathway would be evaluated based on potential to release factors, refining the surface water pathway score.

Note that the absence of contamination for a particular pathway based on a one-time sampling event does not necessarily mean that releases have not occurred. Weather conditions, seasonal variations affecting ground water and surface water flow, and the selected sample locations may not be conducive to demonstrating contamination. If other evidence supports presence of contamination, the investigator should collect additional samples during the expanded SI to further test site hypotheses.

Three categories of target contamination (Level I, Level II, and potential) are used to assign HRS values to the nearest target (e.g., well, intake, food chain individual, resident, or individual) and the population and sensitive environment factors:
- Level I contamination: concentrations for targets that meet the criteria for observed releases or observed contamination, and are at or above media-specific benchmark concentrations.

- Level II contamination: concentrations for targets that either meet the criteria for observed releases or observed contamination but are less than media-specific benchmarks, or meet the criteria for actual contamination based on direct observation.

- Potential contamination: targets potentially threatened by releases (i.e., targets that are not actually exposed to contamination via that pathway or threat).

If none of the hazardous substances eligible to be evaluated at a target has an applicable benchmark, the actual contamination at the target is designated Level II. If a hazardous substance benchmark has not been established for a particular hazardous substance, the default level (Level II) is used for targets that meet the criteria for actual contamination.

The investigator should ensure that targets exposed to actual and potential contamination have been adequately documented. Among the three factor categories for an HRS pathway-likelihood of release, waste characteristics, and targets-the targets factor category is the only category that is not limited to a maximum value. Therefore, this category has the largest potential to affect the site score.

During the PA, the investigator hypothesizes whether targets are suspected to be exposed to actual contamination using professional judgement. During the SI, samples are collected to demonstrate the presence or absence of hazardous substances at these targets and to distinguish the level of actual contamination. Note that such sample evidence need not meet HRS requirements to document actual contamination, but only need show that actual contamination is likely to be documented upon further investigation. For example, if samples from nearby drinking water wells have elevated chromium concentrations, they could be used to confirm a PA suspected release to ground water and confirm hypotheses that specific ground water targets are exposed to actual contamination. The chromium 
concentrations found in these samples also could be used to distinguish the level of contamination, thus refining the ground water pathway score.

\subsubsection{Check Scoring and Collect Additional Information}

Personnel with HRS experience should check scores. In most cases, a preliminary site score will accurately indicate whether the site should be considered for further investigation or possible listing. However, this preliminary score may differ from the final score documented for the site. Some of these differences may occur because previous analytical data only partially supported scoring observed releases and targets exposed to actual contamination, but further sampling did not. Some unusual conditions or circumstances may result in an incorrect site recommendation because of simplifications inherent to the SI screening score. Before resources are committed to further investigation, experienced HRS personnel should review the preliminary site score to determine if it is reasonable.

Investigators initially should complete the preliminary score, review all pathway scores, and verify key HRS factors or scoring considerations. Elements that should be verified include:

- Observed releases

- Areas of observed surficial contamination

- Property boundaries for soil exposure targets

- Targets exposed to actual contamination

- Factor values whose data are near a break point to next higher or lower factor value

- Aquifer boundaries, discontinuities, and interconnections

- Quality of analytical data

The preliminary score may indicate that another scoring tool should be used, or that alternative scenarios to score the site may be appropriate. If SI results did not support a PA hypothesis for a significant pathway (e.g., suspected ground water release), the investigator may consider evaluating factors involving the alternate hypothesis (e.g., potential to release to ground water). The investigator should collect additional information to score the pathway, as necessary.

The preliminary site score should be analyzed to determine where more data should be collected during the SI or during additional investigation (e.g., the expanded SI or prior to preparing the HRS package). Additional information should be collected if significant HRS information cannot be adequately documented, or if newer information would change the site score above or below the cutoff.

Also, the investigator should ensure that the available information reflects current site conditions, and is not based on unreasonable assumptions or estimates, particularly at the end of the single or expanded SI. In some cases, this review will identify factors for which additional information is needed. If conditions have significantly changed since the previous investigation-perhaps due to a residential development, a natural catastrophe, or recent waste disposal activities-the appropriate non-sampling information should be updated during the SI. For example:

The previous SI was performed in September 1991 for a site consisting of a large surface impoundment. During an October 1992 hurricane, the diking around the impoundment failed. A considerable portion of the site may now be contaminated at the ground surface. Some factors that may require updating include: 1) distance to surface water, 2) source type, and 3) containment. Sampling from the area of surficial contamination also may be appropriate during the next investigation.

For some sites, the investigator may be unable to fully meet the objectives of the SI, particularly with respect to testing site hypotheses. Chapter 6 discusses circumstances where additional evaluation of the SI results may be necessary. 


\section{CHAPTER 6 REPORTING REQUIREMENTS}

To fulfill SI reporting requirements, the SI investigator should complete two work products: a narrative report and scoresheets. The narrative report summarizes the findings of the field investigation, particularly the contamination associated with the site and migration pathways. The scoresheets evaluate the data according to the HRS. Scoresheets are considered preliminary and deliberative, and, as such, are confidential. They should not be attached to the narrative report and may not be released until EPA makes a final site disposition decision.

\subsection{NARRATIVE REPORT}

After scoring the site, the investigator prepares a narrative report summarizing what is known about the site, the activities conducted during the SI, and all information researched. The report should:

- Describe the history and nature of waste handling at the site;

- Describe known hazardous substances;

- Describe pathways of concern for these substances;

- Identify and describe human population and environmental targets; and

- Present SI analytical results.

EPA and other agencies will refer to the narrative report during future site evaluations. Following EPA Regional guidelines, the report may be a letter report or a stand-alone document transmitted under separate cover. Factual statements in the report should be keyed by number to supporting references attached to the report. References not generally available to the public also should be attached. Information that rules out specific factors (e.g., "No sensitive environments were identified within 4 miles of the site") should be included and documented.

The structure and content of each SI report should follow the suggested format provided in the annotated outline (Exhibit 6-1) or as recommended per Regional guidelines. The body of the report begins with site and source characterization and moves logically through threats and targets associated with each pathway. The Summary and Conclusion section summarizes the most important characteristics of the site and identifies significant pathways and targets. Depending on the complexity of the site and the amount of information presented, narrative text may range from 10 to 12 pages and up to 20 pages, excluding attachments and references. All reports and scoresheets should include a numbered reference list and attached references.

The narrative report is a public information resource that describes the steps taken to inspect the site and provides information on the site based on EPA's inspection. It should contain sufficient information and documentation to support EPA's site disposition recommendation. . For sites not warranting further investigation, this means demonstrating that further Superfund activity is not necessary. For sites warranting further investigation, this means demonstrating sufficient cause for additional response. In either case, the SI report serves as the basis for subsequent planning.

The SI report should be restricted to factual statements. SI scores and site recommendations, which EPA considers deliberative and protected from disclosure, should not be included or referred to in the report. The investigator should check with EPA Regional officials to ensure that the SI report is consistent with current EPA policy on releasable information. The summary and conclusion should summarize the major findings of the field investigation and highlight objective data supporting major conclusions. This section should discuss all hazardous substances detected in sources at the site and in samples from the migration pathways and the soil exposure pathway.

Avoid using HRS terminology in the narrative report. While many HRS factors may be discussed, the investigator should not refer to them as "factors," or cite the HRS. The narrative report is a record of the investigation that lay persons and interested citizens 


\section{EXHIBIT 6-1: SI NARRATIVE REPORT FORMAT}

\section{INTRODUCTION}

- State that an SI was performed, the name of the agency performing it, and the authority under which it was conducted (e.g., CERCLA as amended by SARA, and EPA contract or cooperative agreement).

- State the site name, CERCLIS identification number, and location (street address, city, county, State, latitude/longitude coordinates). If necessary, provide brief directions to the site.

- State the purpose, scope, and objectives of the SI.

\section{SITE DESCRIPTION AND REGULATORY HISTORY}

- Identify the type of site (e.g., plating facility, chemical plant, municipal landfill), whether it is active or inactive, and years of operation. Describe its physical setting (e.g., topography, local land uses). Include the appropriate portion of a USGS 7.5-minute topographic map locating the site and showing a 1-mile radius. On the map, identify the surface water drainage route; nearest well, drinking water intake, and residence; and wetlands and other sensitive environments. Include a drafted sketch showing site layout, source areas, and features on and around the site.

- Briefly summarize dates and scope of previous investigations.

- Describe prior land use and past regulatory activities including the site's RCRA status, permits, permit violations, and inspections by local, State, or Federal authorities. Discuss any citizen complaints.

\section{OPERATIONAL HISTORY AND WASTE CHARACTERISTICS}

- Provide an operational history of the site. Identify current and former owners and operators, and describe site activities. Identify and describe wastes generated, waste disposal practices, waste source areas, waste source containment, and waste quantities. Indicate source areas on the site sketch.

- Discuss any previous sampling at the site; provide dates of sampling events and sample types. Summarize analytical results in a table. Include a site map of all previous sample locations.

- Discuss SI source sampling results. List in a table each waste source sample and summarize analytical results. Include a site map of all waste source and pathway sample locations.

- Identify hazardous substances associated with sources.

- Describe accessibility to source areas.

\section{GROUND WATER}

- Describe the local geologic and hydrogeologic setting (e.g., stratigraphy, formations, aquifers, karst features, confining layers, depth and permeability to each aquifer). 


\section{EXHIBIT 6-1: SI NARRATIVE REPORT FORMAT (continued)}

\section{GROUND WATER (continued)}

- Discuss ground water use within a 4-mile radius of the sources. Identify the nearest private and municipal drinking water wells and state the distance from sources. Quantify drinking water populations served by wells within 4 miles, differentiating between private and municipal wells and specifying aquifers. Identify any municipal wells that are part of a blended system; state number of wells, locations, pumping rates, and aquifer from which water is drawn. Identify wells in karst aquifers.

- Identify designated wellhead protection areas (WHPA) and specify location.

- Discuss any previous ground water sampling results; provide dates of sampling events and the depths and names of sampled aquifers.

- List in a table each well or spring sampled during the SI, provide the depth from which it draws drinking water and the screened interval, quantify the population associated with it, and identify its distance from site sources. Discuss SI ground water sampling results. List in a table each sample and summarize analytical results. Include a site map of sample locations. Identify drinking water wells exposed to hazardous substances and quantify the drinking water populations served by each.

\section{SURFACE WATER}

- Describe the local hydrologic setting, including site location with respect to floodplains, and the overland and in-water segments of the surface water migration path. State the distance from the site to the probable point of entry (PPE) into surface water. Identify the water bodies within the in-water segment, and state the length of reach and flow or depth characteristics of each; describe tidal influence. Include a drafted sketch of the surface water migration path. Describe upgradient drainage areas, onsite drainage (including storm drains, ditches, culverts, etc.), facility discharges into surface water, permits, and historical information, including floods, fish kills, fishery closures, and other events.

- Indicate whether surface water within the target distance limit supplies drinking water. Identify the location and state the distance from the PPE to each drinking water intake. Quantify the drinking water population served by surface water and identify blended systems.

- Indicate whether surface water within the target distance limit contains fisheries. Identify and state the distance from the PPE to each fishery; briefly characterize each fishery.

- Indicate whether sensitive environments are present within or adjacent to the in-water segment. Identify and state the distance from the PPE to each sensitive environment. Describe each sensitive environment and state the frontage length of wetlands on surface water.

- Discuss any previous surface water sampling results, dates, locations, and types of samples.

- Discuss SI surface water sampling results. List in a table each sample and summarize analytical results. Identify surface water intakes exposed to hazardous substances and quantify the drinking water populations served by each. Identify fisheries exposed to hazardous substances and quantify the food chain population associated with each. Identify sensitive environments and wetlands exposed to hazardous substances; quantify the frontage of exposed wetlands. 


\section{EXHIBIT 6-1: SI NARRATIVE REPORT FORMAT (continued)}

\section{SOIL EXPOSURE}

- State the number of workers on properties with site-related contamination.

- State the number of people who live on properties with site-related contamination and within 200 feet of an area of observed contamination. State the hazardous substance concentration and compare to health based benchmarks.

- Identify schools and day care facilities within 200 feet from an area of observed contamination on the school property and state the number of attendees.

- Identify terrestrial sensitive environments and resources in an area of observed contamination.

- State the number of people who live within 1 mile travel distance of the site.

- Discuss any previous sampling results of sources of surficial materials, including dates and locations.

- Discuss SI surficial source samples. List each sample in a table and summarize analytical results.

\section{AIR}

- Identify the location of, and state the distance to, the nearest individual. State the population within 4 miles of the site, including students and workers. Identify sensitive environments on sources and within 4 miles.

- Discuss any previous air sampling results, including dates, locations, sampling procedures, and meteorological conditions.

- Discuss SI air sampling procedures and results. Identify sample locations on a map. List in a table each sample and summarize analytical results.

\section{SUMMARY AND CONCLUSION}

- Briefly summarize the major aspects of the site and its history that relate to the release or threatened release of hazardous substances and the exposure of targets. Briefly summarize principal pathways and targets of concern.

- Summarize sampling results, including substances detected in site sources and in environmental media.

\section{PHOTODOCUMENTATION LOG}

- As an attachment, provide photographs of the site taken during the SI depicting pertinent site features such as waste source areas, containment conditions, stained soil, stressed vegetation, drainage routes, and sample locations. Describe each photograph in captions or accompanying text. Key each photo to its location on the site sketch. 


\section{EXHIBIT 6-1: SI NARRATIVE REPORT OUTLINE (concluded)}

\begin{tabular}{|l}
\hline - APPENDICES \\
- QA Report \\
- Other attachments \\
REFERENCES \\
- List, in bibliographic citation format, all references cited in the SI report. \\
- Attach copies of references cited in the SI report. Include complete copies of site-specific references \\
(e.g., USGS topographic maps, records of communication, drinking water population apportionment and \\
calculation worksheets, GEMS and other database printouts, waste handling records or shipping \\
manifests). Include only the title page and pertinent excerpts of publicly available references (e.g., \\
geologic reports).
\end{tabular}

should be able to read and understand. The report should not refer to HRS values or scores.

\subsection{SCORE AND DOCUMENTATION}

Prior to documenting the SI score, the investigator should complete a preliminary site score, review all pathway scores, and verify key HRS factors or scoring considerations. Personnel with HRS experience should be consulted to check the score. All relevant additional information should be collected before preparing a final SI score.

When developing the SI score, the investigator should start with general site information, followed by source characteristics, and then individual pathway information. Assumptions used in scoring should be supported by references, field observations, and other notes. These materials should be well-organized and clear to reviewers and EPA Regional and State officials.

Several tools are available to score the site (see Section 5.4.1), including SI worksheets (see Appendix C) and PREscore. The SI worksheets contain brief instructions and tables to record the results of SI samples and other analytical data. They provide HRS tables and minimum tools to apply collected data and develop a rough (preliminary or site screening) SI score. Alternatively, PREscore-generated HRS scoresheets may be submitted with the SI narrative report to fulfill reporting requirements.

Analysis of a preliminary site score should focus on factors that require data collection during the SI or additional investigation. The investigator should judge whether sampling is justified. The sample plan should be designed to support the site score, with each sample serving a specific purpose. For example:

The preliminary site score developed at the end of the focused SI was 20.00 . The investigator noted that a municipal well approximately 600 feet away from the site was evaluated as Level II contamination although hazardous substance concentrations approached benchmark levels. The investigator proposed resampling the municipal well and two additional wells during the expanded SI, because if these wells were found to be contaminated above benchmark levels (i.e., Level I), the site score would increase to 50.00 .

Additional evaluation of the SI results may be necessary if analytical data are inadequate and the 
investigator is unable to fully meet the SI objectives for scoring. If additional evaluation is warranted, the SI investigator should consult with EPA Regional officials before completing the site score or drafting the SI narrative report. Further investigation, such as collecting additional samples or performing special field activities, may be necessary to obtain better information for scoring. If so, the scope of the follow up investigation could be reduced to the essentials, with the previous SI results used in planning these activities. Table 6-1 provides action options for situations where additional evaluation may be needed.

\subsection{REVIEWS}

Review of the SI report and scoresheets involves evaluation by three parties, each with particular functions.

- The SI investigator should perform a detailed review of the SI report and scoresheets, particularly for completeness and internal consistency.

- A reviewer with considerable site assessment experience should examine these materials to provide an independent evaluation of the SI results and should determine whether the available analytical data are open to any alternative interpretations that would significantly affect site scoring.

- EPA Regional officials or State personnel should review the draft narrative report, SI scoresheets, and other materials to ensure that the results are reasonable and reflect site conditions. The final review should verify that the SI meets its objectives and that the appropriate hypotheses were tested.

After the three part review, the SI reports and materials can be finalized.

SI review ensures an appropriate site recommendation. For sites receiving SEA recommendations, the review should confirm that the judgments and data reasonably support the conclusion that the site poses little threat or that EPA will address the site under other statutes. For sites receiving further action recommendations, the review ensures that the SI results reasonably support the need for further investigation.

Some sites may require a more detailed review of the site score and analytical results to ensure that a recommended follow up investigation is warranted. Furthermore, the review will evaluate the need for subsequent investigation, such as installing monitoring wells, collecting additional soil samples, and collecting more non-sampling information.

After the review of a focused SI, EPA makes one of three recommendations:

- SEA;

- Further action (e.g., expanded SI) recommended; or

- Priority for preparation of HRS package.

Screening recommendations are usually made by comparing the focused SI score to 28.50. In certain cases, some form of further action other than the expanded SI may be appropriate-for example, a site where a domestic well is contaminated but lacks sufficient users to result in a site score greater than the cutoff score. In such a case, it may be prudent to recommend that the local health department, or other authority, be appraised of the situation. At any site, emergency response action may be recommended regardless of site score.

After the review of the expanded SI, EPA Regional management will determine the priority for preparation of an HRS package. If the site is being considered for the NPL, EPA will establish a schedule to prepare the HRS package, which consists of the HRS documentation record, reference materials, and site narrative summary along with other administrative requirements (see Regional Quality Control Guidance for NPL Candidate Sites, OSWER Directive 9345.1-08, 1991). Preparation of the HRS package is outside the scope of SI activities. 
TABLE 6-1: ADDITIONAL EVALUATION OF SI RESULTS

\begin{tabular}{|c|c|}
\hline CONDITION & POSSIBLE ACTIONS \\
\hline $\begin{array}{l}\text { Analytical data do not meet } \\
\text { appropriate DUCs for screening }\end{array}$ & $\begin{array}{l}\text { Consider using data to refine or reformulate site hypotheses } \\
\text { Consider scoring the site based on potential to release to migration } \\
\text { pathways } \\
\text { Use PREscore to determine factors that will significantly affect site } \\
\text { score after evaluating substance-specific waste characteristics (e.g., } \\
\text { toxicity, mobility, persistence) } \\
\text { Use SI worksheets or other scoring tools to estimate site score based } \\
\text { on reasonable projections to screen the site } \\
\text { Consider another investigation similar in scope to the previous SI }\end{array}$ \\
\hline $\begin{array}{l}\text { Analytical data do not meet } \\
\text { appropriate DUCs for listing }\end{array}$ & $\begin{array}{l}\text { Consider using data to screen the site from further action } \\
\text { Consider using data to refine or reformulate site hypotheses } \\
\text { Consider collecting additional non-sampling information } \\
\text { Use PREscore to determine factors that will significantly affect } \\
\text { pathway or site score after evaluating substance-specific waste } \\
\text { characteristics (e.g., toxicity, mobility, persistence) } \\
\text { Consider resampling at site }\end{array}$ \\
\hline $\begin{array}{l}\text { Some analytical data do not fully } \\
\text { support site score for screening or } \\
\text { listing }\end{array}$ & $\begin{array}{l}\text { Consider if the data significantly affect the pathway or site score } \\
\text { Consider scoring the pathways based on potential to release, } \\
\text { particularly ground water or surface water pathways }\end{array}$ \\
\hline $\begin{array}{l}\text { Hazardous substances used to score } \\
\text { observed releases or targets } \\
\text { exposed to actual contamination } \\
\text { are not conclusively attributable to } \\
\text { the site }\end{array}$ & $\begin{array}{l}\text { Review operational histories of nearby sites } \\
\text { Consider expanding the site description to include other sources, if } \\
\text { possible } \\
\text { Evaluate whether these hazardous substances are naturally-occurring } \\
\text { or ubiquitous or are significantly higher than regional or local levels }\end{array}$ \\
\hline $\begin{array}{l}\text { Analytical data support Level II } \\
\text { contamination for some targets but } \\
\text { Level I contamination is needed to } \\
\text { achieve a site score } \geq 28.50\end{array}$ & $\begin{array}{l}\text { Review the hazardous substances detected at the Level II target; } \\
\text { determine if media-specific benchmarks are available for those } \\
\text { substances } \\
\text { If benchmarks are available, consider resampling at a few, non- } \\
\text { random locations }\end{array}$ \\
\hline
\end{tabular}


TABLE 6-1: ADDITIONAL EVALUATION OF SI RESULTS (concluded)

\begin{tabular}{|l|l||}
\hline \multicolumn{1}{|c|}{ CONDITION } & \multicolumn{1}{|c|}{ POSSIBLE ACTIONS } \\
\hline \hline $\begin{array}{l}\text { Analytical data support Level I } \\
\text { contamination for some targets but } \\
\text { not enough targets for a site score } \\
\geq 28.50\end{array}$ & $\begin{array}{l}\text { Examine concentrations of hazardous substances detected at Level I } \\
\text { targets; review whether such concentrations are likely at other targets } \\
\text { not sampled } \\
\text { If such concentrations are likely, consider sampling at additional } \\
\text { locations }\end{array}$ \\
\hline $\begin{array}{l}\text { Score is just below 28.50 based on } \\
\text { significant pathways }\end{array}$ & $\begin{array}{l}\text { Consider evaluating all four pathways based on non-sampling } \\
\text { information } \\
\text { Consider collecting additional samples }\end{array}$ \\
\hline
\end{tabular}




\section{GLOSSARY}

Actual contamination: A target exposed to hazardous substances based on analytical data or through direct observation.

Apportioned population: In the evaluation of drinking water target populations associated with a blended system, the portion of the population evaluated as being served by an individual well or intake within the system.

Aquifer: Rock or sediment that is saturated and sufficiently permeable to transmit economic quantities of water to wells and springs. Not all ground water is in an aquifer.

Background: The natural ambient concentration of a hazardous substance. Includes both naturally occurring concentrations and concentrations from human-made sources other than the site being evaluated.

Blended system: A drinking water supply system that can or does combine (e.g., via connecting valves) water from more than one well or surface water intake, or from a combination of wells and intakes.

Computer-Aided Data Review and Evaluation (CADRE): A PC based software program designed to aid the analytical data review for CLP RAS data according to the QC criteria defined in EPA's Laboratory Data Validation Functional Guidelines for Evaluating Organic Analyses.

CERCLA Information System (CERCLIS): EPA's computerized inventory and tracking system for potential hazardous waste sites.

CLP Analytical Results Database (CARD): A national database designed to store and integrate CLP results and QA/QC data. CARD consists of Superfund chemical analysis and analytical information on hazardous waste sites. Analytical data entered into CARD can be downloaded into electronic software applications, such as CADRE.
Coastal tidal waters: Surface water body type that includes embayments, harbors, sounds, estuaries, and back bays. Such water bodies are in the interval seaward from the mouths of rivers and landward from the 12-mile baseline marking the transition to the ocean water body type.

Comprehensive Environmental Response, Compensation, and Liability Act of 1980 (CERCLA): Legislation that established the Federal Superfund for response to uncontrolled releases of hazardous substances to the environment.

Contaminated soil: Soil onto which available evidence indicates that a hazardous substance was spilled, spread, disposed, or deposited.

Contract Laboratory Program (CLP): A nationwide network of commercial laboratories under contract to EPA that provides analytical data of known and documented quality for Superfund enforcement actions. The CLP consists of routine and non-routine standardized analytical procedures and associated quality control requirements managed under a broad quality assurance program, which includes sample projections, sample scheduling, chain-of-custody requirements, reporting and documentation requirements, audits, and data evaluations.

Data Quality Objectives (DQOs): The full set of qualitative and quantitative constraints needed to specify the level of uncertainty that a manager can accept when making a decision based on data. The DQO process is a planning tool that enables the site manager to specify the quality of the data (analytical methods and services to be used) required to support the objectives of the site investigation.

Data Use Categories (DUCs): A level of data quality defined by a specific combination of method, QA/QC, documentation, and review requirements.

Depth to aquifer: The vertical distance between the lowest known point of hazardous substances to the top of the aquifer being evaluated. 
Distance to surface water: The shortest distance that overland runoff would follow from a source to surface water.

Drinking water population: The number of residents, workers, and students who drink water drawn from wells or surface water intakes located within target distance limits.

Drums: Portable containers designed to hold a standard 55-gallon volume of wastes.

Emergency response: An action taken to eliminate, control, or otherwise mitigate a threat posed to the public health or environment due to release or threatened release of a hazardous substance. Removals are relatively short-term actions to respond to situations requiring immediate action.

Factor: The basic element of the HRS requiring data collection and evaluation to assign a score.

Factor category: A set of related HRS factors. Each HRS pathway consists of three factor categorieslikelihood of release or exposure, targets, and waste characteristics.

Field Analytical Support Project (FASP): Field sampling techniques designed to provide sample screening information during the field activities and provide real-time analytical data. Sample analysis is performed from a field base, mobile laboratory, or with portable instruments.

Federal Register (FR): Daily publication of the Government Printing Office; contains public notices, rules, and regulations issued by the Federal Government. Cited as "<volume> FR <page>."

Fishery: An area of a surface water body from which food chain organisms are taken or could be taken for human consumption on a subsistence, recreational, or commercial basis. Food chain organisms include fish, shellfish, crustaceans, amphibians, and amphibious reptiles.

Geographical Exposure Modeling System (GEMS): Population database maintained by EPA's Office of Toxic Substances that provides residential populations in specified distance categories around a point location.
Hazard Ranking System (HRS): Scoring system used by EPA to assess the relative threat associated with actual or potential releases of hazardous substances at sites. The HRS is the primary way of determining whether a site is to be included on the NPL.

Hazardous constituent: Hazardous substance.

Hazardous substance: Material defined as a hazardous substance, pollutant, or contaminant in CERCLA Sections 101(14) and 101(33).

Hazardous waste: Any material containing a hazardous substance, pollutant, or contaminant that is or was in a source.

Investigation-derived wastes (IDW): Wastes generated during the process of collecting samples during CERCLA investigations that must be handled according to all applicable or relevant and appropriate requirements. These wastes include soil, ground water, used personal protective equipment, decontamination fluids, and disposable sampling equipment.

Karst: A kind of terrain with characteristics of relief and drainage arising from a high degree of rock solubility. The majority of karst conditions occur in limestone areas, but karst may also occur in areas of dolomite, gypsum, or salt deposits. Features associated with karst terrain may include irregular topography, abrupt ridges, sinkholes, caverns, abundant springs, disappearing streams, and the lack of a well-developed surface drainage system of tributaries and streams.

Lake: A type of surface water body that includes:

- Natural and artificially-made lakes or ponds that lie along rivers or streams (but excluding the Great Lakes).

- Isolated but perennial lakes, ponds, and wetlands.

- Static water channels or oxbow lakes contiguous to streams or rivers.

- Streams or small rivers, without diking, that merge into surrounding perennially-inundated wetlands.

- Wetlands contiguous to water bodies defined as lakes are considered to be part of the lake. 
Landfill: An engineered (by excavation or construction) or natural hole in the ground into which wastes have been disposed by backfilling or contemporaneous soil deposition with waste disposal.

Land treatment: Landfarming or other land treatment method of waste management in which liquid wastes or sludges are spread over land and tilled; or liquids are injected at shallow depths into soils.

National Contingency Plan (NCP): National Oil and Hazardous Substances Pollution Contingency Plan, commonly known as the National Contingency Plan. Regulation that establishes roles, responsibilities, and authorities for responding to hazardous substance releases. The NCP established the HRS as the principal mechanism for placing sites on the NPL.

National Priorities List (NPL): Under the Superfund program, the list of sites with releases and potential releases of hazardous substances, pollutants, and contaminants that appear to pose the greatest threat to public health, welfare, and the environment.

No Further Remedial Action Planned (NFRAP): Site disposition decision that no further response under the Federal Superfund program is necessary. Replaced by "Site Evaluation Accomplished" (SEA) recommendation.

Non-CLP Analytical Services: Analytical activities procured outside of the Contract Laboratory Program (CLP). Non-CLP data are data that are generated using non-CLP analytical services and are not produced under the CLP's quality assurance program. Non-CLP data can be generated by laboratories that participate in the CLP, by CLP Statement of Work analytical methods, and may even be presented to the user in CLP deliverable format. However, if the analytical services were not obtained through the CLP/Regional Sample Control Center (RSCC) route, they are considered to be non-CLP analytical services.

No suspected release: A professional judgment PA conclusion based on site and pathway conditions that a hazardous substance is not likely to have been released to the environment. (No suspected release is the PA terminology analogous to the HRS potential to release.)
Observed contamination: The evaluation of a release of a hazardous substance to the ground surface based on analytical data appropriate for the soil exposure pathway.

Observed release: The evaluation of a release of a hazardous substance to the environment based on analytical data of the migration pathway or direct observation of the release into the migration pathway media.

Ocean: A type of surface water body that includes:

- Ocean areas seaward from a baseline distance of 12 miles from shore.

- The Great Lakes, including wetlands contiguous to them.

PA-Score: EPA's computer program that automates scoring sites during the PA.

Pathway: The environmental medium through which a hazardous substance may threaten targets. The HRS evaluates the migration and threat potential through the ground water, surface water, air, and soil exposure pathways.

Pile: Any non-containerized accumulation above the ground surface of solid, non-flowing wastes; includes open dumps. Some types of piles are:

Chemical Waste Pile-consists primarily of discarded chemical products, by-products, radioactive wastes, or used or unused feedstocks

Scrap Metal or Junk Pile-consists primarily of scrap metal or discarded durable goods, such as appliances, automobiles, auto parts, or batteries, composed of materials that contain or have contained a hazardous substance

Tailings Pile-consists primarily of any combination of overburden from a mining operation and tailings from a mineral mining, beneficiation, or processing operation

Trash Pile-consists primarily of paper, garbage, or discarded non-durable goods that contain or have contained a hazardous substance 
Potential contamination: A target located within the target distance limit that is subject to a potential release of hazardous substances from the site or for which no actual contamination has been established.

Preliminary Assessment (PA): Initial stage of site assessment under Superfund; designed to distinguish between sites that pose little or no threat to human health and the environment and sites that require further investigation.

PREscore: EPA's computer program that automates scoring sites according to the HRS.

Primary target: A target, based on professional judgment of site and pathway conditions and target characteristics known at the PA, that has a relatively high likelihood of exposure to a hazardous substance. (Primary target is the PA terminology analogous to an HRS target exposed to actual contamination.)

Probable Point of Entry (PPE): The point at which overland runoff from the site most likely enters surface water.

Quality Assurance/Quality Control (QA/QC): Planned, systematic procedures or methods to provide a high degree of confidence in the quality of work products or laboratory results.

Removal: An action taken to eliminate, control, or otherwise mitigate a threat posed to the public health or environment due to release or threatened release of a hazardous substance. Removals are relatively shortterm actions to respond to situations requiring immediate action.

Resident: A person whose place of residence (fullor part-time) is within the target distance limit.

Resident individual: Under the soil exposure pathway, a person living or attending school or day care on a property with observed contamination and within 200 feet of an area of observed contamination associated with the site.

Resident population: Under the soil exposure pathway, the number of residents and students on a property with observed contamination and within 200 feet of an area of observed contamination associated with the site.
Resource Conservation and Recovery Act of 1976 (RCRA): Legislation that established cradle-to-grave accountability for hazardous wastes, from point of generation to point of ultimate disposal.

Routine Analytical Services (RAS): Standardized CLP laboratory services that provide analyses of organic and inorganic compounds in water or solid samples.

Secondary target: A target, based on professional judgement of site and pathway conditions and target characteristics known at the PA, that has a relatively low likelihood of exposure to a hazardous substance. (Secondary target is the PA terminology analogous to an HRS target exposed to potential contamination.)

Sensitive environment: A terrestrial or aquatic resource, fragile natural setting, or other area with unique or highly-valued environmental or cultural features.

Site: The area consisting of the aggregation of sources, the areas between sources, and areas that may have been contaminated due to migration from sources; site boundaries are independent of property boundaries.

Site Evaluation Accomplished (SEA): Site disposition decision that no further response under the Federal Superfund program is necessary. A SEA recommendation denotes that EPA has completed its assessment at a site and has determined that no further steps to list the site on the NPL need to be taken unless information indicating that this decision was not appropriate make a recommendation for listing appropriate at a later time. The SEA recommendation replaced the "No Further Remedial Action Planned" (NFRAP) recommendation (see Henry Longest Memorandum, May 11, 1992).

Site Inspection (SI): The second stage of site assessment under Superfund. SIs are performed at sites that receive a further action recommendation after the PA, and build on PA information. SIs typically include sampling to identify hazardous substances, releases, and targets exposed to actual contamination and help characterize sites that pose the greatest threats to human health and the environment. 
Source: An area where a hazardous substance may have been deposited, stored, disposed, or placed. Also, soil that may have become contaminated as a result of hazardous substance migration. In general, however, the volumes of air, ground water, surface water, and surface water sediments that may have become contaminated through migration are not considered sources.

Special Analytical Services (SAS): Nonstandardized laboratory services that provide analyses for organics, inorganics, dioxin, and other compounds in a variety of matrices. SAS analyses need to be scheduled on an as-needed basis.

Standard Operating Procedures (SOPs): Established Regional, State or contractor procedures approved by EPA to address non-site specific investigation activities and issues. These procedures cover topics such as sampling protocols, chain-of-custody requirements, and quality assurance sampling requirements.

Stream flow: The average rate of flow of a water body, expressed in cubic feet per second (cfs).

Stream or river: A type of surface water body that includes:

- Perennially-flowing waters from point of origin to the ocean or to coastal tidal waters, whichever comes first, and wetlands contiguous to these flowing waters.

- Aboveground portions of disappearing rivers.

- Artificially-made ditches, only insofar as they perennially flow into other surface water.

- Intermittently-flowing waters and contiguous intermittently-flowing ditches in areas where mean annual precipitation is less than 20 inches.

Student: A full- or part-time attendee of an educational institution or day care facility located within the target distance limit.

Superfund Accelerated Cleanup Model (SACM): A process for streamlining Superfund cleanups. The site assessment activities under SACM integrate elements of removal assessments, site assessments (PA/SI), remedial investigations (RI), and risk assessments; these are conducted concurrently where appropriate or advisable.
Superfund Amendments and Reauthorization Act of 1986 (SARA): Legislation which extended the Federal Superfund program and mandated revisions to the HRS.

Superfund Chemical Data Matrix (SCDM): EPA's database of hazardous substances and their chemical characteristics (such as toxicity, mobility, persistence) and media-specific benchmark concentrations.

Surface impoundment: A topographic depression, excavation, or diked area, primarily formed from earthen materials (lined or unlined) and designed to hold accumulated liquid wastes, wastes containing free liquids, or sludges that were not backfilled or otherwise covered during periods of deposition. A depression may be dry if deposited liquid has evaporated, volatilized, or leached.or wet with exposed liquid. Structures that may be more specifically described as lagoon pond, aeration pit, settling pond, tailings pond, sludge pit, etc. Also a surface impoundment that has been covered with soil after the final deposition of waste materials (i.e., buried or backfilled).

Surface water: A naturally-occurring, perennial water body; also, some artificially made and intermittently flowing water bodies.

Suspected release: A professional judgement PA conclusion based on site and pathway conditions that a hazardous substance is likely to have been released to the environment. Suspected release is the PA terminology analogous to an HRS observed release.

Tanks and non-drum containers: Any stationary device designed to contain accumulated wastes and constructed primarily of fabricated materials (such as wood, concrete, steel, or plastic) that provide structural support; any portable or mobile device in which waste is stored or otherwise handled.

Target: A receptor that is within the target distance limit for a particular pathway. Targets include wells and surface water intakes supplying drinking water, populations, human food chain organisms, sensitive environments, wellhead protection areas, and resources.

Target Analyte List (TAL): The list of inorganic analytes that is specified in the CLP Statement of Work for inorganics analysis. 
Target Compound List (TCL): The list of organic compounds that is specified in the CLP Statement of Work for organics analysis.

Target distance limit: The distance over which the HRS evaluates targets. Target distance limits vary by pathway: ground water and air pathways-a 4-mile radius around site sources; surface water pathway -15 miles downstream from the probable point of entry to surface water; soil exposure pathway-200 feet (for the resident population threat) and 1 mile (for the nearby population threat) from areas of observed contamination.

Terrestrial sensitive environment: A terrestrial resource, fragile natural setting, or other area with unique or highly valued environmental or cultural features.
Water body type: Classification of a surface water body. Water body types include: streams and rivers; lakes; oceans (includes the Great Lakes); and coastal tidal waters. See the specific definition of each water body type for more detail.

Wetland: A type of sensitive environment characterized as an area that is sufficiently inundated or saturated by surface or ground water to support vegetation adapted for life in saturated soil conditions. Wetlands generally include swamps, marshes, bogs, and similar areas.

Worker: In the soil exposure pathway, a person who is employed on a full- or part-time basis and whose workplace is within 200 feet of observed contamination. In the migration pathways, a person whose place of employment is within the target distance limit. 


\section{REFERENCES CITED}

American National Standards Institute, 1978. Radiation Protection Instrumentation Test and Calibration. Report No. ANSI N323.

American National Standards Institute, 1986. Quality Assurance Program Requirements for Nuclear Facilities. Report No. ANSI/ASME NQA-1.

American National Standards Institute, 1987. Selection, Qualification and Training of Personnel for Nuclear Power Plants. Report No. ANSI/ANS-3.1.

Conference of Radiation Control Program Directors, Inc., 1979. Ionizing Radiation Measurement Criteria for Regulatory Purposes. Prepared for National Bureau of Standards. NBS GCR 79-173.

Keith, L.H., 1991. Environmental Sampling and Analysis. American Chemical Society. Washington, D.C.

Keith, L.H., 1990. "Environmental Sampling: A Summary" Environmental Science and Technology, Vol. 25, No. 5, pp. 610-617.

National Council on Radiation Protection and Measurements, 1976. Environmental Radiation Measurements, NCRP Report No. 50.

National Council on Radiation Protection and Measurements, 1976. Tritium Measurement Techniques, NCRP Report No. 47.

National Council on Radiation Protection and Measurements, 1978. Instrumentation and Monitoring Methods for Radiation Protection. NCRP Report No. 57.

National Council on Radiation Protection and Measurements, 1985. A Handbook of Radioactivity Measurements Procedures. NCRP Report No. 58.

National Institute for Occupational Safety and Health, 1984. Manual of Analytical Methods (Third Edition). Volumes 1-7 and Supplements.

Schleien, B., and Terpilak, M.S., (eds.), 1984. The Health Physics and Radiological Health Handbook, Nucleon Associates, Inc.

U.S. Congress, 1976. Resource Conservation and Recovery Act of 1976. Public Law 94-580.

U.S. Congress, 1980. Comprehensive Environmental Response, Compensation, and Liability Act of 1980. Public Law 96-510.

U.S. Congress, 1986. Superfund Amendments and Reauthorization Act of 1986. Public Law 99-499.

U.S. Department of Energy, 1983. Environmental Measurements Laboratory (EML) Procedures Manual. Environmental Measurements Laboratory. EML-300.

U.S. Environmental Protection Agency, 1979. Radiochemical Analytical Procedures for Analysis of Environmental Samples. Office of Radiation Programs. EMSL-LV-0539-17. 
U.S. Environmental Protection Agency, 1984. Radiochemical Procedures Manual. Office of Radiation Programs. EPA/520/5-84-006.

U.S. Environmental Protection Agency, 1987. A Compendium of Superfund Field Operations Methods. Office of Solid Waste and Emergency Response. Directive 9355.0-14.

U.S. Environmental Protection Agency, 1988. Guidance for Conducting Remedial Investigations and Feasibility Studies under CERCLA. Office of Solid Waste and Emergency Response. Directive 9355.3-01.

U.S. Environmental Protection Agency, 1988. Laboratory Data Validation Functional Guidelines for Evaluating Organic Analyses. EPA/540/2-88-503.

U.S. Environmental Protection Agency, 1989. National Priorities List for Uncontrolled Hazardous Waste Sites_-Final Rule Covering Sites Subject to the Subtitle C Corrective Action Authorities of the Resource Conservation and Recovery Act. 54 FR 41000, October 4, 1989.

U.S. Environmental Protection Agency, 1990. Hazard Ranking System; Final Rule. 55 FR 51532, December 14, 1990.

U.S. Environmental Protection Agency, 1990. National Oil and Hazardous Substances Pollution Contingency Plan. 40 CFR Part 300. 55 FR 8666, March 8, 1990.

U.S. Environmental Protection Agency, 1990. Superfund Removal Procedures. Office of Solid Waste and Emergency Response. Directive 9360.3-01.

U.S. Environmental Protection Agency, 1990. Samplers Guide to the Contract Laboratory Program. Office of Emergency and Remedial Response. Directive 9240.0-06.

U.S. Environmental Protection Agency, 1991. Management of Investigation-Derived Wastes During Site Inspections. Office of Emergency and Remedial Response. Directive 9345.3-02.

U.S. Environmental Protection Agency, 1991. Guidance for Performing Preliminary Assessments under CERCLA. Office of Solid Waste and Emergency Response. Directive 9345.0-01A.

U.S. Environmental Protection Agency, 1991. PA-Score Software, Users Manual \& Tutorial, Version 1.0. Office of Solid Waste and Emergency Response. Directive 9345.1-11.

U.S. Environmental Protection Agency, 1991. PREscore Software, Users Manual \& Tutorial, Version 1.0. Office of Solid Waste and Emergency Response. Directive 9345.1-04.

U.S. Environmental Protection Agency, 1991. Regional Quality Control Guidance for NPL Candidate Sites. Office of Solid Waste and Emergency Response. Directive 9345.1-08.

U.S. Environmental Protection Agency, 1991. The Revised Hazard Ranking System: Evaluating Sites After Waste Removals. Office of Solid Waste and Emergency Response. Directive 9345.1-03FS.

U.S. Environmental Protection Agency, 1991. Site Assessment Information Directory. Office of Emergency and Remedial Response.

U.S. Environmental Protection Agency, 1991. Superfund Chemical Data Matrix (SCDM). Office of Solid Waste and Emergency Response. Directive 9345.1-13. Revised semi-annually. 
U.S. Environmental Protection Agency, 1991. User's Guide to the Contract Laboratory Program (CLP). Office of Emergency and Remedial Response. Directive 9240.0-01D

U.S. Environmental Protection Agency, 1992. Community Relations in Superfund: A Handbook. Office of Solid Waste and Emergency Response. Directive 9230.0-03C.

U.S. Environmental Protection Agency, 1992. Superfund Accelerated Cleanup Model (SACM). Don R. Clay Memorandum, April 7, 1992. Office of Solid Waste and Emergency Response. Directive 9203.1-01.

U.S. Environmental Protection Agency, 1992. Guidance on Implementation of the Superfund Accelerated Cleanup Model (SACM) Under CERCLA and the NCP. Don R. Clay and Lisa Friedman Memorandum, July 7, 1992. Office of Solid Waste and Emergency Response and Office of General Counsel. Directive 9203.1-03.

U.S. Environmental Protection Agency, 1992. Estimating the Potential for Occurrence of DNAPL at Superfund Sites, Office of Solid Waste and Emergency Response. Directive 9355.4-07FS.

U.S. Environmental Protection Agency, 1992. "Site Evaluation Accomplished" Memorandum from Henry Longest, Director, Office of Emergency and Remedial Response. May 11, 1992.

U.S. Environmental Protection Agency. Guidance for Data Useability in Site Assessment. Office of Solid Waste and Emergency Response. Directive 9345.1-05, in development.

U.S. Environmental Protection Agency. Hazard Ranking System (HRS) Guidance Manual. Office of Solid Waste and Emergency Response. Directive 9345.1-07, in development.

U.S. Nuclear Regulatory Commission, 1979. Quality Assurance for Radiological Monitoring Programs (Normal Operations)-Effluent Streams and the Environment. Regulatory Guide No. 4.15, Revision 1.

U.S. Nuclear Regulatory Commission, 1983. Radiological Assessment: A Textbook on Environmental Dose Analysis. Office of Nuclear Reactor Regulation. Publication NUREG/CR-3332. 


\section{SUPPLEMENTAL REFERENCES}

American Society for Testing and Materials, 1983. Thin-Walled Tube Sampling of Soils. Annual Book of ASTM Standards.

American Society for Testing and Materials, 1984. Penetration Test and Split-Barrel Sampling of Soils. Annual Book of ASTM Standards.

Keith, L.H., ed., 1988. Principles of Environmental Sampling, American Chemical Society, Washington, D.C.

National Council on Radiation Protection and Measurements, 1987. Exposure of the Population in the United States and Canada from Natural Background Radiation. NCRP Report No. 94.

U.S. Environmental Protection Agency, 1983. Characterization of Hazardous Waste Sites - A Methods Manual: Volume II - Available Sampling Methods. Office of Research and Development.

U.S. Environmental Protection Agency, 1987. Section 404(b)(1) Guidelines for Specification of Disposal Sites for Dredged or Fill Material; Definitions. 40 CFR 230.3(t).

U.S. Environmental Protection Agency, 1987. Hazardous Waste Management System: Definitions. 40 CFR 260.10.

U.S. Environmental Protection Agency, 1987. Identification and Listing of Hazardous Waste; Definition of Hazardous Waste. 40 CFR 261.3.

U.S. Environmental Protection Agency, 1987. Data Quality Objectives for Remedial Response Activities: Volume 1 - Development Process. Office of Solid Waste and Emergency Response. Directive 9355.0-7B. 


\title{
APPENDIX A \\ SI SAMPLE PLAN (EXAMPLE)
}

This appendix provides an example of a sample plan for an SI at a fictitious site, following the form and content discussed in Section 3.6.2. Note that this guidance example does not include complete references, such as applicable SOPs and SOGs, an equipment list, or a site specific health and safety plan and IDW plan.

\author{
SITE INSPECTION SAMPLE PLAN \\ PALMETTO LANDFILL \\ PALMETTO COUNTY, SOUTH CAROLINA \\ EPA ID NO. SCD123456789 \\ Prepared Under TDD No. Y9-87912-43 \\ Contract No. 99-99-9999
}

APRIL 9, 1992

XYZ Corporation

Prepared By

Joseph Brown

Project Manager
Lucy Pauling

Project Coordinator
Approved By

Maria Gomez

Regional Project Manager 


\section{CONTENTS}

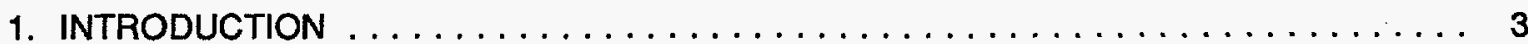

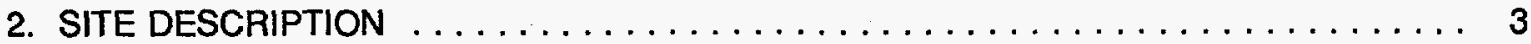

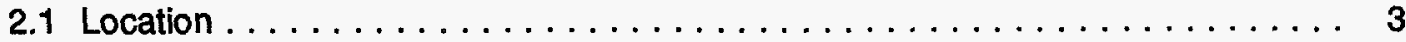

2.2 Site Description/History . . . . . . . . . . . . . . . . . . . 3

2.3 Operational History and Waste Characteristics $\ldots \ldots \ldots \ldots \ldots \ldots \ldots . . \ldots$

3. COLLECTION OF NON-SAMPLING DATA $\ldots \ldots \ldots \ldots \ldots \ldots \ldots \ldots \ldots$

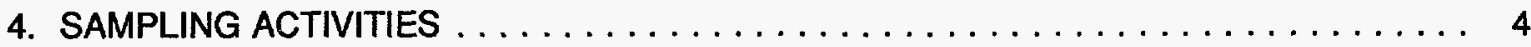

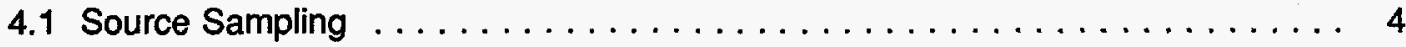

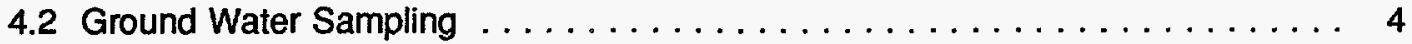

4.3 Surface Water Sampling . . . . . . . . . . . . . . . . . . 4

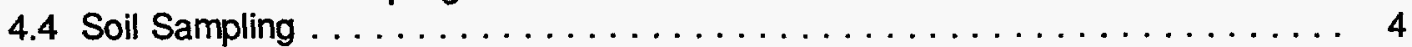

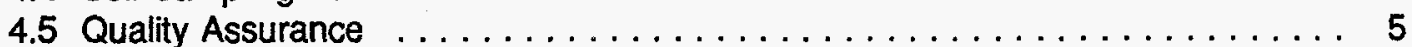

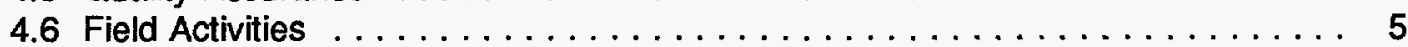

4.7 Quality Control Procedures $\ldots \ldots \ldots \ldots \ldots \ldots \ldots \ldots \ldots \ldots \ldots \ldots$

5. INVESTIGATION-DERIVED WASTES PLAN $\ldots \ldots \ldots \ldots \ldots \ldots \ldots \ldots \ldots \ldots$

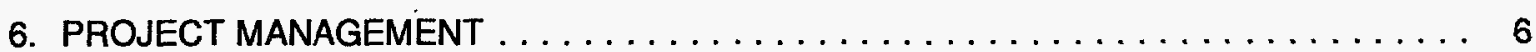

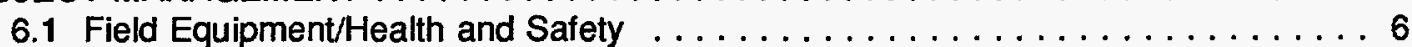

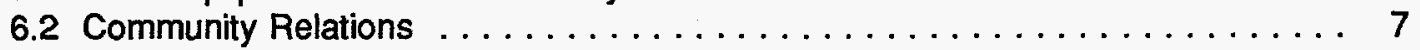

6.3 Project Schedule $\ldots \ldots \ldots \ldots \ldots \ldots \ldots \ldots \ldots \ldots \ldots \ldots \ldots \ldots$

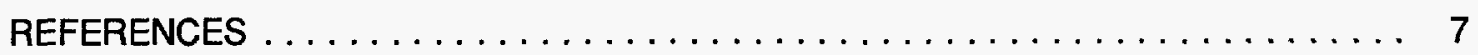

Table 1 - Proposed Samples

Table 2 - Cost Summary

Figure 1 - Sample Locations: Source, Surface Water Sediment, and Soil Figure 2 - Sample Locations: Ground Water

ATTACHMENT A - Health and Safety Plan [omitted] ATTACHMENT B - Equipment List [omitted] ATTACHMENT C - Applicable Standard Operating Guidelines [omitted] ATTACHMENT D - Drinking Water Well Survey [omitted] 


\section{INTRODUCTION}

Under the authority of the Comprehensive Environmental Response, Compensation, and Liability Act of 1980 (CERCLA) and the Superfund Amendments and Reauthorization Act of 1986 (SARA), the U.S. Environmental Protection Agency (EPA), Waste Management Division, Region 4 will conduct a focused site inspection (SI) at the Palmetto Landfill in Palmetto County, South Carolina. The focused SI will investigate the threat to human health and the environment posed by the site (Reference 1). The scope of the investigation will include collecting source samples to determine types and concentrations of hazardous substances onsite and collecting media samples to investigate migration of hazardous substances from the site.

\section{SITE DESCRIPTION}

\subsection{Location}

Palmetto Landfill is located at 6250 Palmetto Drive in rural Palmetto County, South Carolina, 1.5 miles east of Angleton (Figure 3). The geographic coordinates are $18^{\circ} 28^{\prime} 43^{\prime \prime} \mathrm{N}$ latitude and $66^{\circ} 07^{\prime} 33^{\prime \prime} \mathrm{W}$ longitude [sic] (Reference 2). To reach the site, travel east from Angleton approximately 0.25 mile from the intersection of Rt. 149 and Palmetto Drive.

The climate of Palmetto County is characteristically temperate; summers are warm and humid with daily temperatures reaching $90^{\circ} \mathrm{F}$ or higher, and winters are generally mild with daily average temperatures $55^{\circ}$ to $60^{\circ} \mathrm{F}$. Mean annual rainfall is 46 inches, while net precipitation is 10.87 inches (Reference 3, pp. 7, 10).

\subsection{Site Description/History}

The landfill property covers approximately 10 acres, approximately 6 acres of which were used for disposal of wastes (Reference 4). The property is located on flat terrain that slopes toward the northeast boundary (Reference 5) and Wildlife Creek, a small, slowly flowing stream (Reference 6, p. 124). The landfill property is rectangular and bordered on three sides by a ditch constructed to intercept ground water upgradient of the site and divert it around the buried wastes (Reference 4). Since the ditch is 8 to 10 feet deep, it does not fulfill this function entirely as it does not completely transect the aquifer. However, it does create a barrier to runoff from areas upgradient of the site. Vegetation is stressed along the banks of the ditch (Reference 5). Water in the ditch is an orange-brown color and is oily in appearance (Reference 5; Reference 7, p. 4). No buildings or other structures are on the property. The property is surrounded by an electric chain link fence in good condition, and there is a locked entrance gate across the access road to the facility (Reference 5; Reference 7, p. 3).

\subsection{Operational History and Waste Characteristics}

Smith and Moore Disposal Services, 1111 Main Street, Angleton, South Carolina, owns Palmetto Landfill. The landfill opened in April 1970 for disposal of municipal garbage and household debris. Wastes were deposited in ditches 7 to 10 feet deep and covered with soil at the end of each day. Beginning in October 1978, the landfill accepted industrial wastes on a limited basis. Smith and Moore kept no formal records of the amounts and types of wastes received. The landfill did receive a one-time shipment of approximately 500 gallons of trichloroethene (TCE) waste (Reference 4). Landfilling operations were discontinued in July 1980 when the landfill reached capacity. A 2-foot soil cover was placed over the entire landfill (Reference 4).

Palmetto Landfill operated under permit number 999-999 issued by the South Carolina Department of Health and Environmental Concerns [sic] (SCDHEC). SCDHEC personnel inspected the landfill to verify the closure 
met the permit requirements. SCDHEC personnel have inspected the landfill several times at irregular intervals. To date, there has been no sampling or response action at Palmetto Landfill (Reference 8).

\section{COLLECTION OF NON-SAMPLING DATA}

Non-sampling data collection activities will include verifying population and environmental information as well as new information. The integrity of the landfill cover and location of wetlands will be verified by visual inspection. The SI will investigate if either of two Federal endangered species, the Bald Eagle and the Salt Marsh Harvest Mouse, which have critical habitats in Palmetto County, lives onsite. A drive-by survey will be performed to confirm the locations of private wells in the area and a well system questionnaire will be distributed to persons using private wells. Additional data will be gathered as necessary from the office.

\section{SAMPLING ACTIVITIES}

The objectives of the SI are to collect analytical data to identify hazardous substances at the site and investigate whether hazardous substances have been released to the environment and whether the substances have impacted human health and the environment. The plan (Figure 1) calls for waste source, surface water sediment, ground water, and soil samples. The SE Regional Contract Laboratory in Tallahassee will perform full TCL analysis of all samples.

\subsection{Source Sampling}

Sources will be sampled where breaches in the landfill cap and a leachate seep were identified during the PA. These locations were chosen to identify hazardous substances at the site. Waste samples will include black sludge-like material from a small depression in the landfill cap near the center of the site, a sample from an area of stressed vegetation northeast of the depression, and a leachate sample from the perimeter ditch east of the landfill. A duplicate leachate sample will be collected from the perimeter ditch.

\subsection{Ground Water Sampling}

Ground water samples will be taken from the six residential wells hypothesized as primary targets during the PA. These samples will test whether hazardous substances have been released to the ground water and whether the release has impacted drinking water wells.

\subsection{Surface Water Sampling}

Surface water samples will be taken to determine whether a release to surface water has occurred and whether the release has impacted the fishery in Wildlife Creek, wetlands along its banks, and habitats of endangered species associated with the creek. During the PA, the fishery, wetlands, and sensitive environments were evaluated as primary targets. One sediment sample will be taken at each drainage point of entry to Wildlife Creek (fishery), at the section of wetland closest to the site, and at an area in the wetland approximately 500 feet downstream from the first sample. Depending on location of endangered species habitats, it may be necessary to alter this plan. Two background sediment samples will be collected upstream of the probable points of entry to Wildlife Creek north of the site.

\subsection{Soil Sampling}

A soil sample will be collected offsite, 1500 feet from the landfill. A soil sample will be taken on the property of the nearest residence to investigate if it is affected by the site.

$$
-4-
$$




\subsection{Quality Assurance}

Quality assurance and quality control (QA/QC) for this sampling event will be provided by a combination of field blanks and duplicates. One aqueous field blank will be taken during ground water sampling to test for contamination possibly introduced by sample containers and preservatives. One duplicate sample each will be taken from the nearest well, the downstream entry to Wildlife Creek (fishery), and the leachate. Duplicate samples will test the reliability of sampling procedures and results.

All sample collection, preservation, QA/QC preparation of field blanks and duplicates, and chain-of-custody procedures used during sampling activities will be in accordance with the standard operating guidelines (SOGs) specified in the Engineering and Support Branch Standard Operating Procedures and Quality Assurance Manual, U.S. Environmental Protection Agency, Environmental Services Division, Region IV, Atlanta, Georgia, April 1986.

\subsection{Field Activities}

Field personnel are scheduled to travel to the site on September 3, 1991. EPA Region 4 has requested access to the facility September 4 . Residents with private wells to be sampled have been requested to provide access to sampling personnel on September 4. All environmental samples and non-sampling information will be collected in one day. Field personnel are scheduled to leave the site the morning of September 5.

Field work will begin with a site reconnaissance in the morning to verify that planned sample locations are appropriate and accessible. During the reconnaissance, ambient air will be monitored with OVA and HNu meters. Radiation screening will be conducted during the site reconnaissance with a Victoreen Radiation Detector and Mini-Alert according to EPA SOG No. 18, Revision 0. A drive-by survey will verify the location of wetlands, the closest resident, private well users, and the population within approximately 0.25 mile of the site. If necessary, original plans will be modified. Upon collection, all samples will be prepared and packaged for shipping.

Two 2-person teams will be deployed. Sampling will start after the original sample plan and any necessary modifications are confirmed. Proposed sample locations are shown in Figures 2 and 3.

The ground water sampling team will visit each residence to obtain an unfiltered sample (none of the residences have filter treatment) from the spigot nearest the well. Each resident will be asked to complete a well system questionnaire regarding well depth, persons per household, etc. (Attachment $D$ ). This team also will collect a soil sample from the residential property 300 feet from the site. Since this residence is also the location of a private well, both soil and ground water will be sampled during the same visit. Soil samples will be collected 6 to 12 inches below ground surface according to EPA SOG No. 10, Revision 0 , and placed in an unpreserved 4-ounce container.

The second sampling team will collect surface water sediment samples according to EPA SOG No. 10a, Revision 0 , starting with the most downstream sample and proceeding upstream. Sediment samples will be collected with a disposable scoop from an area of slow flow; a portion of the collected material will be placed into a sterile container.

After completing the surface water sampling, the second team will collect waste source samples in the following order: 1) an aqueous sample from the east perimeter ditch, 2) a sediment sample of the sludge-like material in the landfill cap depression, and 3) a soil sample from the area of stressed vegetation.

$-5-$ 
The surface water sample will be collected by submerging a sterile container below the surface of the water, according to EPA SOG No. 9, Revision 0. Surface water samples to be analyzed for organics will be collected in 44-ml septumed vials and preserved with 100 microliters of 7,000 ppm mercuric chloride solution to a final concentration of $16 \mathrm{ppm}$. The surface water sample for inorganic analysis will be collected in a 4-ounce polyethylene container, filtered, and preserved with nitric acid to a pH of less than 2.0 .

\subsection{Quality Control Procedures}

All sampling equipment will be decontaminated between sample locations according to EPA SOG №. 23, Revision 0 , and sample containers will be rinsed with deionized water. All samples will be stored in coolers on ice until they reach the laboratory. Chain of custody will be maintained according to EPA SOG No. 21, Revision 0 by field personnel until samples are handed over to the SE Regional Contract Laboratory in Tallahassee.

\section{INVESTIGATION-DERIVED WASTES PLAN}

Investigation-derived wastes include personal protective equipment, disposable sampling equipment, purged ground water, and soil not collected as a sample. Personal protective equipment and disposable sampling equipment (DE) will be decontaminated and rendered nonhazardous. All dry personal protective equipment and DE will be double-bagged and deposited offsite at the EPA Region 4 warehouse.

Purged ground water is expected to be nonhazardous under the Resources Conservation and Recovery Act (RCRA). Per signed agreements with owners of the off-site wells to be sampled, ground water will be poured onto the ground next to the wells and allowed to infiltrate. Any quantities of soils that are not collected as samples will be spread around the sample location and covered with surficial soil. These soils are anticipated to be RCRA nonhazardous. Any sediments not collected as samples will be returned to the surface water.

\section{PROJECT MANAGEMENT}

The project manager for the Palmetto Landfill SI, Joseph Brown, will schedule field activities and personnel requirements, verify site access authority obtained through the EPA Project Officer, direct and oversee all onsite and offsite activities associated with the investigation. The project manager also will document and manage all collected samples. The project safety officer is Joan Locke. Max Villeroy, Wanda Grouper, and A.J. Hoyt will collect and prepare samples and support all other field operations as required. The estimated technical hours total 440 (Table 2). Twenty-one proposed CLP samples are summarized in Table 1.

\subsection{Field Equipment/Health and Safety}

Safety monitoring equipment will include OVA, $\mathrm{HNu}$, Victoreen Radiation Detector, and TLD badge. Field respiratory protection will be level $\mathrm{C}$ during the site reconnaissance. If non-methane contaminants and radiation levels are safely below background and action levels, the reconnaissance will continue at level $\mathrm{D}$. Protection during SI onsite sampling activities will begin at level $D$; if radiation and volatile contaminants are detected, sampling will continue at level C. Offsite sampling will be conducted at level D protection. Field dress for reconnaissance will include slush boots, Tyvek 1422A, disposable gloves, and hardhat. For onsite sampling, butyl or nitrile gloves will be worn over the disposable gloves, and the hardhat will include a faceshield. Field dress for offsite sampling entails regular cotton work clothes, work boots, and disposable gloves. Other items required for this investigation include sample containers and sampling tools, deionized water rinse, alconox wash, and decontamination assembly. (See Attachment B for more specific information). 


\subsection{Community Relations}

The local community has been made aware of the date of the SI field activities. Community relations have progressed smoothly thus far.

\subsection{Project Schedule}

The project is expected to start in early June 1991 and end by January 31, 1992. Non-sampling data collection will begin in June and continue through late October. The SI field work will take place in early September. When the field tasks are completed, preparation of the draft SI report will begin. Analytical results will be validated by the middle of December, and the final SI report and HRS score will be completed by the end of January.

\section{REFERENCES}

1. XYZ Corporation, Preliminary Assessment, Palmetto Landfill, Palmetto County, South Carolina, TDD No. Y9-8765-43, June 10, 1991.

2. U.S. Geological Survey, 7.5-minute topographic quadrangle maps of South Carolina: Angleton, 1963, photo revised 1983; Palmetto, 1975; Winchester, 1975; Danvers, 1963.

3. U.S. Department of Commerce, 1983. "The Climatic Atlas of the United States."

4. Jennifer Doe, Manager for Smith and Moore Disposal Services, telephone conversation with Joe Brown, XYZ Corporation, May 1, 1991. Re: Waste Disposal Practices at Palmetto Landfill.

5. Joseph Brown, XYZ Corporation, Photodocumentation Log of Palmetto Landfill Preliminary Assessment, May 7, 1991.

6. A.P. Park, The Surface Water Resources of Palmetto County, South Carolina. South Carolina Water Resources Commission Report No. 101B.

7. Joseph Brown, XYZ Corporation, Field Logbook for Offsite Reconnaissance of Palmetto Landfill, TDDY9-8765-43, May 1991.

8. John Hill, Technician for South Carolina Department of Health and Environmental Concerns, telephone conversation with Joe Brown, XYZ Corporation, May 2, 1991. Re: Remediation and sampling at Palmetto Landfill. 
TABLE 1: PROPOSED SAMPLES

\begin{tabular}{|c|c|c|}
\hline PURPOSE & SAMPLE & LOCATION AND OBJECTIVE \\
\hline \multirow{6}{*}{$\begin{array}{l}\text { Ground } \\
\text { Water }\end{array}$} & PL-GW-1 & Well 300' $S$ of landfill, determine presence/absence of hazardous substances \\
\hline & PL-GW-3 & Well $1200^{\prime} \mathrm{SE}$ of landfill, determine presence/absence of hazardous substances \\
\hline & PL-GW-4 & Well $1200^{\prime}$ NE of landfill, determine presence/absence of hazardous substances \\
\hline & PL-GW-5 & Well $1000^{\prime} \mathrm{N}$ of landfill, determine presence/absence of hazardous substances \\
\hline & PL-GW-6 & Well $1200^{\prime} \mathrm{N}$ of landfill, determine presence/absence of hazardous substances \\
\hline & PL-GW-7 & Well $1200^{\prime} \mathrm{N}$ of landfill, determine presence/absence of hazardous substances \\
\hline \multirow[t]{2}{*}{ QA/QC } & PL-GW-8 & $\begin{array}{l}\text { Field blank for detection of contaminated vials or preservatives or errors in } \\
\text { sampling protocol }\end{array}$ \\
\hline & PL-GW-2D & Duplicate of PL-GW-1 \\
\hline \multirow{6}{*}{$\begin{array}{c}\text { Surface } \\
\text { Water } \\
\text { Sediment }\end{array}$} & PL-SD-1 & $\begin{array}{l}500 \text { ' downstream of PL-SD-2 to determine presence/absence of hazardous } \\
\text { substances in wetland and establish frontage of contaminated wetland }\end{array}$ \\
\hline & PL-SD-2 & $\begin{array}{l}\text { Most upstream portion of wetland to determine presence/absence of hazardous } \\
\text { substances in wetland }\end{array}$ \\
\hline & PL-SD-3 & $\begin{array}{l}\text { NE intersection of drainage ditch and Wildlife Creek to determine } \\
\text { presence/absence of hazardous substances in fishery }\end{array}$ \\
\hline & PL-SD-5 & $\begin{array}{l}\text { NW intersection of drainage ditch and Wildlife Creek to determine } \\
\text { presence/absence of hazardous substances in fishery }\end{array}$ \\
\hline & PL-SD-6 & $\begin{array}{l}100^{\prime} \text { upstream of the PPE into creek to determine presence/absence of hazardous } \\
\text { substances }\end{array}$ \\
\hline & PL-SD-7 & 200 ' upstream of the PPE into creek to determine absence of hazardous substances \\
\hline QA/QC & PL-SD-4D & Duplicate of PL-SD-3 \\
\hline \multirow[t]{2}{*}{ Soil } & PL-SS-1 & $\begin{array}{l}\text { From nearest residential property } 300^{\circ} \mathrm{SW} \text { of landfill at depth of } 1.5^{\prime} \text { to determine } \\
\text { if hazardous substances from the site are on residential property }\end{array}$ \\
\hline & PL-SS-2 & Native soil $1500^{\prime} \mathrm{NW}$ of landfill to represent background conditions \\
\hline \multirow[t]{3}{*}{$\begin{array}{l}\text { Waste } \\
\text { Sources }\end{array}$} & PL-WS-1 & $\begin{array}{l}\text { Waste sample at depth of } 0.5^{\circ} \text { from landfill depression to determine types and } \\
\text { concentrations of hazardous substances onsite }\end{array}$ \\
\hline & PL-WS-2 & $\begin{array}{l}\text { Soil from area of stressed vegetation at depth of } 0.5^{\prime} \text { to determine types and } \\
\text { concentrations of hazardous substances onsite }\end{array}$ \\
\hline & PL-WS-3 & $\begin{array}{l}\text { Leachate from east side of ditch to determine types and concentrations of } \\
\text { hazardous substances onsite; also to detect observed release to surface water }\end{array}$ \\
\hline QA/QC & PL-WS-4D & Duplicate of PL-WS-3 \\
\hline
\end{tabular}

$-8-$ 


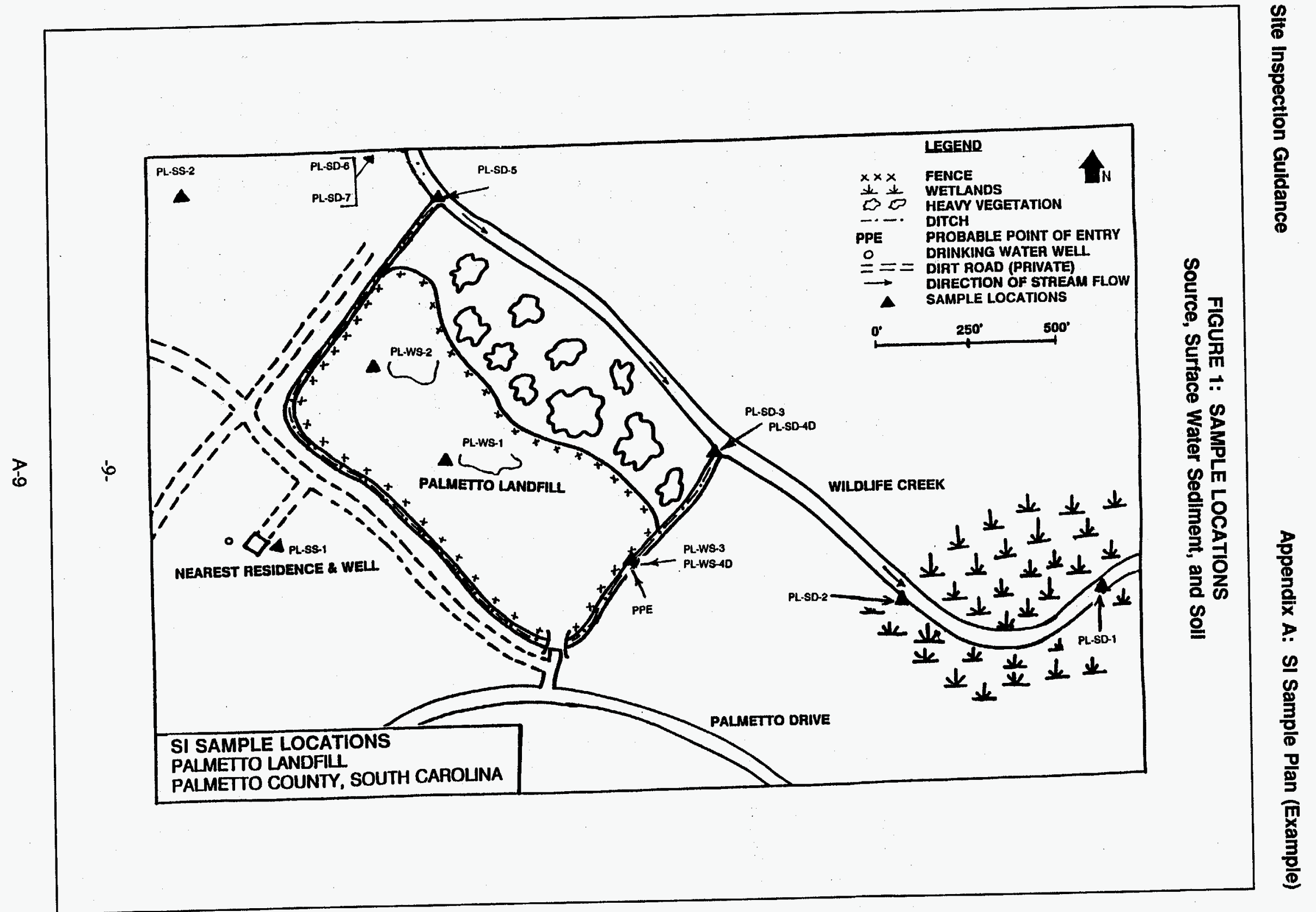




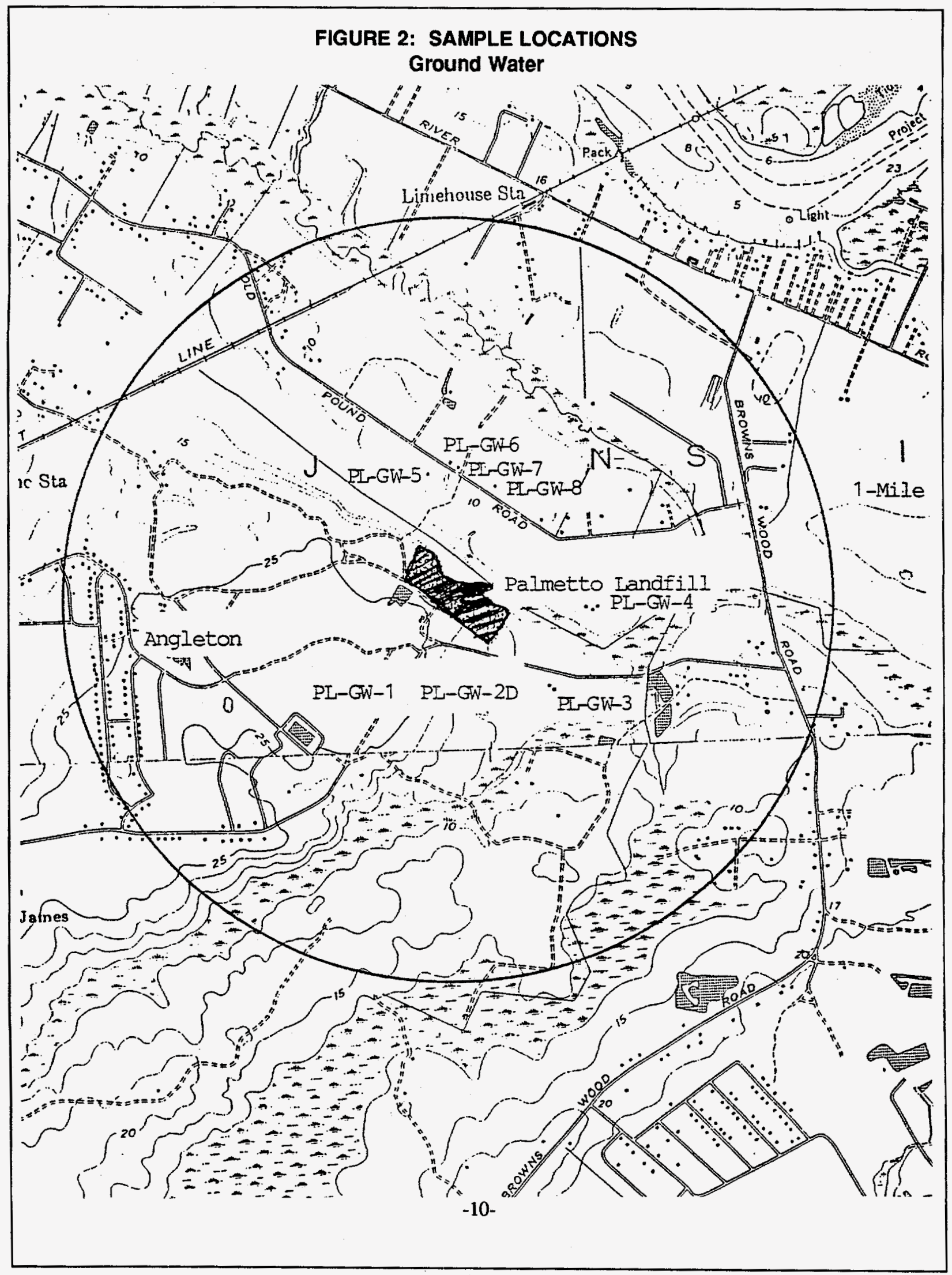


TABLE 2: COST SUMMARY

\begin{tabular}{|l|c|c||}
\hline \multicolumn{1}{|c|}{ TASK } & $\begin{array}{c}\text { ESTIMATED } \\
\text { TECHNICAL } \\
\text { HOURS }\end{array}$ & $\begin{array}{c}\text { COST } \\
\text { (@ \$ per } \\
\text { hour) }\end{array}$ \\
\hline Review PA and supporting materials & 30 & \\
\hline Prepare SI workplan & 50 & \\
\hline Obtain access; make advance arrangements & 20 & \\
\hline Collect site information from office & 40 & \\
\hline Travel to and from site and perform field work & 150 & \\
\hline Complete information gathering & 30 & \\
\hline Evaluate sample results & 40 & \\
\hline Prepare SI report and evaluate site score & 80 & \\
\hline $\begin{array}{l}\text { CLP analysis: } 21 \text { samples (17 environmental, } 3 \text { duplicates, } \\
1 \text { field blank) }\end{array}$ & & $\$ 25,200$ \\
\hline TOTAL & 440 & $\$$ \\
\hline
\end{tabular}




\section{APPENDIX B}

\section{SI DATA SUMMARY}

The investigator may use the SI Data Summary to compile analytical data and non-sampling information concerning the site. The Data Summary can be a checklist to:

- Summarize previous and newly-collected information

- Identify factors that have not been fully evaluated

- Focus additional data collection efforts

A completed SI Data Summary may facilitate entering data into PREscore or other SI scoring and HRS documentation tools.

Responses on the SI Data Summary need not be typed; legible handwriting is acceptable.

The Data Summary is not a mandatory requirement for SI reporting; EPA Regional guidelines may recommend using other mechanisms to summarize information collected during the $S I$ or to compile previous information about the site.

SI Data Summary entries marked with an asterisk (*) are optional during a focused SI. For pathways investigated during an expanded SI, all Data Summary entries should be completed.

If necessary, continuation pages to summarize additional analytical results should be photocopied and included with the Data Summary. A sample location map should be provided or referenced for all analytical results.

The last page of the Data Summary may be used to describe additional site information regarding a specific data element. In addition, this page may be used to describe or summarize site information that has not been collected, is not available, or is not well documented. 


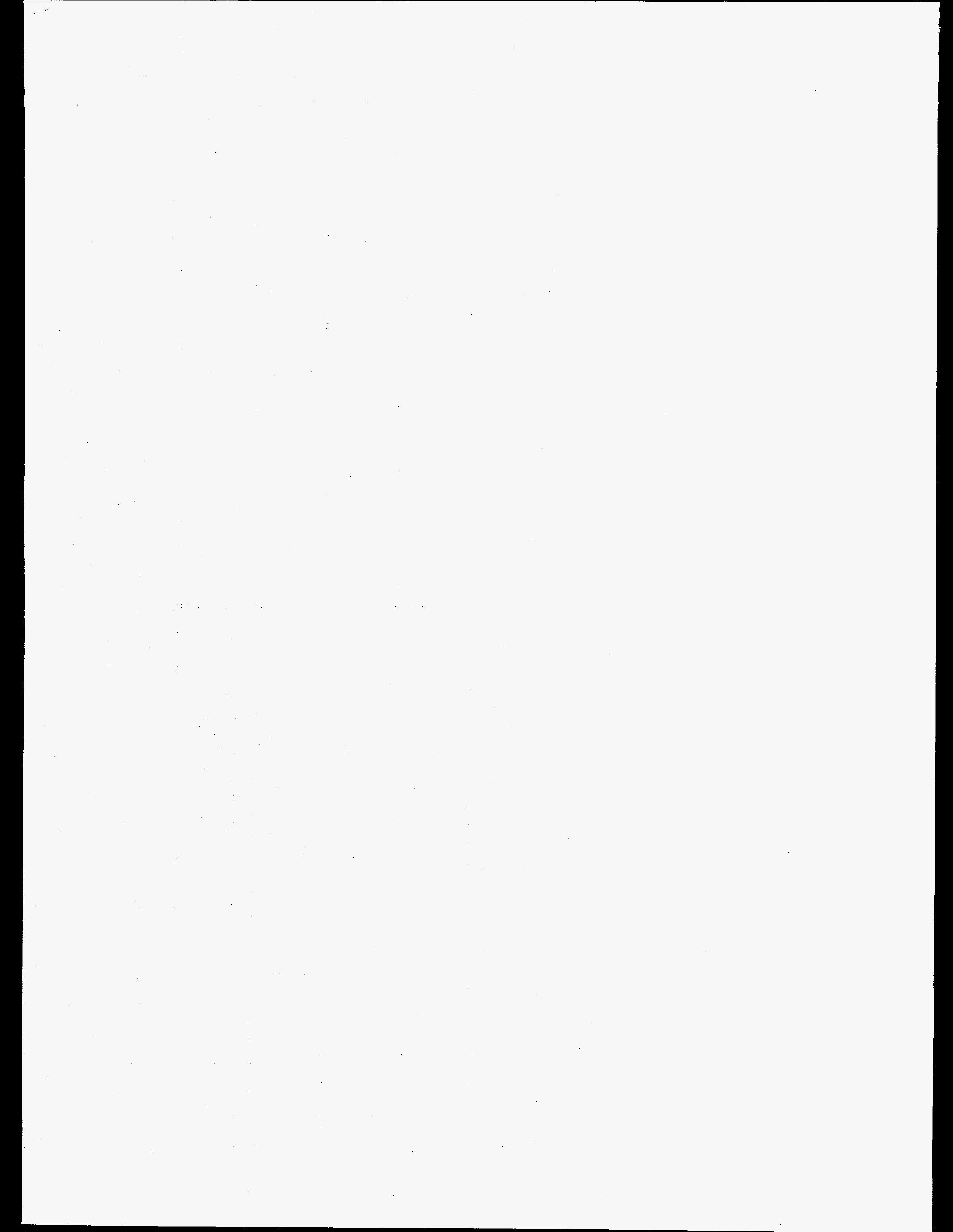




\section{GENERAL SITE INFORMATION}

1. CERCLIS ID No.

Address

City

County State Zip Code

Congressional District

2. Owner name

Owner address

City State
Operator name

Operator address

City

State

3. Type of ownership (check all that apply):

$\square$ Private $\square$ Federal/Agency

$\square$ Other

$\square$ State $\square$ County $\square$ Municipal Reference(s)

4. Approximate size of property: acres

Reference(s)

5. Latitude Longitude

Reference(s)

6. Site status: $\square$ Active $\square$ Inactive $\square$ Unknown

Reference(s)

7. Years of operation: From: to: $\square$ Unknown

Reference(s)

8. Previous investigations:

Type

Agency/State/Contractor

Date

Reference(s)

Reference(s)

Reference(s)

Reference(s)

Reference(s)

Reference(s) 


\section{WASTE SOURCE INFORMATION}

1. Waste source types (check all that apply)

$\square$ Constituent

$\square$ Wastestream (type)

$\square$ Landfill

$\square$ Drums

$\square$ Contaminated soil

$\square$ Land treatment

$\square$ Tanks or non-drum containers (type)

$\square$ Pile (type)

$\square$ Surface impoundment (buried)

$\square$ Surface impoundment (backfilled)

$\square$ Other

Reference(s)

2. Types of wastes (check all that apply)

$\square$ Organic chemicals

$\square$ Inorganic chemicals

$\square$ Municipal wastes

$\square$ Radionuclides

$\square$ Metals

$\square$ Pesticides/Herbicides

$\square$ Solvents

$\square$ Other

Reference(s)

3. Summarize history of waste disposal operations:

Reference(s) 
4. Source characterization (Attach pages to show quantity and calculations.)

Source 1 name:

Source type

Describe source:

Ground water migration containment:

Surface water migration containment:

Air migration (gas and migration) containment:

Physical state of wastes: $\square$ Liquid $\square$ Solid $\square$ Sludge/Slury $\square$ Gas $\square$ Unknown Constituent quantity of hazardous substances:

Wastestream quantity containing hazardous substances: Volume of source $\left(\mathrm{yd}^{3}\right)$ :

Area of source $\left(\mathrm{ft}^{2}\right)$ : (specify units) (specify units)

Hazardous substances associated with source 1:

Reference(s)

Source 2 name:

Source type

Describe source:

Ground water migration containment:

Surface water migration containment:

Air migration (gas and migration) containment:

Physical state of wastes: $\square$ Liquid $\square$ Solid $\square$ Sludge/Slurry $\square$ Gas $\square$ Unknown Constituent quantity of hazardous substances: (specify units)

Wastestream quantity containing hazardous substances:

Volume of source $\left(\mathrm{yd}^{3}\right)$ : Area of Source $\left(\mathrm{ft}^{2}\right)$ : (specify units)

Hazardous substances associated with source 2:
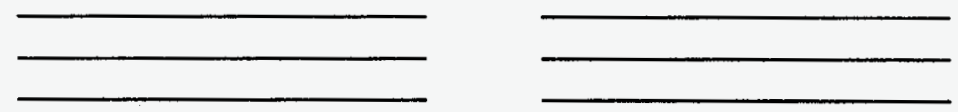

Reference(s) 
CONTINUATION PAGE FOR SOURCE CHARACTERIZATION

Source \# Name

Source type

Describe source:

Ground water migration containment:

Surface water migration containment:

Air migration (gas and migration) containment:

Physical state of wastes: $\square$ Liquid $\square$ Solid $\square$ Sludge/Slurry $\square$ Gas $\square$ Unknown Constituent quantity of hazardous substances:

Wastestream quantity containing hazardous substances:

Volume of source $\left(\mathrm{yd}^{3}\right)$ :

Area of source $\left(\mathrm{ft}^{2}\right)$ :

Hazardous substances associated with source \#

Reference(s)

Source \# Name

Source type

Describe source:

Ground water migration containment:

Surface water migration containment:

Air migration (gas and migration) containment:

Physical state of wastes: $\square$ Liquid $\square$ Solid $\square$ Sludge/Slurry $\square$ Gas $\square$ Unknown Constituent quantity of hazardous substances:

Wastestream quantity containing hazardous substances:

Volume of source $\left(y d^{3}\right)$ :

Area of source $\left(\mathrm{ft}^{2}\right)$ :

Hazardous substances associated with source \#

Reference(s) 
5. Description of removal or remedial activities

If a removal has occurred, identify the removal authority and describe the activities. Specify the date(s) of the removal.

Reference(s) 


\section{GROUND WATER INFORMATION}

1. Ground water drinking water use within 4 miles of site sources:

$\square$ Municipal $\square$ Private $\square$ Both $\square$ No Drinking Water Use

Reference(s)

2. Is ground water contaminated?

$\square$ Yes $\square$ No $\square$ Uncertain but likely $\square$ Uncertain but not likely

$\square$ Additional sampling required

Is analytical evidence available?

$\square$ Yes $\square$ No

Reference(s)

3. Is ground water contamination attributable to the site?

$\square$ Yes $\square$ No $\square$ Additional sampling required

Reference(s)

4. Are drinking water wells contaminated?

$\square$ Yes $\square$ No $\square$ Uncertain but likely $\square$ Uncertain but not likely

$\square$ Additional sampling required

Is analytical evidence available? $\square$ Yes $\square$ No

Reference(s)

5.* Net precipltation (HRS Section 3.1.2.2): inches

Reference(s)

6. County average number of persons per residence: Reference(s)

7. Discuss general stratigraphy underlying the site. Attach sketch of stratigraphic column.

Reference(s)

8. Using Table GW-1 (next page), summarize geology underlying the site (starting with formation \#1 as closest to ground surface). Indicate if formation is interconnected with overlying formation. 
TABLE GW-1: SITE GEOLOGY

\begin{tabular}{|l|c|c|c|c|c|}
\hline NAME OF FORMATION & $\begin{array}{c}\text { INTER- } \\
\text { CONNECT? } \\
\text { (Yes/no) }\end{array}$ & $\begin{array}{c}\text { TYPE OF } \\
\text { MATERIAL }\end{array}$ & $\begin{array}{c}\text { AVERAGE } \\
\text { THICKNESS } \\
\text { (FEET) }\end{array}$ & $\begin{array}{c}\text { HYDRAULIC } \\
\text { CONDUCTIVITY } \\
\text { (CM/SEC) }\end{array}$ & $\begin{array}{c}\text { USED FOR } \\
\text { DRINKING } \\
\text { WATER? }\end{array}$ \\
\hline 1. & & & & & \\
\hline 2. & & & & & \\
\hline 3. & & & & & \\
\hline 4. & & & & & \\
\hline 5. & & & & & \\
\hline 6. & & & & & \\
\hline
\end{tabular}

Reference(s)

9. Does a karst aquifer underlie any site source?

$\square$ Yes $\square$ No

Reference(s)

10. Depth to top of aquifer: feet Elevation:

Reference(s)

11. In the table below, enter the number of people obtaining drinking water from wells located within 4 miles of the site. For each aquifer, attach population calculation sheets. Key aquifer to formations listed in Table GW-1.

POPULATION SERVED BY WELLS WITHIN DISTANCE CATERGORIES BY AQUIFER

\begin{tabular}{|c|l|l|l|}
\hline $\begin{array}{c}\text { DISTANCE OF WELL(S) } \\
\text { FROM SITE SOURCES }\end{array}$ & $\begin{array}{c}\text { AQUIFER A: INCLUDES } \\
\text { FORMATIONS }\end{array}$ & $\begin{array}{c}\text { AQUIFER B: INCLUDES } \\
\text { FORMATIONS }\end{array}$ & $\begin{array}{l}\text { AQUIFER C: INCLUDES } \\
\text { FORMATIONS }\end{array}$ \\
\hline $1 / 4$ mile or less & & & \\
\hline$>1 / 4$ to $1 / 2$ mile & & & \\
\hline$>1 / 2$ to 1 mile & & & \\
\hline$>1$ to 2 miles & & & \\
\hline$>2$ to 3 miles & & & \\
\hline$>3$ to 4 miles & & & \\
\hline
\end{tabular}

Reference(s)

12. Is ground water from multiple wells blended prior to distribution?

$\square$ Yes $\square$ No

Reference(s) 
13. Is ground water blended with surface water?

$\square$ Yes $\square$ No

Briefly describe:

14. Distance from any incompletely contained source available to ground water to nearest drinking water well (HRS Section 3.3.1): feet Reference(s)

15. Briefly describe standby drinking water wells within 4 miles of sources at the site:

Reference(s)

16. Using Table GW-2, summarize ground water analytical results for all sampling Investigations. Include and identify background ground water sample results.

17.* Ground water resources within 4 miles of slte sources (HRS Section 3.3.3):

$\square$ Irrigation (5-acre minimum) of commercial food or commercial forage crops

$\square$ Commercial livestock watering

$\square$ Ingredient in commercial food preparation

$\square$ Supply for commercial aquaculture

$\square$ Supply for major or designated water recreation area, excluding drinking water use

$\square$ Water usable for drinking water but no drinking water wells are within 4 miles

$\square$ None of the above

Reference(s)

18. Wellhead protection area (WHPA) within 4 miles of slte sources (HRS Section 3.3.4):

$\square$ Source with non-zero containment factor value lies within or above WHPA

O Observed ground water contamination attributable to site source(s) lies within WHPA

$\square$ WHPA lies within 4 miles of site sources

$\square$ None

Reference(s)

Additional ground water pathway description:

References(s) 


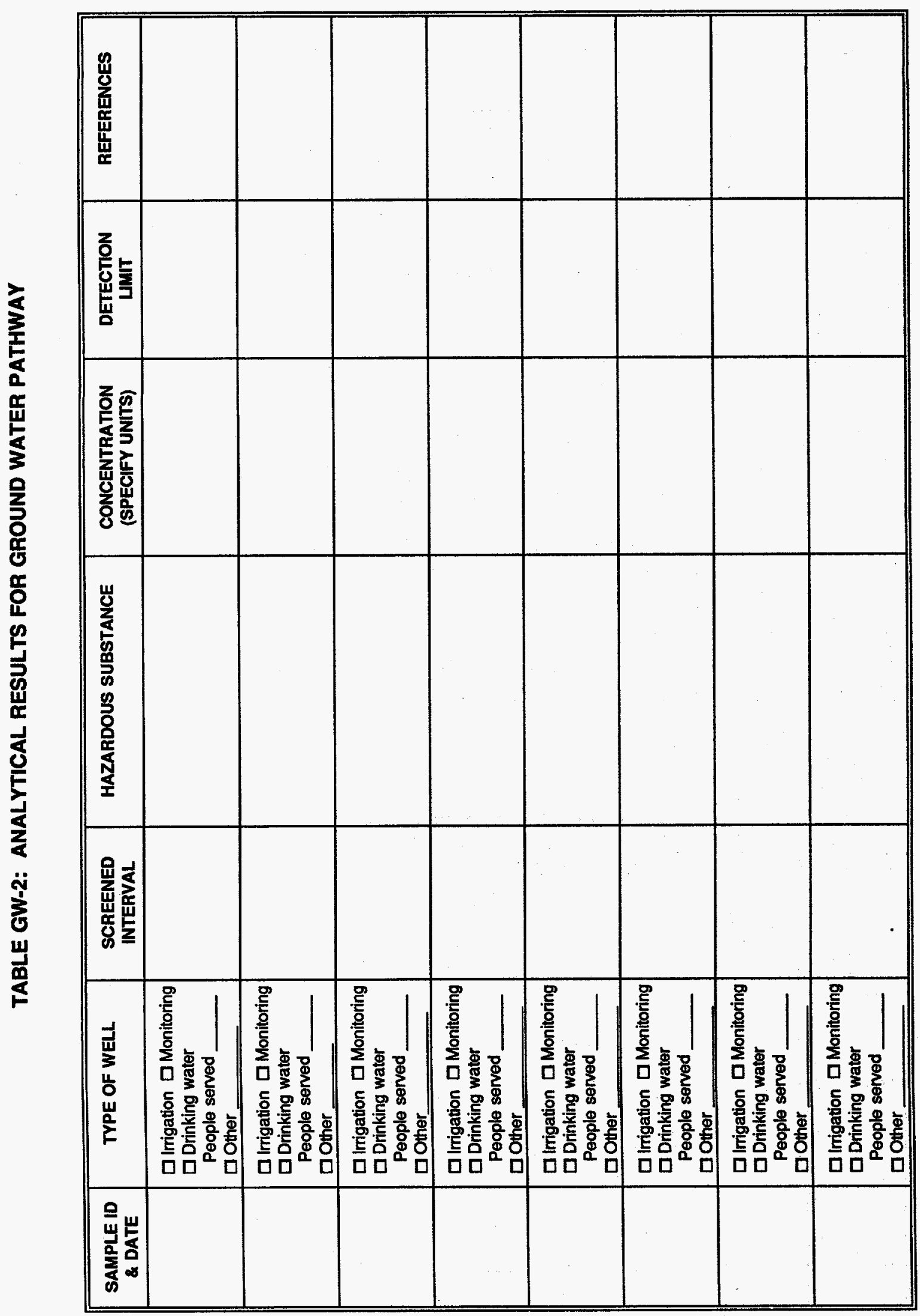




\section{SURFACE WATER INFORMATION}

Complete this section of the data summary for each watershed if there are multiple watersheds. Photocopy this page if necessary.

1. Describe surface water migration path from site sources to at least $\mathbf{1 5}$ miles downstream. Attach a sketch of the surface water migration route.

Reference(s)

2. Is surface water contaminated?

$\square$ Yes $\square$ No $\square$ Uncertain but likely $\square$ Uncertain but not likely

Is analytical evidence available? $\square$ Yes $\square$ No

Additional sampling required Reference(s)

3. Is surface water contamination attributable to the site?

$\square$ Yes $\square$ No $\square$ Additional sampling required

Reference(s)

4. Floodplain category in which slte sources are located (check all that apply):
$\square$ 1-year
$\square$ 10-year
$\square$ 100-year
$\square 500$-year $\square$ None
Reference(s)

5. Describe flood containment for each source (HRS Section 4.1.2.1.2.2):

Source \#1

Flood containment

Source \#2 Flood containment

Source \#3 Flood containment

Source \# Flood containment

Source \# Flood containment

Source \# Flood containment

Source \# Flood containment

Reference(s)

6. Shortest overland dlstance to surface water from any source (HRS Section 4.1.2.1.2.1.3): feet

Reference(s)

7.* Size of drainage area (HRS Section 4.4.3): Acres

Reference(s) 
8.* Describe predominant soil group within the drainage area (HRS Section 4.1.2.1.2.1.2).

Reference(s)

9.* 2-year 24-hour rainfall (HRS Section 4.1.2.1.2.1.2): inches

Reference(s)

$10 .^{\star}$ Elevation of the bottom of nearest surface water body: feet above sea level

Reference(s)

11. ${ }^{*}$ Elevation of top of uppermost aquifer:

feet above sea level

Reference(s)

12. Predominant type of water body between probable point of entry to surface water and nearest drinking water intake:
$\square$ River
$\square$ Lake
Reference(s)

13. Identify all drinking water intakes, fisheries, and sensitive environments within $\mathbf{1 5}$ miles downstream.

\begin{tabular}{|l|l|l|l|l|l||}
\hline TARGET NAMETYPE & $\begin{array}{c}\text { WATER } \\
\text { BODY TYPE }\end{array}$ & $\begin{array}{c}\text { DISTANGE } \\
\text { FROM PPE }\end{array}$ & $\begin{array}{c}\text { FLOW } \\
\text { (CFS) }\end{array}$ & $\begin{array}{c}\text { TARGET } \\
\text { CHARACTERISTICS' }\end{array}$ & $\begin{array}{c}\text { TARGET } \\
\text { SAMPLED? }\end{array}$ \\
\hline & & & & & \\
\hline & & & & & \\
\hline & & & & & \\
\hline & & & & & \\
\hline & & & & & \\
\hline
\end{tabular}

${ }^{1}$ If target is a drinking water intake, provide number of people served by intake.

If target is a fishery, provide species and annual production of human food chain organisms

(pounds per year).

If target is a wetland, specify wetland frontage (in miles). Attach calculation pages.

Reference(s)

14. Is surface water drinking water blended prior to distribution?

$\square$ Yes $\square$ No

Reference(s) 
15. Describe any standby drinking water intakes within 15 miles downstream.

Reference(s)

16. ${ }^{*}$ Surface water resources within 15 miles downstream (HRS Section 4.1.2.3.3):

$\square$ Irrigation (5-acre minimum) of commercial food or commercial forage crops

$\square$ Commercial livestock watering

$\square$ Ingredient in commercial food preparation

$\square$ Major or designated water recreation area, excluding drinking water use

$\square$ Water designated by the state for drinking water use but is not currently used

$\square$ Water usable for drinking water but no drinking water intakes within 15 miles downstream

$\square$ None of the above

Reference(s)

17. Using Table SW-1, summarize surface water analytical results for all sampling investigations. Include and identify background sample results. 
TABLE SW-1: SUMMARY OF ANALYTICAL RESULTS FOR SURFACE WATER PATHWAY

\begin{tabular}{|c|c|c|c|c|c|c|c|}
\hline $\begin{array}{c}\text { SAMPLE ID } \\
\text { \& DATE }\end{array}$ & $\begin{array}{c}\text { SAMPLE } \\
\text { TYPE }\end{array}$ & SAMPLE OBJECTIVE & $\begin{array}{l}\text { TARGET } \\
\text { NAME }\end{array}$ & $\begin{array}{l}\text { HAZARDOUS } \\
\text { SUBSTANCE }\end{array}$ & $\begin{array}{l}\text { CONCENTRATION } \\
\text { (SPECIFY UNITS) }\end{array}$ & $\begin{array}{l}\text { DETECTION } \\
\text { UMIT } \\
\end{array}$ & REFERENCES \\
\hline & $\begin{array}{l}\square \text { Aqueous } \\
\square \text { Sediment } \\
\square \text { Other }\end{array}$ & $\begin{array}{l}\text { QRelease पFishery } \\
\square \text { Drinking water } \\
\square \text { Sensitive environment } \\
\text { Distance from PPE }\end{array}$ & & & & & \\
\hline & $\begin{array}{l}\square \text { Aqueous } \\
\square \text { Sediment } \\
\square \text { Other }\end{array}$ & $\begin{array}{l}\text { QRelease 口 Fishery } \\
\square \text { Drinking water } \\
\square \text { Sensitive environment } \\
\text { Distance from PPE }\end{array}$ & & & & & \\
\hline & $\begin{array}{l}\text { 口Aqueous } \\
\square \text { Sediment } \\
\square \text { Other }\end{array}$ & $\begin{array}{l}\text { 口Release } \square \text { Fishery } \\
\text { Q Drinking water } \\
\square \text { Sensitive environment } \\
\text { Distance from PPE }\end{array}$ & & & & & \\
\hline & $\begin{array}{l}\square \text { Aqueous } \\
\square \text { Sediment } \\
\square \text { Other }\end{array}$ & $\begin{array}{l}\square \text { Release } \square \text { Fishery } \\
\square \text { Drinking water } \\
\square \text { Sensitive environment } \\
\text { Distance from PPE }\end{array}$ & & & & & \\
\hline & $\begin{array}{l}\square \text { Aqueous } \\
\square \text { Sediment } \\
\square \text { Other }\end{array}$ & $\begin{array}{l}\square \text { Release } \square \text { Fishery } \\
\square \text { Drinking water } \\
\square \text { Sensitive environment } \\
\text { Distance from PPE }\end{array}$ & & & & & \\
\hline & $\begin{array}{l}\square \text { Aqueous } \\
\square \text { Sediment } \\
\square \text { Other }\end{array}$ & $\begin{array}{l}\square \text { Release } \square \text { Fishery } \\
\square \text { Drinking water } \\
\square \text { Sensitive environment } \\
\text { Distance from PPE }\end{array}$ & & & & & \\
\hline & $\begin{array}{l}\text { पAqueous } \\
\square \text { Sediment } \\
\square \text { Other }\end{array}$ & $\begin{array}{l}\text { QRelease } \square \text { Fishery } \\
\text { Q Drinking water } \\
\square \text { Sensitive environment } \\
\text { Distance from PPE }\end{array}$ & & & & & \\
\hline & $\begin{array}{l}\square \text { Aqueous } \\
\square \text { Sediment } \\
\square \text { Other }\end{array}$ & $\begin{array}{l}\text { QRelease } \square \text { Fishery } \\
\square \text { Drinking water } \\
\square \text { Sensitive environment } \\
\text { Distance from PPE }\end{array}$ & & & & & \\
\hline & $\begin{array}{l}\square \text { Aqueous } \\
\square \text { Sediment } \\
\square \text { Other }\end{array}$ & $\begin{array}{l}\square \text { Release } \square \text { Fishery } \\
\square \text { Drinking water } \\
\text { Q Sensitive environment } \\
\text { Distance from PPE } \\
\end{array}$ & & & & & \\
\hline
\end{tabular}




\section{SOIL INFORMATION}

1. Is surficial or soil contamination present at the site?

$\square$ Yes $\square$ No $\square$ Uncertain but likely $\square$ Uncertain but not likely

$\square$ Additional sampling required

Is analytical evidence available? $\square$ Yes $\square$ No

Reference(s)

2. Is surficial or soil contamination attributable to the site?

$\square$ Yes $\square$ No $\square$ Additional sampling required

3. Is surficial contamination on the property and within 200 feet of a residence, school, daycare center, or workplace?

$\square$ Yes $\square$ No $\square$ Uncertain but likely $\square$ Uncertain but not likely

$\square$ Additional sampling required

Is analytical evidence available? $\square$ Yes $\square$ No

Reference(s)

4.* Total area of surficlal contamination (HRS Section 5.2.1.2): square feet

Reference(s)

5.* Attractiveness/accessibility of the areas of observed contamination (HRS Section 5.2.1.1). Check all that apply:

$\square$ Designated recreational area

$\square$ Used regularly, or accessible and unique recreational area

$\square$ Moderately accessible with some use

$\square$ Slightly accessible with some use

$\square$ Accessible with no use

$\square$ Inaccessible with some use

Inaccessible with no use

Reference(s)

6. Using Table SE-1, summarize analytical results detecting surficial contamination within 200 feet of a residence, school, daycare center, or workplace. Include and identify background sample results.

7. Using Table SE-2, summarize analytical results detecting surficial contamination within the boundary of a resource or a terrestrial sensitive environment. Include and identify background sample results if not listed in Table SE-1.

8. Population within 1-mile travel distance from site. Do not include populations from Table SE-1.

\begin{tabular}{|l|l|}
\hline DISTANCE FROM SITE SOURCES & POPULATION \\
\hline $1 / 4$ mile or less & \\
\hline$>1 / 4$ to $1 / 2$ mile & \\
\hline$>1 / 2$ to 1 mile & \\
\hline
\end{tabular}

Reference(s) 
TABLE SE-1: ANALYTICAL RESULTS FOR SOIL EXPOSURE PATHWAY

\begin{tabular}{|c|c|c|c|c|c|c|c|}
\hline $\begin{array}{c}\text { SAMPLE ID } \\
\text { DATE }\end{array}$ & $\begin{array}{l}\text { SAMPLE } \\
\text { DEPTH }\end{array}$ & TYPE OF PROPERTY & POPULATION & $\begin{array}{l}\text { HAZARDOUS } \\
\text { SUBSTANCE }\end{array}$ & $\begin{array}{l}\text { CONCENTRATION } \\
\text { (SPECIFY UNITS) }\end{array}$ & $\begin{array}{l}\text { DETECTION } \\
\text { UMIT }\end{array}$ & REFERENCES \\
\hline & & $\begin{array}{l}\text { 口Residence Q School } \\
\text { a Daycare center } \\
\square \text { Workplace }\end{array}$ & & & & & \\
\hline & & $\begin{array}{l}\text { 口Residence a School } \\
\text { 口 Daycare center } \\
\text { QWorkolace }\end{array}$ & & & & & \\
\hline & & $\begin{array}{l}\text { QResidence DSchool } \\
\text { Q Daycare center } \\
\text { aWorkplace }\end{array}$ & & & & & \\
\hline & & 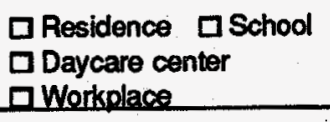 & & & & & \\
\hline & & $\begin{array}{l}\text { 口Residence a School } \\
\text { a Daycare center } \\
\text { a Workplace }\end{array}$ & & & & & \\
\hline & & $\begin{array}{l}\text { 口Residence 口School } \\
\text { 口 Daycare center } \\
\text { QWorkplace }\end{array}$ & & & & & \\
\hline & & $\begin{array}{l}\text { 口Residence uschool } \\
\text { 口 Daycare center } \\
\text { a Workplace }\end{array}$ & & & & & \\
\hline & & $\begin{array}{l}\square \text { Residence } \square \text { School } \\
\square \text { Daycare center } \\
\square \text { Workplace }\end{array}$ & & & & & \\
\hline
\end{tabular}


TABLE SE-2: ANALYTICAL RESULTS FOR SOIL EXPOSURE PATHWAY

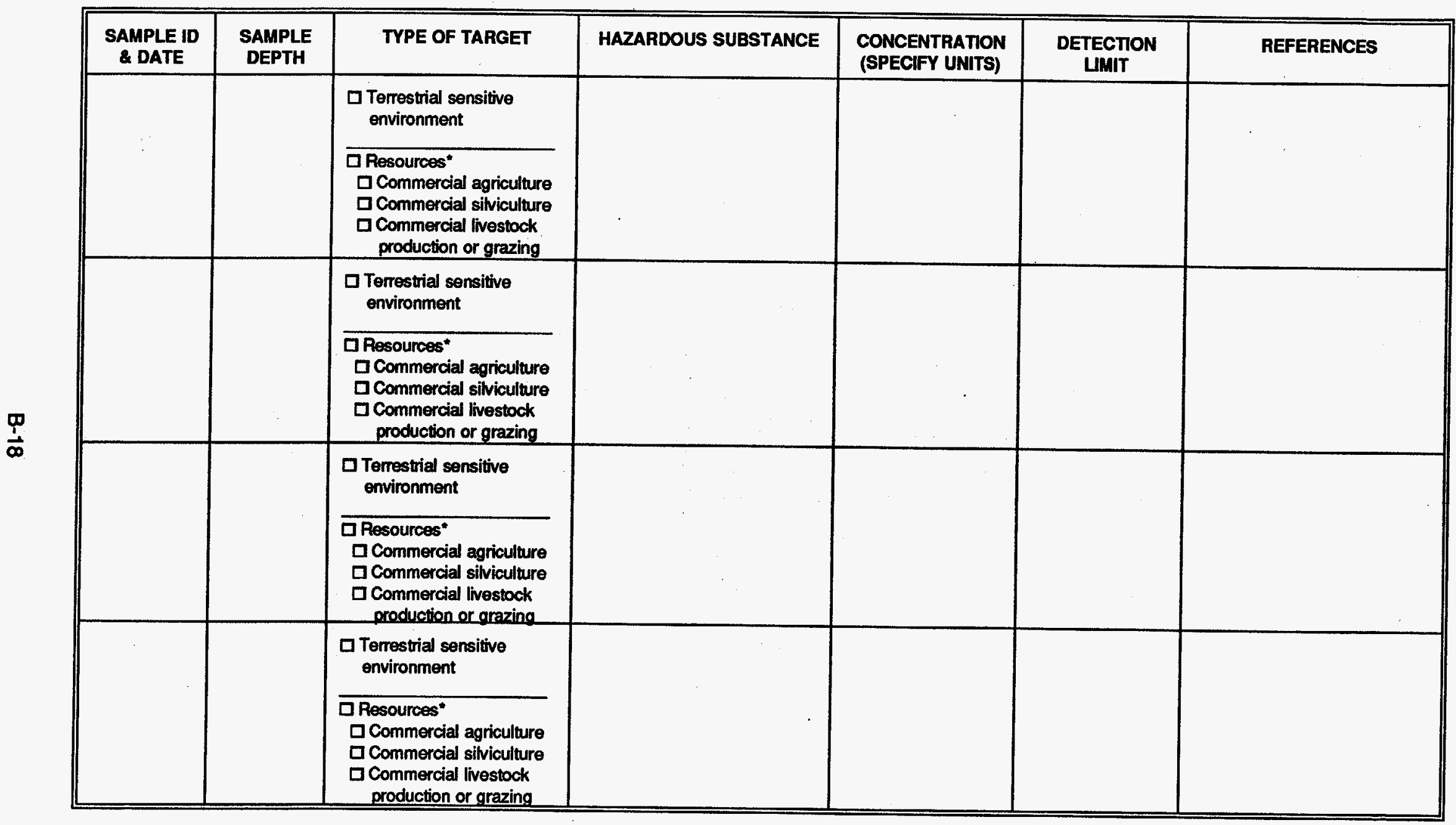




\section{AIR INFORMATION}

1. Is air contamination present at the site?

$\square$ Yes $\square$ No $\square$ Uncertain but likely $\square$ Uncertain but not likely

$\square$ Additional sampling required

Is analytical evidence available? $\square$ Yes $\square$ No Reference(s)

2. Is alr contamination attributable to the site?

$\square$ Yes $\square$ No $\square$ Additional sampling required

3. Are populations, sensitive environments, or wetlands exposed to airborne hazardous substances released from the site?

$\square$ Yes $\square$ No $\square$ Uncertain but likely $\square$ Uncertain but not likely

$\square$ Additional sampling required

Is analytical evidence available? $\square$ Yes $\square$ No Reference(s)

4. Evidence of biogas release from any of the following source types at the site:

$\square$ Below-ground containers or tanks $\square$ Landfill $\square$ Buried surface impoundment

Reference(s)

5.* Particulate migration potential factor value: (HRS Figure 6-2)

6.* Particulate mobility factor value: (HRS Figure 6-3)

7. Distance from any incompletely contained source to nearest residence or regularly occupled area: miles

Reference(s)

8. Population within $\mathbf{4}$ miles of site sources.

\begin{tabular}{|l|l|}
\hline DISTANCE FROM SITE SOURCES & POPULATION \\
\hline 0 (within site sources) & \\
\hline $1 / 4$ mile or less & \\
\hline$>1 / 4$ to $1 / 2$ mile & \\
\hline$>1 / 2$ to 1 mile & \\
\hline$>1$ to 2 miles & \\
\hline$>2$ to 3 miles & \\
\hline$>3$ to 4 miles & \\
\hline
\end{tabular}

Reference(s)

9." Resources within $1 / 2$ mlle of site sources (HRS Section 6.3.3):

$\square$ Commercial agriculture

$\square$ Commercial silviculture

$\square$ Major or designated recreation area

$\square$ None of the above

Reference(s) 
10. Sensitive environments and wetlands within 4 miles of the site.

\begin{tabular}{|c|l|l|l|}
\hline $\begin{array}{c}\text { NAME/DESCRIPTION/LOCATION OF } \\
\text { SENSITIVE ENVIRONMENT OR } \\
\text { WETLAND }\end{array}$ & $\begin{array}{c}\text { DISTANCE FROM } \\
\text { SITE (MILES) }\end{array}$ & $\begin{array}{c}\text { TYPE OF SENSITIVE } \\
\text { ENVIRONMENT }\end{array}$ & $\begin{array}{c}\text { WETLAND SIZE } \\
\text { (ACRES) }\end{array}$ \\
\hline & & & \\
\hline & & & \\
\hline & & & \\
\hline & & & \\
\hline & & & \\
\hline
\end{tabular}

Reference(s)

11. Using Table Air-1, summarize air analytical results for all sampling investigations. Include and identify background sample results. 
TABLE AIR-1: SUMMARY OF ANALYTICAL RESULTS FOR AIR PATHWAY

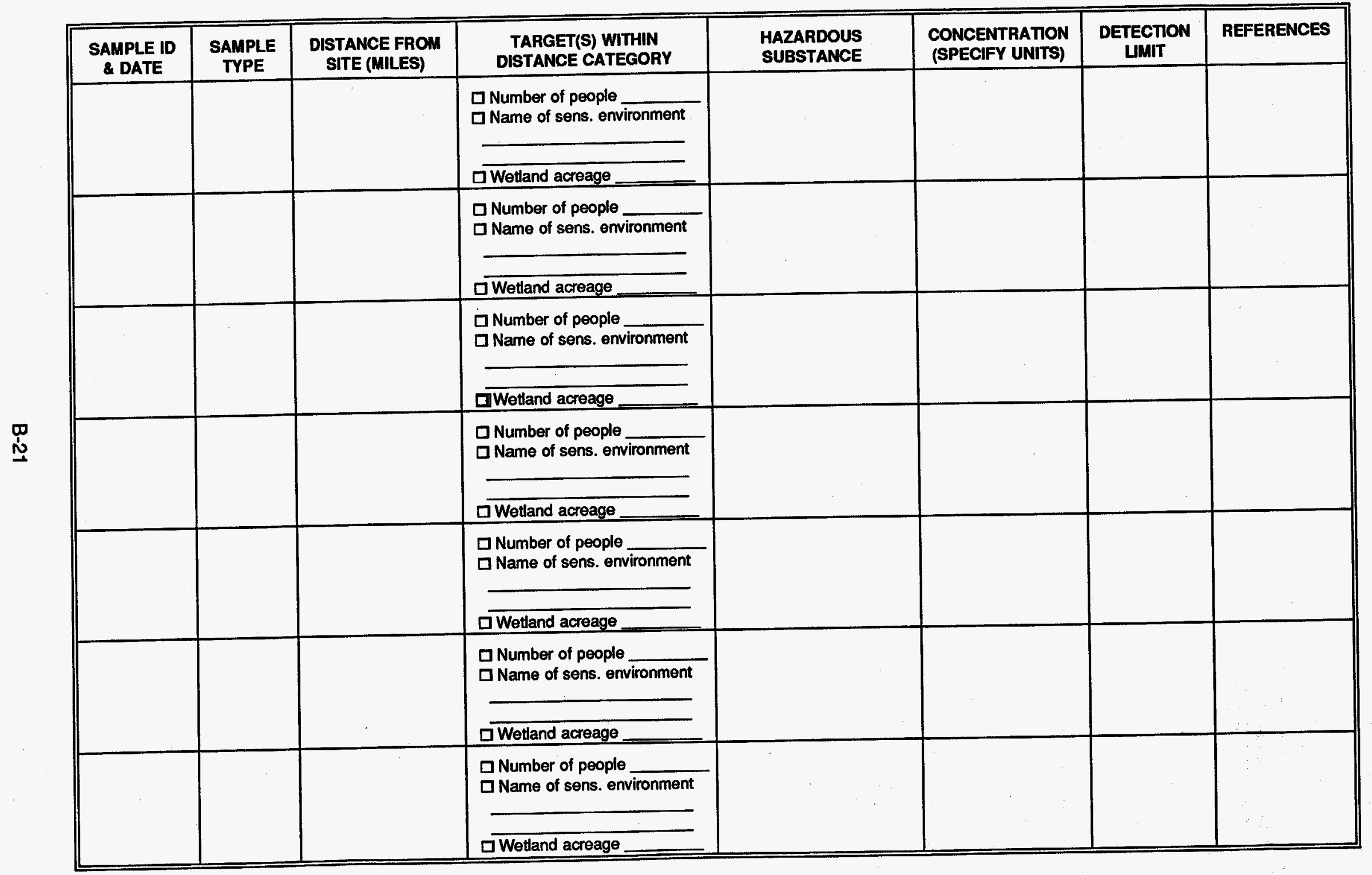


Reference(s) 


\section{APPENDIX C}

\section{SITE INSPECTION WORKSHEETS}

This appendix consists of worksheets that can be used to generate an SI site score. Completion of these worksheets is not required, but the SI investigator must evaluate an SI score, either by these worksheets, PREscore, or other Regional scoring tools.

The worksheets consist of instructions and data tables to be filled in with scores from HRS reference tables. The data tables may also call for Data Type and References.

DATA TYPE: The Data Type columns should be filled in with an $\mathbf{H}, \mathbf{Q}$, or + if the data are HRS quality and well documented. The Data Type column should be filled in with an $\mathbf{E}, \mathbf{X}$, or - if the data represent estimates, approximations, or are not fully documented. This type identifies data gaps for the expanded SI to investigate.

REFERENCES: The Reference columns should be filled in with coded reference numbers. The numbered reference list should be attached or the numbering should be cross-referenced to the SI Narrative Report.

The SI investigator will need the current Superfund Chemical Data Matrix (SCDM) OSWER Directive 9345.1-13 (revised semi-annually) to complete these worksheets. 



\section{SITE INSPECTION WORKSHEETS}

CERCLIS IDENTIFICATION NUMBER

SITE LOCATION

STTE NAME: LEGAL, COMMON, OR DESCRIPTIVE NAME OF STIE

STREET ADDRESS, ROUTE, OR SPECIFIC LOCATION IDENTIFIER

\begin{tabular}{|l|l|l|l|}
\hline CITY & STATE & ZIP CODE & $\begin{array}{l}\text { TELEPHONE } \\
(i)\end{array}$ \\
\hline COORDINATES: LATTUDE and LONGITUDE & TOWNSHIP, RANGE, AND SECTION \\
\hline
\end{tabular}

\begin{tabular}{|c|c|c|c|c|c|}
\hline \multicolumn{6}{|c|}{ OWNER/OPERATOR IDENTIFICATION } \\
\hline \multicolumn{3}{|l|}{ OWNER } & \multicolumn{3}{|c|}{ OPERATOR } \\
\hline \multicolumn{3}{|c|}{ OWNER ADDRESS } & \multicolumn{3}{|c|}{ OPERATOR ADDRESS } \\
\hline \multicolumn{3}{|l|}{ CITY } & \multicolumn{3}{|l|}{ CITY } \\
\hline STATE & ZIP CODE & $\begin{array}{l}\text { TELEPHONE } \\
\left(\begin{array}{c}()\end{array}\right.\end{array}$ & STATE & ZIP CODE & $\begin{array}{l}\text { TELEPHONE } \\
\left(\begin{array}{c}()\end{array}\right.\end{array}$ \\
\hline
\end{tabular}

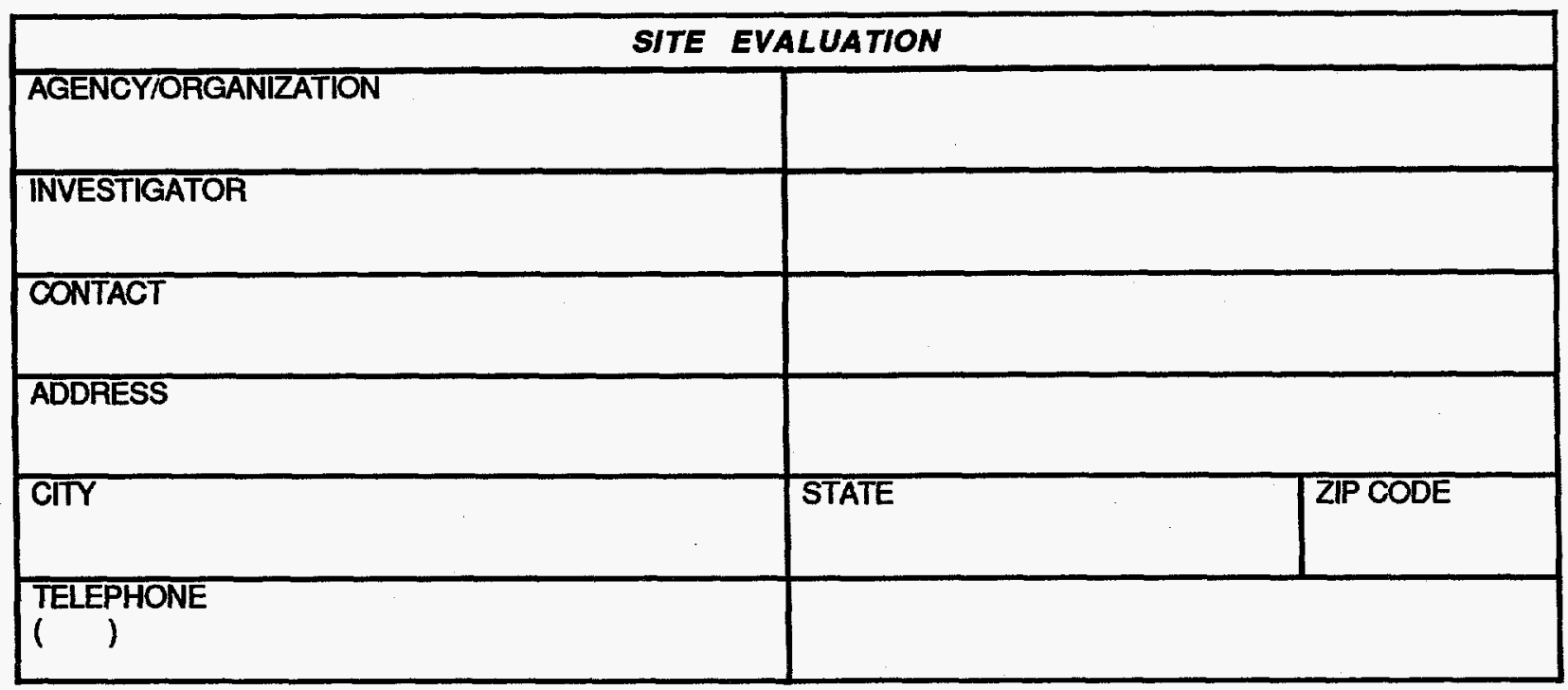




\section{GENERAL INFORMATION}

Site Description and Operational HIstory: Provide a brief description of the site and its operational history. State the site name, owner, operator, type of facility and operations, size of property, active or inactive status, and years of waste generation. Summarize waste treatment, storage, or disposal activities that have or may have occurred at the site; note whether these activities are documented or alleged. Identify all source types and prior spills, floods, or fires. Summarize highlights of the PA and other investigations. Cite references. 


\section{GENERAL INFORMATION (continued)}

Slie Sketch: Provide a sketch of the site. Indicate all pertinent features of the site and nearby environments including sources of wastes, areas of visible and buried wastes, buildings, residences, access roads, parking areas, fences, fields, drainage pattems, water bodies, vegetation, wells, sensitive environments, and other features. 


\section{GENERAL INFORMATION (continued)}

Source Descriptions: Describe all sources at the site. Identify source type and relate to waste disposal operations. Provide source dimensions and the best available waste quantity information. Describe the condition of sources and all containment structures. Cite references.

\section{SOURCE TYPES}

Landfill: A man-made (by excavation or construction) or natural hole in the ground into which wastes have come to be disposed by backfilling, or by contemporaneous soil deposition with waste disposal.

Surface Impoundment: A natural topographic depression, man-made excavation, or diked area, primarily formed from earthen materials (lined or unlined) and designed to hold an accumulation of liquid wastes, wastes containing free liquids, or sludges not backfilled or othenwise covered; depression may be wet with exposed liquid or dry if deposited liquid has evaporated, volatilized or leached; structures that may be described as lagoon, pond, aeration pit, settling pond, tailings pond, sludge pit; also a surface impoundment that has been covered with soil after the final deposition of waste materials (i.e., buried or backfilled).

Drum: A portable container designed to hold a standard 55-gallon volume of wastes.

Tank and Non-Drum Container: Any device, other than a drum, designed to contain an accumulation of waste that provides structural support and is constructed primarily of fabricated materials (such as wood, concrete, steel, or plastic); any portable or mobile device in which waste is stored or otherwise handled.

Contaminated Soil: An area or volume of soil onto which hazardous substances have been spilled, spread, disposed, or deposited.

Plle: Any non-containerized accumulation above the ground surface of solid, non-flowing wastes; includes open dumps. Some types of waste piles are:

- Chemical Waste Pile:

- Scrap Metal or Junk Pile:

- Tailings Pile:

- Trash Pile:
A pile consisting primarily of discarded chemical products, byproducts, radioactive wastes, or used or unused feedstocks.

A pile consisting primarily of scrap metal or discarded durable goods (such as appliances, automobiles, auto parts, batteries, etc.) composed of materials containing hazardous substances.

A pile consisting primarily of any combination of overburden from a mining operation and tailings from a mineral mining, beneficiation, or processing operation.

A pile consisting primarily of paper, garbage, or discarded nondurable goods containing hazardous substances.

Land Treatment: Landfarming or other method of waste management in which liquid wastes or sludges are spread over land and tilled, or liquids are injected at shallow depths into soils.

Other: Sources not in categories listed above. 


\section{GENERAL INFORMATION (continued)}

Source Description: Include description of containment per pathway for ground water (see HRS Table 3-2), surface water (see HRS Table 4-2), and air (see HRS Tables 6-3 and 6-9).

Hazardous Waste Quantity (HWQ) Calculation: SI Tables 1 and 2 (See HRS Tables 2-5, 2-6, and 5-2). 
SI TABLE 1: HAZARDOUS WASTE QUANTITY (HWQ) SCORES FOR SINGLE SOURCE SITES AND FORMULAS FOR MULTIPLE SOURCE SITES

\begin{tabular}{|c|c|c|c|}
\hline & & $\begin{array}{r}\text { SIn } \\
\text { (ass) }\end{array}$ & $\begin{array}{l}\text { Source Sites } \\
\text { d HWQ scores) }\end{array}$ \\
\hline $\begin{array}{c}\text { (Column } 1 \text { ) } \\
\text { TIER } \\
\end{array}$ & $\begin{array}{l}\text { (Column 2) } \\
\text { Source Type }\end{array}$ & $\begin{array}{l}\text { (Column 3) } \\
H W Q=10\end{array}$ & $\begin{array}{l}\text { (Column 4) } \\
H W Q=100\end{array}$ \\
\hline $\begin{array}{c}\text { A } \\
\text { Hazardous } \\
\text { Constituent } \\
\text { Quantlty }\end{array}$ & $N / A$ & $\begin{array}{l}\text { HWQ }=1 \text { if } \\
\text { Hazardous } \\
\text { Constituent } \\
\text { Quantity data are } \\
\text { complete } \\
\text { HWQ }=10 \text { if } \\
\text { Hazardous } \\
\text { Constituent } \\
\text { Quantity data are } \\
\text { not complete }\end{array}$ & $>100$ to $10,000 \mathrm{lbs}$ \\
\hline $\begin{array}{c}\text { B } \\
\text { Hazardous } \\
\text { Wastestream } \\
\text { Quantity }\end{array}$ & N/A & $\leq 500,000 \mathrm{lbs}$ & $>500,000$ to 50 million lbs \\
\hline$\underset{\text { volume }}{\mathbf{C}}$ & $\begin{array}{l}\text { Landfill } \\
\text { Surface } \\
\text { impoundment } \\
\text { Drums } \\
\text { Tanks and non-drum } \\
\text { containers } \\
\text { Contaminated soil } \\
\text { Pile } \\
\text { Other }\end{array}$ & $\begin{array}{l}\leq 6.75{\text { million } \mathrm{ft}^{3}}^{3} \\
\leq 250,000 \mathrm{yd}^{3} \\
\leq 6,750 \mathrm{ft}^{3} \\
\leq 250 \mathrm{yd}^{3} \\
\leq 1,000 \text { drums } \\
\leq 50,000 \text { gallons } \\
\leq 6.75 \mathrm{million}^{3} \mathrm{ft}^{3} \\
\leq 250,000 \mathrm{yd}^{3} \\
\leq 6,750 \mathrm{ft}^{3} \\
\leq 250 \mathrm{yd}^{3} \\
\leq 6,750 \mathrm{ft}^{3} \\
\leq 250 \mathrm{yd}^{3}\end{array}$ & $\begin{array}{l}>6.75 \text { million to } 675 \text { million } \mathrm{ft}^{3} \\
>250,000 \text { to } 25{\text { million } \mathrm{yd}^{3}}^{3} \\
>6,750 \text { to } 675,000 \mathrm{ft}^{3} \\
>250 \text { to } 25,000 \mathrm{yd}^{3} \\
>1,000 \text { to } 100,000 \text { drums } \\
>50,000 \text { to } 5 \text { million gallons } \\
>6.75 \text { million to } 675 \text { million } \mathrm{ft}^{3} \\
>250,000 \text { to } 25{\text { million } \mathrm{yd}^{3}}^{3} \\
>6,750 \text { to } 675,000 \mathrm{ft}^{3} \\
>250 \text { to } 25,000 \mathrm{yd}^{3} \\
>6,750 \text { to } 675,000 \mathrm{ft}^{3} \\
>250 \text { to } 25,000 \mathrm{yd}^{3}\end{array}$ \\
\hline$\underset{\text { Area }}{\text { D }}$ & $\begin{array}{l}\text { Landfill } \\
\text { Surface } \\
\text { impoundment } \\
\text { Contaminated soil } \\
\text { Pile } \\
\text { Land treatment }\end{array}$ & $\begin{array}{l}\leq 340,000 \mathrm{ft}^{2} \\
\leq 7.8 \text { acres } \\
\leq 1,300 \mathrm{ft}^{2} \\
\leq 0.029 \text { acres } \\
\leq 3.4 \text { million } \mathrm{ft}^{2} \\
\leq 78 \text { acres } \\
\leq 1,300 \mathrm{ft}^{2} \\
\leq 0.029 \text { acres } \\
\leq 27,000 \mathrm{ft}^{2} \\
\leq 0.62 \text { acres }\end{array}$ & $\begin{array}{l}>340,000 \text { to } 34 \text { million } \mathrm{ft}^{2} \\
>7.8 \text { to } 780 \text { acres } \\
>1,300 \text { to } 130,000 \mathrm{ft}^{2} \\
>0.029 \text { to } 2.9 \text { acres } \\
>3.4 \text { million to } 340 \text { million } \mathrm{ft}^{2} \\
>78 \text { to } 7,800 \text { acres } \\
>1,300 \text { to } 130,000 \mathrm{ft}^{2} \\
>0.029 \text { to } 2.9 \text { acres } \\
>27,000 \text { to } 2.7 \text { million } \mathrm{ft}^{2} \\
>0.62 \text { to } 62 \text { acres }\end{array}$ \\
\hline
\end{tabular}

$$
\text { C-8 }
$$


TABLE 1 (CONTINUED)

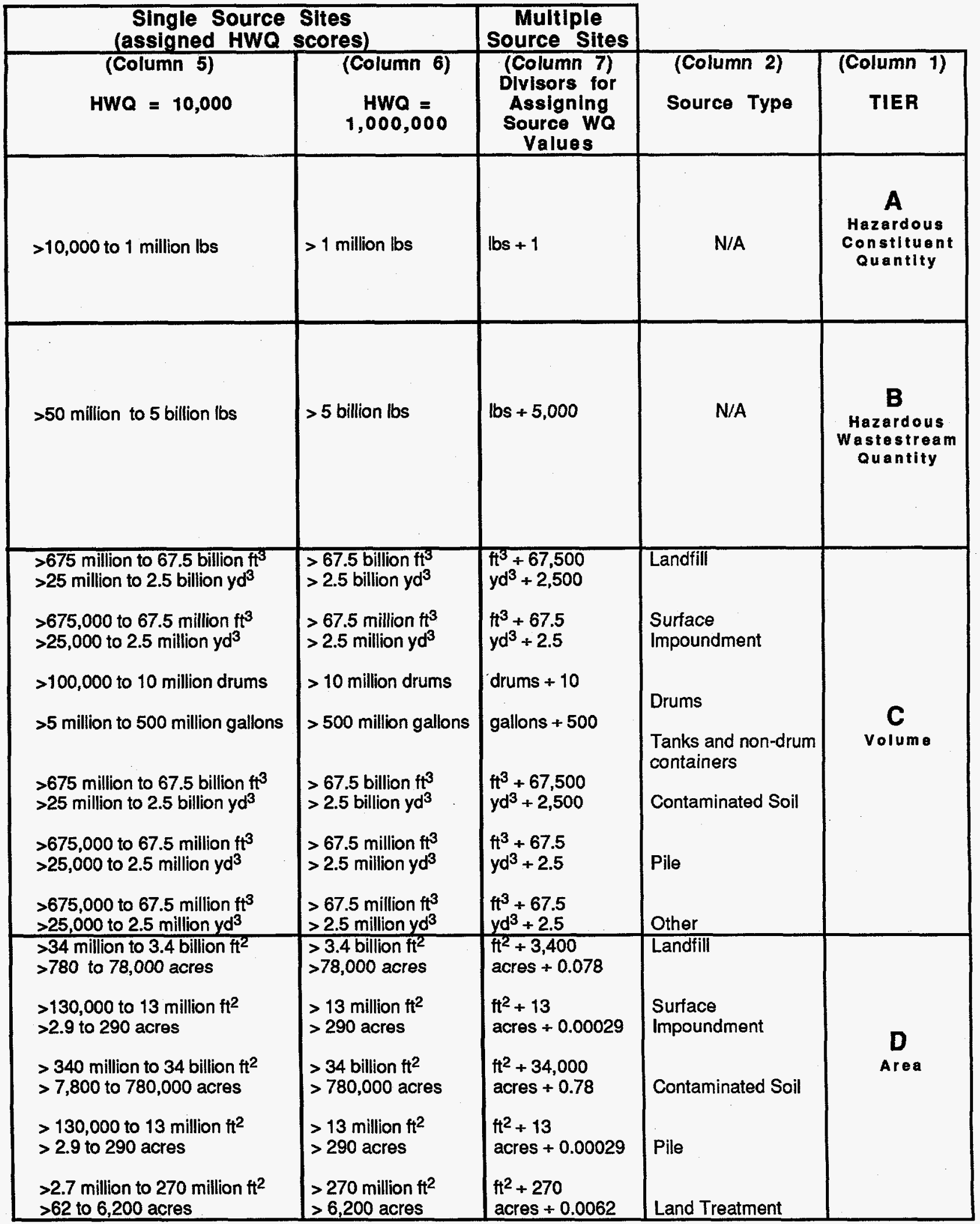




\section{HAZARDOUS WASTE QUANTITY (HWQ) CALCULATION}

For each migration pathway, evaluate HWQ associated with sources that are available (i.e., incompletely contained) to migrate to that pathway. (Note: If Actual Contamination Targets exist for ground water, surface water, or air migration pathways, assign the calculated HWQ score or 100 , whichever is greater, as the HWQ score for that pathway.) For each source, evaluate HWQ for one or more of the four tiers (SI Table 1; HRS Table 2-5) for which data exist: constituent quantity, wastestream quantity, source volume, and source area. Select the tier that gives the highest value as the source HWQ. Select the source volume HWQ rather than source area HWQ if data for both tiers are available.

Column 1 of SI Table 1 indicates the quantity tier. Column 2 lists source types for the four tiers. Columns $3,4,5$, and 6 provide ranges of waste amount for sites with only one source, corresponding to HWQ scores at the tops of the columns. Column 7 provides formulas to obtain source waste quantity values at sites with multiple sources.

1. Identify each source type.

2. Examine all waste quantity data available for each source. Record constituent quantity and waste stream mass or volume. Record dimensions of each source.

3. Convert source measurements to appropriate units for each tier to be evaluated.

4. For each source, use the formulas in the last column of SI Table 1 to determine the waste quantity value for each tier that can be evaluated. Use the waste quantity value obtained from the highest tier as the quantity value for the source.

5. Sum the values assigned to each source to determine the total site waste quantity.

6. Assign HWQ score from SI Table 2 (HRS Table 2-6).

Note these exceptions to evaluate soil exposure pathway HWO (see HRS Table 5-2):

- The divisor for the area (square feet) of a landfill is 34,000 .

- The divisor for the area (square feet) of a pile is 34 .

- Wet surface impoundments and tanks and non-drum containers are the only sources for which volume measurements are evaluated for the soil exposure pathway.

SI TABLE 2: HWQ SCORES FOR SITES
\begin{tabular}{|c|c|}
\hline Site WQ Total & HWQ Score \\
\hline 0 & 0 \\
\hline $1^{\mathrm{a}}$ to 100 & $1^{\mathrm{b}}$ \\
\hline$>100$ to 10,000 & 100 \\
\hline$>10,000$ to 1 million & 10,000 \\
\hline$>1$ million & $1,000,000$ \\
\hline
\end{tabular}

a If the WQ total is between 0 and 1 , round it to 1 .

b If the hazardous constituent quantity data are not complete, assign the score of 10 . 
SI TABLE 3: WASTE CHARACTERIZATION WORKSHEET

Site Name:

References

\section{Sources:}

1.

3.

\begin{tabular}{|c|c|c|c|c|c|c|c|c|c|c|c|c|c|c|c|}
\hline \multirow{3}{*}{ SOURCE } & \multirow{3}{*}{$\begin{array}{l}\text { HAZARDOUS } \\
\text { SUBSTANCE }\end{array}$} & \multirow{3}{*}{ TOXICITY } & \multirow{2}{*}{\multicolumn{2}{|c|}{$\begin{array}{c}\text { GROUND } \\
\text { WATER } \\
\text { PATHWAY }\end{array}$}} & \multicolumn{11}{|c|}{ SURFACE WATER PATHWAY } \\
\hline & & & & & \multicolumn{4}{|c|}{ OVERLAND/FLOOD } & \multicolumn{3}{|c|}{ MIGRATION } & \multicolumn{4}{|c|}{$\begin{array}{l}\text { GROUND WATER TO } \\
\text { SURFACE WATER }\end{array}$} \\
\hline & & & $\begin{array}{c}\text { GW } \\
\text { Mobility } \\
\text { (HRS } \\
\text { Table } \\
\text { 3-8) } \\
\end{array}$ & $\begin{array}{c}\text { Tox/ } \\
\text { Mobility } \\
\text { Value } \\
\text { (HRS } \\
\text { Table } \\
\text { 3-9) } \\
\end{array}$ & $\begin{array}{c}\text { Per (HPS } \\
\text { Tables } \\
4-10 \text { and } \\
4-11 \text { ) }\end{array}$ & $\begin{array}{c}\text { Toxper } \\
\text { Value } \\
\text { (HRS } \\
\text { Table } \\
\text { 4-12) } \\
\end{array}$ & $\begin{array}{c}\text { Bioac Pot. } \\
\text { (HRS } \\
\text { Table } \\
4-15) \\
\end{array}$ & $\begin{array}{l}\text { Tox/ } \\
\text { Pers/ } \\
\text { Bioac } \\
\text { Value } \\
\text { (HARS } \\
\text { Tabble } \\
\text { 4-16) } \\
\end{array}$ & $\begin{array}{l}\text { Ecotox } \\
\text { (HRS } \\
\text { Table } \\
\text { 4-19) } \\
\end{array}$ & $\begin{array}{c}\text { Ecotox/ } \\
\text { Pers } \\
\text { (HRS } \\
\text { Table } \\
4-20 \text { ) }\end{array}$ & $\begin{array}{l}\text { Ecotox/ } \\
\text { Pers' } \\
\text { Bioacc } \\
\text { Value } \\
\text { (HAS } \\
\text { Tabio } \\
\text { 4-21) }\end{array}$ & $\begin{array}{l}\text { Tox/ } \\
\text { Mob/ } \\
\text { Pers } \\
\text { Value } \\
\text { (HRS } \\
\text { Table } \\
\text { 4-26) }\end{array}$ & $\begin{array}{l}\text { Tox/ } \\
\text { Mob/ } \\
\text { Pers } \\
\text { Bioacc } \\
\text { Value } \\
\text { (HRS } \\
\text { Table } \\
4-28 \text { ) }\end{array}$ & $\begin{array}{l}\text { Ecotor/ } \\
\text { Mob/ } \\
\text { Pers } \\
\text { Value } \\
\text { (HRS } \\
\text { Table } \\
\text { 4-29) }\end{array}$ & $\begin{array}{l}\text { Ecotox/ } \\
\text { Mob/ } \\
\text { Perf } \\
\text { Bioacc } \\
\text { Value } \\
\text { (HRS } \\
\text { Table } \\
\text { 4-30) }\end{array}$ \\
\hline & & & & & & & & & & & & & & & \\
\hline & & & & & & & & & & & & & & & \\
\hline & & & & & & & & & & & & & & & \\
\hline & & & & & & & & & & & & & & & \\
\hline & & & & & & & & & & & & & & & \\
\hline & & & & & & & & & & & & & & & \\
\hline & & & & & & & & & & & & & & & \\
\hline & & & & & & & & & & & & & & & \\
\hline & & & & & & & & & & & & & & & \\
\hline & & & & & & & & & & & & & & & \\
\hline & & & & & & & & & & & & & & & \\
\hline & & & & & & & & & & & & & & & \\
\hline & & & & & & & & & & & & & & & \\
\hline & & & & & & & & & & & & & & & \\
\hline
\end{tabular}




\section{Ground Water Observed Release Substances Summary Table}

On SI Table 4, list the hazardous substances associated with the site detected in ground water samples for that aquifer. Include only those substances directly observed or with concentrations significantly greater than background levels. Obtain toxicity values from the Superfund Chemical Data Matrix (SCDM). Assign mobility a value of 1 for all observed release substances regardless of the aquifer being evaluated. For each substance, multiply the toxicity by the mobility to obtain the toxicity/mobility factor value; enter the highest toxicity/mobility value for the aquifer in the space provided.

\section{Ground Water Actual Contamination Targets Summary Table}

If there is an observed release at a drinking water well, enter each hazardous substance meeting the requirements for an observed release by well and sample ID on SI Table 5 and record the detected concentration. Obtain benchmark, cancer risk, and reference dose concentrations from SCDM. For MCL and MCLG benchmarks, determine the highest percentage of benchmark obtained for any substance. For cancer risk and reference dose, sum the percentages for the substances listed. If benchmark, cancer risk, or reference dose concentrations are not available for a particular substance, enter N/A for the percentage. If the highest benchmark percentage or the percentage sum calculated for cancer risk or reference dose equals or exceeds $100 \%$, evaluate the population using the well as a Level I target. If these percentages are less than $100 \%$ or all are N/A, evaluate the population using the well as a Level II target for that aquifer. 
SI TABLE 4: GROUND WATER OBSERVED RELEASE SUBSTANCES (BY AQUIFER)

\begin{tabular}{|l|l|l|l|l}
\hline Sample ID & Hazardous Substance & $\begin{array}{c}\text { Bckgrd. } \\
\text { Conc. }\end{array}$ & $\begin{array}{c}\text { Toxicity/ } \\
\text { Mobility }\end{array}$ & References \\
\hline & & & & \\
\hline & & & & \\
\hline & & & & \\
\hline & & & & \\
\hline & & & & \\
\hline & & & & \\
\hline & & & & \\
\hline & & & & \\
\hline
\end{tabular}

SI TABLE 5: GROUND WATER ACTUAL CONTAMINATION TARGETS

Well ID:

Level I.

Level II

Population Served

References

\begin{tabular}{|c|c|c|c|c|c|c|c|c|}
\hline Sample ID & Hazardous Substance & $\begin{array}{l}\text { Conc. } \\
(\mu g / L)\end{array}$ & $\begin{array}{c}\text { Benchmark } \\
\text { Conc. } \\
\text { (MCL or MCLG) }\end{array}$ & $\begin{array}{c}\% \text { of } \\
\text { Benchmark }\end{array}$ & $\begin{array}{c}\text { Cancer Risk } \\
\text { Conc. }\end{array}$ & $\begin{array}{l}\% \text { of Cancer } \\
\text { Risk Conc. }\end{array}$ & RfD & $\%$ of RfD \\
\hline & & & & & & & & \\
\hline & & & & & - & & & \\
\hline & & & & & & & & \\
\hline & & & & & & & & \\
\hline & & & $\begin{array}{l}\text { Highest } \\
\text { Percent }\end{array}$ & & $\begin{array}{c}\text { Sum of } \\
\text { Percents }\end{array}$ & & $\begin{array}{c}\text { Sum of } \\
\text { Percents }\end{array}$ & \\
\hline
\end{tabular}

Well ID:

Level I

Level II

Population Served

References

\begin{tabular}{|c|c|c|c|c|c|c|c|c|}
\hline Sample ID & Hazardous Substance & $\begin{array}{l}\text { Conc. } \\
(\mu g / L)\end{array}$ & $\begin{array}{c}\text { Benchmark } \\
\text { Conc. } \\
\text { (MCL or MCLG) }\end{array}$ & $\begin{array}{c}\% \text { of } \\
\text { Benchmark }\end{array}$ & $\begin{array}{c}\text { Cancer Risk } \\
\text { Conc. }\end{array}$ & $\begin{array}{l}\% \text { of Cancer } \\
\text { Risk Conc. }\end{array}$ & RED & $\%$ of RfD \\
\hline & & & & & & & & \\
\hline & & & & & & & & \\
\hline & & & & & & & & \\
\hline & & & & & & & & \\
\hline & & & & & & & & 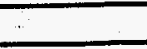 \\
\hline & & & $\begin{array}{l}\text { Highest } \\
\text { Percent }\end{array}$ & & $\begin{array}{c}\text { Sum of } \\
\text { Percents }\end{array}$ & & $\begin{array}{c}\text { Sum of } \\
\text { Percents }\end{array}$ & \\
\hline
\end{tabular}




\section{GROUND WATER PATHWAY GROUND WATER USE DESCRIPTION}

Describe Ground Water Use within 4 Miles of the Site:

Describe generalized stratigraphy, aquifers, municipal and private wells

Show Calculations of Ground Water Drinking Water Populations for each Aquifer: Provide apportionment calculations for blended supply systems.

County average number of persons per household: Reference 


\section{GROUND WATER PATHWAY WORKSHEET}

\section{LIKELIHOOD OF RELEASE}

Data

1. OBSERVED RELEASE: If sampling data or direct observation support a release to the aquifer, assign a score of 550 . Record observed release substances on SI Table 4.

2. POTENTIAL TO RELEASE: Depth to aquifer: feet. If sampling data do not support a release to the aquifer, and the site is in karst terrain or the depth to aquifer is 70 feet or less, assign a score of 500; otherwise, assign a score of 340 . Optionally, evaluate potential to release according to HRS Section 3 .

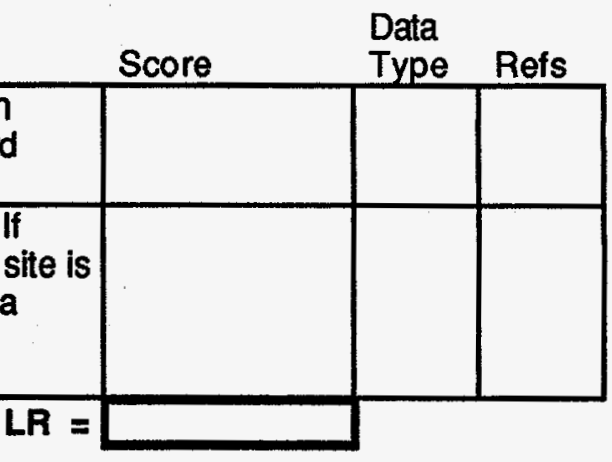

\section{TARGETS}

Are any wells part of a blended system? Yes_ No If yes, attach a page to show apportionment calculations.

3. ACTUAL CONTAMINATION TARGETS: If analytical evidence indicates that any target drinking water well for the aquifer has been exposed to a hazardous substance from the site, evaluate the factor score for the number of people served (SI Table 5).

Level I: people $\times 10=$

Level II: people $\times 1=$

Total $=$

4. POTENTIAL CONTAMINATION TARGETS: Determine the number of people served by drinking water wells for the aquifer or overlying aquifers that are not exposed to a hazardous substance from the site; record the population for each distance category in SI Table 6a or $6 \mathrm{~b}$. Sum the population values and multiply by 0.1 .

5. NEAREST WELL: Assign a score of 50 for any Level I Actual Contamination Targets for the aquifer or overlying aquifer. Assign a score of $\mathbf{4 5}$ if there are Level II targets but no Level I targets. If no Actual Contamination Targets exist, assign the Nearest Well score from SI Table $6 a$ or $6 b$. If no drinking water wells exist within 4 miles, assign 0.

6. WELLHEAD PROTECTION AREA (WHPA): If any source lies within or above a WHPA for the aquifer, or if a ground water observed release has occurred within a WHPA, assign a score of 20; assign 5 if neither condition applies but a WHPA is within 4 miles; otherwise assign 0.

7. RESOURCES: Assign a score of 5 if one or more ground water resource applies; assign 0 if none applies.

- Irrigation (5 acre minimum) of commercial food crops or commercial forage crops

- Watering of commercial livestock

- Ingredient in commercial food preparation

- Supply for commercial aquaculture

- Supply for a major or designated water recreation area, excluding drinking water use 
SI TABLE 6 (From HRS TABLE 3-12): VALUES FOR POTENTIAL CONTAMINATION GROUND WATER TARGET POPULATIONS

\section{SI Table 6a: Other Than Karst Aquifers}

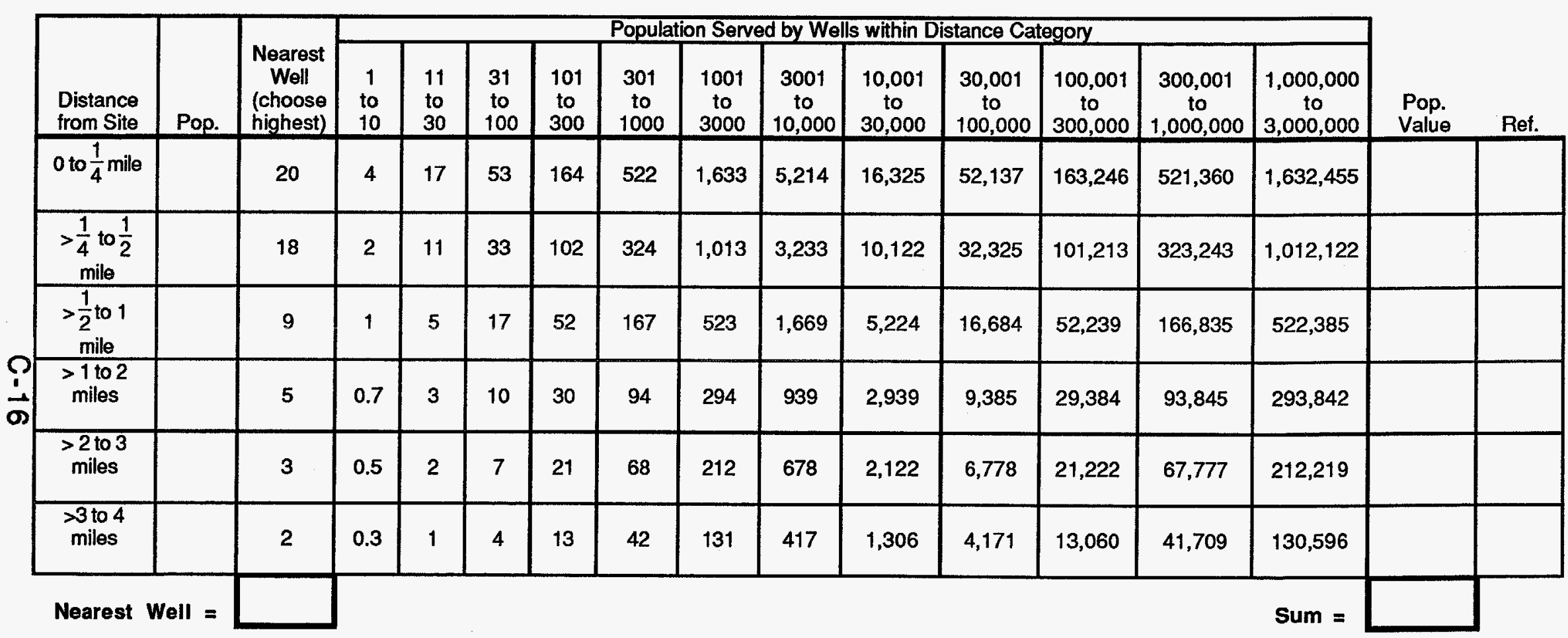


SI TABLE 6 (From HRS TABLE 3-12): VALUES FOR POTENTIAL CONTAMINATION GROUND WATER TARGET POPULATIONS (continued)

\section{SI Table 6b: Karst Aquifers}

\begin{tabular}{|c|c|c|c|c|c|c|c|c|c|c|c|c|c|c|c|c|}
\hline \multirow[b]{2}{*}{$\begin{array}{l}\text { Distance } \\
\text { from Site } \\
\end{array}$} & \multirow[b]{2}{*}{ Pop. } & \multirow[b]{2}{*}{$\begin{array}{c}\text { Nearest } \\
\text { Well } \\
\text { (choose } \\
\text { highest) }\end{array}$} & \multicolumn{12}{|c|}{ Population Served by Wells with in Distance Category } & \multirow[b]{2}{*}{$\begin{array}{l}\text { Pop. } \\
\text { Value }\end{array}$} & \multirow[b]{2}{*}{ Ref. } \\
\hline & & & $\begin{array}{c}1 \\
\text { to } \\
10\end{array}$ & $\begin{array}{l}11 \\
\text { to } \\
30 \\
\end{array}$ & $\begin{array}{c}31 \\
\text { to } \\
100\end{array}$ & $\begin{array}{c}101 \\
\text { to } \\
300\end{array}$ & $\begin{array}{c}301 \\
\text { to } \\
1000\end{array}$ & $\begin{array}{c}1001 \\
\text { to } \\
3000 \\
\end{array}$ & $\begin{array}{c}3001 \\
\text { to } \\
10,000 \\
\end{array}$ & $\begin{array}{c}10,001 \\
\text { to } \\
30,000\end{array}$ & $\begin{array}{c}30,001 \\
\text { to } \\
100,000 \\
\end{array}$ & $\begin{array}{c}100,001 \\
\text { to } \\
300,000 \\
\end{array}$ & $\begin{array}{c}300,001 \\
\text { to } \\
1,000,000\end{array}$ & $\begin{array}{c}1,000,000 \\
\text { to } \\
3,000,000\end{array}$ & & \\
\hline 0 to $\frac{1}{4}$ mile & & 20 & 4 & 17 & 53 & 164 & 522 & 1,633 & 5,214 & 16,325 & 52,137 & 163,246 & 521,360 & $1,632,455$ & & \\
\hline $\begin{array}{c}>\frac{1}{4} \text { to } \frac{1}{2} \\
\text { mile }\end{array}$ & & 20 & 2 & 11 & 33 & 102 & 324 & 1,013 & 3,233 & 10,122 & 32,325 & 101,213 & 323,243 & $1,012,122$ & & \\
\hline $\begin{array}{c}>\frac{1}{2} \text { to } 1 \\
\text { mile }\end{array}$ & & 20 & 2 & 9 & 26 & 82 & 261 & 817 & 2,607 & 8,163 & 26,068 & 81,623 & 260,680 & 816,227 & & \\
\hline $\begin{array}{c}>1 \text { to } 2 \\
\text { miles }\end{array}$ & & 20 & 2 & 9 & 26 & 82 & 261 & 817 & 2,607 & 8,163 & 26,068 & 81,623 & 260,680 & 816,227 & & \\
\hline $\begin{array}{c}>2 \text { to } 3 \\
\text { miles }\end{array}$ & & 20 & 2 & 9 & 26 & 82 & 261 & 817 & 2,607 & 8,163 & 26,068 & 81,623 & 260,680 & 816,227 & & \\
\hline $\begin{array}{c}>3 \text { to } 4 \\
\text { miles }\end{array}$ & & 20 & 2 & 9 & 26 & 82 & 261 & 817 & 2,607 & 8,163 & 26,068 & 81,623 & 260,680 & 816,227 & & \\
\hline
\end{tabular}




\section{GROUND WATER PATHWAY WORKSHEET (concluded)}

\begin{tabular}{|c|c|c|c|c|c|}
\hline WASTE & \multicolumn{2}{|c|}{ CHARACTERISTICS } & Score & $\begin{array}{l}\text { Data } \\
\text { Type }\end{array}$ & $\begin{array}{l}\text { Does } \\
\text { not } \\
\text { Apply }\end{array}$ \\
\hline \multicolumn{3}{|c|}{$\begin{array}{l}\text { If any Actual Contamination Targets exist for the aquifer or } \\
\text { overlying aquifers, assign the calculated hazardous waste } \\
\text { quantity score or a score of } 100, \text { whichever is greater; if no Actual } \\
\text { Contamination Targets exist, assign the hazardous waste } \\
\text { quantity score calculated for sources available to migrate to } \\
\text { ground water. }\end{array}$} & & & \\
\hline \multicolumn{3}{|c|}{$\begin{array}{l}\text { Assign the highest ground water toxicity/mobility value from SI } \\
\text { Table } 3 \text { or } 4 \text {. }\end{array}$} & & & \\
\hline \multicolumn{3}{|c|}{$\begin{array}{l}\text { 10. Multiply the ground water toxicity/mobility and hazardous waste } \\
\text { quantity scores. Assign the Waste Characteristics score from the } \\
\text { table below: (from HRS Table 2-7) }\end{array}$} & & & \\
\hline & \begin{tabular}{|l} 
Product \\
0 \\
$>0$ to $<10$ \\
10 to $<100$ \\
100 to $<1,000$ \\
1,000 to $<10,000$ \\
10,000 to $<1 E+05$ \\
$1 E+05$ to $<1 E+06$ \\
$1 E+06$ to $<1 E+07$ \\
$1 E+07$ to $<1 E+08$ \\
$1 E+08$ or greater \\
\end{tabular} & \begin{tabular}{l|} 
WC Score \\
0 \\
1 \\
2 \\
3 \\
6 \\
10 \\
18 \\
32 \\
56 \\
100 \\
\end{tabular} & & & \\
\hline
\end{tabular}

Multiply LR by T and by WC. Divide the product by 82,500 to obtain the ground water pathway score for each aquifer. Select the highest aquifer score. If the pathway score is greater than 100, assign 100.

GROUND WATER PATHWAY SCORE:

$$
\frac{\text { LRR X T X WC }}{82,500}
$$




\section{SURFACE WATER PATHWAY}

\section{Sketch of the Surface Water Migration Route:}

Label all surface water bodies. Include runoff route and drainage direction, probable point of entry, and 15-mile target distance limit. Mark sample locations, intakes, fisheries, and sensitive environments.

Indicate flow directions, tidal influence, and rate. 


\section{SURFACE WATER PATHWAY}

\section{Surface Water Observed Release Substances Summary Table}

On SI Table 7, list the hazardous substances detected in surface water samples for the watershed, which can be attributed to the site. Include only those substances in observed releases (direct observation) or with concentration levels significantly above background levels. Obtain toxicity, persistence, bioaccumulation potential, and ecotoxicity values from SCDM. Enter the highest toxicity/persistence, toxicity/persistence/bioaccumulation, and ecotoxicity/persistence/ecobioaccumulation values in the spaces provided.

- $\mathrm{TP}=$ Toxicity $\times$ Persistence

- $\mathrm{TPB}=\mathrm{TP} \times$ bioaccumulation

- $E T P B=E P x$ bioaccumulation $(E P=$ ecotoxicity $\times$ persistence $)$

\section{Drinking Water Actual Contamination Targets Summary Table}

For an observed release at or beyond a drinking water intake, on SI Table 8 enter each hazardous substance by sample ID and the detected concentration. For surface water sediment samples detecting a hazardous substance at or beyond an intake, evaluate the intake as Level II contamination. Obtain benchmark, cancer risk, and reference dose concentrations for each substance from SCDM. For MCL and MCLG benchmarks, determine the highest percentage of benchmark obtained for any substance. For cancer risk and reference dose, sum the percentages of the substances listed. If benchmark, cancer risk, or reference dose concentrations are not available for a particular substance, enter N/A for the percentage. If the highest benchmark percentage or the percentage sum calculated for cancer risk or reference dose equals or exceeds $100 \%$, evaluate the population served by the intake as a Level I target. If the percentages are less than $100 \%$ or all are N/A, evaluate the population served by the intake as a Level II target. 
SI TABLE 7: SURFACE WATER OBSERVED RELEASE SUBSTANCES

\begin{tabular}{|c|c|c|c|c|c|c|}
\hline Sample ID & Hazardous Substance & $\begin{array}{l}\text { Bckgrd. } \\
\text { Conc. }\end{array}$ & $\begin{array}{c}\text { Toxicity/ } \\
\text { Persistence } \\
\end{array}$ & $\begin{array}{c}\text { Toxicity/ } \\
\text { Persis./ } \\
\text { Bioaccum } \\
\end{array}$ & $\begin{array}{c}\text { Ecotoxicity/ } \\
\text { Persis/ } \\
\text { Ecobioaccum }\end{array}$ & References \\
\hline & & & & & & \\
\hline & & & & & & \\
\hline & & & & & & \\
\hline & & & & & & \\
\hline & & & & & & \\
\hline & & & & & & \\
\hline & & & & & & \\
\hline & & & & & & \\
\hline & & & & & & \\
\hline & & & & & & \\
\hline & $\mathrm{H}$ & est Values & & & & \\
\hline
\end{tabular}

\section{SI TABLE 8: SURFACE WATER DRINKING WATER ACTUAL CONTAMINATION TARGETS}

Intake ID:

Sample Type

Level I

Level II

Population Served

References

\begin{tabular}{|c|c|c|c|c|c|c|c|c|}
\hline Sample ID & Hazardous Substance & $\begin{array}{l}\text { Conc. } \\
(\mu \mathrm{g} / \mathrm{L})\end{array}$ & $\begin{array}{c}\text { Benchmark } \\
\text { Conc. } \\
\text { (MCL or MCLG) }\end{array}$ & $\begin{array}{c}\% \text { of } \\
\text { Benchmark }\end{array}$ & $\begin{array}{c}\text { Cancer Risk } \\
\text { Conc. } \\
\end{array}$ & $\begin{array}{l}\% \text { of Cancer } \\
\text { Risk Conc. }\end{array}$ & RiD & $\%$ of RfD \\
\hline & & & & & & & & \\
\hline & & & & & & & & \\
\hline & & & & & & & & \\
\hline & & & & & & & & \\
\hline & & 1 & & & & & & \\
\hline & & & $\begin{array}{l}\text { Highest } \\
\text { Percent }\end{array}$ & & $\begin{array}{c}\text { Sum of } \\
\text { Percents }\end{array}$ & & $\begin{array}{c}\text { Sum of } \\
\text { Percents }\end{array}$ & \\
\hline
\end{tabular}

Intake ID:

Sample Type

Levell

Level II ___ Population Served

References

\begin{tabular}{|c|c|c|c|c|c|c|c|c|}
\hline Sample ID & Hazardous Substance & $\begin{array}{l}\text { Conc. } \\
(\mu \mathrm{g} / \mathrm{L})\end{array}$ & $\begin{array}{c}\text { Benchmark } \\
\text { Conc. } \\
\text { (MCL or MCLG) }\end{array}$ & $\begin{array}{c}\% \text { of } \\
\text { Benchmark }\end{array}$ & $\begin{array}{c}\text { Cancer Risk } \\
\text { Conc. } \\
\end{array}$ & $\begin{array}{l}\% \text { of Cancer } \\
\text { Risk Conc. }\end{array}$ & $\mathrm{R} F \mathrm{D}$ & $\%$ of $\mathrm{AfD}$ \\
\hline & & & & & & & & \\
\hline & & & & & & & & \\
\hline & & & & & & & & \\
\hline & & & & & & & & \\
\hline & & & & & & & & \\
\hline & & & $\begin{array}{l}\text { Highest } \\
\text { Percent }\end{array}$ & & $\begin{array}{l}\text { Sum of } \\
\text { Percents }\end{array}$ & & $\begin{array}{l}\text { Sum of } \\
\text { Percents }\end{array}$ & \\
\hline
\end{tabular}




\section{SURFACE WATER PATHWAY \\ LIKELIHOOD OF RELEASE AND DRINKING WATER THREAT WORKSHEET}

LIKELIHOOD OF RELEASE-

OVERLAND/FLOOD MIGRATION

Data

1. OBSERVED RELEASE: If sampling data or direct observation support a release to surface water in the watershed, assign a score of 550. Record observed release substances on SI Table 7.

2. POTENTIAL TO RELEASE: Distance to surface water: _f (feet) If sampling data do not support a release to surface water in the watershed, use the table below to assign a score from the table below based on distance to surface water and flood frequency.

\begin{tabular}{|l|c|}
\hline Distance to surface water $<2500$ feet & 500 \\
\hline Distance to surface water $>2500$ feet, and: & \\
\hline Site in annual or 10-yr floodplain & 500 \\
\hline Site in 100-yr floodplain & 400 \\
\hline Site in 500-yr floodplain & 300 \\
\hline Site outside 500-yr floodplain & 100 \\
\hline
\end{tabular}

Optionally, evaluate surface water potential to release according to HRS Section 4.1.2.1.2

LR $\mathrm{E}$

LIKELIHOOD OF RELEASE

GROUND WATER TO SURFACE WATER MIGRATION

1. OBSERVED RELEASE: If sampling data or direct observation support a release to surface water in the watershed, assign a score of 550. Record observed release substances on SI Table 7.

NOTE: Evaluate ground water to surface water migration only for a surface water body that meets all of the following conditions:

1) A portion of the surface water is within 1 mile of site sources having a containment factor greater than 0 .

2) No aquifer discontinuity is established between the source and the above portion of the surface water body.

3) The top of the uppermost aquifer is at or above the bottom of the surface water.

Elevation of top of uppermost aquifer

Elevation of bottom of surface water body

2. POTENTIAL TO RELEASE: Use the ground water potential to release. Optionally, evaluate surface water potential to release according to HRS Section 3.1.2. 


\section{SURFACE WATER PATHWAY \\ LIKELIHOOD OF RELEASE AND DRINKING WATER THREAT WORKSHEET \\ (CONTINUED)}

DRINKING WATER THREAT TARGETS

Data

Record the water body type, flow, and number of people served by each drinking water intake within the target distance limit in the watershed. If there is no drinking water intake within the target distance limit, assign 0 to factors 3,4 , and 5 .

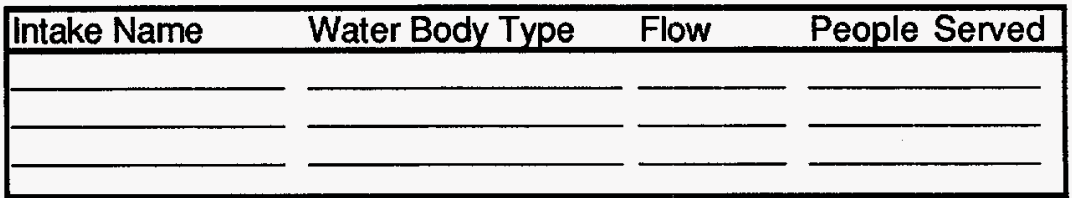

Are any intakes part of a blended system? Yes No

If yes, attach a page to show apportionment calculations.

3. ACTUAL CONTAMINATION TARGETS: If analytical evidence indicates a drinking water intake has been exposed to a hazardous substance from the site, list the intake name and evaluate the factor score for the drinking water population (SI Table 8).

Level l:

people $\times 10=$

Level II: people $\times 1=$

4. POTENTIAL CONTAMINATION TARGETS: Determine the number of people served by drinking water intakes for the watershed that have not been exposed to a hazardous substance from the site. Assign the population values from SI Table 9. Sum the values and multiply by 0.1 .

5. NEAREST INTAKE: Assign a score of 50 for any Level I Actual Contamination Drinking Water Targets for the watershed. Assign a score of $\mathbf{4 5}$ if there are Level II targets for the watershed, but no Level I targets. If no Actual Contamination Drinking Water Targets exist, assign a score for the intake nearest the PPE from SI Table 9. If no drinking water intakes exist, assign 0.

6. RESOURCES: Assign a score of 5 if one or more surface water resource applies; assign 0 if none applies.

- Irrigation (5 acre minimum) of commercial food crops or commercial forage crops

- Watering of commercial livestock

- Ingredient in commercial food preparation

- Major or designated water recreation area, excluding drinking water use 
SI TABLE 9 (From HRS Table 4-14): DILUTION-WEIGHTED POPULATION VALUES FOR POTENTIAL CONTAMINATION FOR SURFACE WATER MIGRATION PATHWAY

\begin{tabular}{|c|c|c|c|c|c|c|c|c|c|c|c|c|}
\hline \multirow[b]{2}{*}{$\begin{array}{l}\text { Type of Surface Water } \\
\text { Body }\end{array}$} & \multirow[b]{2}{*}{ Pop. } & \multirow[b]{2}{*}{$\begin{array}{c}\text { Nearest } \\
\text { Intake }\end{array}$} & \multicolumn{9}{|c|}{ Number of people } & \multirow[b]{2}{*}{$\begin{array}{l}\text { Pop. } \\
\text { Value }\end{array}$} \\
\hline & & & 0 & $\begin{array}{l}1 \\
\text { to } \\
10 \\
\end{array}$ & $\begin{array}{l}11 \\
\text { to } \\
30 \\
\end{array}$ & $\begin{array}{c}31 \\
\text { to } \\
100 \\
\end{array}$ & $\begin{array}{l}101 \\
\text { to } \\
300 \\
\end{array}$ & $\begin{array}{c}301 \\
\text { to } \\
1,000\end{array}$ & $\begin{array}{c}1,001 \\
\text { to } \\
3,000\end{array}$ & $\begin{array}{c}3,001 \\
t 0 \\
10,000 \\
\end{array}$ & $\begin{array}{c}10,001 \\
\text { to } \\
30,000 \\
\end{array}$ & \\
\hline Minimal Stream (<10 cfs) & & 20 & 0 & 4 & 17 & 53 & 164 & 522 & 1,633 & 5,214 & 16,325 & \\
\hline $\begin{array}{l}\text { Small to moderate stream } \\
\text { (10 to } 100 \mathrm{cfs})\end{array}$ & & 2 & 0 & 0.4 & 2 & 5 & 16 & 52 & 163 & 521 & 1,633 & \\
\hline $\begin{array}{l}\text { Moderate to large stream } \\
(>100 \text { to } 1,000 \text { cfs) }\end{array}$ & & 0 & 0 & 0.04 & 0.2 & 0.5 & 2 & 5 & 16 & 52 & 163 & \\
\hline $\begin{array}{l}\text { Large Stream to river } \\
(>1,000 \text { to } 10,000 \mathrm{cfs})\end{array}$ & & 0 & 0 & 0.004 & 0.02 & 0.05 & 0.2 & 0.5 & 2 & 5 & 16 & \\
\hline $\begin{array}{l}\text { Large River } \\
(>10,000 \text { to } 100,000 \mathrm{cfs})\end{array}$ & & 0 & 0 & 0 & 0.002 & 0.005 & 0.02 & 0.05 & 0.2 & 0.5 & 16 & \\
\hline $\begin{array}{l}\text { Very Large River } \\
(>100,000 \text { cfs) }\end{array}$ & & 0 & 0 & 0 & 0 & 0.001 & 0.002 & 0.005 & 0.02 & 0.05 & 0.2 & \\
\hline $\begin{array}{l}\text { Shallow ocean zone or } \\
\text { Great Lake } \\
\text { (depth }<20 \text { feet) }\end{array}$ & & 0 & 0 & 0 & 0.002 & 0.005 & 0.02 & 0.05 & 0.2 & 0.5 & 2 & \\
\hline $\begin{array}{l}\text { Moderate ocean zone or } \\
\text { Great Lake } \\
\text { (Depth } 20 \text { to } 200 \text { feet) }\end{array}$ & & 0 & 0 & 0 & 0 & 0.001 & 0.002 & 0.005 & 0.02 & 0.05 & 0.2 & \\
\hline $\begin{array}{l}\text { Deep ocean zone or Great } \\
\text { Lake } \\
\text { (depth }>200 \text { feet) }\end{array}$ & & 0 & 0 & 0 & 0 & 0 & 0.001 & 0.003 & 0.008 & 0.03 & 0.08 & \\
\hline $\begin{array}{l}\text { 3-mile mixing zone in quiet } \\
\text { flowing river } \\
(\geq 10 \mathrm{cfs})\end{array}$ & & 10 & 0 & 2 & 9 & 26 & 82 & 261 & 817 & 2,607 & 8,163 & \\
\hline Nearest I & $k \theta=$ & & & & & & & & & & Sum $=$ & \\
\hline
\end{tabular}

References 


\section{SURFACE WATER PATHWAY}

\section{Human Food Chain Actual Contamination Targets Summary Table}

On SI Table 10, list the hazardous substances detected in sediment, aqueous, sessile benthic organism tissue, or fish tissue samples (taken from fish caught within the boundaries of the observed release) by sample ID and concentration. Evaluate fisheries within the boundaries of observed releases detected by sediment or aqueous samples as Level II, if at least one observed release substance has a bioaccumulation potential factor value of 500 or greater (see SI Table 7). Obtain benchmark, cancer risk, and reference dose concentrations from SCDM. For FDAAL benchmarks, determine the highest percentage of benchmark obtained for any substance. For cancer risk and reference dose, sum the percentages for the substances listed. If benchmark, cancer risk, or reference dose concentrations are not available for a particular substance, enter N/A for the percentage. If the highest benchmark percentage sum calculated for cancer risk or reference dose equals or exceeds $100 \%$, evaluate this portion of the fishery as subject to Level I concentrations. If the percentages are less than $100 \%$ or all are N/A, evaluate the fishery as a Level II target.

\section{Sensitive Environment Actual Contamination Targets Summary Table}

On SI Table 11, list each hazardous substance detected in aqueous or sediment samples at or beyond wetlands or a surface water sensitive environment by sample ID. Record the concentration. If contaminated sediments or tissues are detected at or beyond a sensitive environment, evaluate the sensitive environment as Level II. Obtain benchmark concentrations from SCDM. For AWQC/AALAC benchmarks, determine the highest percentage of benchmark of the substances detected in aqueous samples. If benchmark concentrations are not available for a particular substance, enter N/A for the percentage. If the highest benchmark percentage equals or exceeds $100 \%$, evaluate that part of the sensitive environment subject to Level I concentrations. If the percentage is less than $100 \%$, or all are N/A, evaluate the sensitive environment as Level II. 
SI TABLE 10: HUMAN FOOD CHAIN ACTUAL CONTAMINATION TARGETS FOR WATERSHED

Fishery ID: Sample Type

Levell

Level II

References

\begin{tabular}{|c|c|c|c|c|c|c|c|c|}
\hline Sample ID & Hazardous Substance & $\begin{array}{l}\text { Conc. } \\
\text { (mg/kg) }\end{array}$ & $\begin{array}{l}\text { Benchmark } \\
\text { Concentration } \\
\text { (FDAAL) }\end{array}$ & $\begin{array}{c}\% \text { of } \\
\text { Benchmark }\end{array}$ & $\begin{array}{l}\text { Cancer Risk } \\
\text { Concentration. }\end{array}$ & $\begin{array}{c}\% \text { of Cancer } \\
\text { Risk } \\
\text { Concentration }\end{array}$ & PfD & $\%$ of RiD \\
\hline & & & & & & & & \\
\hline & & & & & & & & \\
\hline & & & & & & & & \\
\hline & & & & & $\sqrt{n}$ & & & \\
\hline & & & $\begin{array}{l}\text { Highest } \\
\text { Percent }\end{array}$ & & $\begin{array}{c}\text { Sum of } \\
\text { Percents }\end{array}$ & & $\begin{array}{l}\text { Sum of } \\
\text { Percents }\end{array}$ & \\
\hline
\end{tabular}

SI TABLE 11: SENSITIVE ENVIRONMENT ACTUAL CONTAMINATION TARGETS FOR WATERSHED

Environment ID:_ Sample Type

Level I

Level II

Environment Value

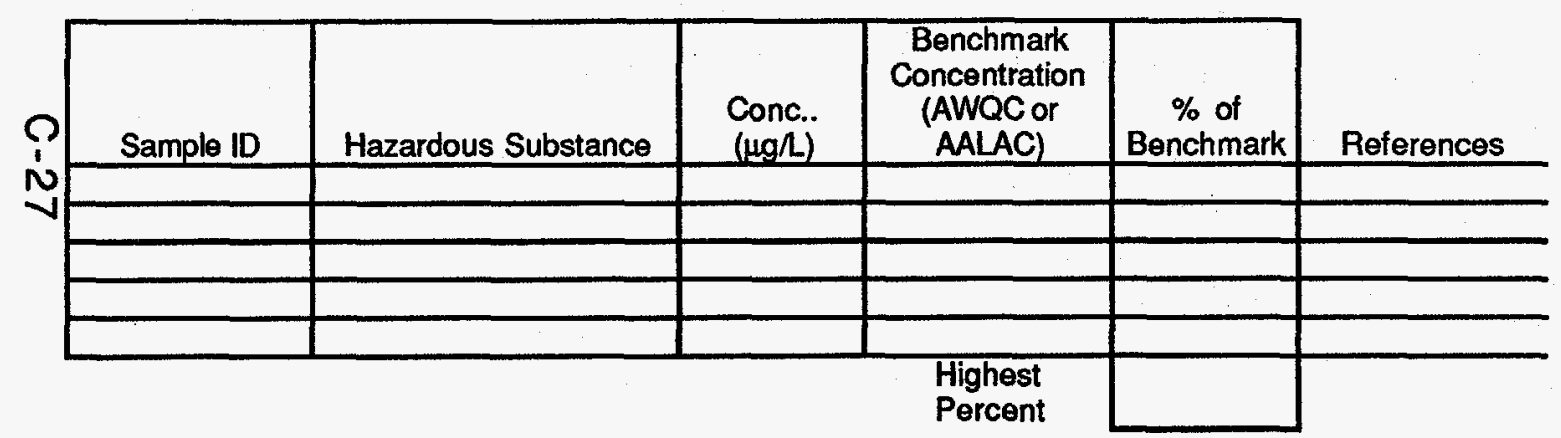

Environment ID: Sample Type

Level I

Level II

Environment Value

\begin{tabular}{|c|c|c|c|c|c|}
\hline Sample ID & Hazardous Substance & $\begin{array}{l}\text { Conc.. } \\
(\mu \mathrm{g} \Lambda)\end{array}$ & $\begin{array}{l}\text { Benchmark } \\
\text { Concentration } \\
\text { (AWOC or } \\
\text { AALAC) } \\
\end{array}$ & $\begin{array}{c}\% \text { of } \\
\text { Benchmark }\end{array}$ & References \\
\hline & & & & & \\
\hline & & & & & \\
\hline & & & & & \\
\hline & & & & & \\
\hline & & & $\begin{array}{l}\text { Highest } \\
\text { Percent }\end{array}$ & & \\
\hline
\end{tabular}




\section{SURFACE WATER PATHWAY (continued) HUMAN FOOD CHAIN THREAT WORKSHEET}

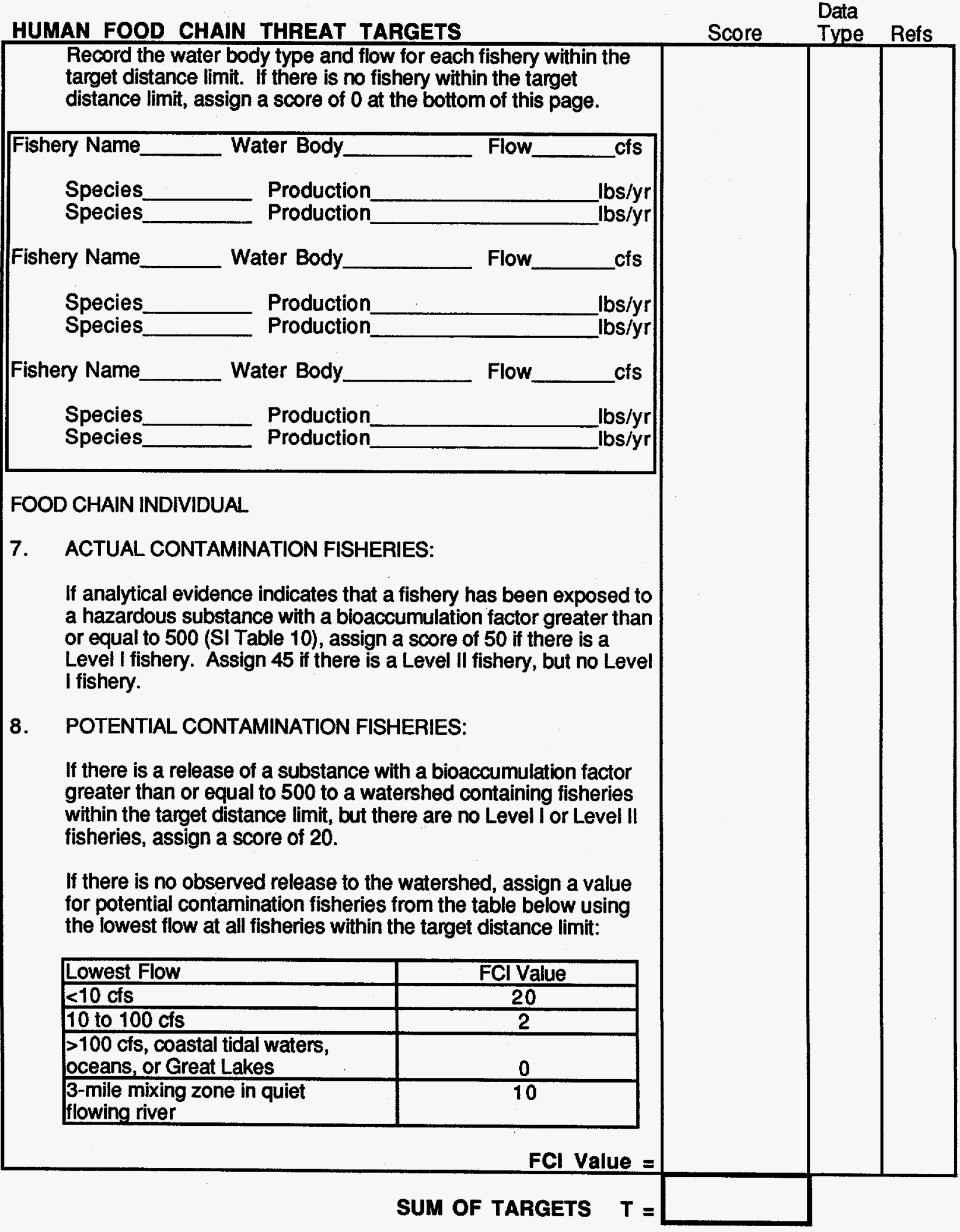




\section{SURFACE WATER PATHWAY (continued) ENVIRONMENTAL THREAT WORKSHEET}

When measuring length of wetlands that are located on both sides of a surface water body, sum both frontage lengths. For a sensitive environment that is more than one type, assign a value for each type.

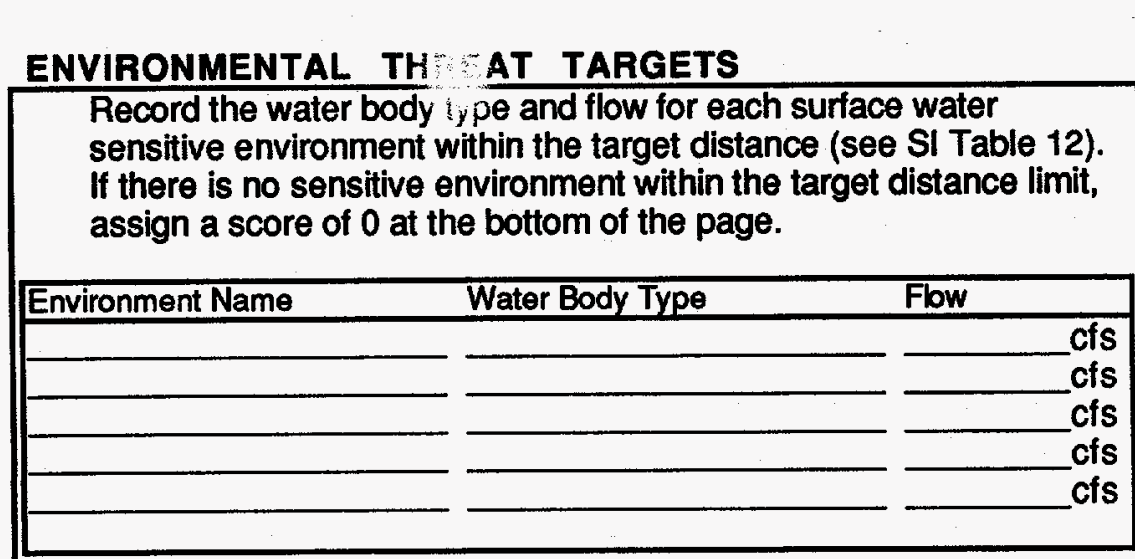

Data

9. ACTUAL CONTAMINATION SENSITIVE ENVIRONMENTS: If sampling data or direct observation indicate any sensitive environment has been exposed to a hazardous substance from the site, record this information on SI Table 11, and assign a factor value for the environment (SI Tables 13 and 14).

\begin{tabular}{||l|l|l|l||}
\hline Environment Name & $\begin{array}{l}\text { Environment Type and } \\
\text { Value (SI Tables 13 \& 14) }\end{array}$ & $\begin{array}{l}\text { Multiplier (10 for } \\
\text { Level I, 1 for } \\
\text { Level il) }\end{array}$ & Product \\
\hline & & $x$ & \\
\hline & & $x$ & \\
\hline & & $x$ & \\
\hline & & $x$ & Sum = \\
\hline
\end{tabular}

10. POTENTIAL CONTAMINATION SENSITIVE ENVIRONMENTS:

\begin{tabular}{|r|r|l|l|l||}
\hline Flow & $\begin{array}{l}\text { Dilution Weight } \\
\text { (SI Table 12) }\end{array}$ & $\begin{array}{l}\text { Environment Type and } \\
\text { Value (SI Tables 13 \& 14) }\end{array}$ & $\begin{array}{l}\text { Pot. } \\
\text { Cont. }\end{array}$ & Product \\
\hline cfs & $x$ & $x$ & $0.1=$ & \\
\hline cfs & $x$ & $x$ & $0.1=$ & \\
\hline cfs & $x$ & $x$ & $0.1=$ & \\
\hline cfs & $x$ & $x$ & $0.1=$ & \\
\hline cfs & $x$ & $x$ & $0.1=$ & \\
\hline
\end{tabular}

$\mathbf{T}=$ 
SI TABLE 12 (HRS Table 4-13):

SURFACE WATER DILUTION WEIGHTS

\begin{tabular}{|l|l|l|}
\hline \multicolumn{2}{|l|}{ Type of Surface Water Body } & \multicolumn{1}{|l|}{$\begin{array}{l}\text { Assigned } \\
\text { Dilution } \\
\text { Weight }\end{array}$} \\
\hline Descriptor & Flow Characteristics & 1 \\
\hline Minimal stream & $<10$ cfs & 0.1 \\
\hline Small to moderate stream & 10 to 100 cfs & 0.01 \\
\hline Moderate to large stream & $>100$ to 1,000 cfs & 0.001 \\
\hline Large stream to river & $>1,000$ to 10,000 cfs & 0.0001 \\
\hline Large river & $>10,000$ to 100,000 cfs & 0.00001 \\
\hline Very large river & $>100,000$ cfs & 0.001 \\
\hline Coastal tidal waters & Flow not applicable; depth not applicable & 0.001 \\
\hline Shallow ocean zone or Great Lake & Flow not applicable; depth less than 20 feet & 0.0001 \\
\hline Moderate depth ocean zone or Great Lake & Flow not applicable; depth 20 to 200 feet & 0.000005 \\
\hline Deep ocean zone or Great Lake & Flow not applicable; depth greater than 200 feet & 0.5 \\
\hline 3-mile mixing zone in quiet flowing river & 10 cfs or greater & \\
\hline
\end{tabular}


SI TABLE 13 (HRS TABLE 4-23):

SURFACE WATER AND AIR SENSITIVE ENVIRONMENTS VALUES

\begin{tabular}{|c|c|}
\hline SENSITIVE ENVIRONMENT & $\begin{array}{l}\text { ASSIGNED } \\
\text { VALUE }\end{array}$ \\
\hline $\begin{array}{l}\text { Critical habitat for Federal designated endangered or threatened species } \\
\text { Marine Sanctuary } \\
\text { National Park } \\
\text { Designated Federal Wilderness Area } \\
\text { Ecologically important areas identified under the Coastal Zone Wilderness Act } \\
\text { Sensitive Areas identified under the National Estuary Program or Near Coastal } \\
\text { Water Program of the Clean Water Act } \\
\text { Critical Areas identified under the Clean Lakes Program of the Clean Water Act } \\
\text { (subareas in lakes or entire small lakes). } \\
\text { National Monument (air pathway only) } \\
\text { National Seashore Recreation Area } \\
\text { National Lakeshore Recreation Area }\end{array}$ & 100 \\
\hline $\begin{array}{l}\text { Habitat known to be used by Federal designated or proposed endangered or threatened species } \\
\text { National Preserve } \\
\text { National or State Wildlife Refuge } \\
\text { Unit of Coastal Barrier Resources System } \\
\text { Coastal Barrier (undeveloped) } \\
\text { Federal land designated for the protection of natural ecosystems } \\
\text { Administratively Proposed Federal Wilderness Area } \\
\text { Spawning areas critical for the maintenance of fish/shellfish species within a } \\
\text { river system, bay, or estuary } \\
\text { Migratory pathways and feeding areas critical for the maintenance of } \\
\text { anadromous fish species within river reaches or areas in lakes or coastal } \\
\text { tidal waters in which the fish spend extended periods of time } \\
\text { Terrestrial areas utilized by large or dense aggregations of vertebrate animals } \\
\text { (semi-aquatic foragers) for breeding } \\
\text { National river reach designated as recreational }\end{array}$ & 75 \\
\hline $\begin{array}{l}\text { Habitat known to be used by State designated endangered or threatened species } \\
\text { Habitat known to be used by a species under review as to its Federal endangered } \\
\text { or threatened status } \\
\text { Coastal Barrier (partially developed) } \\
\text { Federally designated Scenic or Wild River }\end{array}$ & 50 \\
\hline $\begin{array}{l}\text { State land designated for wildlife or game management } \\
\text { State designated Scenic or Wild River } \\
\text { State designated Natural Area } \\
\text { Particular areas, relatively small in size, important to maintenance of unique biotic communities }\end{array}$ & 25 \\
\hline $\begin{array}{l}\text { State designated areas for the protection of maintenance of aquatic life under the Clean Water } \\
\text { Act }\end{array}$ & 5 \\
\hline Wetlands $\quad$ See Sl Table 14 (Surface Water Pathway) or SI Table 23 (Air Pathway) & \\
\hline
\end{tabular}

\section{SI TABLE 14 (HRS TABLE 4-24): SURFACE WATER WETLANDS FRONTAGE VALUES}

\begin{tabular}{|c|c|}
\hline Total Length of Wetlands & Assigned Value \\
\hline $\begin{array}{l}\text { Less than } 0.1 \text { mile } \\
0.1 \text { to } 1 \text { mile } \\
\text { Greater than } 1 \text { to } 2 \text { miles } \\
\text { Greater than } 2 \text { to } 3 \text { miles } \\
\text { Greater than } 3 \text { to } 4 \text { miles } \\
\text { Greater than } 4 \text { to } 8 \text { miles } \\
\text { Greater than } 8 \text { to } 12 \text { miles } \\
\text { Greater than } 12 \text { to } 16 \text { miles } \\
\text { Greater than } 16 \text { to } 20 \text { miles } \\
\text { Greater than } 20 \text { miles }\end{array}$ & $\begin{array}{r}0 \\
25 \\
50 \\
75 \\
100 \\
150 \\
250 \\
350 \\
450 \\
500\end{array}$ \\
\hline
\end{tabular}




\section{SURFACE WATER PATHWAY (concluded) \\ WASTE CHARACTERISTICS, THREAT, AND PATHWAY SCORE SUMMARY}

WASTE CHARACTERISTICS

Score

14. If an Actual Contamination Target (drinking water, human food

chain, or environmental threat) exists for the watershed, assign

the calculated hazardous waste quantity score, or a score of 100 , whichever is greater.

15. Assign the highest value from SI Table 7 (observed release) or SI Table 3 (no observed release) for the hazardous substance waste characterization factors below. Multiply each by the surface water hazardous waste quantity score and determine the waste characteristics score for each threat.

\begin{tabular}{|l|r|r|r||}
\hline & Substance Value & HWQ & Product \\
\hline Drinking Water Threat & & & \\
Toxicity/Persistence & & & \\
\hline Food Chain Threat & & & \\
Toxicity/Persistence & & & \\
Bioaccumulation & & & \\
\hline $\begin{array}{l}\text { Environmental Threat } \\
\text { Ecotoxicity/Persistence/ } \\
\text { Ecobioaccumulation }\end{array}$ & & & \\
\hline
\end{tabular}

WC Score (from Table)

(Maximum of 100)

\begin{tabular}{|l|l|}
\hline Product & WC Score \\
\hline 0 & 0 \\
$>0$ to $<10$ & 1 \\
10 to $<100$ & 2 \\
100 to $<1,000$ & 3 \\
1,000 to $<10,000$ & 6 \\
10,000 to $<1 E+05$ & 10 \\
$1 E+05$ to $<1 E+06$ & 18 \\
$1 E+06$ to $<1 E+07$ & 32 \\
$1 E+07$ to $<1 E+08$ & 56 \\
$1 E+08$ to $<1 E+09$ & 100 \\
$1 E+09$ to $<1 E+10$ & 180 \\
$1 E+10$ to $<1 E+11$ & 320 \\
$1 E+11$ to $<1 E+12$ & 560 \\
$1 E+12$ or greater & 1000 \\
\hline
\end{tabular}

SURFACE WATER PATHWAY THREAT SCORES

\begin{tabular}{|l|l|l|l|l|}
\hline \multicolumn{1}{|c|}{ Threat } & $\begin{array}{c}\text { Likelihood of Release } \\
\text { (LR) Score }\end{array}$ & Targets (T) Score & $\begin{array}{c}\text { Pathway Waste } \\
\text { Characteristics (WC) } \\
\text { Score (determined } \\
\text { above) }\end{array}$ & $\begin{array}{c}\text { Threat Score } \\
\frac{\text { LR } \times \text { T } \times \text { WC }}{82,500}\end{array}$ \\
\hline Drinking Water & & & & (maximum of 100) \\
\hline Human Food Chain & & & & (maximum of 100) \\
\hline Environmental & & & & (maximum of 60) \\
\hline
\end{tabular}

SURFACE WATER PATHWAY SCORE (Drinking Water Threat + Human Food Chain Threat + Environmental Threat) 


\section{SOIL EXPOSURE PATHWAY}

If there is no observed contamination (e.g., ground water plume with no known surface source), do not evaluate the soil exposure pathway. Discuss evidence for no soil exposure pathway.

\section{Soll Exposure Resident Population Targets Summary}

For each property (duplicate page 35 as necessary):

If there is an area of observed contamination on the property and within 200 feet of a residence, school, or day care center, enter on Table 15 each hazardous substance by sample ID. Record the detected concentration. Obtain cancer risk, and reference dose concentrations from SCDM. Sum the cancer risk and reference dose percentages for the substances listed. If cancer risk or reference dose concentrations are not available for a particular substance, enter N/A for the percentage. If the percentage sum calculated for cancer risk or reference dose equals or exceeds $100 \%$, evaluate the residents and students as Level I. If both percentages are less than $100 \%$ or all are N/A, evaluate the targets as Level II. 


\section{SI TABLE 15: SOIL EXPOSURE RESIDENT POPULATION TARGETS}

\begin{tabular}{|c|c|c|c|c|c|c|c|c|}
\hline Residence ID & & & Level I_____ & Lev & 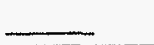 & Population & & \\
\hline Sample ID & Hazardous Substance & $\begin{array}{c}\text { Conc. } \\
\text { (mg/kg) }\end{array}$ & $\begin{array}{l}\text { Cancer Risk } \\
\text { Concentration }\end{array}$ & $\begin{array}{c}\% \text { of } \\
\text { Cancer } \\
\text { Risk Conc. }\end{array}$ & PID & $\%$ of RfD & Toxicity Value & References \\
\hline & & & & & & & & \\
\hline & & & & & & & & \\
\hline & & & & & & & & \\
\hline & & & & & & & & \\
\hline & & & & & & & & \\
\hline & & & $\begin{array}{l}\text { Highest } \\
\text { Percent }\end{array}$ & & $\begin{array}{l}\text { Sum of } \\
\text { Percents }\end{array}$ & & $\begin{array}{c}\text { Sum of } \\
\text { Percents }\end{array}$ & \\
\hline
\end{tabular}

\begin{tabular}{|c|c|c|c|c|c|c|c|c|}
\hline \multicolumn{3}{|l|}{ Residence ID: } & Level I___ & \multicolumn{2}{|c|}{ Level II } & \multicolumn{2}{|l|}{ Population } & \multirow[b]{2}{*}{ References } \\
\hline Sample ID & Hazardous Substance & $\begin{array}{l}\text { Conc. } \\
(\mathrm{mg} / \mathrm{kg})\end{array}$ & $\begin{array}{l}\text { Cancer Risk } \\
\text { Concentration }\end{array}$ & $\begin{array}{c}\% \text { of } \\
\text { Cancer } \\
\text { Risk Conc }\end{array}$ & RfD & $\%$ of RfD & Toxicity Value & \\
\hline & & & & & & & & \\
\hline & & & & & & & & \\
\hline & & & & & & & & \\
\hline & & & & & & & & \\
\hline & & & $\begin{array}{l}\text { Highest } \\
\text { Percent }\end{array}$ & & $\begin{array}{l}\text { Sum of } \\
\text { Percents }\end{array}$ & & $\begin{array}{l}\text { Sum of } \\
\text { Percents }\end{array}$ & \\
\hline
\end{tabular}

\begin{tabular}{|c|c|c|c|c|c|c|c|c|}
\hline \multicolumn{3}{|c|}{ Residence ID: } & Level I & \multicolumn{2}{|c|}{ Level II } & \multicolumn{2}{|l|}{ Population } & \multirow[b]{2}{*}{ References } \\
\hline Sample ID & Hazardous Substance & $\begin{array}{l}\text { Conc. } \\
(\mathrm{mg} / \mathrm{kg})\end{array}$ & $\begin{array}{c}\text { Cancer Risk } \\
\text { Concentration }\end{array}$ & $\begin{array}{c}\% \text { of } \\
\text { Cancer } \\
\text { Risk Conc. }\end{array}$ & RAD & $\%$ of RfD & Toxicity Value & \\
\hline & & & & & & & & \\
\hline & & & & & & & & \\
\hline & & & & & & & & \\
\hline & & & & & & & & \\
\hline & & & $\begin{array}{l}\text { Highest } \\
\text { Percent }\end{array}$ & & $\begin{array}{c}\text { Sum of } \\
\text { Percents }\end{array}$ & & $\begin{array}{l}\text { Sum of } \\
\text { Percents }\end{array}$ & \\
\hline
\end{tabular}




\section{SOIL EXPOSURE PATHWAY WORKSHEET RESIDENT POPULATION THREAT}

\section{LIKELIHOOD OF EXPOSURE}

1. OBSERVED CONTAMINATION: If evidence indicates presence of observed contamination (depth of 2 feet or less), assign a score of 550 ; otherwise, assign a 0 . Note that a likelihood of exposure score of 0 results in a soil exposure pathway score of 0 .

Data Score Type Refs LE =

TARGETS

2. RESIDENT POPULATION: Determine the number of people occupying residences or attending school or day care on or within 200 feet of areas of observed contamination (HRS section 5.1.3).

Level I:

Level II: people $\times 10$ people $\times 1$

$=$

$=$

Sum $=$

3. RESIDENT INDIVIDUAL: Assign a score of 50 if any Levell resident population exists. Assign a score of 45 if there are Level II targets but no Level I targets. If no resident population exists (i.e., no Levell or Level II targets), assign 0 (HRS Section 5.1.3).

4. WORKERS: Assign a score from the table below for the total number of workers at the site and nearby facilities with areas of observed contamination associated with the site.

\begin{tabular}{|c|c|}
\hline Number of Workers & Score \\
\hline 0 & 0 \\
\hline 1 to 100 & 5 \\
\hline 101 to 1,000 & 10 \\
\hline$>1,000$ & 15 \\
\hline
\end{tabular}

5. TERRESTRIAL SENSITIVE ENVIRONMENTS: Assign a value for each terrestrial sensitive environment (SI Table 16) in an area of observed contamination.

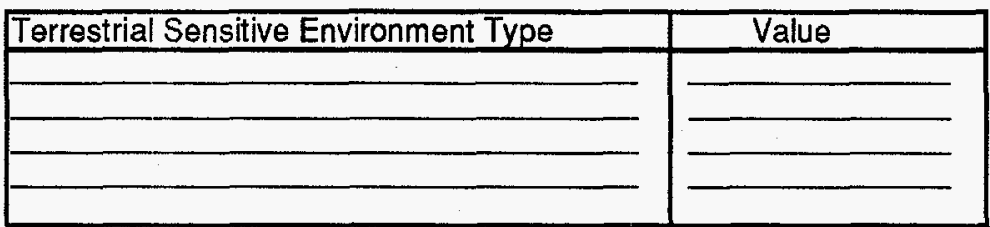

6. RESOURCES: Assign a score of 5 if any one or more of the following resources is present on an area of observed contamination at the site; assign 0 if none applies.

- Commercial agriculture

- Commercial silviculture

- Commercial livestock production or commercial livestock grazing

Total of Targets

$\mathrm{T}=$ 


\section{SI TABLE 16 (HRS TABLE 5-5): SOIL EXPOSURE PATHWAY TERRESTRIAL SENSITIVE ENVIRONMENT VALUES}

\begin{tabular}{|c|c|}
\hline TERRESTRIAL SENSITIVE ENVIRONMENT & ASSIGNED VALUE \\
\hline $\begin{array}{l}\text { Terrestrial critical habitat for Federal designated endangered or } \\
\text { threatened species } \\
\text { National Park } \\
\text { Designated Federal Wilderness Area } \\
\text { National Monument }\end{array}$ & 100 \\
\hline $\begin{array}{l}\text { Terrestrial habitat known to be used by Federal designated or proposed threatened } \\
\text { or endangered species } \\
\text { National Preserve (terrestrial) } \\
\text { National or State terrestrial Wildife Refuge } \\
\text { Federal land designated for protection of natural ecosystems } \\
\text { Administratively proposed Federal Wilderness Area } \\
\text { Terrestrial areas utilized by large or dense aggregations of animals } \\
\text { (vertebrate species) for breeding }\end{array}$ & 75 \\
\hline $\begin{array}{l}\text { Terrestrial habitat used by State designated endangered or threatened species } \\
\text { Terrestrial habitat used by species under review for Federal designated } \\
\text { endangered or threatened status }\end{array}$ & 50 \\
\hline $\begin{array}{l}\text { State lands designated for wildife or game management } \\
\text { State designated Natural Areas } \\
\text { Particular areas, relatively small in size, important to maintenance of } \\
\text { unique biotic communities }\end{array}$ & 25 \\
\hline
\end{tabular}




\section{SOIL EXPOSURE PATHWAY WORKSHEET}

NEARBY POPULATION THREAT

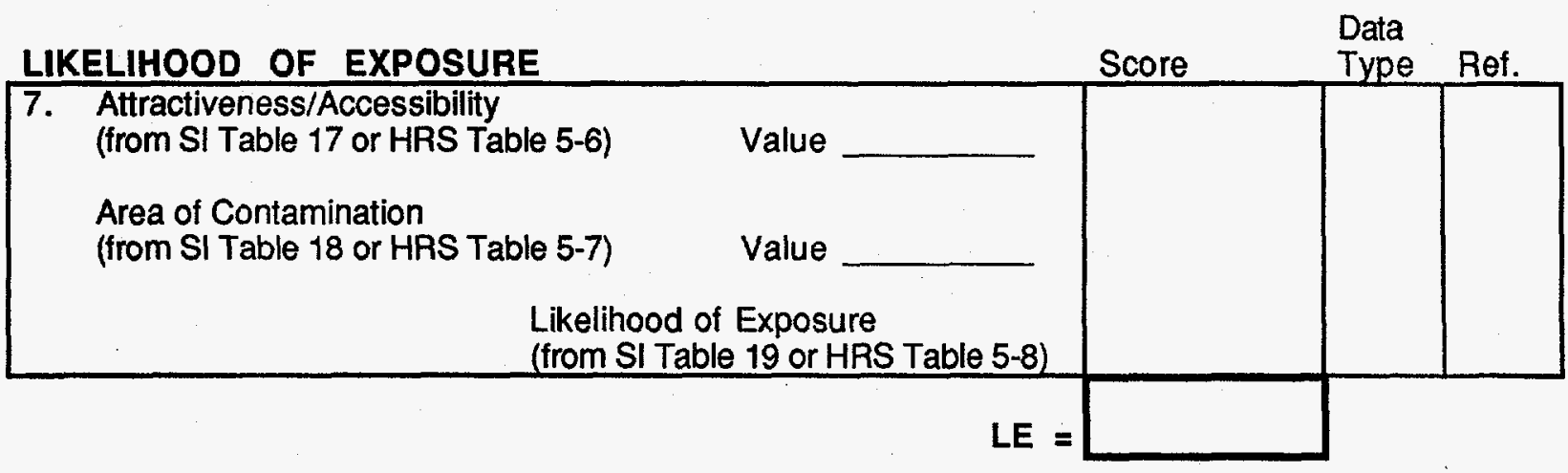

TARGETS

8. Assign a score of 0 if Level I or Level II resident individual has been evaluated or if no individuals live within $1 / 4$ mile travel distance of an area of observed contamination. Assign a score of 1 if nearby population is within $1 / 4$ mile travel distance and no Level I or Level II resident population has been evaluated.

9. Determine the population within 1 mile travel distance that is not exposed to a hazardous substance from the site (i.e., properties that are not determined to be Level I or Level II); record the population for each distance category in SI Table 20 (HRS Table 510). Sum the population values and multiply by 0.1 .

Data Score Type Ref. 
SI TABLE 17 (HRS TABLE 5-6):

ATTRACTIVENESS/ACCESSIBILITY VALUES

\begin{tabular}{|l|c|}
\hline \multicolumn{1}{|c|}{ Area of Observed Contamination } & $\begin{array}{c}\text { Assigned } \\
\text { Value }\end{array}$ \\
\hline Designated recreational area & 100 \\
\hline $\begin{array}{l}\text { Regularly used for public recreation (for example, vacant lots in urban } \\
\text { area) }\end{array}$ & 75 \\
\hline $\begin{array}{l}\text { Accessible and unique recreational area (for example, vacant lots in } \\
\text { urban area) }\end{array}$ & 75 \\
\hline $\begin{array}{l}\text { Moderately accessible (may have some access improvements-for } \\
\text { example, gravel road) with some public recreation use }\end{array}$ & 50 \\
\hline $\begin{array}{l}\text { Slightly accessible (for example, extremely rural area with no road } \\
\text { improvement) with some public recreation use }\end{array}$ & 25 \\
\hline Accessible with no public recreation use & 10 \\
\hline $\begin{array}{l}\text { Surrounded by maintained fence or combination of maintained fence } \\
\text { and natural barriers }\end{array}$ & 5 \\
\hline $\begin{array}{l}\text { Physically inaccessible to public, with no evidence of public recreation } \\
\text { use }\end{array}$ & 0 \\
\hline
\end{tabular}

\section{SI TABLE 18 (HRS TABLE 5-7): AREA OF CONTAMINATION FACTOR VALUES}

\begin{tabular}{|c|c|}
\hline $\begin{array}{c}\text { Total area of the areas of } \\
\text { observed contamination (square feet) }\end{array}$ & $\begin{array}{c}\text { Assigned } \\
\text { Value }\end{array}$ \\
\hline$\leq$ to 5,000 & 5 \\
\hline$>5,000$ to 125,000 & 20 \\
\hline$>125,000$ to 250,000 & 40 \\
\hline$>250,000$ to 375,000 & 60 \\
\hline$>375,000$ to 500,000 & 80 \\
\hline$>500,000$ & 100 \\
\hline
\end{tabular}


SI TABLE 19 (HRS TABLE 5-8): NEARBY POPULATION LIKELIHOOD OF EXPOSURE FACTOR VALUES

\begin{tabular}{|c|c|c|c|c|c|c|c|}
\hline \multirow{2}{*}{$\begin{array}{l}\text { AREA OF } \\
\text { CONTAMINATION } \\
\text { FACTOR VALUE }\end{array}$} & \multicolumn{7}{|c|}{ ATTRACTIVENESS/ACCESSIBILITY } \\
\hline & 100 & 75 & 50 & 25 & 10 & 5 & $\mathbf{0}$ \\
\hline 100 & 500 & 500 & 375 & 250 & 125 & 50 & 0 \\
\hline 80 & 500 & 375 & 250 & 125 & 50 & 25 & 0 \\
\hline 60 & 375 & 250 & 125 & 50 & 25 & 5 & 0 \\
\hline 40 & 250 & 125 & 50 & 25 & 5 & 5 & 0 \\
\hline 20 & 125 & 50 & 25 & 5 & 5 & 5 & 0 \\
\hline 5 & 50 & 25 & 5 & 5 & 5 & 5 & 0 \\
\hline
\end{tabular}

$\stackrel{0}{1}$

SI TABLE 20 (HRS TABLE 5-10): DISTANCE-WEIGHTED POPULATION VALUES FOR NEARBY POPULATION THREAT

\begin{tabular}{|c|c|c|c|c|c|c|c|c|c|c|c|c|c|c|}
\hline \multirow{2}{*}{$\begin{array}{l}\text { Travel Distance } \\
\text { Category } \\
\text { (miles) }\end{array}$} & \multirow{2}{*}{ Pop. } & \multicolumn{12}{|c|}{ Number of people within the travel distance category } & \multirow[b]{2}{*}{$\begin{array}{l}\text { Pop. } \\
\text { Value }\end{array}$} \\
\hline & & $\mathbf{0}$ & $\begin{array}{l}1 \\
\text { to } \\
10 \\
\end{array}$ & $\begin{array}{l}11 \\
10 \\
30 \\
\end{array}$ & $\begin{array}{l}31 \\
\text { to } \\
100 \\
\end{array}$ & $\begin{array}{c}101 \\
10 \\
300 \\
\end{array}$ & $\begin{array}{c}301 \\
t 0 \\
1,000 \\
\end{array}$ & \begin{tabular}{|c|}
1,001 \\
$t 0$ \\
3,000 \\
\end{tabular} & $\begin{array}{c}3,001 \\
10 \\
10,001 \\
\end{array}$ & $\begin{array}{c}10,001 \\
\text { to } \\
30,000 \\
\end{array}$ & $\begin{array}{c}30,001 \\
\text { to } \\
100,000 \\
\end{array}$ & $\begin{array}{c}100,001 \\
t 0 \\
300,000 \\
\end{array}$ & $\begin{array}{c}300,001 \\
t 0 \\
1,000,000 \\
\end{array}$ & \\
\hline Greater than 0 to $\frac{1}{4}$ & & 0 & 0.1 & 0.4 & 1.0 & 4 & 13 & 41 & 130 & 408 & 1,303 & 4,081 & 13,034 & \\
\hline Greater than $\frac{1}{4}$ to $\frac{1}{2}$ & & 0 & 0.05 & 0.2 & 0.7 & 2 & 7 & 20 & 65 & 204 & 652 & 2,041 & 6,517 & \\
\hline Greater than $\frac{1}{2}$ to 1 & & 0 & 0.02 & 0.1 & 0.3 & 1 & 3 & 10 & 33 & 102 & 326 & 1,020 & 3,258 & \\
\hline
\end{tabular}




\section{SOIL EXPOSURE PATHWAY WORKSHEET (concluded)}

\section{WASTE CHARACTERISTICS}

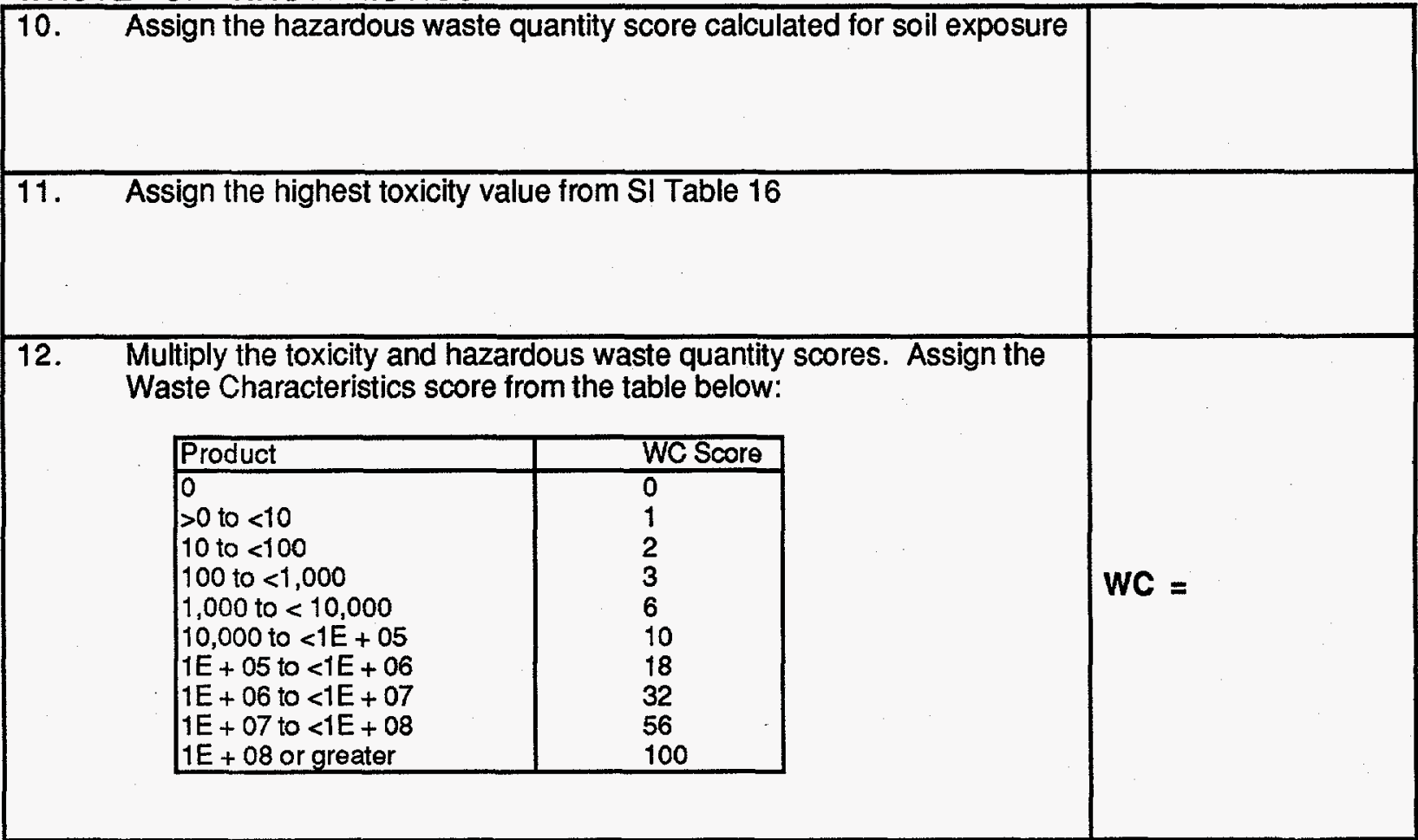

\section{RESIDENT POPULATION THREAT SCORE:}

(Likelihood of Exposure, Question 1;

Targets $=$ Sum of Questions 2, 3, 4, 5, 6)

LEXTXWC

82,500

\section{NEARBY POPULATION THREAT SCORE:}

(Likelihood of Exposure, Question 7;

Targets = Sum of Questions 8, 9)

LE XTXWC

82,500

SOIL EXPOSURE PATHWAY SCORE:

Resident Population Threat + Nearby Population Threat

(Maximum of 100) 


\section{AIR PATHWAY}

\section{Alr Pathway Observed Substances Summary Table}

On SI Table 21, list the hazardous substances detected in air samples of a release from the site. Include only those substances with concentrations significantly greater than background levels. Obtain benchmark, cancer risk, and reference dose concentrations from SCDM. For NAAQS/NESHAPS benchmarks, determine the highest percentage of benchmark obtained for any substance. For cancer risk and reference dose, sum the percentages for the substances listed. If benchmark, cancer risk, or reference dose concentrations are not available for a particular substance, enter N/A for the percentage. If the highest benchmark percentage or the percentage sum calculated for cancer risk or reference dose equals or exceeds $100 \%$, evaluate targets in the distance category from which the sample was taken and any closer distance categories as Level I. If the percentages are less than $100 \%$ or all are N/A, evaluate targets in that distance category and any closer distance categories that are not Level I as Level II. 


\section{SI TABLE 21: AIR PATHWAY OBSERVED RELEASE SUBSTANCES}

\begin{tabular}{|c|c|c|c|c|c|c|c|c|}
\hline \multicolumn{2}{|l|}{ Sample ID: } & \multicolumn{2}{|c|}{ Level I } & Level II & \multicolumn{2}{|c|}{ Distance from Sources (mi) } & References & \multirow[b]{2}{*}{$\%$ of RifD } \\
\hline Hazardous Substance & Conc. $\left(\mu \mathrm{g} / \mathrm{m}^{3}\right)$ & $\begin{array}{l}\text { Gaseous } \\
\text { Particulate }\end{array}$ & $\begin{array}{l}\text { Benchmark } \\
\text { Conc. } \\
\text { (NAAQS or } \\
\text { NESHAPS) }\end{array}$ & $\begin{array}{c}\% \text { of } \\
\text { Benchmark }\end{array}$ & $\begin{array}{c}\text { Cancer Risk } \\
\text { Conc. }\end{array}$ & $\begin{array}{l}\% \text { of Cancer } \\
\text { Risk Conc. }\end{array}$ & RfD & \\
\hline & & & & & & & & \\
\hline & & & & & & & & \\
\hline & & & & & & & & \\
\hline & & & & & & & & \\
\hline & $\begin{array}{r}\text { Highest Toxicity/ } \\
\text { Mobility }\end{array}$ & & $\begin{array}{l}\text { Highest } \\
\text { Percent }\end{array}$ & & $\begin{array}{l}\text { Sum of } \\
\text { Percents }\end{array}$ & & $\begin{array}{l}\text { Sum of } \\
\text { Percents }\end{array}$ & \\
\hline
\end{tabular}

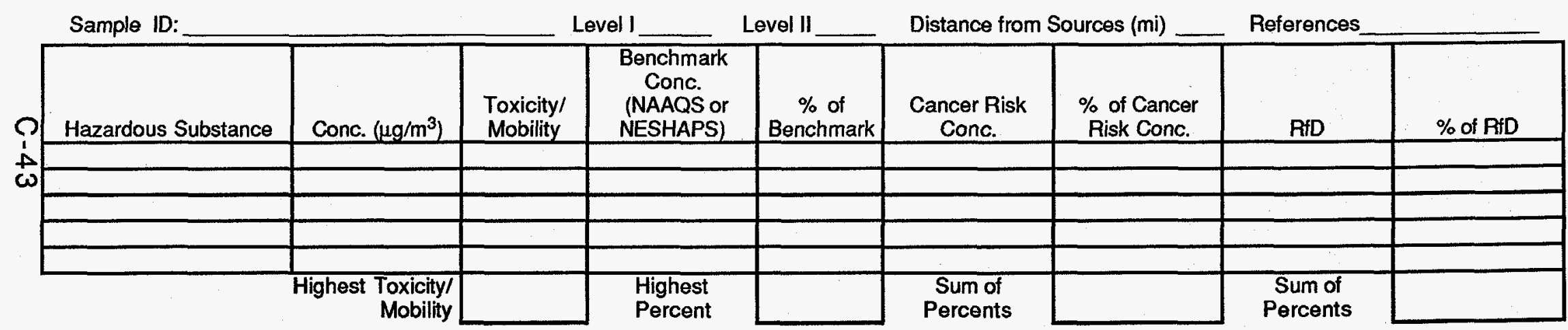

\begin{tabular}{|c|c|c|c|c|c|c|c|c|}
\hline \multicolumn{3}{|l|}{ Sample ID: } & \multicolumn{2}{|c|}{ Level II } & \multicolumn{2}{|c|}{ Distance from Sources (mi) } & \multicolumn{2}{|l|}{ References_ } \\
\hline Hazardous Substance & Conc. $\left(\mu \mathrm{g} / \mathrm{m}^{3}\right)$ & $\begin{array}{l}\text { Toxicity/ } \\
\text { Mobility }\end{array}$ & $\begin{array}{l}\text { Benchmark } \\
\text { Conc. } \\
\text { (NAAQS or } \\
\text { NESHAPS) }\end{array}$ & $\begin{array}{c}\% \text { of } \\
\text { Benchmark }\end{array}$ & $\begin{array}{c}\text { Cancer Risk } \\
\text { Conc. }\end{array}$ & $\begin{array}{l}\% \text { of Cancer } \\
\text { Risk Conc. }\end{array}$ & RiD & $\%$ of RiD \\
\hline & & & & & & & & \\
\hline & & & & & & & & \\
\hline & & & & & & & & \\
\hline & & & & & & & & \\
\hline & $\begin{array}{r}\text { Highest Toxicity/ } \\
\text { Mobility }\end{array}$ & & $\begin{array}{l}\text { Highest } \\
\text { Percent }\end{array}$ & & $\begin{array}{l}\text { Sum of } \\
\text { Percents }\end{array}$ & & $\begin{array}{c}\text { Sum of } \\
\text { Percents }\end{array}$ & \\
\hline
\end{tabular}




\section{AIR PATHWAY WORKSHEET}

LIKELIHOOD OF RELEASE

\begin{tabular}{|c|c|c|c|}
\hline & Score & $\begin{array}{l}\text { Data } \\
\text { Type }\end{array}$ & Refs \\
\hline ved & & & \\
\hline & & & \\
\hline & & & \\
\hline LR $=$ & & & \\
\hline
\end{tabular}

TARGETS

1. OBSERVED RELEASE: If sampling data or direct observation support a release to air, assign a score of 550 . Record observed release substances on SI Table 21.

2. POTENTIAL TO RELEASE: If sampling data do not support a release to air, assign a score of 500 . Optionally, evaluate air migration gaseous and particulate potential to release (HRS Section 6.1.2).

3. ACTUAL CONTAMINATION POPULATION: Determine the number of people within the target distance limit subject to exposure from a release of a hazardous substance to the air.

a) Level I:

b) Level II: people $\times 10=$ people $\times 1=$

4. POTENTIAL TARGET POPULATION: Determine the number of people within the target distance limit not subject to exposure from a release of a hazardous substance to the air, and assign the total population score from SI Table 22. Sum the values and multiply the sum by 0.1 .

5. NEAREST INDIVIDUAL: Assign a score of 50 if there are any Level I targets. Assign a score of 45 if there are Level II targets but no Level I targets. If no Actual Contamination Population exists, assign the Nearest Individual score from SI Table 22.

6. ACTUAL CONTAMINATION SENSITIVE ENVIRONMENTS: SUm the sensitive environment values (SI Table 13) and wetland acreage values (SI Table 23) for environments subject to exposure from the release of a hazardous substance to the air.

\begin{tabular}{|l|r|}
\hline Sensitive Environment Type & Value \\
\hline & \\
\hline & \\
\hline & \\
\hline Wetland Acreage & Value \\
\hline & \\
\hline & \\
\hline & \\
\hline
\end{tabular}

7. POTENTIAL CONTAMINATION SENSITIVE ENVIRONMENTS: Use SI Table 24 to evaluate sensitive environments not subject to exposure from a release.

8. RESOURCES: Assign a score of 5 if one or more air resources apply within 1/2 mile of a source; assign a 0 if none applies.

- Commercial agriculture

- Commercial silviculture

- Major or designated recreation area 


\section{SI TABLE 22 (From HRS TABLE 6-17): VALUES FOR POTENTIAL CONTAMINATION AIR TARGET}

POPULATIONS

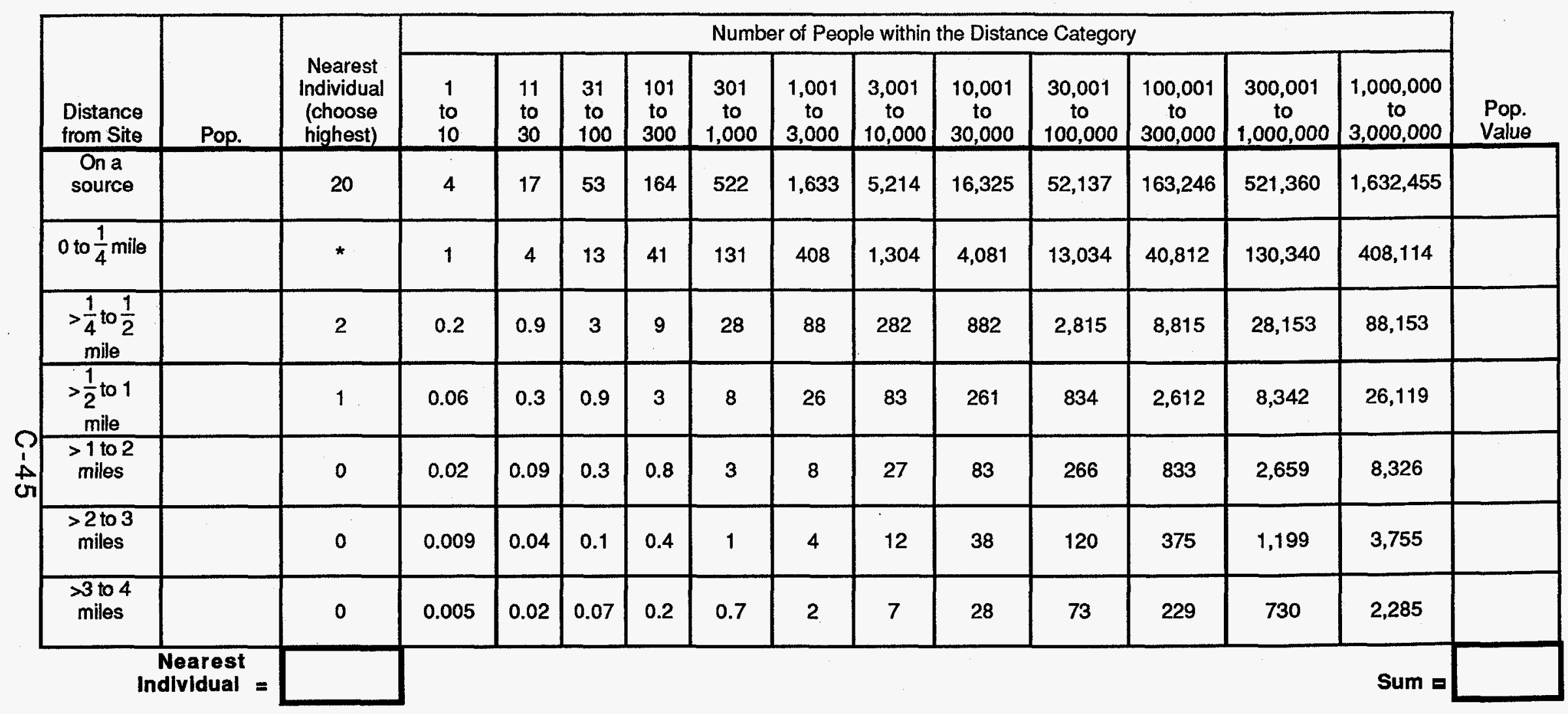

\section{References}

${ }^{*}$ Score $=20$ if the Nearest Individual is within $\frac{1}{8}$ mile of a source; score $=7$ if the Nearest Individual is between $\frac{1}{8}$ and $\frac{1}{4}$ mile of a source. 
SI TABLE 23 (HRS TABLE 6-18): AIR PATHWAY

VALUES FOR WETLAND AREA

\begin{tabular}{|c|c|}
\hline Wetland Area & $\begin{array}{c}\text { Assigned } \\
\text { Value }\end{array}$ \\
\hline$<1$ acre & 0 \\
\hline 1 to 50 acres & 25 \\
\hline$>50$ to 100 acres & 75 \\
\hline$>100$ to 150 acres & 125 \\
\hline$>150$ to 200 acres & 175 \\
\hline$>200$ to 300 acres & 250 \\
\hline$>300$ to 400 acres & 350 \\
\hline$>400$ to 500 acres & 450 \\
\hline$>500$ acres & 500 \\
\hline
\end{tabular}

SI TABLE 24: DISTANCE WEIGHTS AND CALCULATIONS FOR AIR PATHWAY POTENTIAL CONTAMINATION SENSITIVE ENVIRONMENTS

\begin{tabular}{|c|c|c|c|}
\hline Distance & $\begin{array}{l}\text { Distance } \\
\text { Weight }\end{array}$ & $\begin{array}{l}\text { Sensitive Environment Type and } \\
\text { Value (from SI Tables } 13 \text { and } 20 \text { ) }\end{array}$ & Product \\
\hline \multirow[t]{2}{*}{ On a Source } & \multirow[t]{2}{*}{0.10} & $x$ & \\
\hline & & $x$ & \\
\hline \multirow[t]{3}{*}{0 to $1 / 4$ mile } & \multirow[t]{3}{*}{0.025} & $x$ & \\
\hline & & $x$ & \\
\hline & & $x$ & \\
\hline \multirow[t]{3}{*}{$1 / 4$ to $1 / 2$ mile } & \multirow[t]{3}{*}{0.0054} & $x$ & \\
\hline & & $x$ & \\
\hline & & $x$ & \\
\hline \multirow[t]{3}{*}{$1 / 2$ to 1 mile } & \multirow[t]{3}{*}{0.0016} & $x$ & \\
\hline & & $x$ & \\
\hline & & $x$ & \\
\hline \multirow[t]{3}{*}{1 to 2 miles } & \multirow[t]{3}{*}{0.0005} & $x$ & \\
\hline & & $x$ & \\
\hline & & $x$ & \\
\hline \multirow[t]{3}{*}{2 to 3 miles } & \multirow[t]{3}{*}{0.00023} & $x$ & \\
\hline & & $x$ & \\
\hline & & $x$ & \\
\hline \multirow[t]{3}{*}{3 to 4 miles } & \multirow[t]{3}{*}{0.00014} & $x$ & \\
\hline & & $x$ & \\
\hline & & $x$ & \\
\hline$>4$ miles & 0 & $x$ & \\
\hline
\end{tabular}




\section{AIR PATHWAY (concluded)}

\section{WASTE CHARACTERISTICS}

9. If any Actual Contamination Targets exist for the air pathway, assign the calculated hazardous waste quantity score or a score of 100 , whichever is greater; if there are no Actual Contamination Targets for the air pathway, assign the calculated HWQ score for sources available to air migration.

10. Assign the highest air toxicity/mobility value from SI Table 21 .

11. Multiply the air pathway toxicity/mobility and hazardous waste quantity scores. Assign the Waste Characteristics score from the table below:

\begin{tabular}{|l|c|}
\hline Product & WC Score \\
\hline 0 & 0 \\
$>0$ to $<10$ & 1 \\
10 to $<100$ & 2 \\
100 to $<1,000$ & 3 \\
1,000 to $<10,000$ & 6 \\
10,000 to $<1 E+05$ & 10 \\
$1 E+05$ to $<1 E+06$ & 18 \\
$1 E+06$ to $<1 E+07$ & 32 \\
$1 E+07$ to $<1 E+08$ & 56 \\
$1 E+08$ or greater & 100 \\
\hline
\end{tabular}

WC $=$

AIR PATHWAY SCORE:

$\frac{\text { LEE } \times T \times W C}{82,500}$

(maximum of 100 ) 


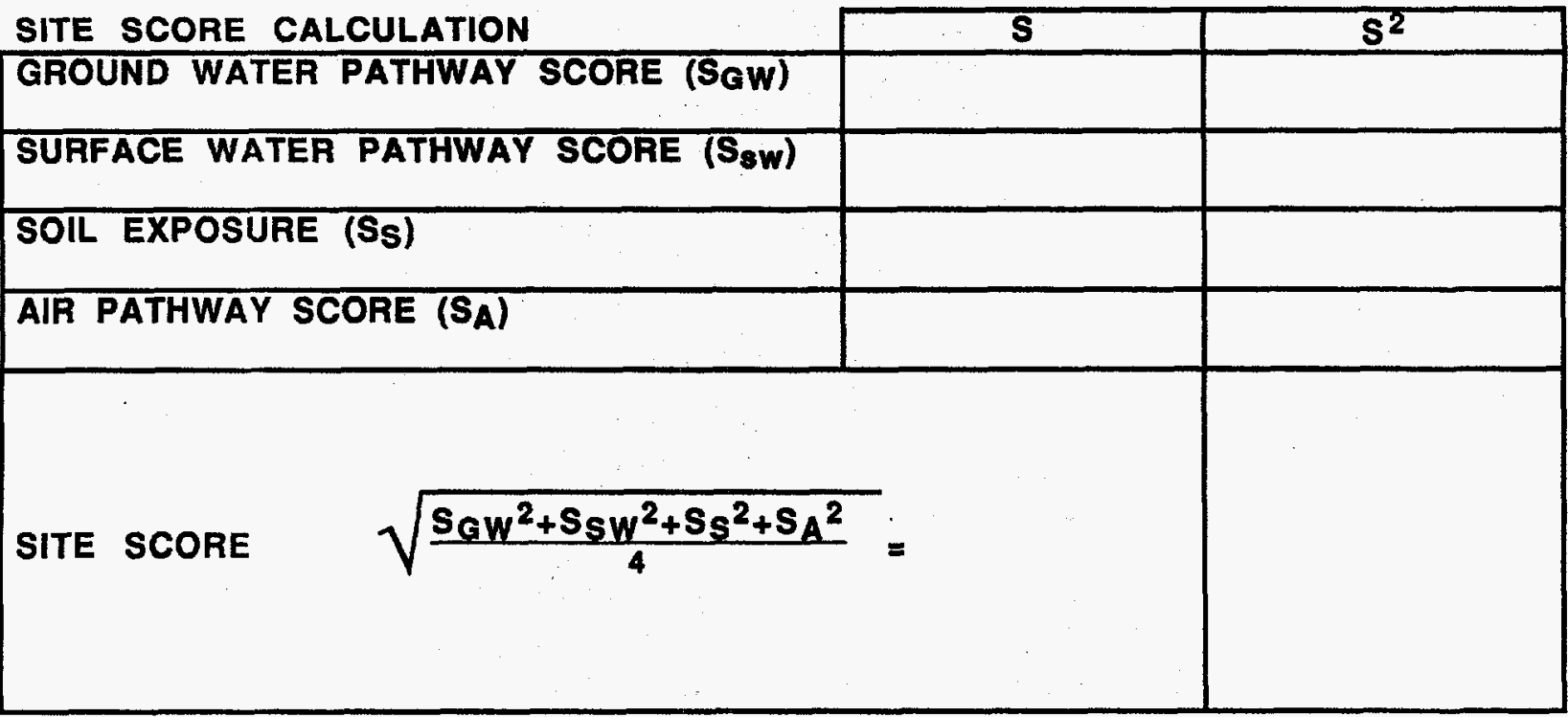

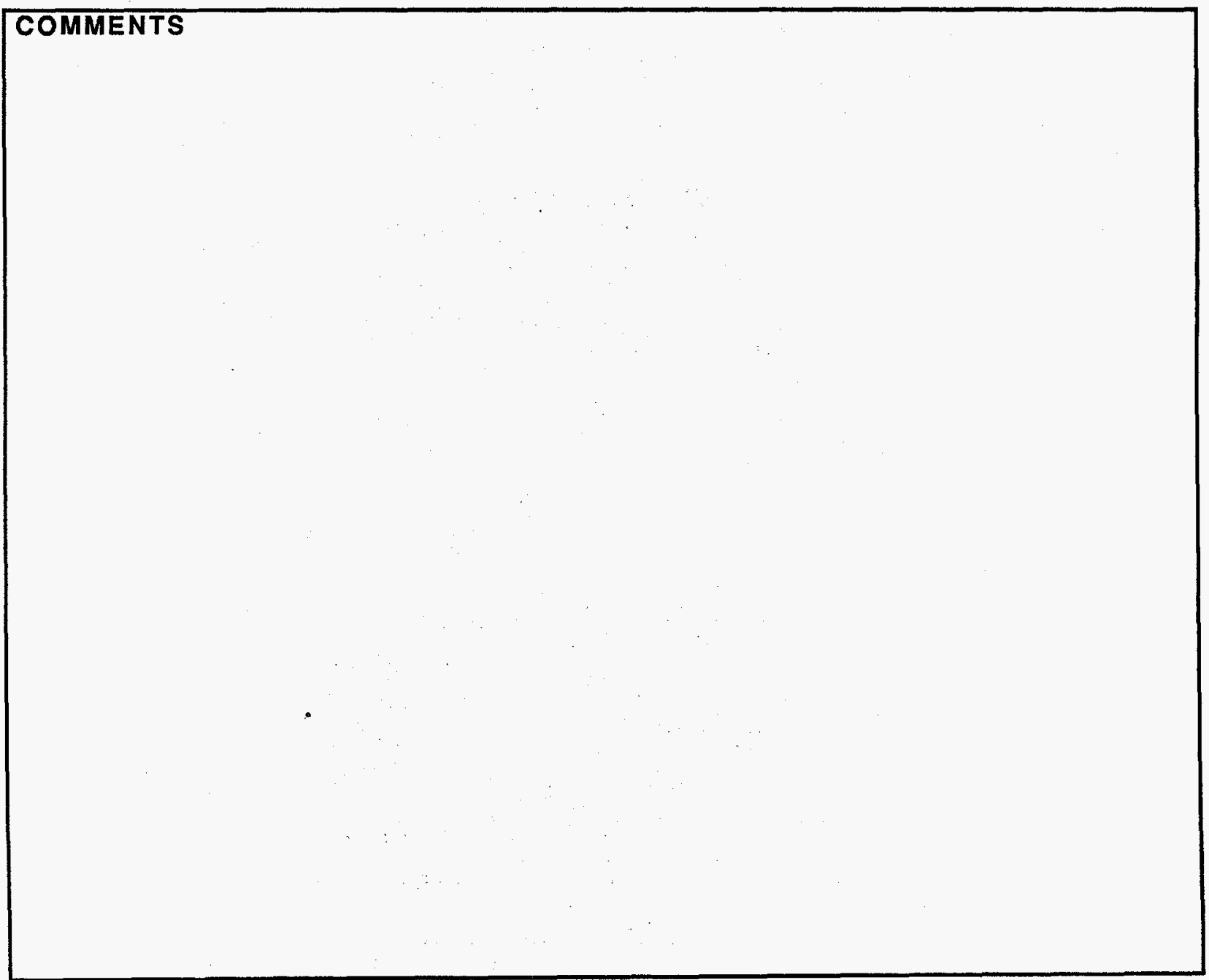




\section{APPENDIX D \\ SI NARRATIVE REPORT (EXAMPLE)}

This appendix provides an example of a narrative report for a $\mathrm{SI}$ at a fictitious site, following the form and content discussed in Chapter 6 . Note that this guidance example does not include reproductions of reference material, full-size USGS topographic quadrangle maps, site photographs and accompanying photodocumentation log, or other applicable attachments.

SITE INSPECTION NARRATIVE REPORT

PALMETTO LANDFILL

PALMETTO COUNTY, SOUTH CAROLINA

TDD NO. Y9-87912-43

JANUARY 29, 1992

XYZ Corporation

Prepared By

Joseph Brown

Project Manager
Lucy Pauling

Project Coordinator
Approved By

Maria Gomez

Regional Project Manager 


\section{CONTENTS}

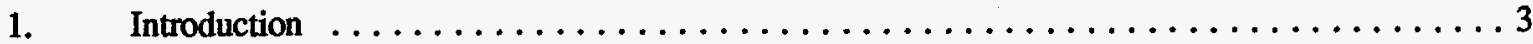

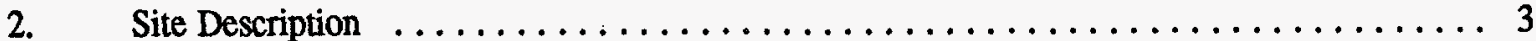

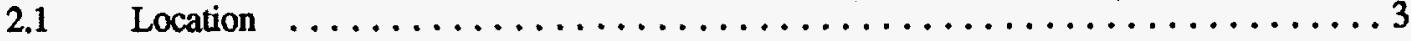

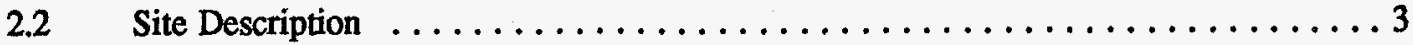

2.3 Operational History and Waste Characteristics $\ldots \ldots \ldots \ldots \ldots \ldots \ldots \ldots$

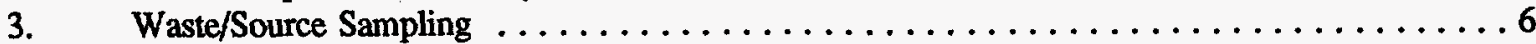

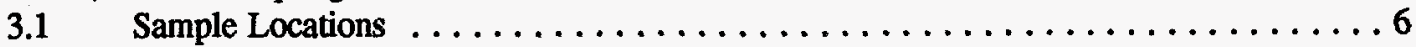

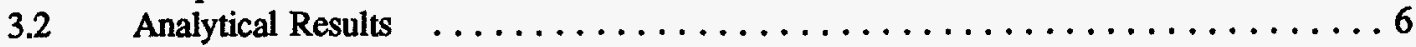

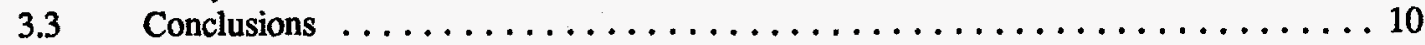

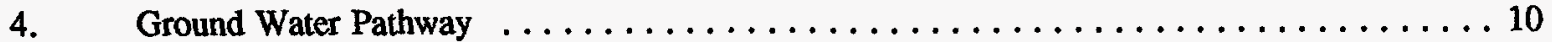

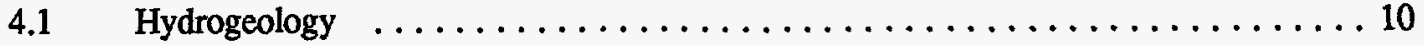

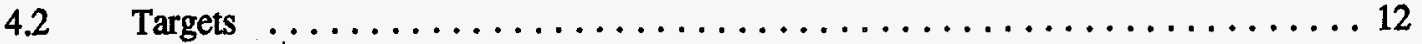

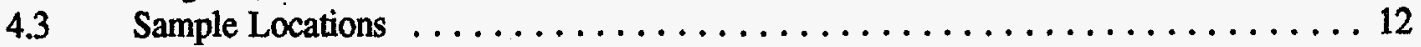

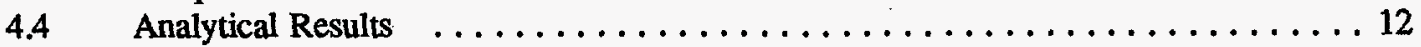

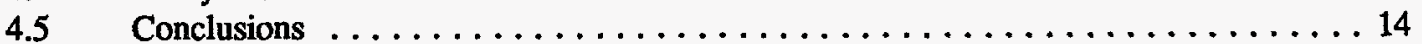

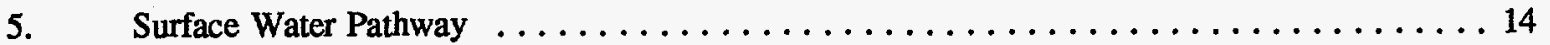

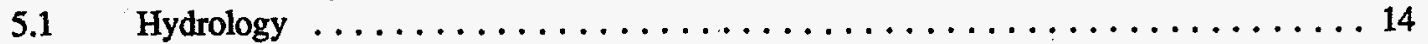

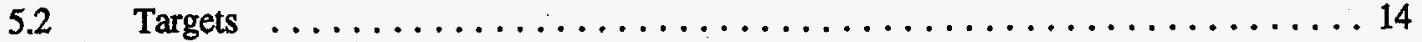

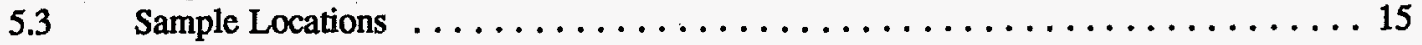

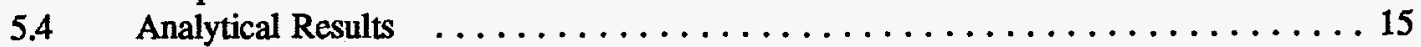

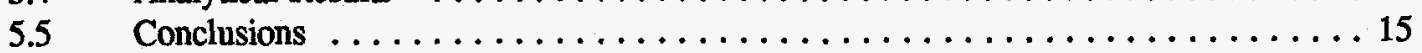

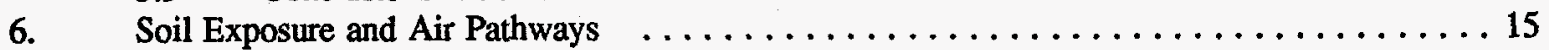

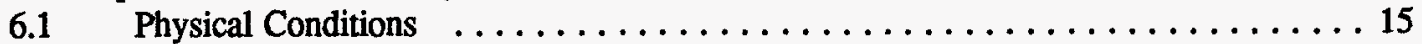

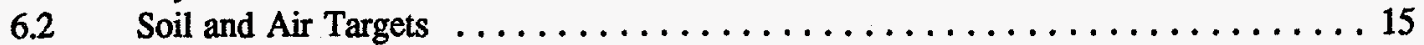

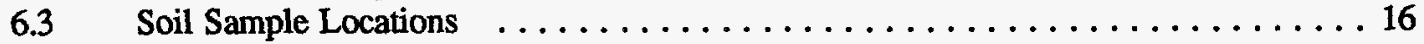

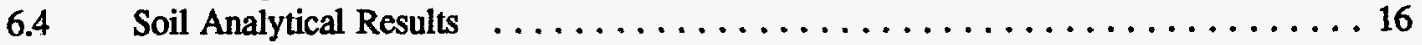

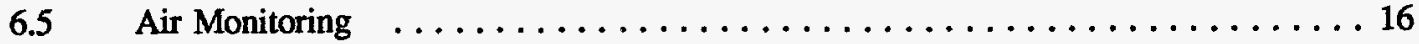

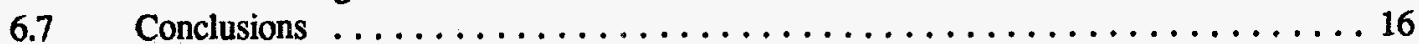

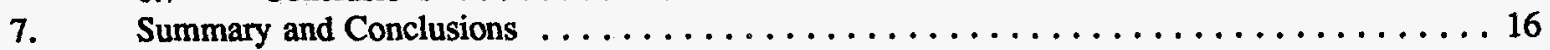

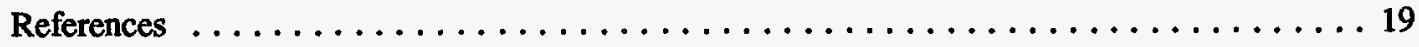

Table 1:

Table 2:

Table 3:

Figure 1:

Figure 2:

Figure 3:

Figure 4:

Figure 5:
Sample Collection $\ldots \ldots \ldots \ldots \ldots \ldots \ldots \ldots \ldots \ldots \ldots \ldots \ldots \ldots \ldots$

Field Measurements for Ground Water Samples $\ldots \ldots \ldots \ldots \ldots \ldots \ldots$

Part 1: Analytical Results for Aqueous Samples . . . . . . . . . . . . 17

Part 2: Analytical Results for Non-Aqueous Samples . . . . . . . . . . . . 18

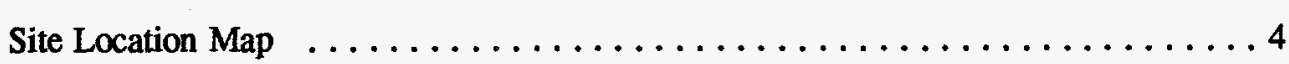

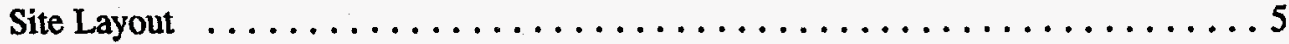

SI Sample Locations $\ldots \ldots \ldots \ldots \ldots \ldots \ldots \ldots \ldots \ldots \ldots \ldots \ldots \ldots$

Well Log From 19 Palmetto Lane $\ldots \ldots \ldots \ldots \ldots \ldots \ldots$

SI Ground Water Sample Locations $\ldots \ldots \ldots \ldots \ldots \ldots \ldots \ldots$ 
Date: $\quad$ January 29,1992

Prepared by: Joseph Brown, XYZ Corporation, Region 4, Atlanta, Georgia

Site:

Palmetto Landfill, 6250 Palmetto Drive

Palmetto County, South Carolina

EPA ID No.: $\quad$ SCD123456789

TDD No.: $\quad$ Y9-8765-43

\section{INTRODUCTION}

Under authority of the Comprehensive Environmental Response, Compensation, and Liability Act of 1980 (CERCLA) and the Superfund Amendments and Reauthorization Act of 1986 (SARA), the U.S. Environmental Protection Agency (EPA), Waste Management Division, Region 4 conducted a site inspection (SI) at the Palmetto Landfill Site near Angleton in Palmetto County, South Carolina. The purpose of this investigation was to collect information concerning conditions at the Palmetto Landfill sufficient to assess the threat posed to human health and the environment and to determine the need for additional investigation under CERCLA or other authority, and, if appropriate, support site evaluation using the Hazard Ranking System (HRS) for proposal to the National Priorities List (NPL). The investigation included reviewing previous information, sampling waste and environmental media to test preliminary assessment (PA) hypotheses and to evaluate and document HRS factors, collecting additional non-sampling information, and interviewing nearby residents.

\section{SITE DESCRIPTION}

\section{$2.1 \quad$ Location}

Palmetto Landfill is located at 6250 Palmetto Drive in a rural area of Palmetto County, South Carolina, approximately 1.5 miles east of the town of Angleton (Figure 1). The geographic coordinates are $18^{\circ} 28^{\prime} 43^{\prime \prime} \mathrm{N}$ latitude and 66 $07^{\prime} 33^{\prime \prime} \mathrm{W}$ longitude (Reference 1).

Palmetto County is characterized by a mild, temperate climate. Summers are warm and humid with daily temperatures reaching $90^{\circ} \mathrm{F}$ or higher. Daily high temperatures during winter are $55^{\circ}$ to $60^{\circ} \mathrm{F}$. Net annual precipitation for the area is 10.87 inches (Reference 2, pp. 7, 10).

\subsection{Site Description}

The site property covers approximately 10 acres, approximately 6 acres of which were used for landfilling of wastes (Reference 3). The landfill is located on relatively flat terrain that slopes gently toward the northeast boundary (Reference 4) and Wildlife Creek, a small, slowly flowing stream (Reference 5, p. 124). The landfill is rectangular in shape and bordered on three sides by a drainage ditch approximately 8 to 10 feet deep and on the fourth side by Wildlife Creek (Reference 3) (Figure 2).

The original purpose of the ditch was to intercept ground water upgradient of the site and direct it around the buried waste (Reference 3). However, because the ditch is less than 10 feet deep and the surficial aquifer is approximately 25 feet deep, the ditch does not completely transect the aquifer. Also, because the ditch 


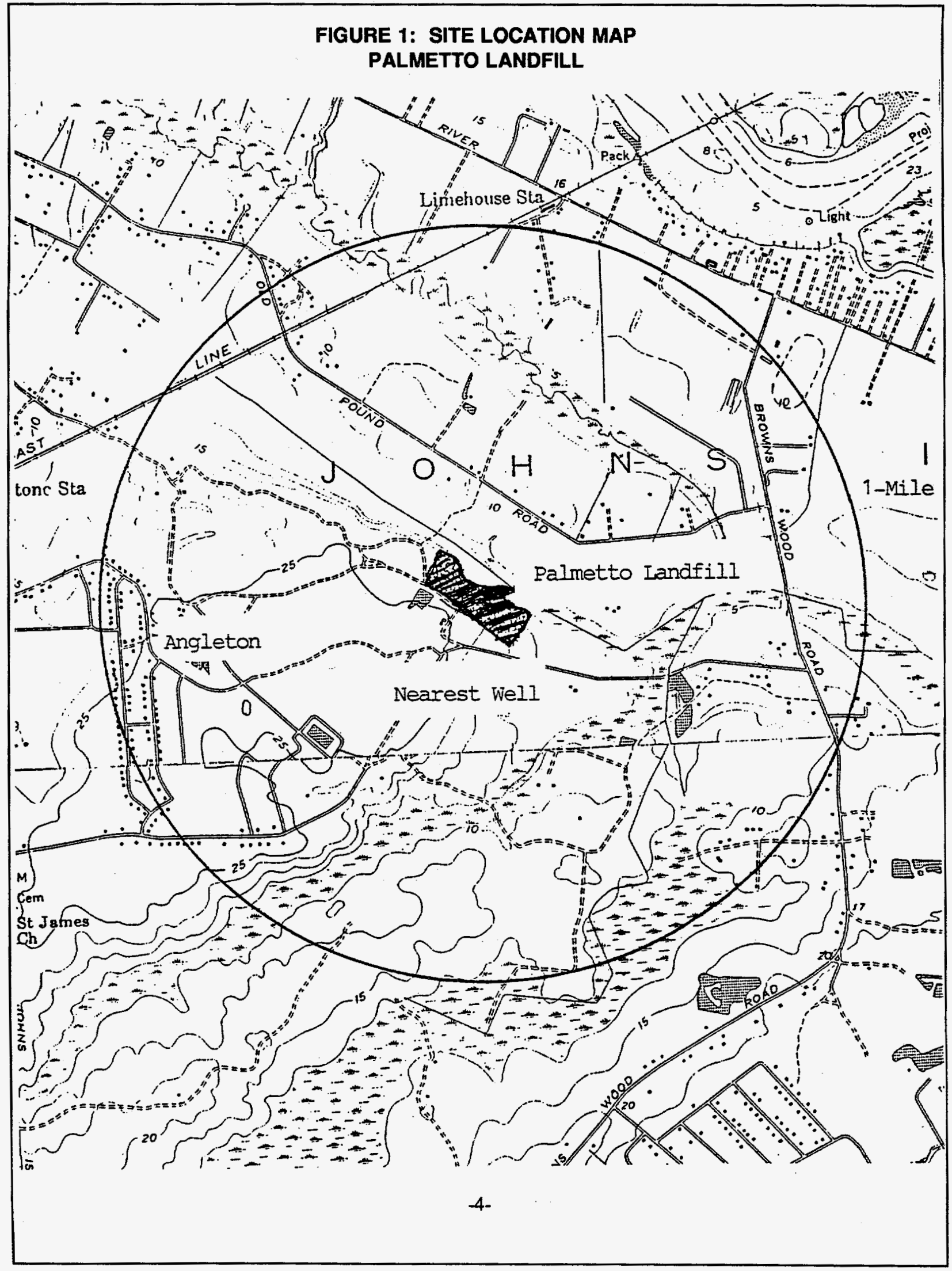




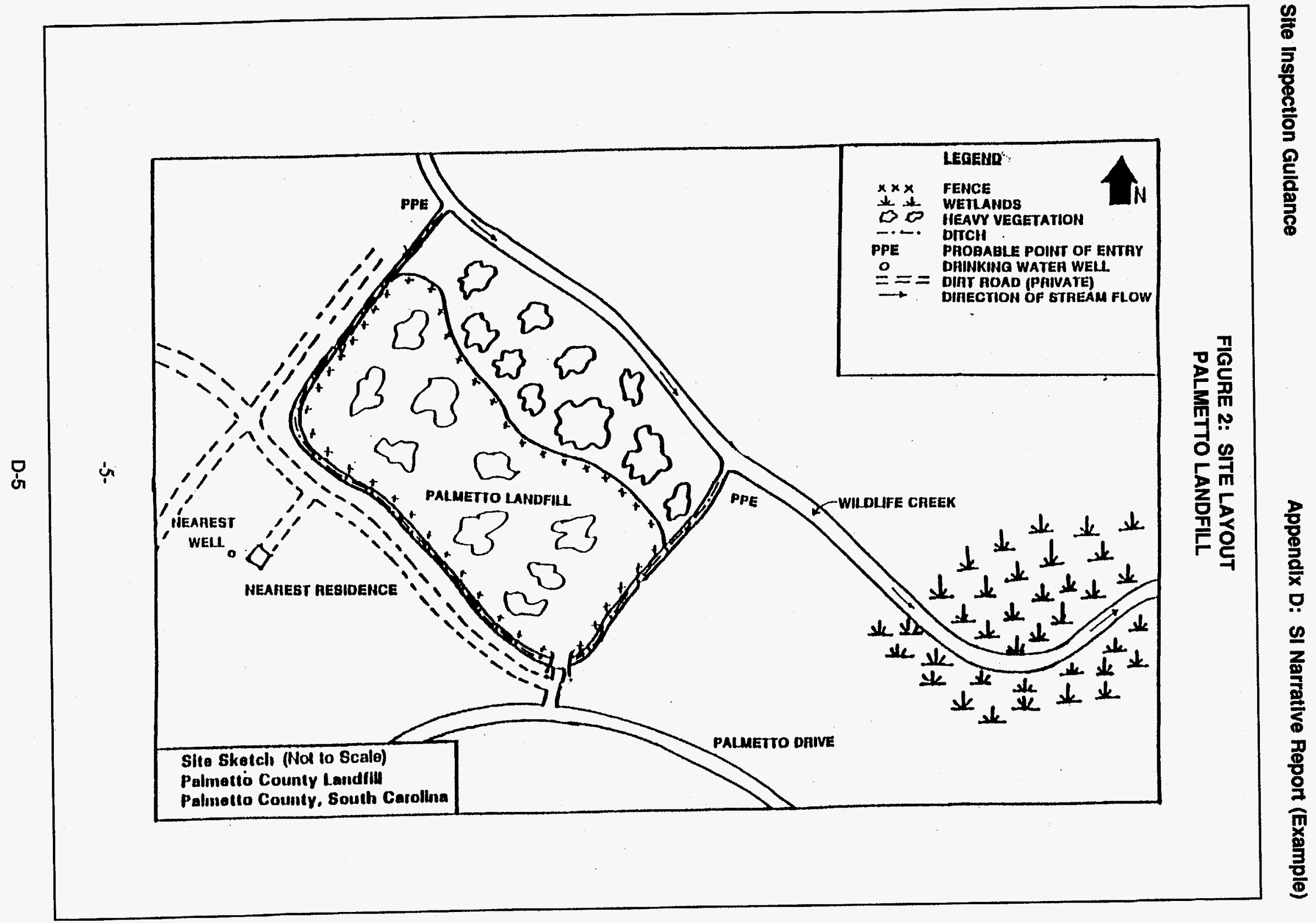


intersects the top of the local water table, it perennially flows. The ditch creates a barrier to runoff from areas upgradient of the site. Along the banks of the ditch there is evidence of stressed vegetation. Water in the eastern segment of the ditch where leachate is draining from the landfill is an orange-brown color and oily in appearance (Reference 4).

No buildings or other structures are on the property. The perimeter of the facility is fenced, the fencing appears to be in good condition, and there is a locked entrance gate across the access road to the site (Reference 4; Reference 7, p. 3). The drainage ditch is located outside of the fenced facility.

\subsection{Operational History and Waste Characteristics}

Smith and Moore Disposal Services, 1111 Main Street, Angleton, South Carolina, owns the ten-acre property. Landfill operations began in April 1970 for disposal of municipal garbage and household debris. Beginning in October 1978, the landfill accepted industrial waste on a limited basis. Smith and Moore kept no formal records of the amounts and types of wastes received. However, there is evidence indicating that the landfill received a one-time shipment of approximately 500 gallons of trichloroethylene (TCE) waste (Reference 3). The common practice of disposal at Palmetto Landfill was to excavate trenches 7 to 10 feet deep, fill the trenches with waste material, and emplace a daily cover of soil. Landfilling operations were discontinued in July 1980 when the landfill reached capacity. Upon closure, a 2-foot soil cover was placed over the entire landfill and seeded (Reference 3).

The soil cap is in relatively good condition except in two places where it appears to have been breached and a small depression is filled with a black sludge-like material (Reference 6). Approximately 200 feet northwest of this depression is an area where vegetation is brown and dying (Reference 6).

Palmetto Landfill operated under permit Number 999-999 issued by the South Carolina Department of Health and Environmental Concerns (SCDHEC). SCDHEC inspected the landfill when it closed and have inspected it several times at irregular intervals. No previous sampling or remedial action is known to have taken place at Palmetto Landfill (Reference 7).

\section{WASTE/SOURCE SAMPLING}

\subsection{Sample Locations}

Table 1 presents sample numbers, locations, and objectives for all samples collected during the SI. Four waste/source samples were collected (Figure 3):

- Two from the landfill surface, one in the small, wet depression and the other 200 feet northwest of the depression in an area of stressed vegetation.

- Two from the drainage ditch where leachate appeared to be leaking out of the site and entering surface water.

\subsection{Analytical Results}

Sample PL-WS-1, collected from the black sludge material, exhibited estimated concentrations of TCE and chlorobenzene. Aldrin, a chlorinated pesticide, also was identified in sample PL-WS-1 at $560 \mathrm{ppb}$ and in sample PL-WS-2 at 75 ppb. Background soil sample PL-SS-2 contained none of these substances. Samples PL-WS-3 and PL-WS-4D exhibited the greatest number of contaminants found at the site. Benzene,

$$
-6-
$$


TABLE 1: SAMPLE COLLECTION

\begin{tabular}{|c|c|c|c|c|}
\hline $\begin{array}{l}\text { Sample } \\
\text { Number }\end{array}$ & $\begin{array}{c}\text { Sample } \\
\text { Type }\end{array}$ & Location & Date & Time \\
\hline PL-WS-1 & $\begin{array}{l}\text { Waste } \\
\text { material }\end{array}$ & $\begin{array}{l}\text { Waste sample collected at depth of } 0.5^{\prime} \text { from } \\
\text { landfill depression to determine types and } \\
\text { concentrations of hazardous substances onsite. }\end{array}$ & $9 / 4 / 91$ & 1400 \\
\hline PL-WS-2 & $\begin{array}{l}\text { Surficial } \\
\text { soil }\end{array}$ & $\begin{array}{l}\text { Soil sample collected at depth of } 0.5 \text { from area } \\
\text { of stressed vegetation to determine types and } \\
\text { concentrations of hazardous substances onsite. }\end{array}$ & 9/4/91 & 1445 \\
\hline PL-WS-3 & $\begin{array}{l}\text { Aqueous } \\
\text { waste }\end{array}$ & $\begin{array}{l}\text { Leachate sample collected from east side of } \\
\text { perimeter ditch to determine types and } \\
\text { concentrations of hazardous substances onsite } \\
\text { and to investigate release to surface water. }\end{array}$ & $9 / 4 / 91$ & 1500 \\
\hline PL-WS-4D & $\begin{array}{l}\text { Aqueous } \\
\text { waste }\end{array}$ & Duplicate of PL-WS-3. & $9 / 4 / 91$ & 1530 \\
\hline PL-GW-1 & Aqueous & $\begin{array}{l}\text { Sample collected from private well approx. } 300^{\prime} \\
\text { south of landfill to investigate release and target } \\
\text { contamination. }\end{array}$ & $9 / 4 / 91$ & 1600 \\
\hline PL-GW-2D & Aqueous & Duplicate of PL-GW-1. & 9/4/91 & 1630 \\
\hline PL-GW-3 & Aqueous & $\begin{array}{l}\text { Sample collected from private well approx. } 1,000^{\prime} \\
\text { southeast of landfill to investigate release and } \\
\text { target contamination. }\end{array}$ & $9 / 4 / 91$ & 1430 \\
\hline PL-GW-4 & Aqueous & $\begin{array}{l}\text { Sample collected from private well } 1,000^{\prime} \text { east of } \\
\text { landfill to investigate contamination. }\end{array}$ & $9 / 4 / 91$ & 1300 \\
\hline PL-GW-5 & Aqueous & $\begin{array}{l}\text { Sample collected from private well } 1,000^{\prime} \text { north of } \\
\text { landfill to investigate contamination. }\end{array}$ & 9/4/91 & 1130 \\
\hline PL-GW-6 & Aqueous & $\begin{array}{l}\text { Sample collected from private well } 1,200^{\prime} \text { north of } \\
\text { landfill to investigate contamination. }\end{array}$ & 9/4/91 & 1000 \\
\hline PL-GW-7 & Aqueous & $\begin{array}{l}\text { Sample collected from private well } 1,200^{\prime} \text { north of } \\
\text { landfill to investigate contamination. }\end{array}$ & 9/4/91 & 0830 \\
\hline PL-GW-8 & Aqueous & Field blank & $9 / 4 / 91$ & 0730 \\
\hline
\end{tabular}


TABLE 1: SAMPLE COLLECTION (Continued)

\begin{tabular}{|c|c|c|c|c|}
\hline $\begin{array}{l}\text { Sample } \\
\text { Number }\end{array}$ & $\begin{array}{c}\text { Sample } \\
\text { Type }\end{array}$ & Location & Date & Time \\
\hline PL-SD-1 & Sediment & $\begin{array}{l}\text { Sample collected approx. } 1,100^{\prime} \text { downstream of } \\
\text { Wildlife Creek in wetland. }\end{array}$ & $9 / 4 / 91$ & 0830 \\
\hline PL-SD-2 & Sediment & $\begin{array}{l}\text { Sample collected approx. } 600^{\prime} \text { downstream of } \\
\text { Wildlife Creek in wetland. }\end{array}$ & $9 / 4 / 91$ & 0900 \\
\hline PL-SD-3 & Sediment & $\begin{array}{l}\text { Sample collected at southern intersection of } \\
\text { perimeter ditch with Wildlife Creek in fishery. }\end{array}$ & $9 / 4 / 91$ & 1000 \\
\hline PL-SD-4D & Sediment & Duplicate of PL-SD-3. & $9 / 4 / 91$ & 1030 \\
\hline PL-SD-5 & Sediment & $\begin{array}{l}\text { Sample collected at northwest intersection of } \\
\text { perimeter ditch with Wildlife Creek in fishery. }\end{array}$ & $9 / 4 / 91$ & 1130 \\
\hline PL-SD-6 & Sediment & $\begin{array}{l}\text { Sample collected approx. } 100 \text { ' upstream from } \\
\text { northwest intersection of perimeter ditch and } \\
\text { Wildlife Creek. }\end{array}$ & $9 / 4 / 91$ & 1200 \\
\hline PL-SD-7 & Sediment & $\begin{array}{l}\text { Sample collected approx. } 200^{\prime} \text { upstream from } \\
\text { northwest intersection of perimeter ditch and } \\
\text { Wildlife Creek. }\end{array}$ & 9/4/91 & 1230 \\
\hline PL-SS-1 & $\begin{array}{l}\text { Surficial } \\
\text { soil }\end{array}$ & $\begin{array}{l}\text { Sample collected at depth of } 1.5^{\prime} \text { approx. } 300^{\prime} \\
\text { southwest of landfill from property of nearest } \\
\text { residence; investigate presence of hazardous } \\
\text { substances in residential property. }\end{array}$ & $9 / 4 / 91$ & 1400 \\
\hline PL-SS-2 & $\begin{array}{l}\text { Surficial } \\
\text { soil }\end{array}$ & Sample from offsite location in native soil. & $9 / 4 / 91$ & 1500 \\
\hline
\end{tabular}




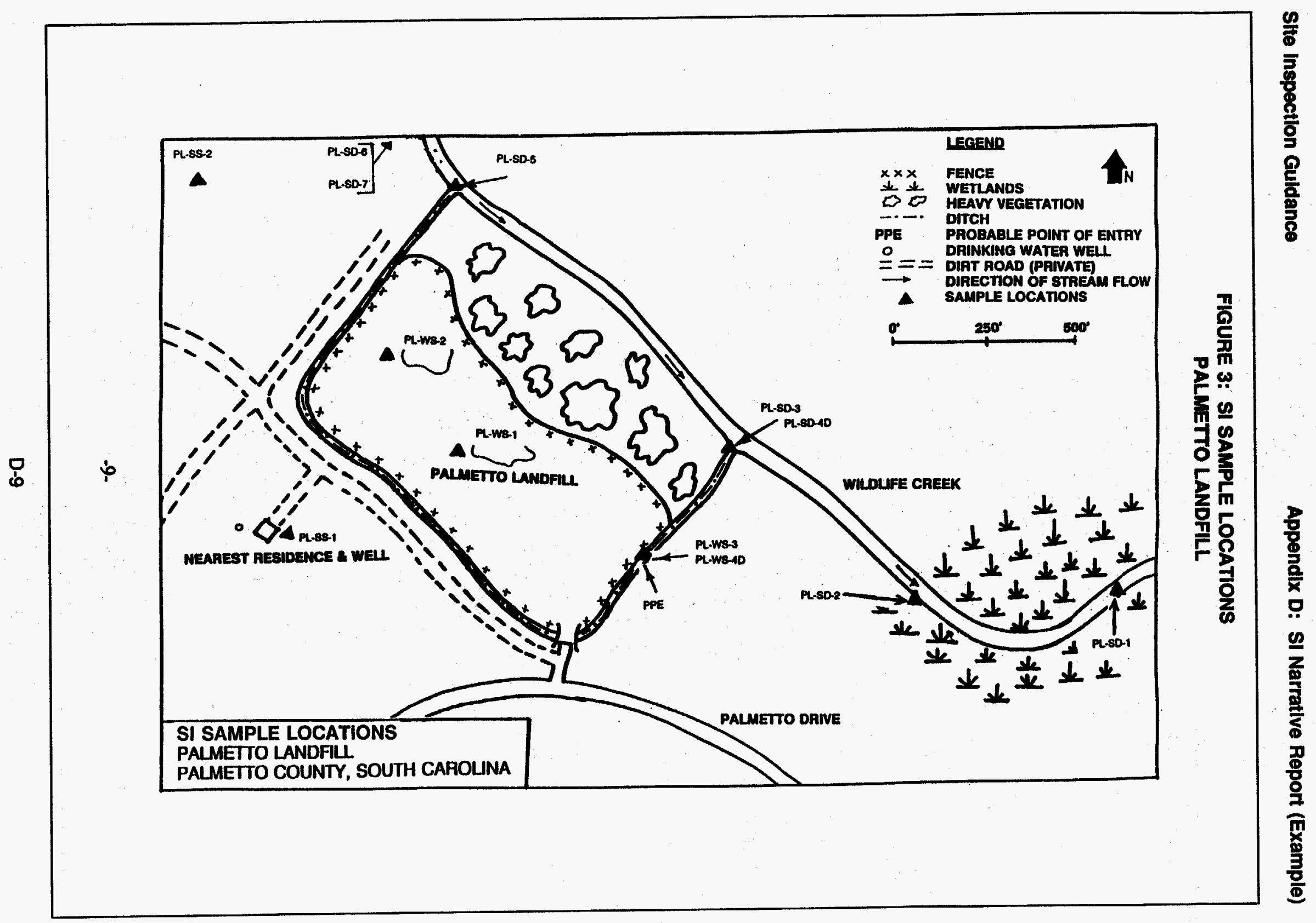


chloroethane, 1,1-dichloroethane, ethylbenzene, and aldrin were found in elevated levels in leachate samples. TCE was detected in leachate samples (PL-WS-3 and PL-WS-4D) at concentrations greater than three times the detection limit. Several metals were detected at elevated levels, most notably arsenic, lead, chromium, and mercury. Toluene and bis(2-ethylhexyl)phthalate, detected in all of the waste source samples, are common laboratory contaminants.

\subsection{Conclusions}

While the landfill was permitted to accept municipal waste, it also accepted industrial wastes on a limited basis beginning in 1978. There are also allegations of a one-time shipment of TCE waste material being deposited at the Palmetto site. Wastes were deposited by a trench method. There are no records of a liner or leachate collection system. While the cap appears to be in good condition, two areas exist where the integrity of the cap appears compromised. Elevated levels of organic and inorganic compounds were detected in samples obtained from breaches in the soil cap and from leachate discharging directly to the drainage ditch.

\section{GROUND WATER PATHWAY}

\subsection{Hydrogeology}

Palmetto County is in the Lower Coastal Plain Physiographic Province. Geologically, this area is characterized by a wedge of overlapping strata that increase in thickness towards the coast. Pleistocene terrace deposits underlie the Palmetto County area. These deposits include the following formations (from youngest to oldest): Jacksonville, Charlestown, Peerless, and Jacob. These formations were deposited from the transgressive/regressive sequences of a glacially controlled Pleistocene sea (Reference 8, p. 12). According to local well logs, the Jacksonville, Charlestown and Peerless formations are the only Pleistocene strata underlying the vicinity of Palmetto Landfill (Reference 9; Reference 10).

The Jacksonville Formation ( 5 to 25 feet thick) is composed of fine-grained sand and shell with interfingering layers of silt and clay. This formation is the only water supply aquifer for rural residents not served by a municipal system. The water is produced under water table conditions at a rate of 25 to 100 gallons per minute (Reference 8, p. 14).

The Charlestown Formation consists of a sandy phosphatic limestone that has altered to a clayey, fine-grained dolomite at depth. The formation is considered to be a confining unit and is 25 to 45 feet thick in the southern Palmetto County area (Reference 8, p. 16).

The Peerless Formation is a porous, dark gray, fine-grained, fossiliferous limestone. This unit, approximately 45 to 60 feet thick, is under artesian conditions and produces brackish water.

Beneath the limestone is the Jacob Formation (60 to 105 feet thick) consisting of sand, silt, and clay. The Jacob Formation also produces brackish water (Reference 8, pp. 17-19).

Precipitation is the primary type of recharge to the Jacksonville Formation. Discharge is by wells, natural seepage, and evapotranspiration. Water flow in this aquifer varies from area to area as water moves by gravity from high to low elevations. Depth to ground water varies from 3 to 15 feet below land surface in Palmetto County (Reference 8, p. 15). At Palmetto Landfill, the depth to ground water is approximately 10 feet, as determined from a well log of a nearby drinking water well (Figure 4) (Reference 9; Reference 10). 
FIGURE 4: WELL LOG FROM 19 PALMETTO LANE

0

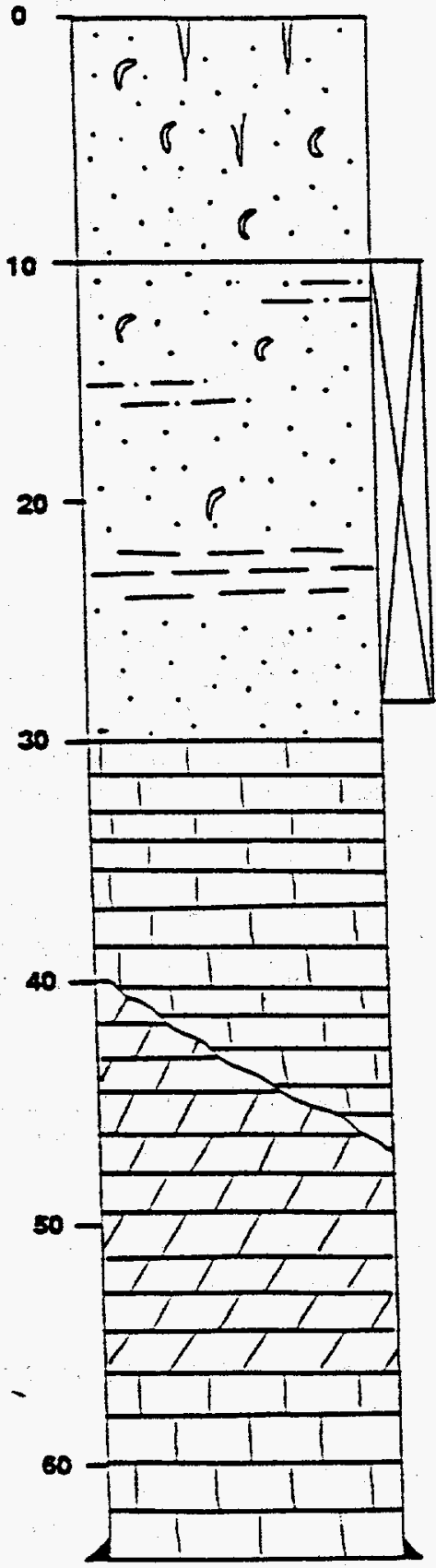

$T D=64^{\circ}$
Surface Soil

Weathered, red, sandy, roots, shells

Jacksonville Formation (top of water rable)

Fine grained, well sorted, unconsoiidated sand, seattered shalls. thin layers of silt and ctay

Completed intervat: $10 \cdot 28^{\circ}$

Produced 75 GPM (initial test)

\section{Chariestown Formation}

White to gray, dense limestone. no visible porasity

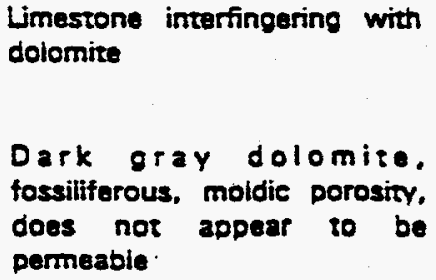

Puartess Formation

Dark gray, fossiliferous limestone, dense, no visible porosity 


\subsection{Targets}

Most people within 4 miles of Palmetto Landfill obtain drinking water from a reservoir operated by the Palmetto County Water Authority (PCWA). The reservoir is located on the Ono River about 35 miles west of Angleton. Three municipal water systems within 4 miles purchase water from PCWA. Discussions with PCWA officials, reconnaissance of the area, and topographic maps have identified residences without municipal water service. These residences obtain drinking water from private wells completed in the Jacksonville Formation (Reference 6, p. 11; Reference 12).

Approximately 239 homes within 4 miles use private wells for drinking water (Reference 12). At 2.7 persons per household (the average for Palmetto County), this equates to 645 residents (Reference 13). The nearest residence relying on a private well is approximately 300 feet to the west of the landfill (Reference 6, p. 10). Within 0.25 mile of the landfill are six residences relying on private wells (Reference 6, p. 10).

There are no wellhead protection areas (WHPA) designated within Palmetto County.

\subsection{Sample Locations}

Ground water samples were collected from the six private wells, all within 0.25 mile of the site, regarded as primary targets during the PA. A duplicate sample was collected from the nearest well. A field blank was collected to detect possible container contamination. Table 1 presents sample numbers, descriptions, and objectives. Figures 3 and 5 show sample locations. Table 2 presents field measurements.

TABLE 2: FIELD MEASUREMENTS FOR GROUND WATER SAMPLES

\begin{tabular}{lllll}
$\begin{array}{l}\text { Sample } \\
\text { Number }\end{array}$ & $\begin{array}{l}\text { Sample } \\
\text { Depth (ft) }\end{array}$ & pH & $\begin{array}{l}\text { Temperature } \\
{ }^{\circ} \mathbf{C}\end{array}$ & $\begin{array}{l}\text { Conductivity } \\
\text { mmhos/cm }\end{array}$ \\
\hline PL-GW-1 & 10 & 5.8 & 23.5 & 650 \\
PL-GW-2D & 10 & 5.6 & 23.0 & 550 \\
PL-GW-3 & 8 & 6.5 & 24.0 & 700 \\
PL-GW-4 & 7 & 7.2 & 23.0 & 480 \\
PL-GW-5 & 11 & 6.5 & 22.0 & 500 \\
PL-GW-6 & 11 & 6.3 & 22.5 & 355 \\
PL-GW-7 & 10 & 6.6 & 23.5 & 250
\end{tabular}

\subsection{Analytical Results}

The nearest drinking water well samples (PL-GW-1 and PL-GW-2D) contained vinyl chloride, TCE, and benzene in highly elevated concentrations. While vinyl chloride was not detected in any source sample, it is a degradation product of TCE, a substance deposited at the site. TCE also was detected at estimated levels in samples PL-GW-4 and PL-GW-3, which also exhibited estimated concentrations of vinyl chloride and chrysene. 


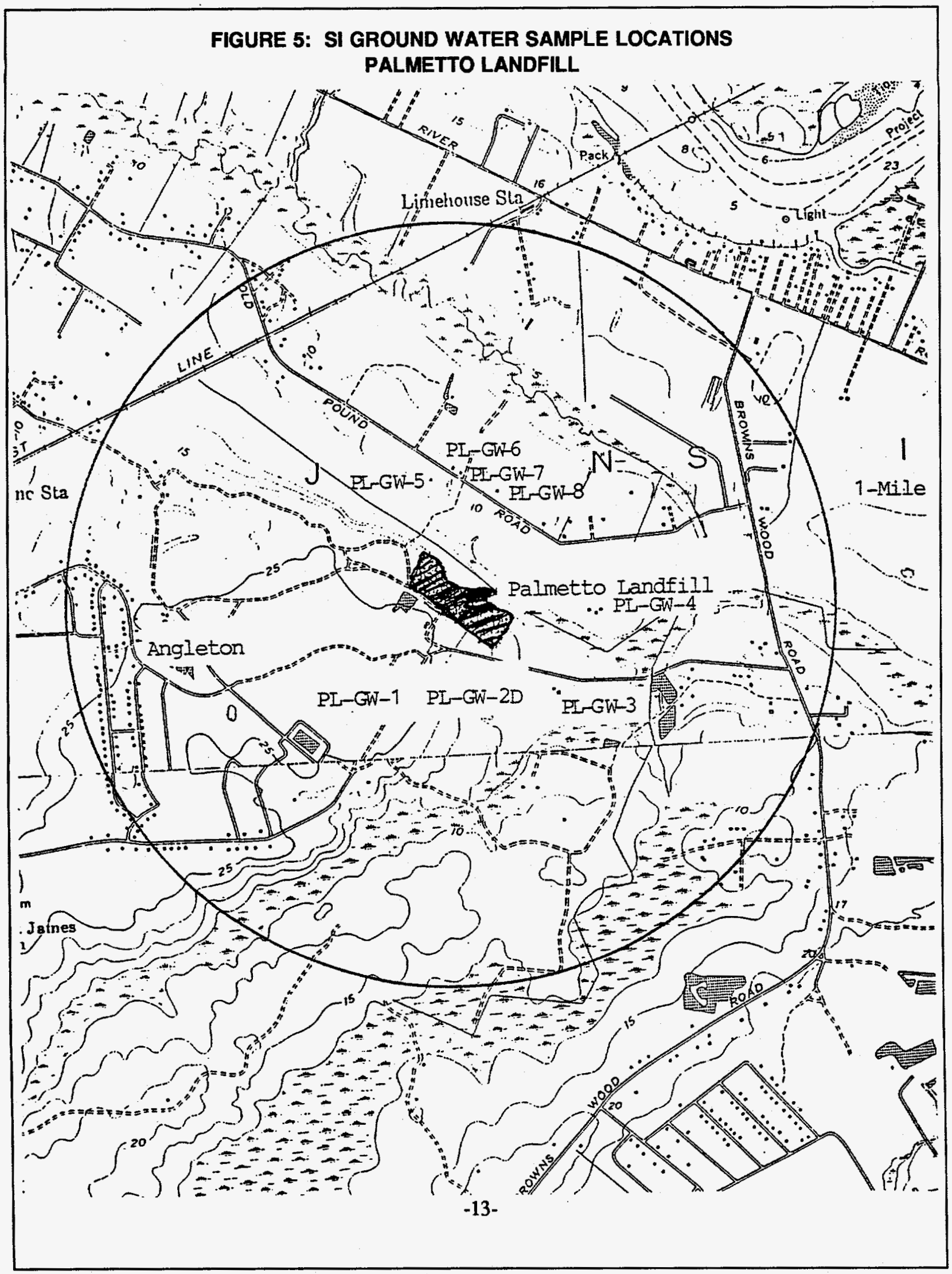


Ethylbenzene was detected in low concentrations in samples PL-GW-5, PL-GW-6, and PL-GW-7. This substance, a component of gasoline, could have come from other offsite sources.

Toluene or bis(2-ethylhexyl)phthalate was detected in all samples except PL-GW-4. Toluene also was detected in the field blank, sample PL-GW-8. These compounds are common laboratory contaminants and could have resulted from laboratory procedures.

Arsenic, cadmium, lead, and chromium were detected at elevated concentrations in PL-GW-1 and PL-GW-2D. All of these hazardous substances were found in the waste/source samples. Zinc was detected in all samples except PL-GW-6.

\subsection{Conclusions}

Due to the lack of any ground water containment system at the landfill, the disposal methods used at the site, and the high water table of the uppermost drinking water aquifer, contaminants could migrate into ground water at this site. Nearby drinking water wells contain hazardous substances similar to those found in samples taken from the source, indicating a release to ground water. The primary source of drinking water for rural domestic users in the area is the shallow aquifer. Samples from the nearest well, located 300 feet from the site, exhibited elevated levels of organic and inorganic compounds.

\section{SURFACE WATER PATHWAY}

\section{$5.1 \quad$ Hydrology}

Palmetto Landfill is bordered on three sides by a perennially flowing drainage ditch. The ditch also creates a localized drainage basin coincident with the 10-acre landfill. Leachate flows from the landfill and enters the ditch approximately 250 feet from where the ditch runs into Wildlife Creek. Overland drainage from the site flows northeast approximately 250 feet into Wildlife Creek, which has an average flow rate of 5 to 10 cubic feet per second (cfs). Wildlife Creek flows approximately 3.0 miles and enters Ono River (Reference 1 ), which has an average flow of $1,000 \mathrm{cfs}$ (Reference 5, p. 132). Approximately 16 miles downstream the Ono River merges with the East River (Reference 5, p. 150).

\subsection{Targets}

No drinking water intakes are within 15 downstream miles of the site. Most residents are served by a reservoir 35 miles upstream of Palmetto Landfill. Residents not served by a municipal system obtain drinking water from private wells (Reference 11).

Wildlife Creek and Ono River are used for recreational fishing. Aquatic species commonly caught include wide mouth bass, shrimp, crabs, and clams. Recreational crawfish fishing occurs in Wildlife Creek and the surrounding wetlands (Reference 14, pp. 13,15).

Numerous wetlands are within 15 downstream miles of the site. The nearest wetland (approximately 250 acres, 0.5 mile frontage) is approximately 0.1 mile downstream from the site on Wildlife Creek (Reference 1). No other sensitive environments are within 15 downstream miles of the site (Reference 15).

$$
-14-
$$




\subsection{Sample Locations}

Samples were collected at all surface water targets identified as primary targets during the PA, with the exception of two sensitive environments. The habitats of two Federally designated endangered species, the Bald Eagle and the Salt Marsh Harvest Mouse, were considered primary targets during the PA because they are known to be found in Palmetto County. However, the SI found that these sensitive environments do not exist in the surface waters (within 15 downstream miles) near the Palmetto landfill.

Seven sediment samples were collected to evaluate the surface water pathway. Table 1 presents sample numbers, descriptions, and objectives; sample locations are shown in Figure 3. The seven samples are:

- Two samples upstream from the site in Wildlife Creek to determine background levels.

- Three from Wildlife Creek at points where the drainage ditch intersects the creek to evaluate the impact of the site on the fishery: one from the northwest intersection point and two from the northeast intersection point.

- Two within the wetland to investigate contamination.

\subsection{Analytical Results}

Downstream sediment samples collected at the northeast intersection (PL-SD-3 and PL-SD-4D) contained elevated concentrations of several hazardous substances. Aldrin, arsenic, chromium, and lead were detected at concentrations significantly greater than those found in the background samples (PL-SD-6 and PL-SD-7). In general, very few organic compounds were found in the sediment samples. Most of the substances were detected at estimated concentrations. Mercury was detected at an estimated level in sample PL-SD-5.

\subsection{Conclusions}

A release of hazardous substances from the site into the drainage ditch was evidenced by the elevated concentrations of TCE, arsenic, chromium, and lead in the leachate sample (PL-WS-3 and PL-WS-4D). Analytical results suggest that these hazardous substances are migrating from the landfill into Wildlife Creek via the drainage ditch. Wildlife Creek is used for recreational fishing. Samples collected from the downstream wetland indicate that it has not been impacted by the site at this time.

\section{SOIL EXPOSURE AND AIR PATHWAYS}

\subsection{Physical Conditions}

When the site was closed in 1980, Palmetto Landfill was covered by 2 feet of clean soil and seeded. A chain link fence was installed around the site (Reference 3). The site is currently heavily vegetated by grass, weeds, and shrubs (Reference 4; Reference 7,p. 2). There is a locked gate across the road to the landfill (Reference 6, p. 2).

\subsection{Soil and Air Targets}

There are no workers at Palmetto landfill. No people live on Palmetto Landfill. The nearest residence is 300 feet to the west, and the nearest school is 0.5 mile to the north (Reference 6, p. 10). Six residences are within 0.25 mile of the site; the total population within 4 miles of the site, as determined by visual observations,

$$
-15-
$$


topographic maps, and the GEMS data base, is 7,989 people (Reference 1; Reference 7, p. 10; Reference 14). A 250-acre wetland is located on Wildlife Creek approximately 0.1 mile from Palmetto Landfill. The critical habitat of the Bald Eagle is within 3 to 4 miles from the site; however the precise location cannot be determined (Reference 15).

\subsection{Soil Sample Locations}

Two samples were collected to investigate the soil exposure pathway-one sample from the property of the nearest residence approximately 300 feet from the site, and the other offsite to establish ambient conditions.

Table 1 presents sample numbers, descriptions, and objectives. Figure 3 shows soil sample locations.

\subsection{Soil Analytical Results}

Lead was detected in slightly elevated concentrations at the nearest residence (PL-SS-1).

\subsection{Air Monitoring}

Portable air quality monitors (OVA and HNu) were carried onsite during the SI. No measurements above background were detected. No formal air monitoring program was conducted.

\subsection{Conclusions}

The site is located in a sparsely populated rural area. The nearest residence is approximately 300 feet southwest of the site, and approximately 7,989 persons live within 4 miles. There was no indication of a release to the air pathway. No hazardous substances were detected in the residential soil sample at concentrations significantly greater than background levels.

\section{SUMMARY AND CONCLUSIONS}

The Palmetto Landfill SI attempted to gather data necessary to evaluate the site as a candidate for the NPL. Waste and environmental samples were collected and analyzed to characterize the types of substances deposited at the site and potential migration pathways. In addition, information was collected to confirm target populations and environments potentially at risk from the site.

Palmetto Landfill accepted an unknown quantity of municipal and industrial waste, including approximately 500 gallons of TCE waste. Wastes were deposited in unlined trenches 7 to 10 feet deep. Landfilling operations ceased when the landfill reached capacity in 1980. The landfill was then covered with 2 feet of soil and seeded. A chain link fence also was installed.

The SI indicated contamination at the landfill and in leachate discharging from the landfill to the drainage ditch at the perimeter of the site. Analytical results of sampling are presented in Table 3. Hazardous substances related to site wastes were detected in the nearest drinking water well. The substances found in the drinking water wells include TCE, vinyl chloride, arsenic, chromium, and lead. Other downgradient wells also may be contaminated.

Evidence of releases from the site was found in surface water sediment samples. Sediment samples collected where the drainage ditch discharges into Wildlife Creek had elevated concentrations of several inorganic compounds, including, arsenic, chromium, and lead. 


\begin{tabular}{|c|c|c|c|c|c|c|c|c|c|c|c|}
\hline \multirow[b]{2}{*}{ SUBSTANCE } & \multicolumn{10}{|c|}{ TABLE 3 (PART 1): ANALYTICAL RESULTS FOR AQUEOUS SAMPLES } & \multirow[b]{2}{*}{$\begin{array}{c}\text { Detoction } \\
\text { Limit }\end{array}$} \\
\hline & PL-WS-3 & PL-WS-4D & PL-GW-1 & PL-GW-2D & PL-GW-3 & PL-GW-4 & PL-GW-5 & PL-GW-6 & PL-GW-7 & PL-GW-8 & \\
\hline ORGANICS, ugI & & & & & & & & & & & CRQL \\
\hline Vinyl Chloride & - & - & $4 \mathrm{~J}$ & 5 & is & -- & - & - & - & - & 10 \\
\hline Chloroethane & $4 \mathrm{~J}$ & 3 & - & -- & - & - & - & - & $\cdots$ & - & 10 \\
\hline Trichloroethylene & 19 & 15 & 7.5 & $4 \mathrm{~J}$ & $2 \mathrm{~J}$ & $1 \mathrm{~J}$ & - & - & - & - & 10 \\
\hline Benzene & 10 & 9 & 2.6 & 3.1 & - & -- & 5 & - & - & - & 10 \\
\hline Toluene & 15 & 20 & 3 & 5 & $\cdots$ & $4 J$ & - & 3 & - & $2 J$ & 10 \\
\hline $\begin{array}{l}\text { Bis(2ethyl- } \\
\text { hexyl)phthalate }\end{array}$ & 32 & $14 \mathrm{~J}$ & 4 & 2 & $5 \mathrm{~J}$ & - & 2 & 2 & 3 & - & 10 \\
\hline 1,1-Dichloroethane & 5 & 8 & - & - & $\cdots$ & -- & - & -- & - & - & 10 \\
\hline Chlorobenzene & - & - & - & - & - & - & - & - & 4J & - & 10 \\
\hline Ethylbenzene & $17 \mathrm{~J}$ & 32 & 3 & $1 \mathrm{~J}$ & $\cdots$ & -- & $2 J$ & $2 J$ & $5 \mathrm{~J}$ & - & 10 \\
\hline Chrysene & - & - & - & - & 2J & - & - & - & - & - & 10 \\
\hline Aldrin & $2 J$ & 7 & - & - & - & - & - & - & - & - & 0.05 \\
\hline INORGANICS, ugA & & & & & & & & & & & CRDL \\
\hline Aluminum & 6,100 & 4,000 & 28,000 & 26,000 & $1,500 \mathrm{~J}$ & 13,000 & 15,000 & 5,300 & 2,600 & - & 200 \\
\hline Arsenic & 31 & 26 & 10 & 6 & - & - & - & - & - & - & 10 \\
\hline Cadmium & 5 & 3 & $2 J$ & 4.2 & - & - & - & - & - & - & 5 \\
\hline Chromium (VI) & $6.5 \mathrm{~J}$ & 5.5 & 12 & $20 \mathrm{~S}$ & 20 & 14 & $5 \mathrm{~J}$ & - & - & - & 10 \\
\hline Iron & 9,000 & 9,000 & 8,400 & 12,000 & 2,200 & 4,900 & 7,800 & 32,000 & 22,000 & - & 100 \\
\hline Lead & 10 & 15 & 6.2 & 8.1 & $5 J$ & $10 \mathrm{~J}$ & $2 J$ & 5 & - & - & 3 \\
\hline Mercury & 0.25 & 0.2 & - & - & - & - & - & - & -- & -- & 0.2 \\
\hline \multirow[t]{3}{*}{ Zine } & 60 & 50 & 32 & 45 & 40 & 15 & $22 \mathrm{~J}$ & - & $5 J$ & - & 20 \\
\hline & \multicolumn{11}{|c|}{$\begin{array}{l}\text { Material analyzed for but not detected above minimum quantitation limit } \\
\text { Estimated value }\end{array}$} \\
\hline & & & & & -18 & & & & & & \\
\hline
\end{tabular}




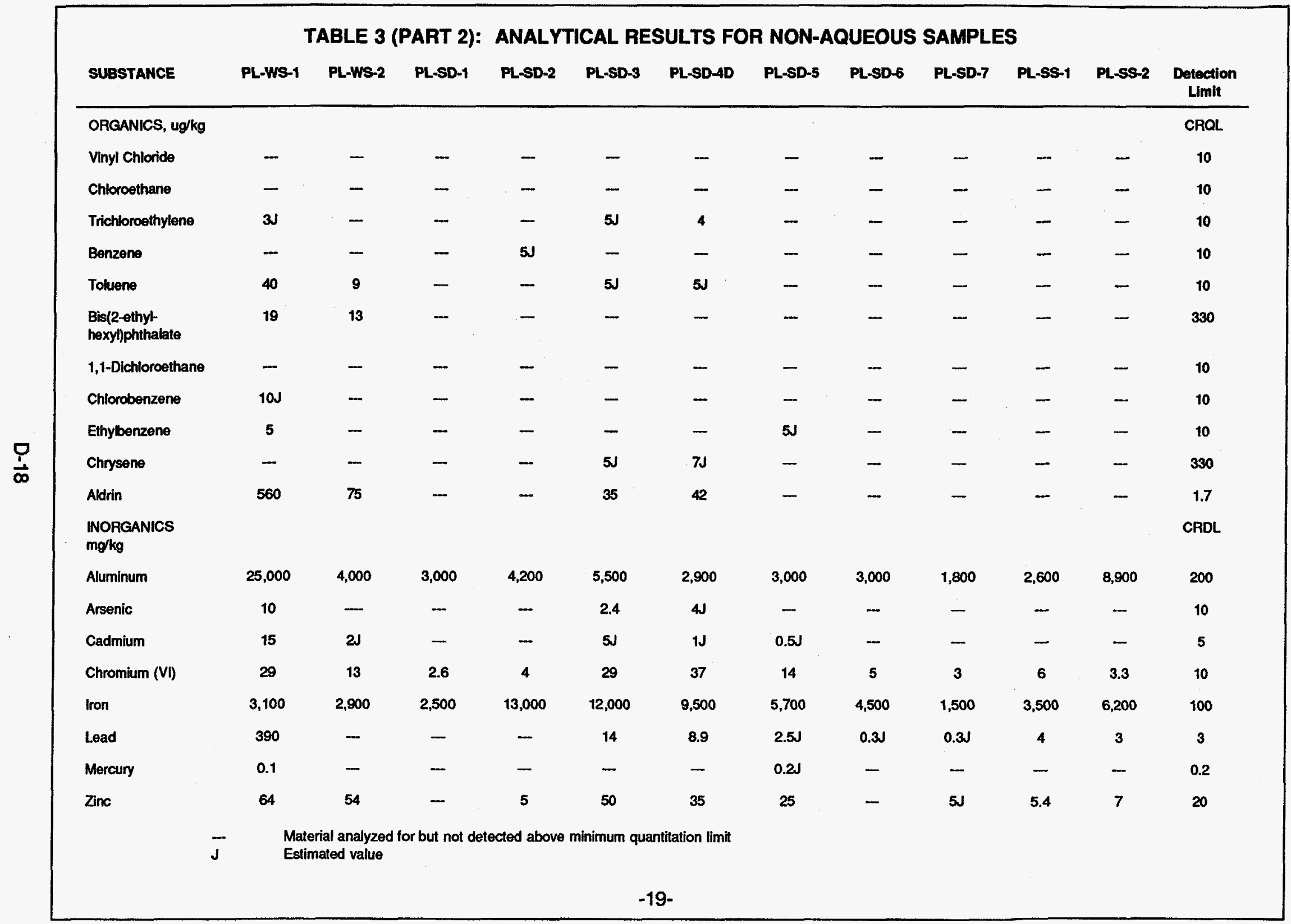




\section{REFERENCES}

1. U.S. Geological Survey, 7.5-minute topographic quadrangle maps of South Carolina: Angleton, 1963, photo revised 1983; Palmetto, 1975; Winchester, 1975; Danvers, 1963.

2. U.S. Department of Commerce, 1983. "The Climatic Atlas of the United States."

3. Jennifer Doe, Manager for Smith and Moore Disposal Services, telephone conversation with Joe Brown, XYZ Corporation, May 1, 1991. Re: Waste Disposal Practices at Palmetto Landfill.

4. Joseph Brown, XYZ Corporation, Photodocumentation Log of Palmetto Landfill Preliminary Assessment, May 7, 1991.

5. A.P. Park, The Surface Water Resources of Palmetto County, South Carolina. South Carolina Water Resources Commission Report No. 101B.

6. Joseph Brown, XYZ Corporation, Field Logbook for Offsite Reconnaissance of Palmetto Landfill, TDDY9-8765-43, May 1991.

7. John Hill, Technician for South Carolina Department of Health and Environmental Concerns, telephone conversation with Joe Brown, XYZ Corporation, May 2, 1991. Re: Remediation and sampling at Palmetto Landfill.

8. J.P. Adams, The Ground Water Resources of Palmetto County, South Carolina. South Carolina Water Resources Commission Report No. 99A, 1982.

9. Donna Johnson, Driller for Joe Blow Drilling Co., telephone conversation with Joe Brown, XYZ Corporation, May 1, 1991. Re: Palmetto County Drilling.

10. Johnson Drilling Company, J.J. Jones Residential Well Log, March 25, 1984.

11. Mark Allen, Technician for Palmetto County Water Authority, telephone conversation with Joe Brown, XYZ Corporation, May 2, 1991. Re: Palmetto County Municipal Water Systems.

12. Palmetto County Water Authority, Municipal Water Supply Distribution Map, April 1991.

13. U.S. Department of Commerce, Bureau of Census, 1990 Census of Population and Housing, South Carolina.

14. A.J. Houston, South Carolina Guide to Recreational Hunting and Fishing, South Carolina Department of Natural Resources, Wildlife and Game Division Report Number A22, 1975.

15. U.S. Fish and Wildlife Service, 1980. Atlantic Coast Ecological Inventory Maps, Palmetto County Panels.

16. U.S. Census Bureau, Geographical Exposure Modeling System (GEMS) Database, South Carolina, 1990.

$-19-$ 


\section{APPENDIX E}

\section{EQUIPMENT LIST}

This appendix suggests an inventory of expendable and non-expendable equipment that generally may support SI field and sampling activities. The list is provided as a possible starting point for a field office to develop a checklist of equipment for site assessment activities. Note that each item of equipment listed here is not required for every $\mathrm{SI}$, nor does this list include every piece of equipment that may be needed for a particular SI. SI investigators should consult the Regional site assessment program for equipment guidelines. 


\section{EXPENDABLE EQUIPMENT}

Item

Quantity Packaged

Amount Required

CHEMICALS

Acetone

Acetone

Trichloroethane

Trichloroethane

Methylene-chloride

Methylene-chloride

Hexane

Gasoline

Gasoline

Nitric Acid

Nitric Acid

Sodium Hydroxide

Motor Oil

2-Cycle Oil

Alconox

Baking Soda

\section{SAMPLE CONTAINERS}

$40 \mathrm{ml}$. VOA Bottles

$1 / 2$ gal. Amber Bottle

1 liter Amber Bottle

8 oz. Glass Jars

1 liter Plastic Bottles

Plastic Bags 8" x 12"

Plastic Bags 10" x 12"

Plastic Bags 12" x 20"

Paint Cans w/lid \& snaps

Paint Cans w/lid \& snaps

Paint Cans w/lid \& snaps

Vermiculite

\section{BOOTS}

Butyl Rubber Boots

Hip Boots (Size ??)

Latex Boot Covers

Tyvek Boot Covers

\section{GLOVES}

Neoprene

Viton

Butyl Rubber

Cotton Work

Latex
5 gal.

$1 \mathrm{gal}$.

5 gal.

1 gal.

$5 \mathrm{gal}$.

1 gal.

1 gal.

$1 \mathrm{gal}$.

5 gal.

$1 \mathrm{gal}$.

$5 \mathrm{ml}$.

1 liter

$1 \mathrm{qt}$.

$1 / 2 \mathrm{pt}$.

1 gal.

2 lb. box

1 each

1 each

1 each

1 each

1 each

100 box

100 box

100 box

1 gal.

$1 / 2 \mathrm{gal}$.

$1 \mathrm{qt}$.

$4 \mathrm{cu}$. ft.
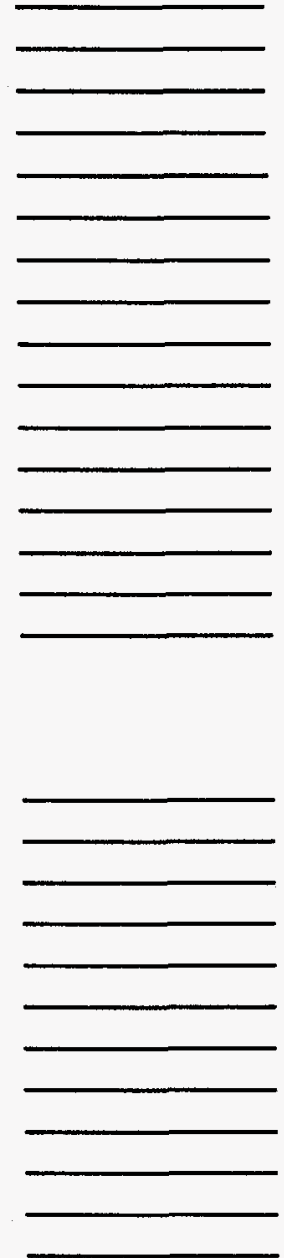


\section{EXPENDABLE EQUIPMENT (Continued)}

Item

GLOVES (Continued)

Leather Work

P.V.C. Surgical

\section{CHEMICAL RESISTANT COVERALLS}

Tyvek SM

Tyvek MED

Tyvek LG

Tyvek XLG

Tyvek XXLG

Saranex SM

Saranex MED

Saranex LG

Saranex XLG

Saranex XXLG

\section{SAMPLE TUBES}

Glass Tube $.5 \mathrm{~mm} \times 300 \mathrm{~mm}$

Glass Tube $1 \mathrm{~mm} \times 300 \mathrm{~mm}$

P.V.C. Tube $2^{\prime \prime} \times 10^{\prime}$

P.V.C. Tube 4" $\times 10^{\prime}$

1 each

1 each

1 each

FILM

C-135-36-100-Prints

C-135-36-200-Prints

C-135-36-400-Prints

C-135-24-100-Prints

C-135-24-200-Prints

C-135-24-400-Prints

C-135-12-100-Prints

C-135-12-200-Prints

C-135-12-400-Prints

C-135-36-200-Slide

B\&W-135-20-400-Prints

SX70 Polaroid

Kodamatic

1 roll

1 roll

1 roll

1 roll

1 roll

1 roll

1 roll

1 roll

1 roll

1 roll

1 roll

1 sgl. pack

1 sgl. pack

\section{ROPE}

Nylon 3/16"

Nylon $1 / 4^{n}$

Manila 1/4"

Manila 1/2"

600 ' roll

$1000^{\prime}$ roll

$100^{\prime}$ roll

$50^{\prime}$ roll 


\section{EXPENDABLE EQUIPMENT (Continued)}

Item

Quantity Packaged

Amount Required

\section{STATIONERY SUPPLIES}

Graph Paper

Manilla Tags

Paper Towels

Ball Point Pens

Indelible Ink Pens

\section{TAPE}

Clear Plastic

Duct

Elec. Vinyl

Filament

Flagging

Masking

Transparent
1 each
1 roll
1 roll
1 roll
$100^{\prime}$ roll
1 roll
1 each

\section{MISCELLANEOUS}

Aluminum Foil

17\# Drums 55 gal.

17\# Drums 35 gal.

Kimwipes

pH Paper

Plastic Roll 10' x 25'

Trash Bags 45 gal.

Vermiculite

$500^{\prime}$ roll

1 each

1 each

box

2 rolls

1 roll

20 box

1 bag

WRITE IN:

*Preservatives, calibrating solutions, sample packing materials, and special items of equipment are the responsibility of the Project Manager. 


\section{NON-EXPENDABLE EQUIPMENT}

Equipment

Amount Required

\section{CAMERAS}

Canon AE1

Polaroid One Step

Polaroid SX70

Camera Bag

Binoculars

\section{AIR MONITORING}

HNU Photoionization Detector

Draeger Tubes (Type: )

Organic Vapor Analyzer

OVA Chart Recorder

Explosimeter

Combination Explosimeter and $\mathrm{O}_{2}$ Indicator

$\mathrm{O}_{2}$ Indicator

Draeger Tube Hand Pump

$\mathrm{H}_{2} \mathrm{~S}$ Gas Indicator

Mercury Sniffer

Photovac

Meteorological Unit

\section{METERS}

Radiation Mini-Alert

Conductivity Meter

pH Meter

Resistivity Meter (Bison)

Resistivity Meter (Soil Test)

Metal Detector

\section{SURVEYING EQUIPMENT}

Optical Rangefinder

Level, Hand 2X

Brunton Transit, w/case

Compass

200' Fiberglass Measuring Tape

300' Fiberglass Measuring Tape

Wheel Distance Recorder

\section{PUMPS AND LIQUID SAMPLING EQUIPMENT}

Double Diaphragm Pump 1"

Submersible Pump 1"

Submersible Pump 2"

Pitcher Pump 2" 
NON-EXPENDABLE EQUIPMENT (Continued)

Equipment

Amount Required

PUMPS AND LIQUID SAMPLING EQUIPMENT (Continued)

Bacon Bomb Sampler

Kemmerer Sampler

LG Well Kit Sampler

SM Well Kit Sampler

SS Bailer

Teflon Bailer

Bottom Filling Bailer

Water Level Indicator

\section{SOIL SAMPLING EQUIPMENT}

Spoons LG

Spoons SM

Spatula LG

Spatula SM

Scoops

Trowel

Large Stainless Steel Bucket

Medium Stainless Steel Bucket

Small Stainless Steel Bucket

Split Spoon Sampler

3" Bucket Auger

3.5" Hand Auger

Dredge

\section{DECON EQUIPMENT}

Indian Tank

Heavy Duty Sprayer

John Deere Power Spray w/gas can

50' Section Garden Hose

Mop

LG Hdl Dairy Brushes

SM Hdl Dairy Brushes

Scrub Brushes

Bottle Brushes

Whisk Brushes

Wire Brushes

\section{STANDBY SAFETY EQUIPMENT}

20\# Fire Extinguishers

$\mathrm{O}_{2}$ Resuscitator

Stretcher

Eye Wash

Trauma Kit 
NON-EXPENDABLE EQUIPMENT (Continued)

Equipment

\section{POWER EQUIPMENT}

Digger Mobile

3 HP Water Pump w/gas can

Generator w/gas can

Power Auger w/gas can

Extension Cord-Heavy Duty 100'

Extension Cord-Light Duty 25'

Remote Drum Opener

\section{SELF CONTAINED BREATHING APPARATUS}

\section{SCBA}

Dual Purpose SCBA

CASCADE System

$45 \mathrm{cu}$. ft. Composite Tanks

Umbilical Breathing Air Lines (50' Sec.)

Umbilical Breathing Air System

330 cu. ft. Class "D" Breathing Air Cylinder

\section{PERSONAL PROTECTION}

Hard Hat

Safety Goggles

Safety Glasses

Splash Shield

Full Face Respirator

Respiratory Cartridges

Butyl Rubber Apron

Encapsulated Suits

Life Vests

Rain Jacket

Rain Pants

\section{HAND TOOLS}

\section{Hacksaw}

Post Hole Digger

Bung Wrench

Rake

Saw

Ax (Bush, Pick, Hand)

Shovel

Amount Required
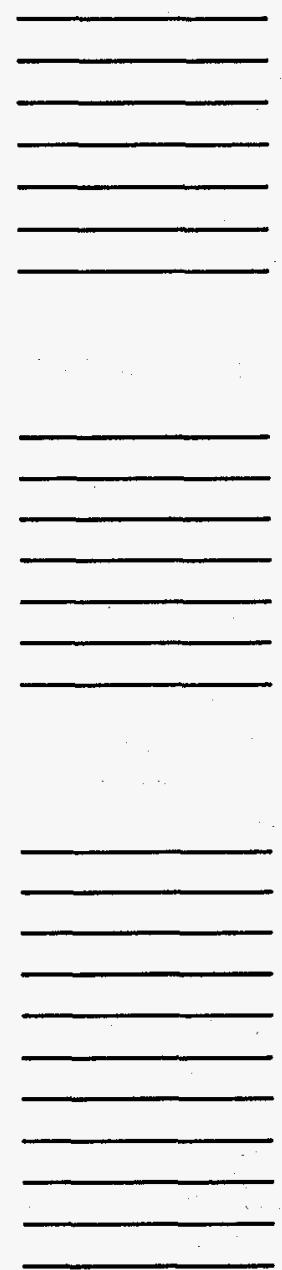
NON-EXPENDABLE EQUIPMENT (Continued)

Equipment

MISCELLANEOUS

Beeper

Ventilation Smoke Tube Assy.

Isotemp Oven

Wind Speed and Direction Finder

Garbage Can

Clipboard

LG Ice Chest

SM Ice Chest

Walkie Talkies

WRITE IN:
Amount Required
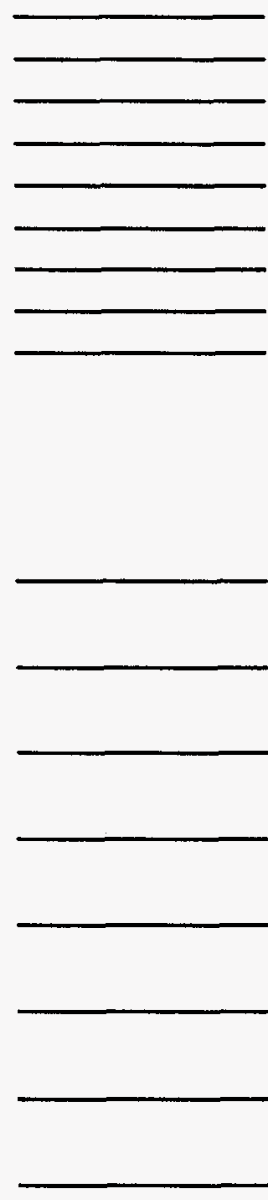